\title{
WestVirginiaUniversity
}

THE RESEARCH REPOSITORY @ WVU

Graduate Theses, Dissertations, and Problem Reports

2003

\section{Crack detection technique for reinforced concrete bridge decks}

Indumathi Chera

West Virginia University

Follow this and additional works at: https://researchrepository.wvu.edu/etd

\section{Recommended Citation}

Chera, Indumathi, "Crack detection technique for reinforced concrete bridge decks" (2003). Graduate Theses, Dissertations, and Problem Reports. 1368.

https://researchrepository.wvu.edu/etd/1368

This Thesis is protected by copyright and/or related rights. It has been brought to you by the The Research Repository @ WVU with permission from the rights-holder(s). You are free to use this Thesis in any way that is permitted by the copyright and related rights legislation that applies to your use. For other uses you must obtain permission from the rights-holder(s) directly, unless additional rights are indicated by a Creative Commons license in the record and/ or on the work itself. This Thesis has been accepted for inclusion in WVU Graduate Theses, Dissertations, and Problem Reports collection by an authorized administrator of The Research Repository @ WVU. For more information, please contact researchrepository@mail.wvu.edu. 


\title{
CRACK DETECTION TECHNIQUE FOR REINFORCED CONCRETE BRIDGE DECKS
}

by

\section{INDUMATHI CHERA}

\author{
A Thesis \\ Submitted to the College of Engineering and Mineral Resources \\ at \\ West Virginia University \\ in partial fulfillment of the requirements \\ for the degree of \\ Master of Science \\ in \\ Mechanical Engineering
}

\begin{abstract}
Committee Members
Dr. Samir N. Shoukry, Chair

Dr. Jacky Prucz, MAE

Dr. Kenneth Means, MAE

Dr. Gergis W. William, CEE
\end{abstract}

Department of Mechanical and Aerospace Engineering

Morgantown, West Virginia

2003 


\section{ABSTRACT \\ CRACK DETECTION TECHNIQUE FOR REINFORCED CONCRETE BRIDGE DECKS}

\section{Indumathi Chera}

Many reinforced concrete bridge decks develop early age transverse cracks, even before the passage of any traffic loads. In an attempt to reduce the frequency of occurrence of such cracks, many states increased the deck thickness, specified a minimum cover of 2.5 -inch above the top reinforcement, and used modified concrete mixes that produce high strength concrete. Such modifications did not reduce the intensity of the problem, and in some cases increased cracking was reported. The exact causes of early age cracking of reinforced concrete bridge decks are not known, however restrained shrinkage, construction sequence, and temperature changes may be some of the factors that contribute to such phenomenon.

This study describes the instrumentation and test results of a reinforced concrete bridge deck constructed on 3-span continuous steel girders. The instrumented bridge is located in Evansville, West Virginia at the intersection of US Route 50 East and WV 92 South. An instrumentation system is developed and implemented specifically to measure and monitor the growth of cracks along the wheel path. The system consists of 30 crackmeters embedded in concrete over the bottom layer of the reinforcement. The crackmeter readings are automatically collected every 20 minutes together with the readings from other sensors that were placed in concrete and on the steel girders to measure: (a) strain in concrete, (b) strain in longitudinal and transverse rebars, (c) temperature gradient through the deck thickness, (d) the bending moment in the steel girders, (e) the overall contraction and expansion of concrete deck, (f) the deflection of the steel girders and (g) the opening of the joint between the concrete deck and the approach slab.

This thesis is focused on developing numerical procedures to predict the occurrence of cracks from crack-meter data. A digital low pass filter was applied to the signals from the crack-meter. The filter cutoff frequency is computed by analyzing the frequency content of the temperature-time history that is collected simultaneously together with the data from crack-meters. The locations of the concrete cracks identified from the measured data were found to be in the regions of high stresses that were identified from the strain measurements through out the deck. Besides validating the new crack detection technique, the detailed instrumentation of the bridge deck reveals that internal stresses, due to the effects of temperature changes are likely to be the main cause of early age cracking in reinforced concrete bridge decks. 
Dedicated to my husband, Raj 


\section{ACKNOWLEDGEMENTS}

Many people have been a part of my work and graduate education, as friends, advisors, and colleagues. Dr Samir .N. Shoukry, The best advisor and friend I could have wished for, he helped me in each stage of my research work. I express my sincere thanks to him for his guidance throughout my research work. It is a privilege to work with him and his research team.

My appreciation goes to Dr. Gergis W. William, Dr. Jacky Prucz, and Dr. Kenneth Means for serving on my committee. Dr. Gergis W. William deserves a special mention for research assistance and help during the stages of my thesis preparation.

I thank all my office mates, especially Mourad and Sirisha, for interesting discussions and insights that helped me to achieve a larger perspective on my work.

Many thanks to all my friends at WVU, particularly my roommates for their inspiration and encouragement through out my research work.

Words cannot truly express my special gratitude and appreciation to my parents, and brother, who always gave me their love and emotional support.

Financial assistance in the form of assistantship and research funds from the West Virginia Department of Highways (WVDOT) is sincerely acknowledged.

Finally, I am forever indebted to my husband Raj for his understanding, endless patience and encouragement when it was most required. It would have been impossible without his emotional support, I dedicate this thesis to him. 


\section{TABLE OF CONTENTS}

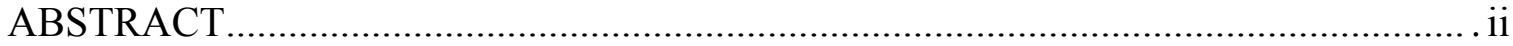

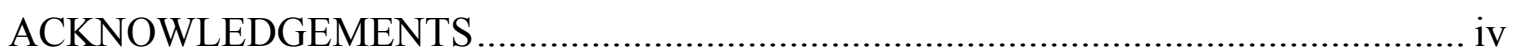

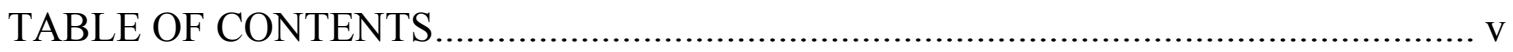

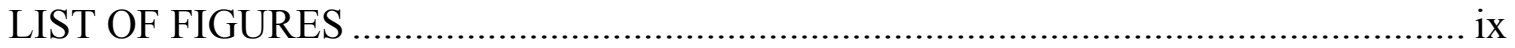

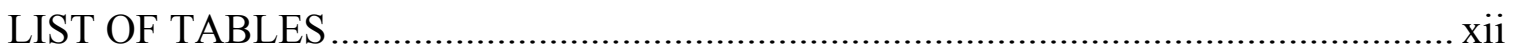

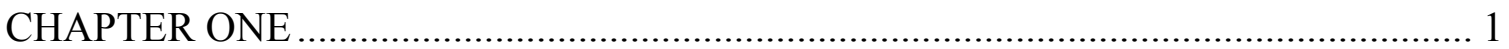

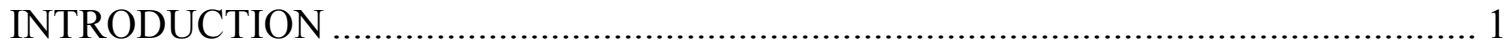

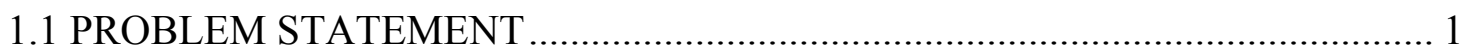

1.2 NEED FOR CURRENT RESEARCH............................................................. 2

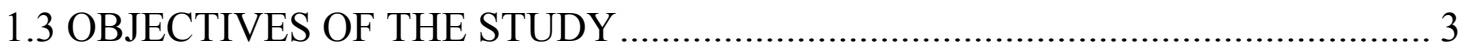

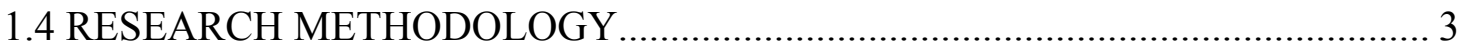

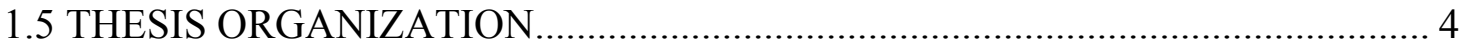

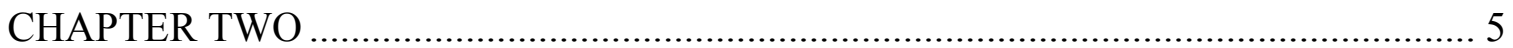

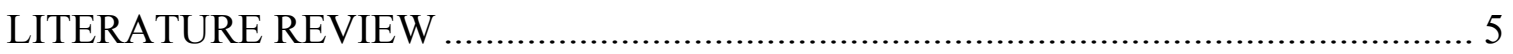

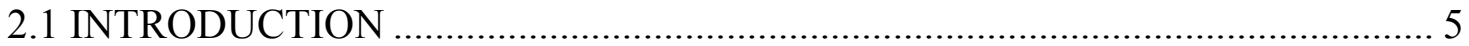

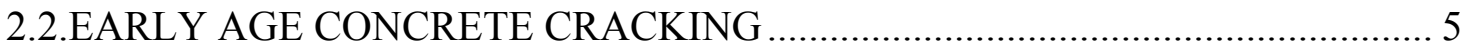

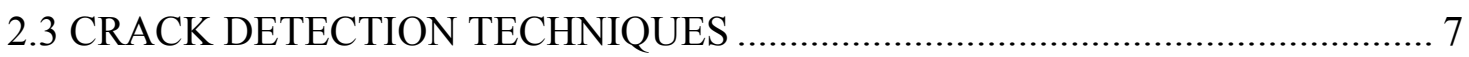

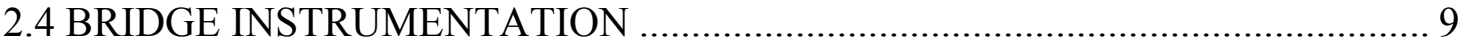

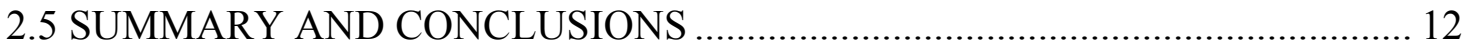

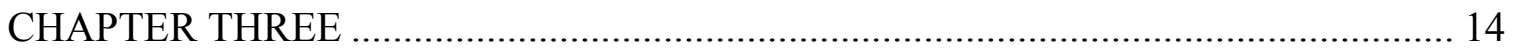

INSTRUMENTATION PLAN AND DATA ACQUISITION SYTEM........................... 14

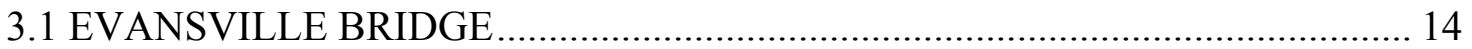

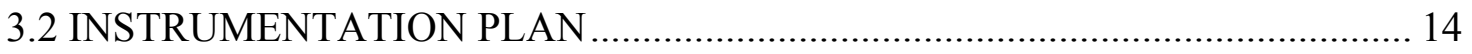

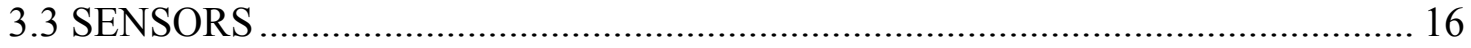

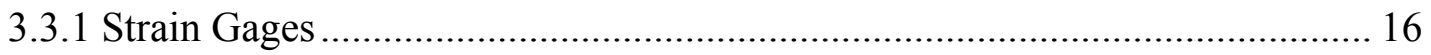

3.3.1.1 Vibrating wire strain gages .................................................................. 17

3.3.1.1.1 Vibrating wire strain gage used on steel girders ................................ 17

3.3.1.1.2 Vibrating wire strain gage used in concrete deck ............................. 18 


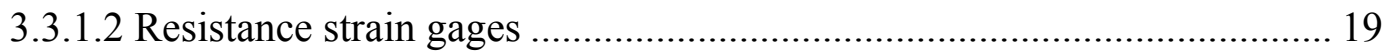

3.3.1.2.1 Resistance wire strain gage used in concrete .................................... 19

3.3.2 Displacement Transducer........................................................................... 20

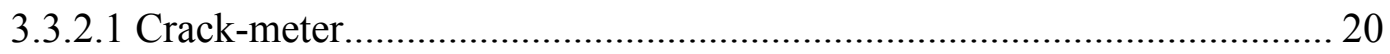

3.3.2.2 Convergence meter ................................................................................ 21

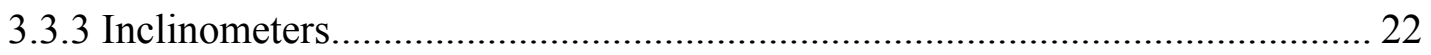

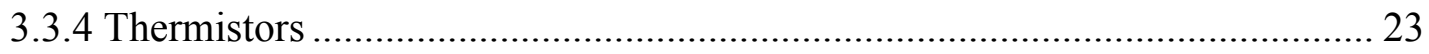

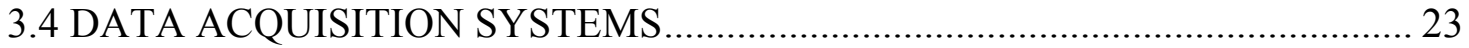

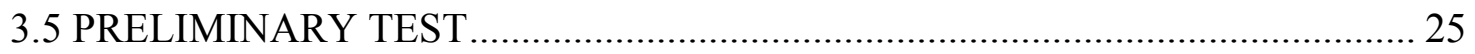

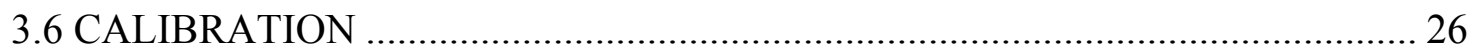

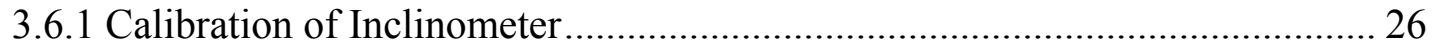

3.7 ERRORS IN THE MEASUREMENT SYSTEM …………................................ 27

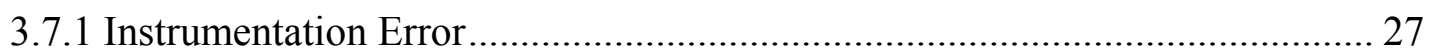

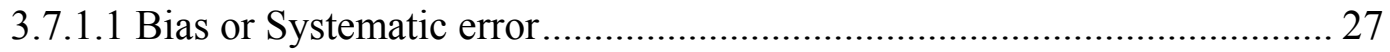

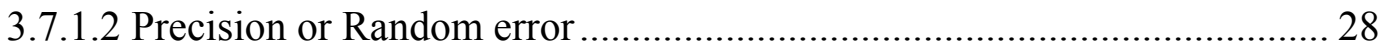

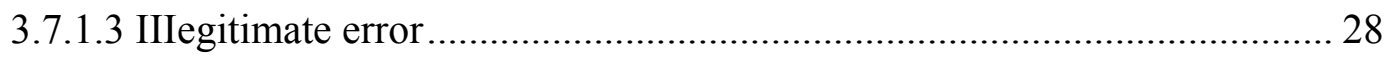

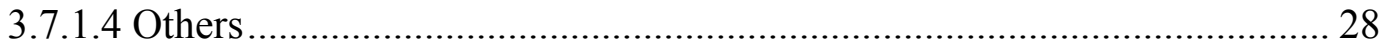

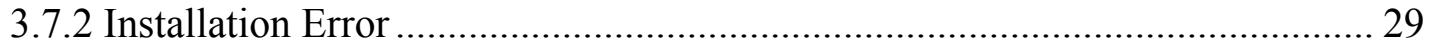

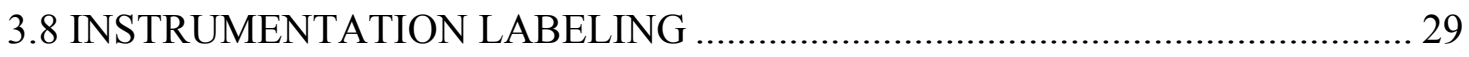

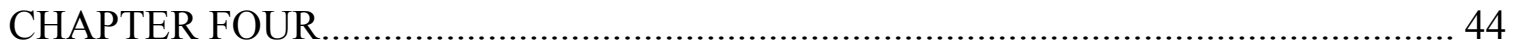

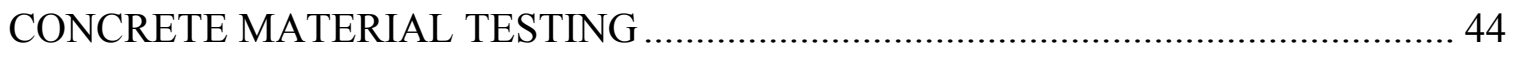

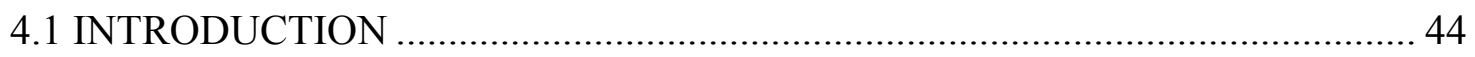

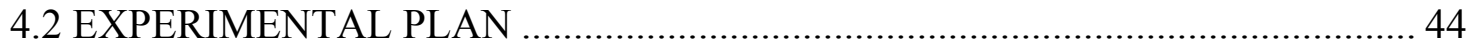

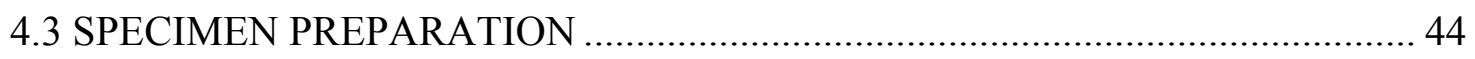

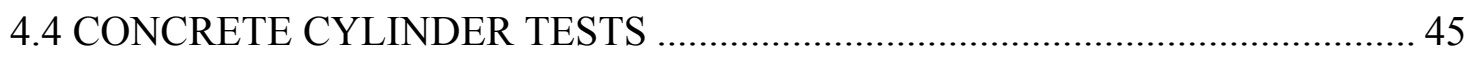

4.4.1 Compressive Strength Tests............................................................................. 45

4.4.2 Splitting Tensile Tests................................................................................ 46

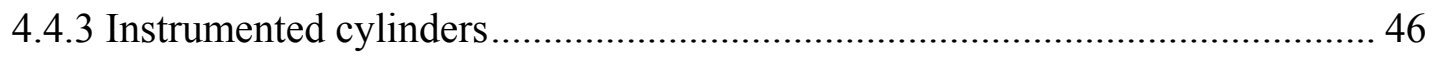

4.5 MATURITY OF THE CONCRETE …………................................................. 47

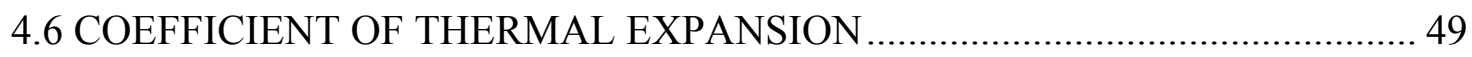




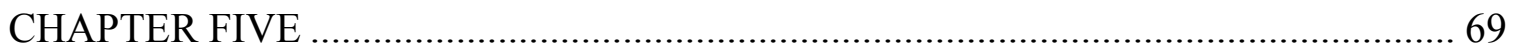

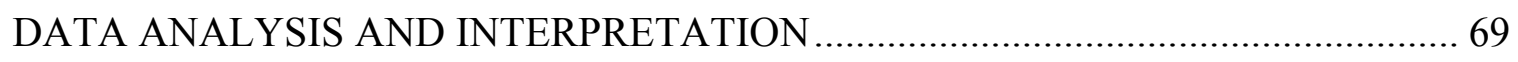

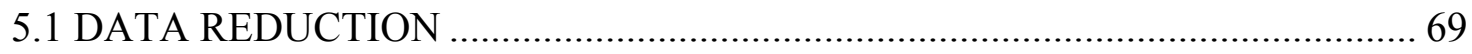

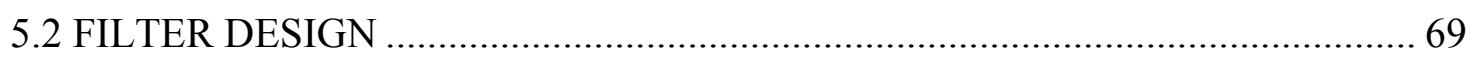

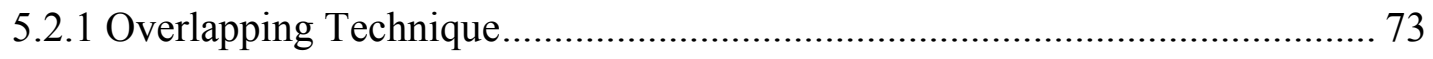

5.3 CRACK ANALYSIS IN EVANSVILLE BRIDGE DECK …………………....... 74

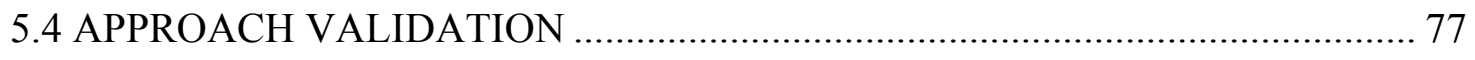

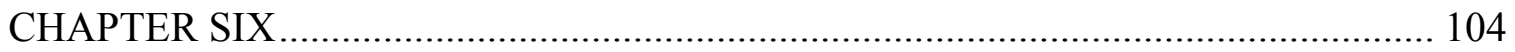

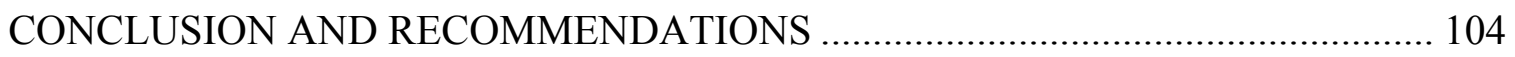

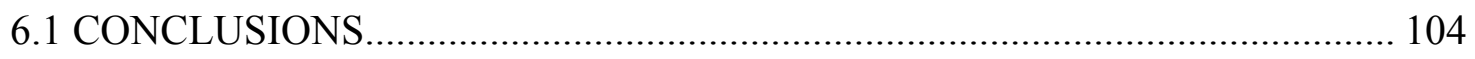

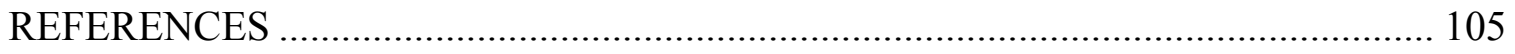

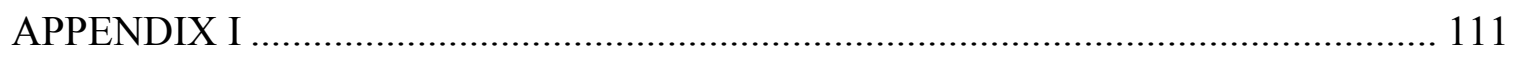

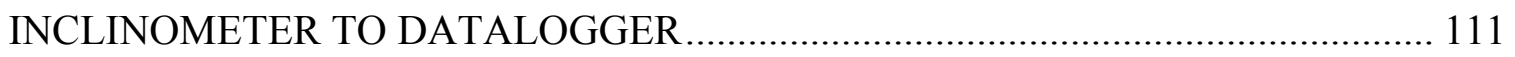

A.1.1 Steps followed to connect Inclinometer to CR10X Data logger....................... 111

A.1.2 Steps followed to configure Multilogger software .......................................... 111

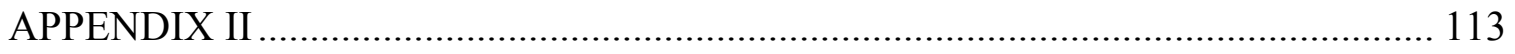

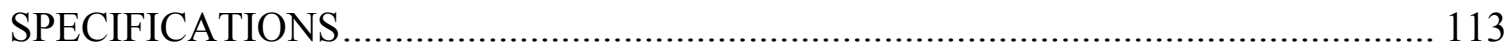

A.2.1 Geokon Model 4200 Vibrating Wire Strain gage ........................................... 113

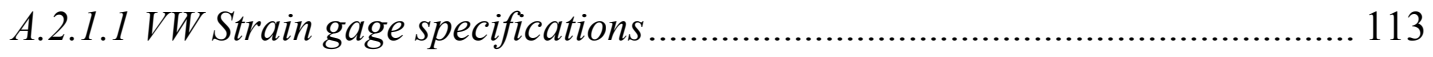

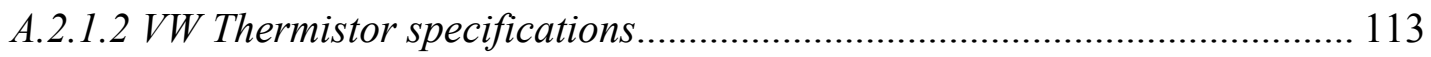

A.2.2 Geokon Model VSM 4000 Vibrating Wire Strain gage (Weldable Strain Gage)

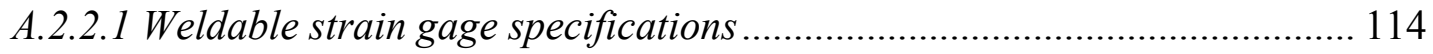

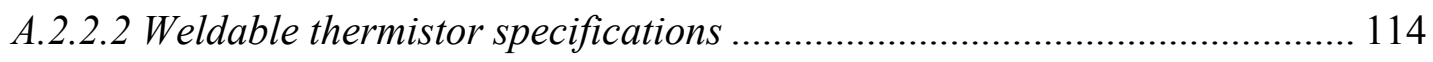

A.2.3 Geokon Model 4911 Vibrating Wire Rebar Strain meters ............................... 115

A.2.3.1 Rebar strain meter specifications ........................................................... 115

A.2.3.2 Rebar stain meter thermistor specifications ............................................. 115 
A.2.4 Geokon Model 4430 VW Deformation meter(crack-meter).......................... 116

A.2.4.1 Deformation meter(crack-meter) specifications.................................... 116

A.2.4.2 Deformation meter(crack-meter) thermistor specifications ....................... 116

A.2.5 Geokon Model 4425 VW Convergence meter............................................. 117

A.2.5.1 Convergence meter specifications ...................................................... 117

A.2.5.2 Convergence meter thermistor specifications ........................................ 117

A.2.6 LCI -14.5 Flexure Suspension Servo Inclinometer .................................... 118

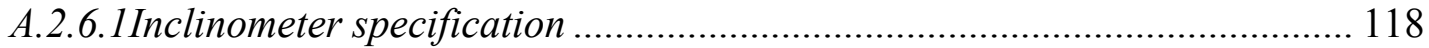

A.2.6.2 Inclinometer electrical specification .................................................... 118

A.2.6.2 Inclinometer environmental specification ............................................ 118

A.2.7 Micro Measurements EGP -5-120 Embedment Strain Gage ......................... 119

A.2.7.1 Embedment strain gage specification.................................................... 119

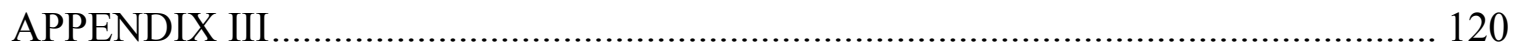

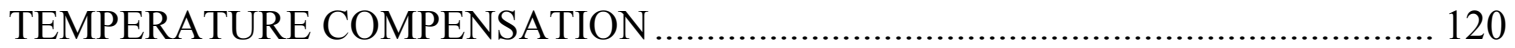

A.3.1 Steps followed to reduce the crack-meters data ........................................ 120

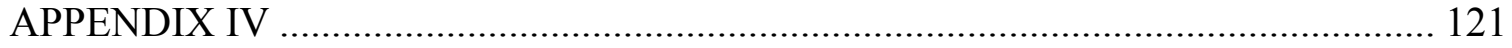

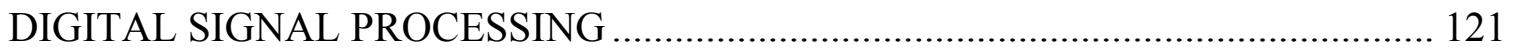

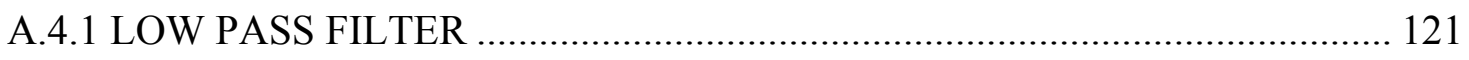

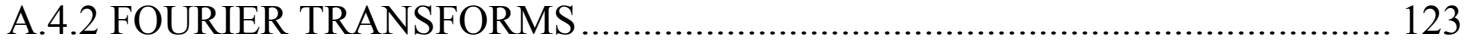

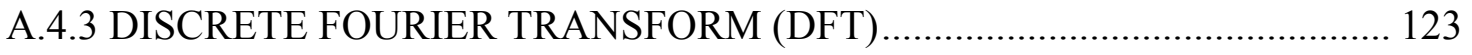

A.4.4 FAST FOURIER TRANSFORM (FFT) ................................................. 123

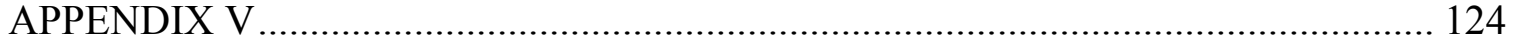

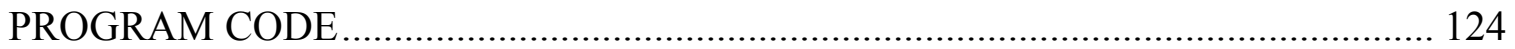

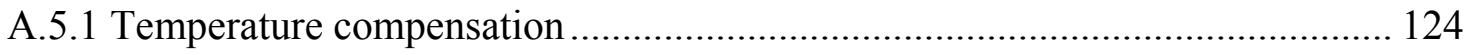

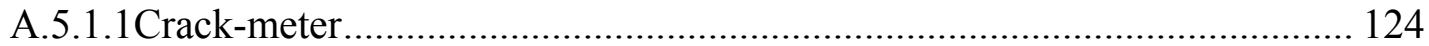

A.5.2 Filter design software (Matlab 6.5) .................................................... 128 


\section{LIST OF FIGURES}

Figure 3.1 Preston county Evansville Bridge (Bridge No. 15721) ………………........... 30

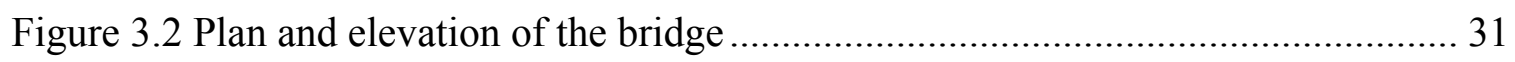

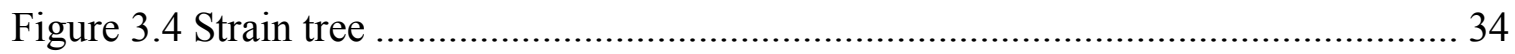

Figure 3.5 Strain tree, Sister bars in a location....................................................... 34

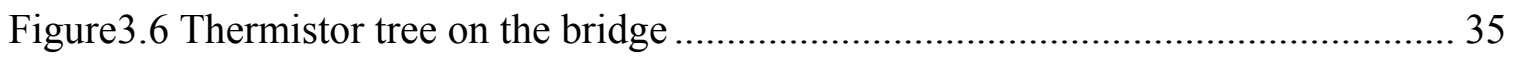

Figure 3.7 Strain tree, Sister bar, Embedment gages in a location .................................. 35

Figure 3.8 Embedment strain gages in a location........................................................ 36

Figure 3.9 Weldable strain gage on the top girder...................................................... 36

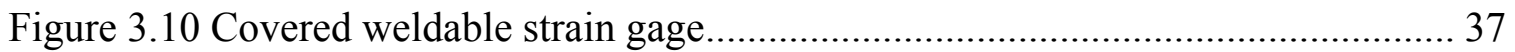

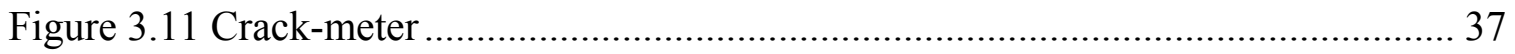

Figure 3.12 Crack-meters aligned over the bridge …………...................................... 38

Figure 3.13 Convergence meter between abutment and pier 1 ….................................. 39

Figure 3.14 Inclinometer after installation ............................................................... 39

Figure 3.15 Multiplexers and Dataloggers used in the project........................................ 40

Figure 3.16 Cables to the instrumentation room......................................................... 41

Figure3.17 Calibration of Jewell LCI Inclinometer......................................................... 42

Figure 5.1 Crack-meter signals from Evansville Bridge .............................................. 80

Figure5.3 Flow chart to represent the overview of the filter design technique ................ 82

Figure 5.5 Overlapping filter design technique with different window sizes................... 84

Figure 5.6 Location of different crack-meters along the bridge ....................................... 85

Figure 5.7 Crack openings on the bridge with temperature drops ................................... 86

Figure 5.8 Crack opening trend and corresponding temperature profile ......................... 87

(a) Crack-meter No. 1 (b) Crack-meter No. 2 (c) Crack-meter No. 3 (d) Crack-meter No.4

(a) Crack-meter No. 6 (b) Crack-meter No. 8 (c) Crack-meter No. 9 (d) Crack-meterNo.10 ...... 88

Figure 5.10 Crack opening trend and corresponding temperature profile ................................. 89

(a) Crack-meter No.11 (b) Crack-meter No.12 (c) Crack-meter No.13 (d) Crack-meter No 14 .. 89

Figure 5.11 Crack opening trend and corresponding temperature profile ............................... 90

(a) Crack-meter No. 15 (b) Crack-meter No. 16 (c) Crack-meter No. 17 (d) Crack-meter No. 1890 
Figure 5.12 Crack opening trend and corresponding temperature profile

(a) Crack-meter No. 19 (b) Crack-meter No. 20 (c) Crack-meter No. 21 (d) Crack-meter No. 2291

Figure 5.13 Crack opening trend and corresponding temperature profile 92

(a) Crack-meter No. 23 (b) Crack-meter No. 24 (c) Crack-meter No. 25 (d) Crack-meter No. 2692

Figure 5.14 Crack opening trend and corresponding temperature profile

93

(a) Crack-meter No. 27 (b) Crack-meter No. 28 (c) Crack-meter No. 29 (d) Crack-meter No. 3093

Figure 5.16 Typical abutment section.................................................................... 95

Figure 5.17 Tensile strength-Stresses measured comparison@ @ location A3, 6.65'....... 96

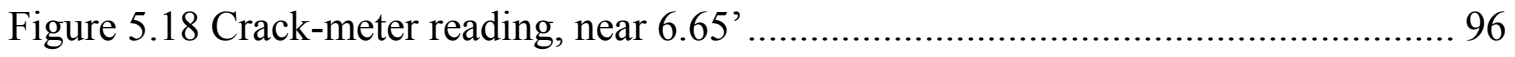

Figure 5.19 Tensile strength-Stresses measured comparison@ location B3, 15.4'....... 97

Figure 5.21 Tensile strength-Stresses measured comparison@ @ location H3, 27.06'..... 98

Figure 5.22 Crack-meter reading, near 27.06' ........................................................... 98

Figure 5.23 Tensile strength-Stresses measured comparison@ location T3, 39.23'..... 99

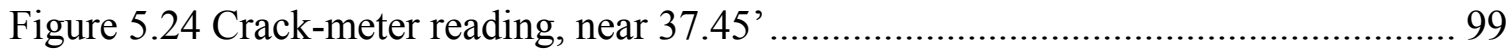

Figure 5.25 Tensile strength-Stresses measured comparison@ location P3, 51.06'... 100

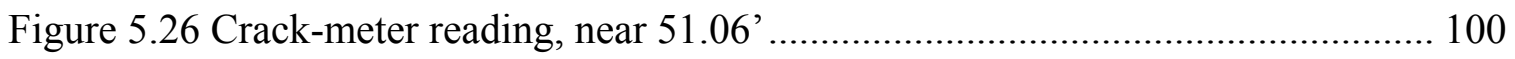

Figure 5.27 Tensile strength-Stresses measured comparison@ location Q3, 64.23'... 101

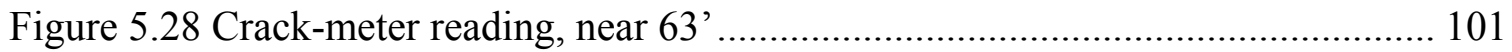

Figure 5.29 Tensile strength-Stresses measured comparison@ location M3, 76.15'... 102

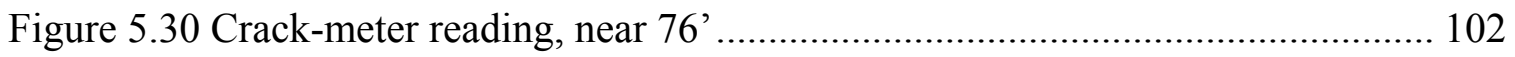

Figure 5.31 Crack was identified at pier, during visual inspection of bridge................ 103

Figure 5.32 Crack was identified at midspan, during visual inspection of bridge ........ 103

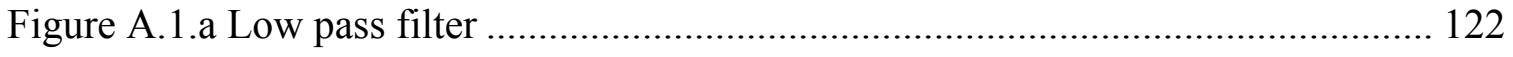

Figure A.1.b Frequency response of an ideal low pass filter.................................... 122

Figure A.1.c Optimum low pass filter.............. $\quad$....................... 122

Figure 4.1 Instrumented concrete cylindrical molds with strain gage ........................... 53

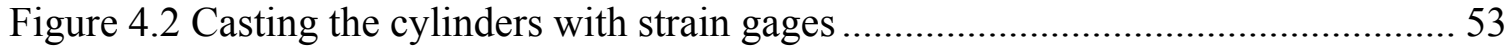

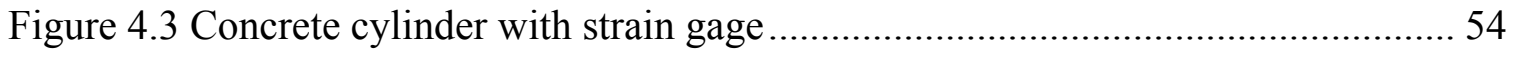

Figure 4.4 Combining the other half of the cylinder after installing the sensor in the lower

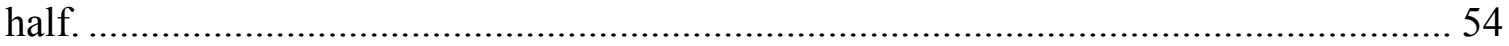

Figure 4.5 Curing of cylindrical specimens at the laboratory .................................... 55 
Figure 4.6 Experimental setup for 6" X 12" cylindrical specimen................................... 56

Figure 4.76 " X12" cylindrical specimen at failure ...................................................... 56

Figure 4.8 Experimental setup for 4" X 8" cylindrical specimen.................................... 58

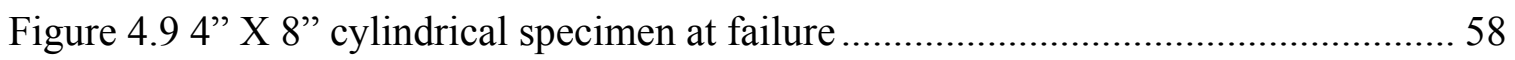

Figure 4.10 Experimental setup for 6" X 12" instrumented specimen............................. 59

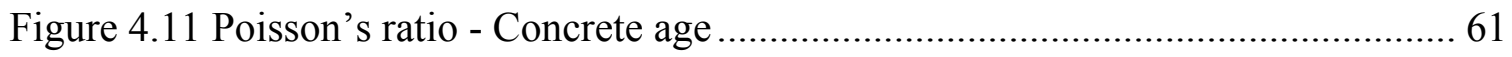

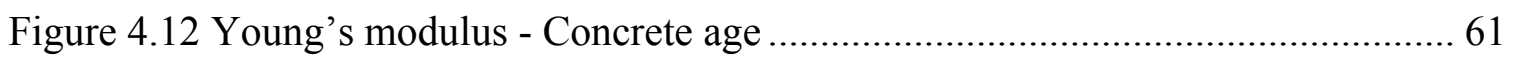

Figure 4.13 Stress - Strain curve for cylinder B, at an age of 2 days ............................. 62

Figure4.14 Stress - Strain curve for cylinder B, at an age of 4 days ................................ 62

Figure 4.17 Stress - Strain curve for cylinder B, at an age of 60 days ............................. 64

Figure 4.18 Stress - Strain curve for cylinder B, at an age of 90 days ............................ 64

Figure 4.20 Curve fit of tensile strength - age models to the data ................................... 65

Figure 4.21 Comparison between in-situ compressive strength and concrete specimen.. 66

Figure4.22 Strain - Temperature history for cylinder A ................................................. 67

Figure 4.23 Strain - Temperature history for cylinder B ................................................... 67

Figure 4.24 Strain - Temperature history for cylinder C..........................66 


\section{LIST OF TABLES}

Table 3.1 Sensor set design for Evansville Bridge................................. 33

Table 3.2 Calibration results for LCI Inclinometer .............................42

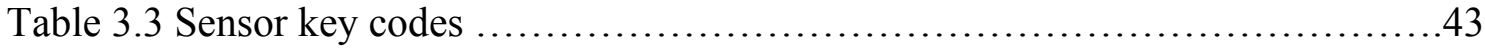

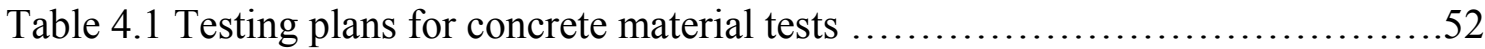

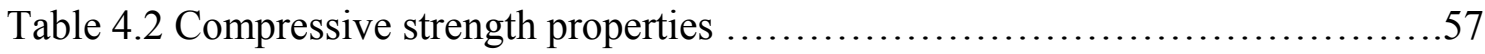

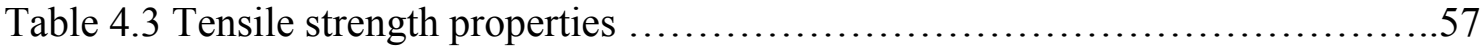

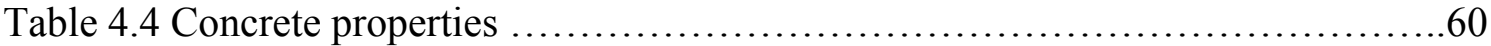




\section{CHAPTER ONE}

\section{INTRODUCTION}

\subsection{PROBLEM STATEMENT}

Many bridges in the United States have developed early age cracking on the concrete bridge decks, even before bridge opening the traffic. Early age cracking occurs due to the internal stresses mostly resulting from combination of factors, such as temperature variations and restrained shrinkage (French et al., 1999). Cracks are normally observed at the joints due to the differential shrinkage of the concrete when a new stage casting is placed (Issa, 1999). Also the internal stresses develop during curing, due to the heat of hydration and vibrations of the adjacent traffic cause early age cracks on the bridge decks (Issa, 1999). A recent study (Schmitt and Darwin, 1999) on evaluating the material properties that causes cracking reveals that the crack intensity increases with increase in water/cement ratio, concrete slump and compressive strength of the concrete. However, besides material properties there is some existing structural factors that need to be further studied in depth to prevent early age cracks on the concrete bridge decks.

Crack occurs when the internal stresses developed during heat of hydration or curing, exceeds the tensile strength of the concrete. This cracking may not be dangerous at the initial stages, but with the time, due to the absorption of deicing chemicals and moisture, it may lead to the corrosion of reinforcing steel and spalling of the concrete structure (Cusson and Repette, 2000). Hence, increased maintenance costs and ultimately affects the service performance of the bridge. In 2000, Federal Highway Administration's (FHWA) national bridge inventory revealed that the expenditures for maintenance costs are the second largest share (after the first capital investment i.e. approximately $64 \%$ of the total highway funds), approximately $31 \%$ of the total highway funds and proves to be increasing very drastically since 1970. In the recent years, several investigators to alleviate the cracks on the concrete bridges and thus improved service life of the pavements have examined the problem of early age cracking. 
In order to understand the concrete cracking phenomenon on the bridges, cracks must be first detected for further studies on behavior of the concrete cracks. Some existing non-destructive methods such as visual inspection (Graybeal et al., 2002, Furr and Fouad, 1981, Pape, 1998, Kyle, 2001, Hadidi et al., 2001), acoustic emission (Newman, 1966) and ground penetrating radar method (Halebe et al., 1994) have been employed for crack detection. Most of the highway agencies in the United States use visual inspection method to detect any defects, however the results depend on the reliability of the individual inspectors, and might need confirmations from more than one inspector. On the other hand, non-destructive techniques require minor traffic interruptions (Jone, 1962, Kadir, 1992). Hence, there is a need to develop appropriate non-destructive crack detection technique that can be used to analyze and detect the cracks by considering all the design, construction details and environmental conditions into account.

\subsection{NEED FOR CURRENT RESEARCH}

Prevention of early age cracks on concrete bridge decks in the United States has been a continuing concern of the bridge engineers. Despite of the large amount of research work addressing the early age cracking, the investigators have not been successful in preventing or reducing the cracks. Particularly during winter season, formation of cracks on the concrete surface will cause the de-icing chemicals to infiltrate through the concrete and results in corrosion of steel reinforcement. This corrosion with the time will cause delamination or spalling of the concrete, which will in turn, increases the rate of corrosion of the steel, and hence affects the structural capacity and durability of the concrete structure (Pepe, 1998). Attempts to correlate concrete material properties to concrete cracking were not successful to give an explanation for the problem (Schmitt and Darwin, 1999). Shiu (1981 report) recommended, the temperature of the concrete to be placed should be to be close to the temperature of the old concrete in construction joints, but there is no information given to control the heat of hydration of the concrete during casting. 
In the concrete bridges, combinations of factors exist for concrete cracks and it is difficult to explain the reasons for degree of cracking, which significantly affects the durability of the bridge. Because of the significance of the problem, it is important to monitor the bridge performance continuously, so that it will capture all the crucial design, construction, maintenance, and performance parameters that cannot be captured or quantified visually or through intermittent monitoring. Hence, effective bridge monitoring system and proper crack detection techniques are essential in order to understand and study the early age cracking of the concrete bridge decks, and also to monitor the short-term and long-term performance of the bridge.

\subsection{OBJECTIVES OF THE STUDY}

The primary objectives of this study are as follows:

1. To develop a sensory system that would detect cracks and estimate the crack openings in the concrete bridge decks.

2. To identify the contribution of temperature variations effect on the early age cracks developed in concrete bridge decks.

3. Data analysis and interpretation for long-term seasonal and short-term traffic loadings effects on the bridge decks.

\subsection{RESEARCH METHODOLOGY}

To achieve the objectives, the research methodology followed can be summarized as:

1. An intensive literature review on early age cracking of bridge decks, methods for crack detection and instrumentation programs.

2. Selection of appropriate sensors and its locations on the bridge for monitoring long-term and short-term performance of the bridge.

3. All sensors were tested and calibrated in the laboratory before its installation.

4. Concrete material tests were conducted on standard concrete cylinders to determine the actual material properties of the concrete used in the bridge. 
5. Development of a new non-destructive technique to detect cracks, particularly on the concrete bridge decks.

6. Finally, data analysis and data interpretation (using step (5)), to monitor the shortterm loading and long-term seasonal effects on the bridge performance.

\subsection{THESIS ORGANIZATION}

In the first chapter, problem statement, the objective and methodology of the project are defined. Chapter 2 of this thesis covers the existing literature review, previous work done to mitigate the problem and the unsolved issues on the related topics. A brief instrumentation plan with the types of sensors that were installed and its installation techniques, explained in chapter 3. Chapter 4, gives a brief introduction to concrete test methods that were performed in the laboratory to get the properties of the actual concrete for the data interpretation purposes. Development of software to detect cracks, data analysis and data interpretation for monitoring the long-term and short-term performance of the bridge, were covered in the chapter 5. A summary and conclusions are presented in chapter 6 . 


\section{CHAPTER TWO}

\section{LITERATURE REVIEW}

\subsection{INTRODUCTION}

Early age cracking of bridge decks is a complex phenomenon, which is associated with excessive shrinkage and temperature variations (Cusson and Repette, 2000). Cracks normally develop when concrete is constrained to shrink or contract due to the resulting tensile stresses, which eventually cause the concrete to crack when stresses developed exceeds the tensile strength of the concrete. With time, these cracks propagate through the deck thickness, thus affecting the serviceability of the bridge structure. In order to reduce the negative effects of cracks, there is a great need for a comprehensive understanding for the causes of early age cracking. This can be achieved through appropriate crack detection method and instrumentation program.

The literature review presented in this chapter includes an overview of the concrete cracking, various existing methods to detect the cracking and instrumentation program.

\subsection{EARLY AGE CONCRETE CRACKING}

Many researchers examined the problem of early age cracking of concrete. Some attributed such a problem to factors in the concrete materials such as mix, slump (Schmitt et al., 1999), while others considered the causes are structural in nature (Cusson and Repette, 2000).

Issa et al. (1999) studied the various causes for cracking in concrete bridge decks, often before a bridge opens to traffic. They conducted laboratory tests to establish the modulus of rupture that a bridge can withstand without cracking. They reported the various loads that cause cracking to be: (1) loads associated with construction and vibration (2) effect of internal stresses. He conducted early age concrete tests at 3,5 and 
12 hours of pour for different concrete mixes. They concluded that the temperatures generated in the concrete due to heat of hydration, during curing and environmental conditions affect the concrete at its early age and may extend up to structural deformation. Hence he recommended that the concrete must be protected during its curing stage with vinyl covers and /or wet burlap. Their experimental results revealed that low slump concrete is less susceptible to cracks than high slump ones. Their field investigation also revealed that inadequate reinforcement between new and old decks result in early age cracking of the joints. From a questionnaire survey, he also concluded that vibrations due to adjacent traffic might increase early age cracking of bridge decks.

Schmitt et al. (1999) attempted to evaluate the effect of material properties on cracking of the bridge decks. He developed correlations between the observed level of cracking and the variables based on the construction documents and. They performed field surveys on 40 bridges to explore the effect of concrete material properties on the deck cracking and searched for recommendations in design and construction techniques to mitigate the problem. From their field surveys, they concluded that the material properties that show desirable effect on cracking are admixtures, slump, compressive strength, water/cement ratio, and air content. Based on their findings, the authors recommended the following:

- Retarding agents accelerate the bridge deck cracks.

- Cracking increases with increasing slump and water/cement ratio.

- Cracking decreases with increase in air content

- Cracking tends to increase with increase in cement content, hence compressive strength of the concrete. He observed a change of 0.59 -in./sq $\mathrm{ft}$ crack to 1.8 -in./sq $\mathrm{ft}$ for a change in compressive strength of $4,500 \mathrm{psi}$ to 6500 psi.

However, they also stated that concluded that evaluation of material properties is not enough to correlate the concrete properties to prevent concrete cracks. 
Shahawy et al. (1996) conducted laboratory tests on instrumented concrete specimens to monitor the bridge behavior during and after construction. The laboratory tests were conducted according to the ASTM designations to measure the concrete compressive strength, modulus of elasticity, poisson's ratio, coefficient of thermal expansion, and strains in the concrete. Standard concrete cylinders of 152.4 X $304.8 \mathrm{~mm}$ (6"X12") were made on the bridge side and then shipped to the construction technology laboratory, where cylinders were stripped from their molds and stored at a constant temperature $\left(22.8{ }^{\circ} \mathrm{C}\right)$ and relative humidity $(50 \%)$. He conducted short-term property tests on concrete ages of $3,7,28,90,180$ and 360 days. Vibrating wire strain gages of type VCE 4200 were positioned at the center of the cylinders before casting to get the longitudinal concrete strains and internal temperature of the concrete. A computercontrolled automatic data acquisition system was used to capture the data. The captured data measures the compressive strains at different concrete ages for different locations.

\subsection{CRACK DETECTION TECHNIQUES}

Cracking in concrete bridge decks, particularly at its early age have significant effects on the serviceability and performance of the bridge. Many studies were conducted to develop a non-destructive method to detect cracks on concrete bridge decks. This section covers the wide range of literature on the existing techniques to detect cracks.

Visual inspection of bridges is commonly used technique by state DOT's to detect cracks on the concrete bridge decks (Furr and Fouad, 1981, Pape, 1998, Kyle, 2001, Hadidi et al., 2001). The Federal Highway Administration (FHWA), conducted visual inspection of highway bridges to detect the defects and cracks on concrete bridge decks (Graybeal et al., 2001). However, such a method depends on the observations of the inspectors and can only detect the surface cracks. With the increasing use of corrugated steel stay in place forms, it is impossible to visually inspect the bottom of the bridge decks. Therefore, other methods based on non-destructive evaluation have been developed for crack detection in concrete bridge decks. 
Acoustic emission is one of the oldest non-destructive testing methods for detecting cracks and growth of micro cracks in the concrete structure (Newman, 1966). Ultrasonic pulse velocity is also a popular method for crack detection and also used for evaluating the quality of the concrete (Jones, 1972). In ultrasonic technique, cracks in concrete structure affects the wavelength and amplitude of the signal recorded depend on the intensity of deterioration. Holography is another non-destructive testing method for detecting cracks in the concrete structure (Luxmoore, 1973). Owen (1976) introduced the use of capacitance strain gauge for continuous monitoring of the cracks, particularly on the steam pipes. According to this study, sudden drastic changes in strain values implies the presence of crack around or near by the gauge location. However, capacitance gauges need to be spot-welded on the surface to be monitored hence limited to very few applications. Kadir (1991) developed an infrared thermography and digital image processing system for deterioration detection on bridge decks. The crack areas in general will have different surface temperatures, Infrared thermography detects and record this temperature differentials on videotapes. Then these images are processed and analyzed using digital image software. Halabe et al. (1994) used ground penetrating radar (GPR) technique to detect surface cracks on the concrete structure. As GPR works on emitting the high electromagnetic waves into the concrete surface, it's well known as non-contact, rapid and safe technique to be used for crack detection.

Recent developments in the sensor technology enhanced the wide use of miniature sensors in the bridge performance and maintenance fields. In 2002, Kuang proved that the plastic optical fibers could be used to detect hairline cracks, failure cracks and also for monitoring the crack propagation in the concrete structures.

Although the aforementioned techniques were successfully used to detect cracks in concrete bridge decks. They could not give an explanation for the occurrence of such cracks or when these cracks initiated, which represents the first step to treat such a problem. Therefore, many researchers started to instrument the bridge deck to monitor the deck performance in an attempt to find out the reasons for crack development. 


\subsection{BRIDGE INSTRUMENTATION}

In 1996, Federal Highway Administration's presented a guideline for bridge instrumentation, with an outline of various basic measurements that can be made on all the bridges with an appropriate instrumentation program (Russell, 1996).

In this report, the author set recommendations for each measurement as:

- Strain gage bars to measure dynamic strains due to live loads and traffic loading.

- Vibrating wire strain gages to measure long-term strains due to dead loads, temperature and moisture changes.

- Thermocouples placed through the depth of the girder to measure the temperature gradient profile.

For instrumentation purpose, author divided the strains into two types: (1) long-term strains (2) short-term strains. He suggested the use of electrical resistance strain gages for dynamic measurements and vibrating wire gages for long-term measurements. Electrical resistance gages measures the output in terms of voltage where as vibrating wire gages measures output in terms of frequency, Hence vibrating wire gages were suggested for long-term strain measurements (Levi, 1999). The author used a basic method to measure the overall change in length of the bridge due to creep and seasonal temperature changes. Such a method includes the use of reference rod with low thermal coefficient of expansion: Rod should be fixed to the bridge at one end and the relative movement between rod and the bridge measures the change in the length of the bridge or portions of the bridge. He stated that monitoring the field performance starts with data collection, data reduction and data interpretation. Interpretation of data requires the physical values of the stresses, thermal coefficient of expansion and modulus of elasticity of the concrete. Thus he recommended determining the mechanical properties from the actual concrete specimen tests. 
Shiu et al. (1981) instrumented three cross sections of one span, box girder bridge to determine time-dependent effects of creep, shrinkage and temperature on the bridge performance. They reported that the bridge construction was divided into three stages, casting the bottom and sides of box girder as the first stage, casting the top of the box as second stage and casting the cantilever deck on the both sides of the girder as the final stage. Their field investigation revealed that the maximum temperature gradients (nearly $50{ }^{\circ} \mathrm{F}$ ) were occurred across the construction joints, when a new stage casting was placed. As a result, internal stresses were induced, which cause early age cracks on the bridge decks. They developed a computer program to calculate the effects of creep, shrinkage and temperature based on the field data using the concrete properties obtained from the laboratory tests. From the results, the authors concluded that the long-term deformation contains four major components: Instantaneous deformation, Creep deformation, Shrinkage deformation and Secondary deformation. Deformations were calculated individually from the physical properties of the concrete and it was found that the strains in the initial 100 days were mostly instantaneous deformations. From the field test results, the author made the following recommendations: 1) To minimize the strain and stress distributions across cross-sections, concrete with elastic properties should be used.2) Care should be taken to control the concrete temperature during casting and curing stages.3) Accurate estimation of dead weight and post tensioning stresses are necessary in calculating the total deformations in the bridges.

Leon et al. (1993) instrumented a steel girder bridge using eight reusable strain sensors and six inclinometers to measure and monitor the load distribution, stresses in the bridge. They emphasized the use of instrumentation program for the purpose of bridge evaluation rather than any inspection methods. The two types of measurements they discussed include, stresses as they affect the strength of the structure and deflections as they affect the bridge serviceability. Strain gage sensors with effective gage length of 5 inch were used for both static and dynamic measurements. Strain gage sensors with effective gage length of 7-inch are used for fatigue measurements. For the purpose of deflection measurements, they used different transducers like linear variable differential transducers, linear potentiometers, inclinometers, some mechanical devices such as dial 
gages and levels. Except the inclinometer, which directly measures the deflection, all other deflection-measuring devices measures deformation by successive integration of the load differential equations, hence the authors recommend the use of inclinometer for deflection measurements. They also concluded that the data from deflection and stress measurements were further analyzed for the purpose of bridge evaluation.

Levi et al. (1999) instrumented a reinforced, steel girder bridge in two phases. The first phase of this project dealt with the appropriate selection of hardware for bridge monitoring where the second phase dealt with the installation and design specifications. From the market survey and laboratory evaluation, they selected certain types of sensors like two types of strain gages: resistance strain gages and vibrating wire strain gages, displacement transducers, accelerometers, crack meters, pressure sensors, inclinometers and extensometers, which are the very common sensors that are being used for instrumentation program. They installed 54 strain gages, tilt meters, accelerometer, displacement transducer, a weather station and a data acquisition system for collecting and storing the data. The authors conducted three types of tests: static load test to measure short term responses due to static loads, slow speed load test to measure short term responses due to moving traffic and long term test to monitor daily and seasonal temperature and environmental effects on the bridge. Data was used to collect at different sample rates (not continuously) and thus the data obtained consists of all the information about the bridge. Data were then analyzed, for both long term and short term monitoring of the bridge at two different sampling rates. The results were discussed in his later report (2001). They reported that the strains in the first few initial days of pouring during heat of hydration were seem to be erratic and irregular. And also they found that the strains were not showing any specific patterns, expect sudden increase and sudden drop in tensile strains. They emphasize the concept of early age cracking due to the fact that the decrease in temperature results in increasing the tensile strains and hence the formation of cracks on the concrete bridge decks. But they could not detect any cracks with their sensors on the concrete bridge decks. However, they recommended the continuous monitoring to detect any damage or any deterioration which improves the maintenance and hence the bridge life. 
Gopalaratnam et al. (2001) instrumented a prestressed girder bridge to get a better view of the early age cracking on the bridge decks. The other objective of his instrumentation program was to measure the temperature gradient across the girder, which in turn allows the computation of residual stresses. Each instrumented cross section of the bridge contains three types of gages: Strain gage bars, Vibrating wire strain gages and Thermocouples. Thermocouples are placed along the depth of the girder to measure temperature gradients. Strain gages and vibrating wire gages were placed together to read both the long-term and short-term strains. Strain and temperature measurements were recorded while the bridge was in service. The field results revealed that the maximum differential temperatures were around $12-22{ }^{\circ} \mathrm{C}$. As a result of these temperature gradients, strain gradients were induced in the girders, and were of the order of \pm 40 microstrains. Two types of cracks, horizontal and diagonal cracks were found on the girders after 6 days from casting. The authors concluded that improved curing procedure allows more uniform temperature changes that provide improved tensile performance or reduced stresses, which will minimize the potential for cracking. They also concluded that the influences of daily and seasonal effects are significant in comparison to the loading tests on the bridge performance.

\subsection{SUMMARY AND CONCLUSIONS}

Issa (1999) explained the various causes for early age cracking and the recommendation to prevent the early age cracking. His experiments revealed the range in physical values of the concrete to withstand cracks and theoretical analysis to support his laboratory results.

The survey results on the evaluation of physical and mechanical properties of concrete by Schmitt (1999) were not good enough to determine which property is responsible for the early age cracking.

The non-destructive methods discussed above have their own advantages and disadvantages. The crack detection method used by Kadir (1993), infrared thermography 
is only economical if used extensively. Other factors limiting its uses include the interruption of traffic flow and weather dependence. Owen (1976), capacitance strain gages method needs the gage to be mounted on the surface to be monitored, which is not possible in the case of bridge decks because of the traffic flow. Other techniques that are commonly used include photo grapy and visual inspection. They all include minor traffic interruptions, might need confirmation from more than one inspector hence increased labor cost and time.

The guidelines for instrumentation program by Russell (1996) were very informative. He explained the necessity for each measurement and the required types of instrumentation. Market survey by Levi (1999) for different types of sensors, gave good idea about all the sensors available for instrumentation purposes. His laboratory evaluation for the sensors and the installation techniques were given a better idea to select the appropriate sensors and techniques. However, the data was not collected continuously, due to which the report fails to explain the details and performance of the bridge in detail.

As there is no particular method that determines the physical property responsible for early age cracking or reasons for crack openings on the bridge decks and method to detect cracks on the bridge, hence there is need to conduct an extensive instrumentation programs to understand the bridge performance under different effects that includes curing of concrete, loading, temperature effect, shrinkage and seasonal effect, in which the first step is to treat the early age cracking with an appropriate crack detection method. 


\section{CHAPTER THREE}

\section{INSTRUMENTATION PLAN AND DATA ACQUISITION SYTEM}

\subsection{EVANSVILLE BRIDGE}

Evansville Bridge is located in Preston County, West Virginia at the crossing of Route WV-92 and Little Sandy Creek, approximately $500 \mathrm{ft}$ south of the interchange between Routes WV-92 and US-50, as shown in Figure 3.1. The bridge is a typical three-span continuous steel girder bridge and has a $55^{\circ}$ skewed angle. The total length of the bridge is $147 \mathrm{ft}$, in which the lengths of the edge spans are $48.5 \mathrm{ft}$ and the central span is $50 \mathrm{ft}$ long. The bridge is supported over two piers and two integral abutments as shown in Figure 3.2. The total bridge width is $44 \mathrm{ft}$ between the parapet toes. The deck accommodates two traffic lanes, each $12 \mathrm{ft}$ wide, and two shoulders of widths 8.5 and 9.0 $\mathrm{ft}$ as shown in Figure 3.2. The minimum thickness of the reinforced concrete bridge deck is 8 -inch. The deck thickness increased over the girders to be 9-inches through haunches. The bridge is constructed in two stages. The construction of the first stage was completed in June 2003. The instrumentation were placed during the first stage of construction over $78 \mathrm{ft}$ long and $15 \mathrm{ft}$ width as illustrated in Figure 3.3.

\subsection{INSTRUMENTATION PLAN}

Instrumentation plan is designed and developed to capture the distribution of strains and temperature fields through the bridge. This provides a complete set of data for actual performance of the bridge in service.

In total 232 sensors were selected to be installed at various locations on the bridge to monitor the bridge behavior due to traffic loads and seasonal effects. Table 3.1 summarizes the number of each type of sensors used in the bridge. Twenty two locations have been selected for the placement of vibrating wire strain gages as shown in Figure 3.3 , each location having 6 or 5(due to technical issues) gages in the form of tree. A 
typical strain gage tree consists of 6 gages; two gages were mounted at each $\mathrm{X}, \mathrm{Y}$ and $\mathrm{Z}$ direction, one being at the top and other at the bottom section as illustrated in Figures 3.4 and 3.5. This design expected to capture the strain distribution in the $\mathrm{X}, \mathrm{Y}$ and $\mathrm{Z}$ direction due to environmental effects.

The vibrating wire sister bars were placed next to the vibrating wire strain gages as shown in Figure 3.5, to check the compatibility between the strain developed in concrete and those developed in the steel reinforcement. Eight locations were selected, two sisters bars, in longitudinal and transverse directions were mounted at each section, two sister bars at the connection between the abutment and approach slab.

Eight weldable gages were selected to be mounted one at the top and the other at the bottom of the steel girder at four positions: near abutment, half span, pier and mid span of the middle span as shown in Figure 3.3. Seven inclinometers were mounted on the bottom flange of the girder B, rest in the middle span between pier 1 and mid-span.

Two convergence meters, one between abutment and pier 1, the other between pier 1 and pier 2 were used to measure any relative movement between the abutments and piers.

A total of 30 crack-meters were used on the bridge to monitor the bridge crack growth and for bridge axial deformation along the wheel paths. Four deformations meters are placed in the construction joint between the deck and approach slab and rest are placed in series through out half-length of the bridge.

For temperature distribution along the thickness of the bridge, two-thermistor trees were installed as shown in Figure 3.6. A thermistor tree consists of 17 thermistors distributed in 8-inch long, 1-inch diameter tube. Eight thermistors were distributed in the first 1-inch and rest at one thermistor per each inch long tube with one at the top and at the bottom of the tube. 
For dynamic measurements, 16 embedment strain gages are installed near the strain gage trees as shown in Figure 3.7. Eight different locations were selected for embedment gages, having two gages at each location, one being at the top and other at the bottom. One such location was illustrated in Figure 3.8.

\subsection{SENSORS}

In general, the basic instrumentation program is concerned with two types of measurements: strains, as they affect the ultimate strength of the structure and deflections, as they affect its serviceability (Schmit, 1992). The main objective of this project is to identify the contribution of temperature variations as well as material and structural factors that lead to early age cracking in the concrete bridge decks. This would require capturing the strain and axial deformation for long-term behavior of the bridge due to seasonal effects and short-term behavior under traffic loads. The instrumentation plan, the selection of the type of the sensors to be installed and the data acquisition system used to capture the data plays an important role in this project. The different categories of the sensors used for this project are:

\section{Strain Gages}

2. Displacement Transducers

3. Inclinometers

4. Thermistors

\subsubsection{Strain Gages}

Strain gage measures the change in its length over the length of the gage. It is the most commonly used type of sensor in the instrumentation programs. The two types of strains need to be measured are:

- Short- term strains

Due to traffic loads, Resistance strain gages are used.

- Long-term strains 
Due to seasonal temperature changes, creep and shrinkage in the concrete structure, Vibrating wire strain gages are used.

The basic types of strain gages used are classified as:

3.3.1.1 Vibrating wire strain gages (for long-term monitoring)

(i) Vibrating wire strain gage used on steel

(ii) Vibrating wire strain gage used in concrete

3.3.1.2 Resistance strain gages (for short-term monitoring)

(i) Resistance wire strain gage used in concrete

\subsubsection{Vibrating wire strain gages}

In vibrating wire strain gages, the deformation of the surface causes the two end blocks to move relative to one another, thus altering the tension in the steel wire. Plucking the wire and measuring its resonant frequency of vibration using an electro magnetic coil measures the tension and hence the resulting deformation. Since the vibrating wire strain gage is based on the natural frequency of the wire, instead of resistance in wire resistance strain gages, the vibrating wire can be used for long-term strain measurements without any drifts or electric noise. The length of the wire changes with the change in temperature implies that tension, natural frequency and strains are temperature dependent. To minimize or nullify this effect, the manufacturer provides temperature correction (Geokon Model VCE 4200, 1997).

\subsection{Vibrating wire strain gage used on steel girders}

The Geokon model VSM 4000 strain gage is designed for arc welding to the steel structures, as shown in the Figure 3.9. The model VSM 4000 is a $5.875^{\prime}$ long with midrange of 3000-microstrain and one micro strain sensitivity. The detachment of the electronic coil in this gage allows a good flexibility in installation, repair and maintenance of the gage. A thermistor is provided inside the gage for temperature measurements. The coefficient of thermal expansion of the gage is same as steel surface 
hence temperature correction/compensation is not necessary (Geokon Model VSM 4000, 1997).

The VSM 4000 vibrating wire strain gages are provided with a set of mounting blocks, one has a single cone point set screw, the other has two oval point set screws. The surface on which strain gage to be mounted was cleaned with surface grinder to remove all rust, dirt and oil. The blocks are fixed to the edge of the strain gage and tightened little bit. Block positions were marked with a marker, and replaced the gage with a spacer, and the blocks are firmly held with the jig for further installation. Then blocks are welded to the edges of the surface on which sensor gage need to be installed. Fix the sensor to the mounting blocks, as shown in the Figure 3.9. As shown in Figure 3.10 , to protect the sensor from environmental conditions, cover the strain gage and end blocks with a plastic cap using the epoxy adhesive.

\subsection{Vibrating wire strain gage used in concrete deck}

The Geokon VCE 4200 vibrating wire strain gage is designed primarily for long term, direct embedment in the concrete. VCE 4200 is a 6-inch long, 3000 micro strain range gage. The gage is a reliable, waterproof rugged design with one micro strain sensitivity, and is unaffected by the length of the cable. The temperature range of the gage varies from $-20{ }^{\circ} \mathrm{C}$ to $+80{ }^{\circ} \mathrm{C}$. The gage is provided with a thermistor in the plucking coil to measure temperature. However, a temperature correction is needed to compensate for the difference between the thermal expansion coefficients of concrete and gage (Geokon Model VCE 4200, 1997).

The Geokon model VCE 4200 gages are installed in a tree fashion so that the gages could read strain distribution in $\mathrm{X}, \mathrm{Y}$ and $\mathrm{Z}$ directions. In order to have both top and bottom strain values, two gages were installed in each direction and hence 6 in total per tree as shown in Figure 3.4. These gages were initially secured in position to the rebar using nylon wire ties and then bonded to the rebar using epoxy adhesive (JB weld). 
The Geokon model 4911 sister bars are also used for direct embedment in the concrete structures. The gage consists of short length high strength steel was welded between two 23.375-inch long reinforcing bars. The model 4911 sister bar is 54.5 -inch long 2500 microstrain range. The gage is reliable, easy to install and read model with 0.4 microstrain resolution, and is unaffected by cable lengths. The gage is located at the center axis of the bar, and therefore no bending moments on the gage. A thermistor is provided inside the gage for temperature measurements (Geokon Model 4911, 1996).

The Geokon model 4911 sister bars were tied to the rebar's using standard iron clamps. Normally it is good practice to tie near ends and at one-third points to avoid unnecessary forces applying on the sensor gage.

\subsubsection{Resistance strain gages}

The wire resistance strain gages are the most widely used strain measurement sensors. The resistance element is cemented to the surface of the member to be strained, and as the length changes due to application of strain, resistivity changes with the strain. It is a resistive elastic unit whose change in resistance is a function of applied strain.

$$
\frac{d R}{R}=s . \in
$$

where, $\mathrm{R}$ is the resistance, $\in$ is the strain, and $\mathrm{s}$ is the gage factor.

Unlike vibrating wire gages, which measure output in terms of frequency, the wire resistance gages measure in terms of voltage. Hence cannot be used for long lengths applications as the gage causes noise and drift in the output signal.

\subsection{Resistance wire strain gage used in concrete}

The Micro measurements, Embedment Strain Gage EGP-5-120 (120 ohm resistance) are specially designed for measuring mechanical strains inside the concrete structures. It consists of K-alloy (Karma alloy) strain gages mounted on a carrier and cast 
into a proprietary polymer cement composite material. The 5-inch outer body of proprietary polymer concrete resists any mechanical damage during pouring, provides protection from moisture and corrosive attack. The gage is rugged, waterproof, reliable and made of a temperature compensated material. Each gage incorporates a heavy-duty 10-foot cable with AWG NO 22 7/35 stranded (0.643-mm diameter) lead wires (Micro measurements).

Embedment gages were tied to the rebar using nylon wire ties and then bonded to the rebar using epoxy adhesive (JB weld) to secure the gage in position.

\subsubsection{Displacement Transducer}

Displacement transducers are designed to measure the expansion or contraction, movements across the cracks or joints. Transducer employs a shaft coupled to a spring, which in turn is coupled to a vibrating wire element. Movement of the shaft changes the tension in the spring and in the wire causing a corresponding change in its frequency (Geokon Model 4430, 1996). The vibrating wire transducer measures the output in terms of frequency, hence useful for long lengths application without appreciable vibration or noise in the signal. It is commonly used for measuring the crack openings, axial deformation, creep characteristics of structures and materials. Most of the transducers are provided with a thermistor for temperature measurement.

There are many types of displacements transducers that can be used for displacement measurement. The transducers used in this project are:

(i) Crack-meter

(ii) Convergence meter

\subsubsection{Crack-meter}

The Geokon Model 4430 deformation meter (Crack-meter) is designed primarily to measure axial strains or deformations in concrete structures. The transducer can be embedded in concrete, in series to give the total deformation pattern along that axis. 
The transducer consists of a vibrating wire sensing element in series with a precision music wire, which is coupled to a movable shaft. As the shaft moves out of the sensor body, both the spring and the vibrating wire elongate causing a change in their tension, which is measured in terms of frequency of the vibration (Geokon Model 4430,1996).

The Geokon model 4430 gages were prewired to the rebar cage using nylon wire ties, as seen in Figure 3.11. The gages are installed in series over the full length of the instrumented portion of the bridge, as shown in Figure 3.12. Tie wires should be connected from the tubes rather than end flanges to avoid shifting or moving of the crack-meters while casting.

\subsubsection{Convergence meter}

The Geokon Model 4425 vibrating wire convergence meter is primarily designed to measure the deformation between two fixed anchor points. In this project, convergence meters were installed in between the abutment and the pier and between the two piers, to give the deformation pattern of the bridge in their spans. The change in the distance between two fixed points are conveyed by the connecting rod and measured by the transducer. The convergence meter can be operated in horizontal, vertical directions. It consists of two anchor points, with $6 \mathrm{~mm}$ diameter connecting rod and a spring tensioned vibrating wire assembly.

The transducer consists of a vibrating wire sensing element in series with a heat treated stress relieved spring which is connected to the wire at one end and a connecting rod at the other end. As the connecting rod is pulled out from the gage body, the spring is elongated causing a change in tension, which is sensed by the vibrating wire element (Geokon Model 4425, 1996).

The Geokon model 4425 transducer is provided with two eyebolt anchor points and a $6 \mathrm{~mm}$ diameter connecting rod. Initially, holes are drilled at the two spans, to 
accommodate the convergence meters anchors using a rebar or any rod. Then turnbuckle assembly was hooked to the convergence meter. Next the pieces of the connecting rods were connected together to fit between the two fixed end points (here, between abutment and pier 1, and between Pier 1 and pier 2 using the swagelok fittings. Carbon connecting rod must be then attached to the sensor using the swagelok fittings as shown in Figure 3.13. Finally the swagelok eyehook was hooked to the anchor bolt. Two convergence meters are installed in the bridge, one between the abutment and pier 1, other between the pier 1 and pier 2 .

\subsubsection{Inclinometers}

The Jewell LCI inclinometers are primarily designed to monitor and measure tilt or change in the inclination of a structural member. The sensing element in a Jewell inertial instrument is the torquer. A torquer used to sense acceleration or tilt is intentionally unbalanced in its plane of allowable angular motion. When acceleration or tilt is present, a torque proportional to the mechanism unbalance and the physical input is developed. The torque results in an angular motion sensed by an optical position detector. The position detector output is compared to a reference voltage, and the difference is an error signal that is the input to a servo amplifier. The servo amplifier output current is applied to the torquer in opposition to the acceleration or tilt torque. The servo amplifier output current is directly proportional to the applied acceleration or sine of the input tilt angle.

Inclinometers can be used to detect tilt from less than one micro radian to more than 50 radians. They utilize closed loop sensor technology to produce a highly accurate output. The inertial sensor output is an analog voltage proportional to tilt from DC through a specified frequency (Jewell Instruments).

Inclinometer is installed on bottom flange of the steel girder, as shown in Figure 3.14. The surface on which inclinometer is mounted should be polished with surface grinder to remove all rust, dirt and oil and cleaned the surface with the acetone. Epoxy 
adhesive is used to mount the inclinometer on the surface. To avoid any noise or drift, inclinometer leads are protected using the epoxy layer as shown in Figure 3.14.

\subsubsection{Thermistors}

Thermistors (THERMally sensitive resISTORS) made of semi conducting materials, which detect thermal environmental changes for use in temperature measurement, control and compensation circuitry. For most components, the resistance rises as the temperature rises. Thermistor is a special type of resistor, which has been deliberately a manufacture, so that its resistance decreases as its temperature rises. Thermistor trees are specifically designed for temperature measurement through the thickness of the bridge deck. Two thermistor trees, each having 17 thermistors were installed on the bridge to give the temperature distribution along the cross-sections.

A typical thermistor tree installed in the site was shown in Figure 3.6. Eight thermistors were installed in the first one-inch of the pipe around the diameter and then a thermistor for an inch depth, hence in total 17 thermistors were used in a tree. This type of arrangement enables to read the temperature profile along the depth of the concrete pavement. Thermistor tree is prewired to the rebar cage in the vertical direction with nylon wire ties. Then the cables are dropped into the holes provided on the bridge.

\subsection{DATA ACQUISITION SYSTEMS}

A data acquisition system is used for gathering, collecting and storing the information about a system or a process. It is the core tool for understanding and monitoring the performance and behavior of any instrumented structures. Figure 3.15

illustrates a typical data acquisition system, consists of a datalogger, multiplexers and multisensor interfaces. 


\section{Mutliplexer}

Geokon 8032 multiplexer can be used for both 16 channels of 4 conductors or 32 channels of 2 conductors applications. The system consists of two components, terminal board for making gage connections and a multiplexer board for switching the gage connections (Geokon Model 8032, 2001).

\section{Multisensor Interface}

Canary systems multi sensor interface allows the use of different types of sensors with varying inputs and outputs to multiplexer, controlled by CR10X controller. It provides the capability of connecting 8 multiplexers to the datalogger. A micro controller from the microchip communicates with CR10X via its control ports using a 26-pin connector, battery and charger connections are made with a 3-point screw terminal located directly below the datalogger connector. Multisensor is connected to the $16 / 32$ channels multiplexer using 8,10-pin connectors on the interface (Canary systems, 1997).

\section{Datalogger}

Campbell Scientifics CR10X measurement and control module is a fully programmable datalogger with non-volatile memory and a back up battery in a small, rugged, sealed module. The standard $\mathrm{CR} 10 \mathrm{X}$ has a $128 \mathrm{~K}$ of flash electronically erasable programmable read only memory and $128 \mathrm{~K}$ static random access memory. Connecting more 16/32-channel multiplexers to the datalogger can expand the number of channels on the datalogger. It can be connected to a maximum of 128 channels using 16 channels multiplexer or 256 channels using 32 channels multiplexer.

The CR10X can be powered by PS12LA sealed rechargeable or BPALK alkaline power supply or any 12-vdc-power supply. For communication, either Campbell Scientifics CR10KD keyboard display or any PC/laptop should be connected to the CR10X I/O port. CR10X must be programmed using multilogger software before it start collecting any measurements (Campbell scientific, 1997). 
Multilogger is a programmable software used to execute all the operations of the datalogger, capture and process the data from CR10X module. Multilogger 2.1.6 is a windows oriented program, allows the user to monitor all the channels and can edit the operations. For the accuracy purpose, the measuring devices connected to the datalogger, need to be periodically calibrated with the datalogger to adjust the calibration factor in the configuration file of the multilogger (Canary systems, 1997).

\subsection{PRELIMINARY TEST}

All the sensors need to be checked in the lab before installation on the bridge. Preliminary check is advisable for all types of sensors to detect faulty gages, using GK 403 readout box and sometimes with datalogger. The GK 403 can store strain readings and also apply calibration factors to convert reading to engineering units. The read out unit reads thermistor temperature directly in ${ }^{\circ} \mathrm{C}$ (Geokon manual). Connect the read out using the flying leads with a connector. The red and black clips are for the vibrating wire gage, white and green leads are for the thermistor and the blue for the shield drain wire. More or less the preliminary tests for all the sensors (Strain gages, crack-meter, and convergence meter) are same.

Steps to do preliminary test:

(i) GK 403: Connect the four lead wires of the strain gage to the read out box and observe the displayed read out unit. The mid-range reading should be around the anticipated range in the manual. Pressure on the gage end should change the reading.

(ii) Campbell scientific datalogger: Connect the lead wires of the strain gage to the multiplexer as per the circuit diagram in the datalogger manual. Then connect the multiplexer to the datalogger, program the datalogger using the multilogger 2.1.0 software, which can then capture data. Readings from the 
datalogger were compared with the Geokon 403 read out unit and then used to check the gage, and its stability to see whether it is noise free, damaged or not.

\subsection{CALIBRATION}

Calibration is the setting or correcting the accuracy or precision of a measuring device, usually by adjusting it to match or conform to a dependably known and unvarying measure. It's also used to determine the sensitivity and resolution of the device.

\subsubsection{Calibration of Inclinometer}

The calibration of inclinometer was developed in the laboratory to adjust the gage factor used in the Multilogger Software. The setup consists of a sine bar, 10-inch long and 2.5-inch wide and a graphite surface plate. The sine bar was placed on the center of the graphite surface plate. Inclinometer to be calibrated was placed on the sine bar edge with the double-sided tape to keep it in a fixed position.

Then the Inclinometer was connected to the datalogger as per the circuit diagram set by Jewell manual and the sequences of steps followed to connect it are explained in the Appendix I. The Inclinometer is an electromechanical device that produces an electrical output proportional to the tilt or angle of an optical position detector. Known heights, which in turn give the angle or slope, in very small incremental steps, were given to inclinometer using gage blocks. The corresponding values measured from the datalogger were noted. Repeat the procedure for different angles varies between $-14.5^{\circ}$ to $+14.5^{\circ}$ and note down the corresponding datalogger readings. Since the presence of any dust on the surface of the gage blocks may alter the accuracy of the measurements, the surfaces of the gage blocks were cleaned thoroughly before each use.

From the known angle and corresponding measured output in terms of voltage, the calibration factor was estimated. The calibration results are summarized in Table3.2. A graph is drawn between the inclinometer voltage Vs sine (angle) as shown in Figure 3.17, 
for accuracy in measurements. The obtained calibration factor has to be set in the inclinometer configuration file used in the datalogger for any further measurements.

\subsection{ERRORS IN THE MEASUREMENT SYSTEM}

The error in measurements is the difference between the measured value and the true physical value of the quantity (Beckwith, 1993). The error cannot be calculated exactly unless true value is known, however, the true value is something, which we can never know exactly and hence the error exactly. Error may be estimated from the calibration of the instruments.

The total errors in this project are classified into two main categories:

(1) Instrumentation Error

(2) Installation Error

\subsubsection{Instrumentation Error}

Possible types of errors from a sensor and data acquisition systems (Instrumentation error) are:

1. Bias or Systematic Error

2. Precision or Random Error

3. Illegimate Error

4. Other

\subsubsection{Bias or Systematic error}

Bias error in a system will cause all the measured values to deviate from the true value by a consistent amount, i.e. either higher or lower than the true value. The common form of the bias error is the calibration error, which is the fixed, systematic component of the total error. It is always assumed that all bias errors have been eliminated by the calibration, which is not possible due to certain limitations of the system. Indeed, the 
bias error can be determined by comparison with a standard device having accuracy much better than the device being tested. Basic forms of the bias errors are, error in the calibration, defective equipment Etc.

\subsubsection{Precision or Random error}

Random error is caused by any factors that randomly affect the measurement of the variables across the sample. The problem with random error is that it does not have any consistent effects across the entire sample like bias error. Instead, it pushes observed scores higher or lower randomly. Random error adds variability to the data but does not affect the average performance of the system. Thus, noise is considered as random error. Among the causes for random errors are, fluctuation in the experimental conditions, disturbance, poor sensitivity of the instrument being tested

\subsubsection{IIIegitimate error}

An illegitimate error occurs when someone makes a mistake or blunders, i.e. involves an operator error e.g., misreading instruments, copying wrong values, Etc. Any data that is suspected to result from an illegitimate error should never be used. Illegitimate errors can be eliminated through proper care or repetition of the measurement.

\subsubsection{Others}

Error results due to lack of consistency in the procedures of the experimenters. These errors may be due to drift in the calibration because of variation in the test or environmental conditions. Backlash, Hysteresis and Mechanical frictions are the other sources of variations in measuring systems. And also, there is always a possibility of human errors in each part of the experiment. 


\subsubsection{Installation Error}

Installation error causes due to improper and poor installation techniques. Hence great care must be taken in validating the installation technique and also not to damage the sensor during installation. For better results, it is always suggested to test the sensors after the installation on the bridge.

\subsection{INSTRUMENTATION LABELING}

All the sensors and cables that are installed in the field are labeled in the laboratory based on its position. A unique code is developed in the lab depends on the type of the sensor, its girder position, its direction and followed by serial number.

The three girders in the span 1 were labeled as A, B and C. The gages within each girder were further identified by its type, location and direction. For example Vibrating wire gages were labeled as $\mathrm{V}$, Thermistors were labeled as $\mathrm{T}$, and Inclinometers were labeled as I, weldable as W and Embedment as E.

The directions are classified as Wheel path (W), Perpendicular to wheel path (P), Vertical to the wheel path (V). Then by its positions like $\mathrm{X}, \mathrm{Y}, \mathrm{Z}$ positions and its location in those positions as explained in Table 3.3. i.e. top or bottom. Followed by dot and its serial number or batch number.

For example: SWA20.25161 represents, Sister bar (S) in the wheel path (W) at abutment (A), I-beam number 2 (2) on top slab (0) with serial number (25161). 


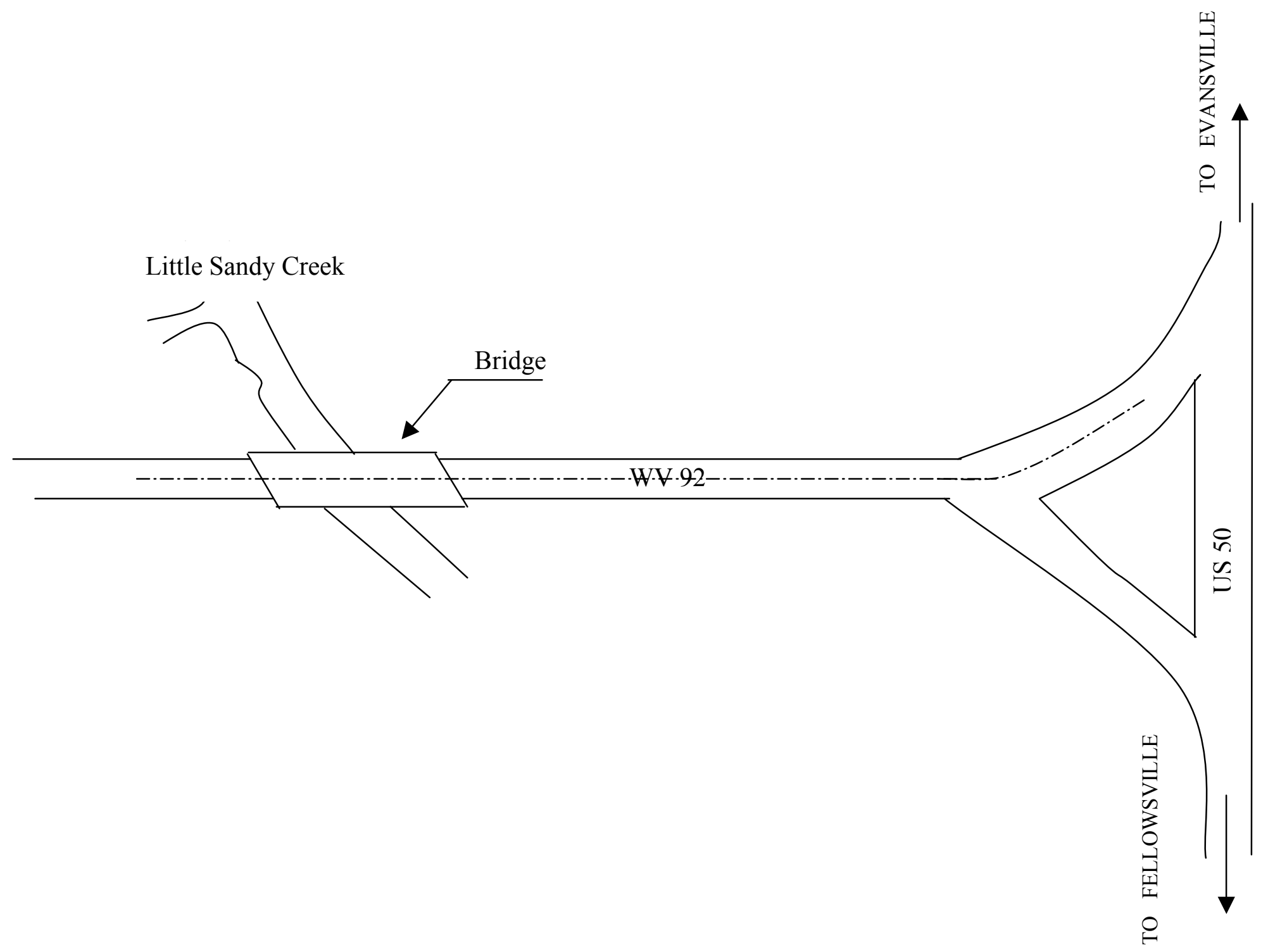

Figure 3.1 Preston county Evansville Bridge (Bridge No. 15721) 

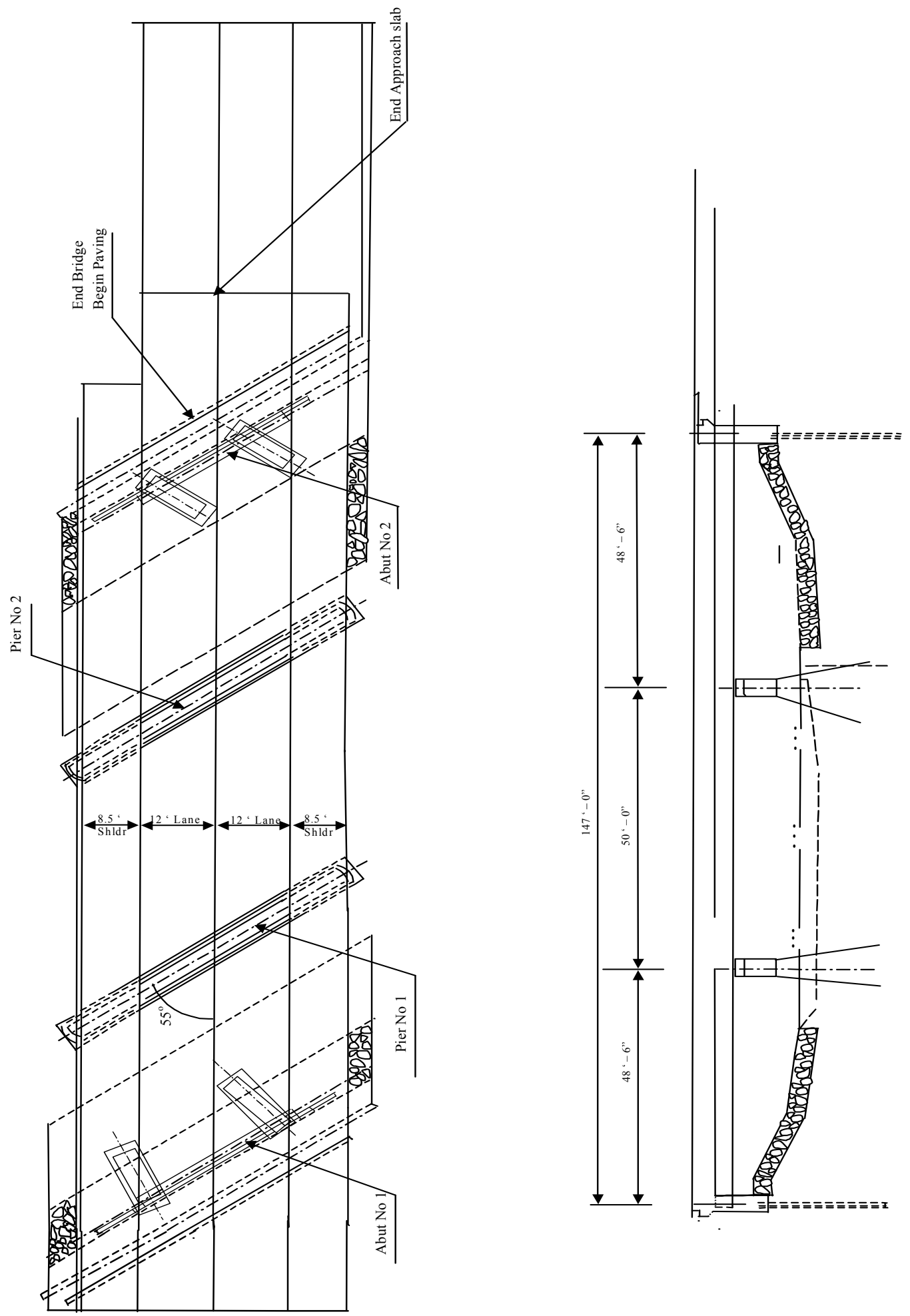

Figure 3.2 Plan and elevation of the bridge 


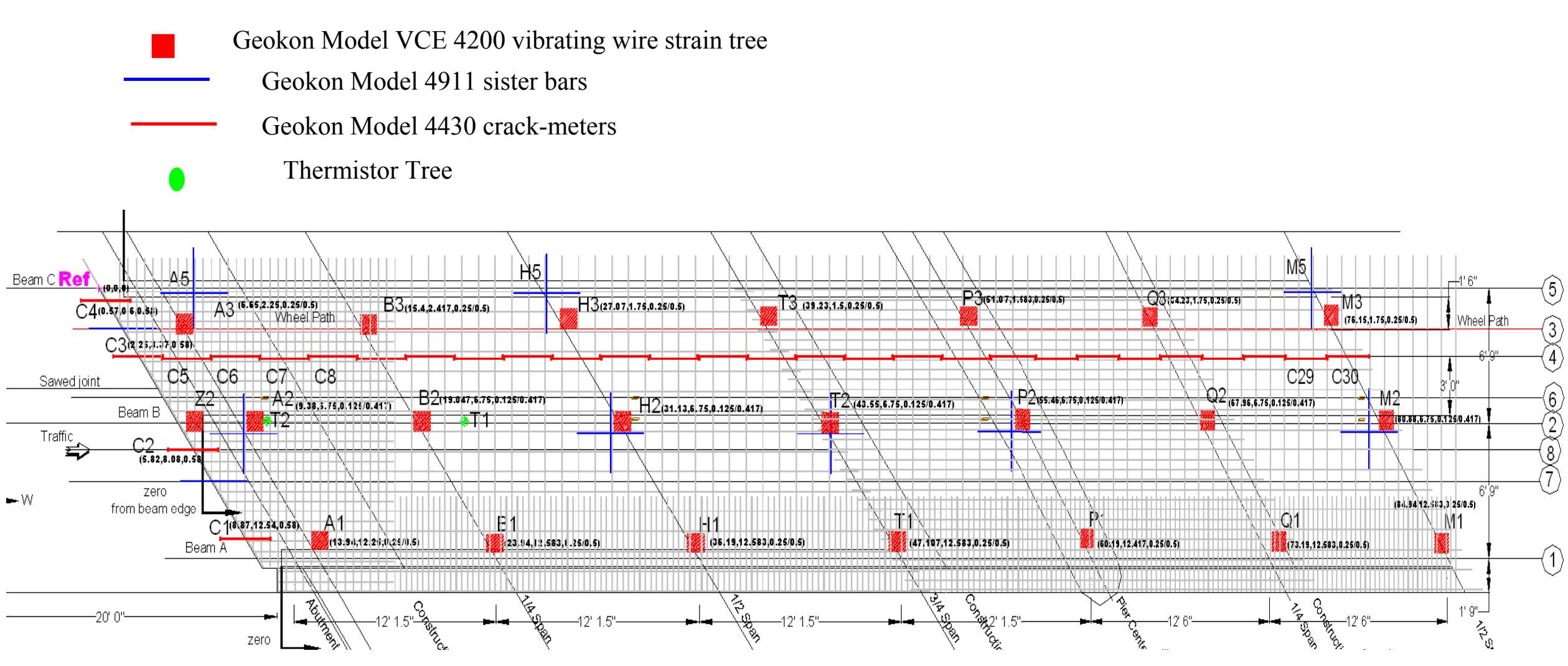

Figure 3.3 Sensor layouts on the bridge 
Table 3.1 Sensor set design for Evansville Bridge

\begin{tabular}{|c|c|c|c|c|}
\hline MEASUREMENT & SENSOR TYPE & $\begin{array}{c}\text { NO. OF } \\
\text { LOCATIONS }\end{array}$ & $\begin{array}{l}\text { GAGE PER } \\
\text { LOCATION }\end{array}$ & $\begin{array}{l}\text { NO. OF } \\
\text { GAGES }\end{array}$ \\
\hline \multirow{4}{*}{ STRAIN } & $\begin{array}{l}\text { VIBRATING WIRE } \\
\text { STRAIN GAGES }\end{array}$ & 22 & $5-6$ & 117 \\
\hline & SISTER BARS & 8 & 2 & 18 \\
\hline & $\begin{array}{l}\text { WELDABLE STRAIN } \\
\text { GAGES }\end{array}$ & 2 & 2 & 8 \\
\hline & $\begin{array}{c}\text { EMBEDMENT STRAIN } \\
\text { GAGES }\end{array}$ & 8 & 2 & 16 \\
\hline \multirow{2}{*}{ DEFLECTION } & CRACK-METERS & 30 & 1 & 30 \\
\hline & $\begin{array}{l}\text { CONVERGENCE } \\
\text { METERS }\end{array}$ & 2 & 1 & 2 \\
\hline SLOPE & INCLINOMETERS & 7 & 1 & 7 \\
\hline TEMPERATURE & THERMISTORS & 2 & 17 & 34 \\
\hline
\end{tabular}

\begin{tabular}{|c|c|c|}
\hline TOTAL: & STRAIN & $=159$ \\
\hline & DEFLECTION & $=32$ \\
\hline & SLOPE & $=7$ \\
\hline & TEMPERATURE & $=34$ \\
\hline & TO & 232 \\
\hline
\end{tabular}




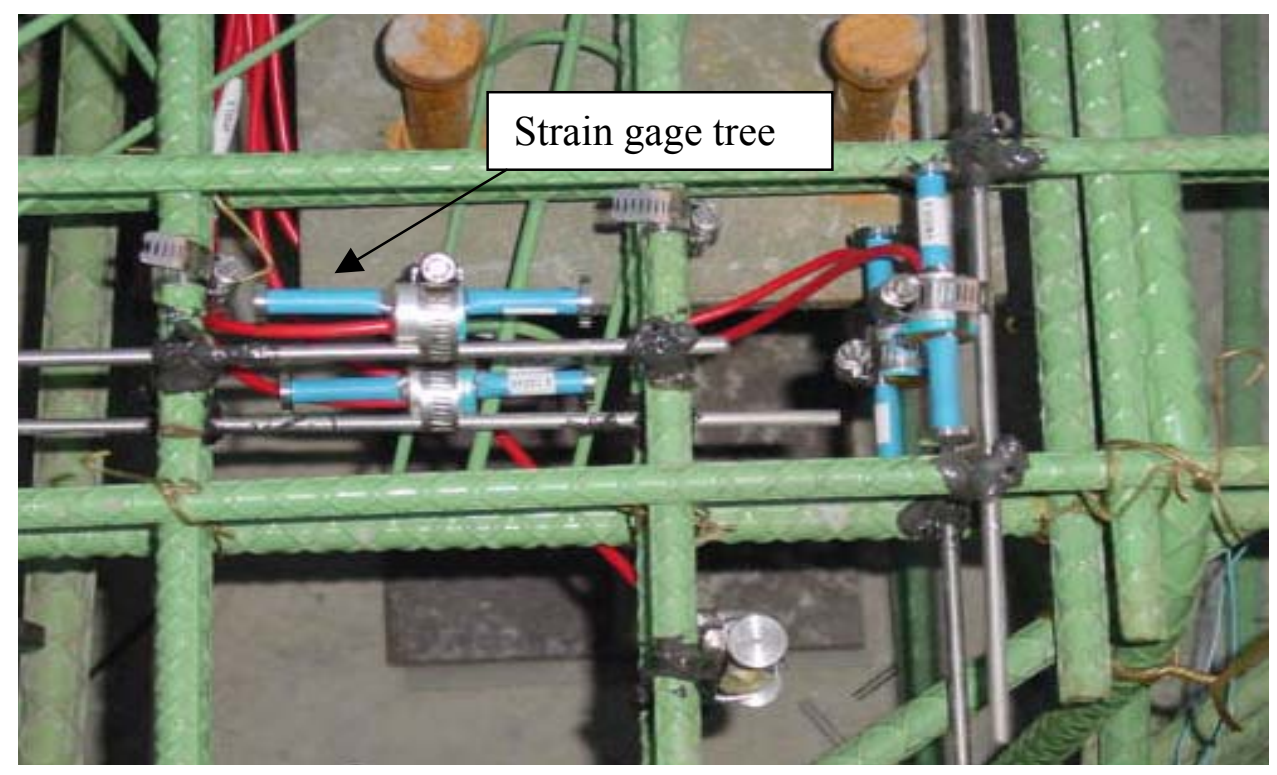

Figure 3.4 Strain tree

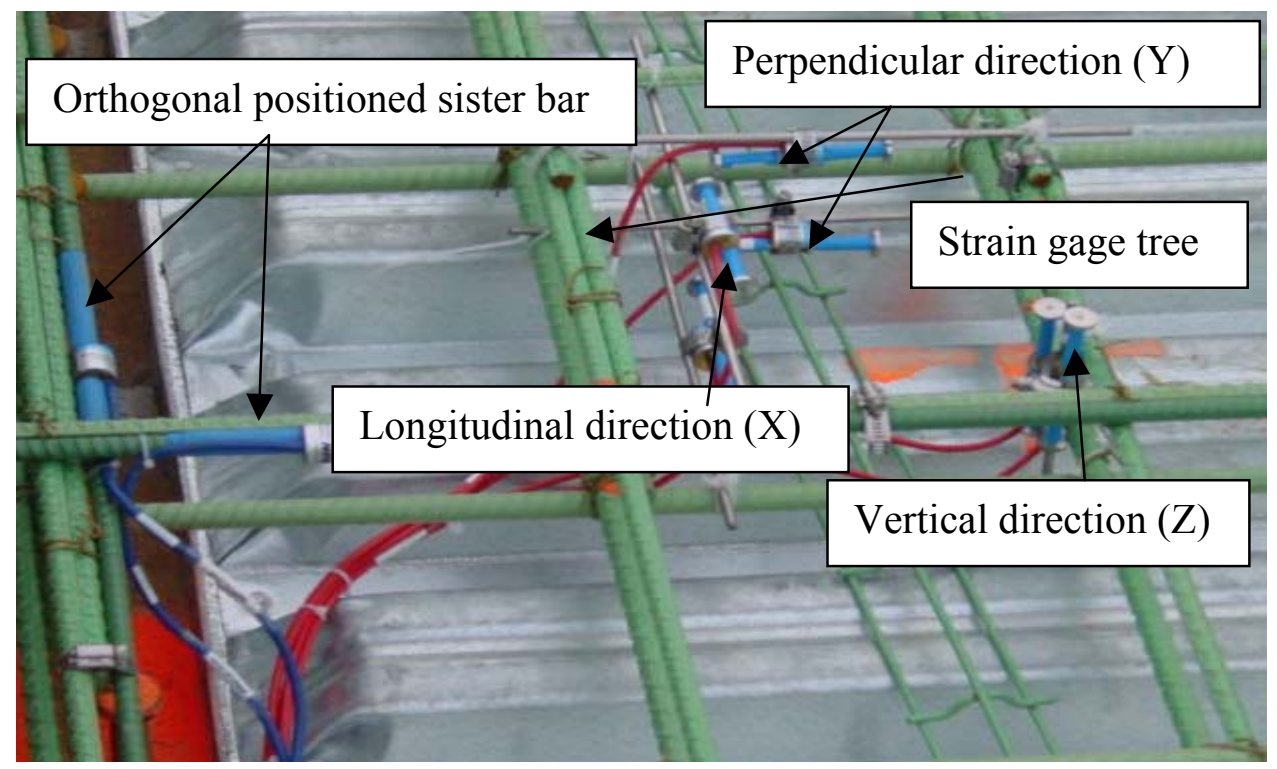

Figure 3.5 Strain tree, Sister bars in a location 


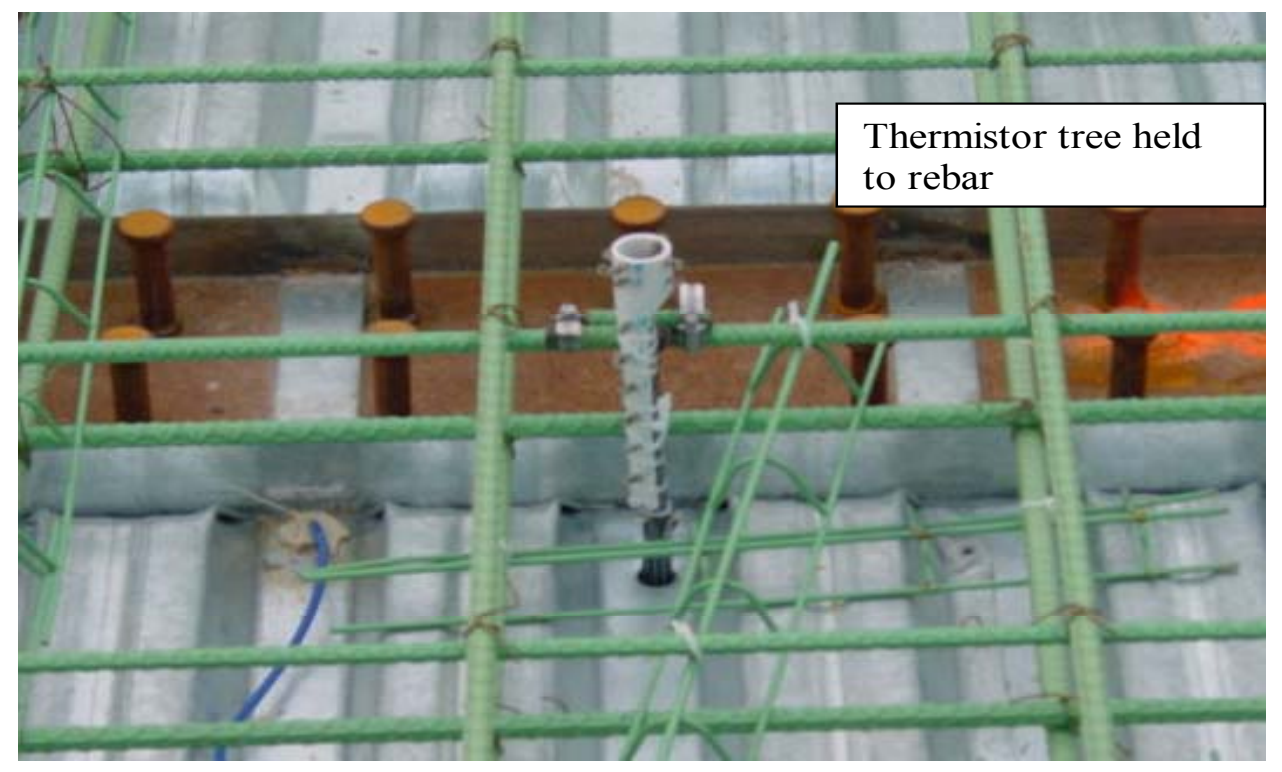

Figure3.6 Thermistor tree on the bridge

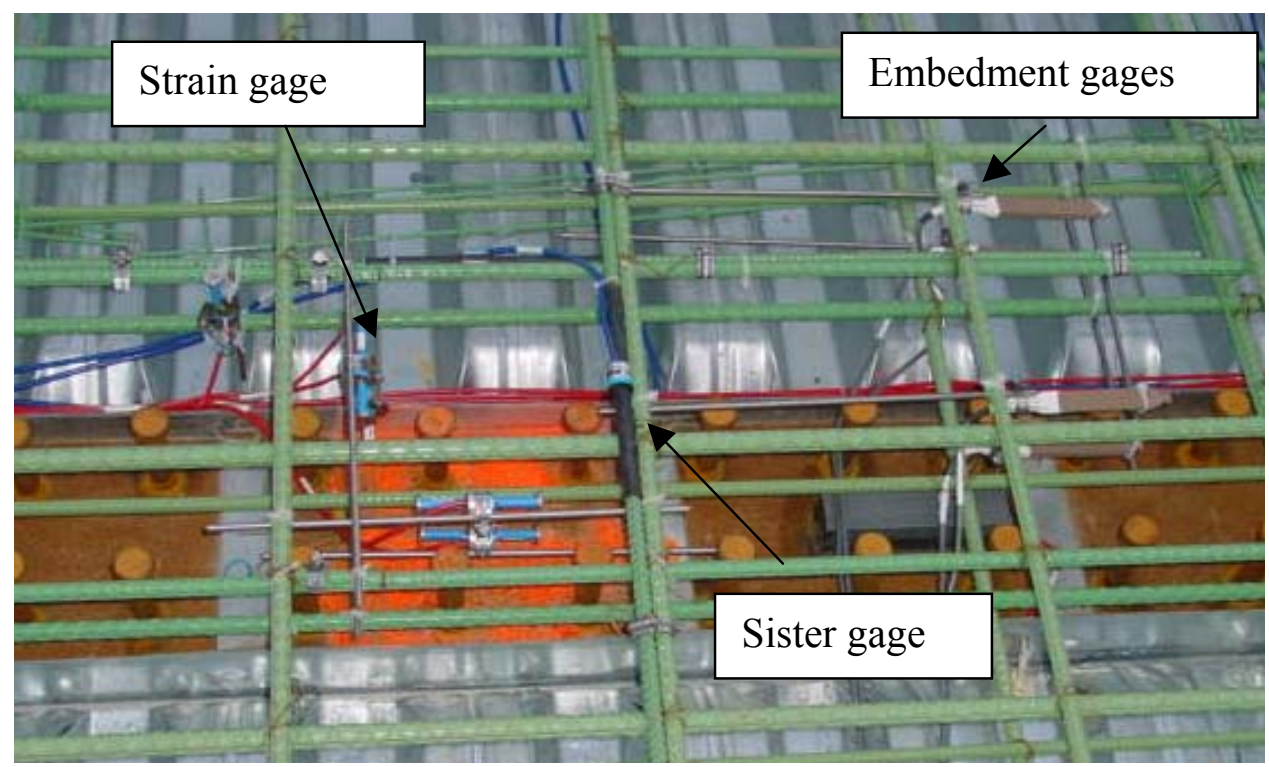

Figure 3.7 Strain tree, Sister bar, Embedment gages in a location 


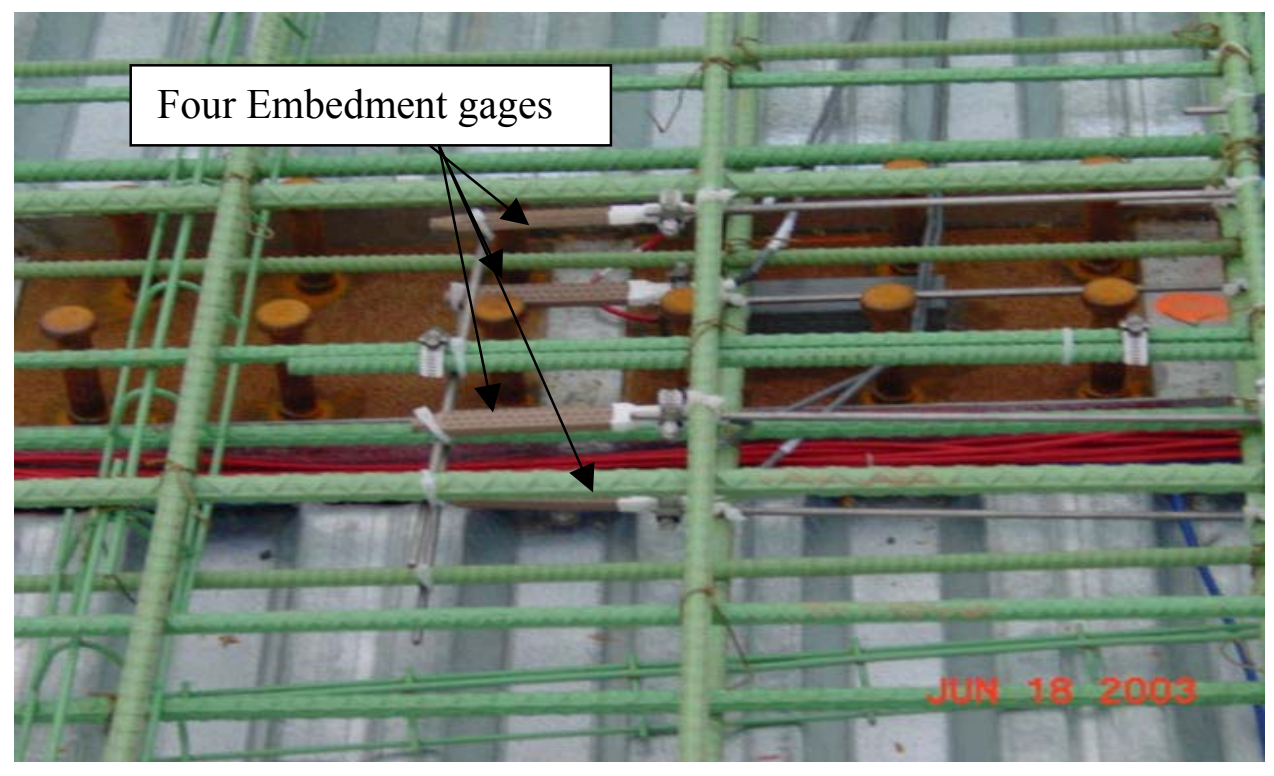

Figure 3.8 Embedment strain gages in a location

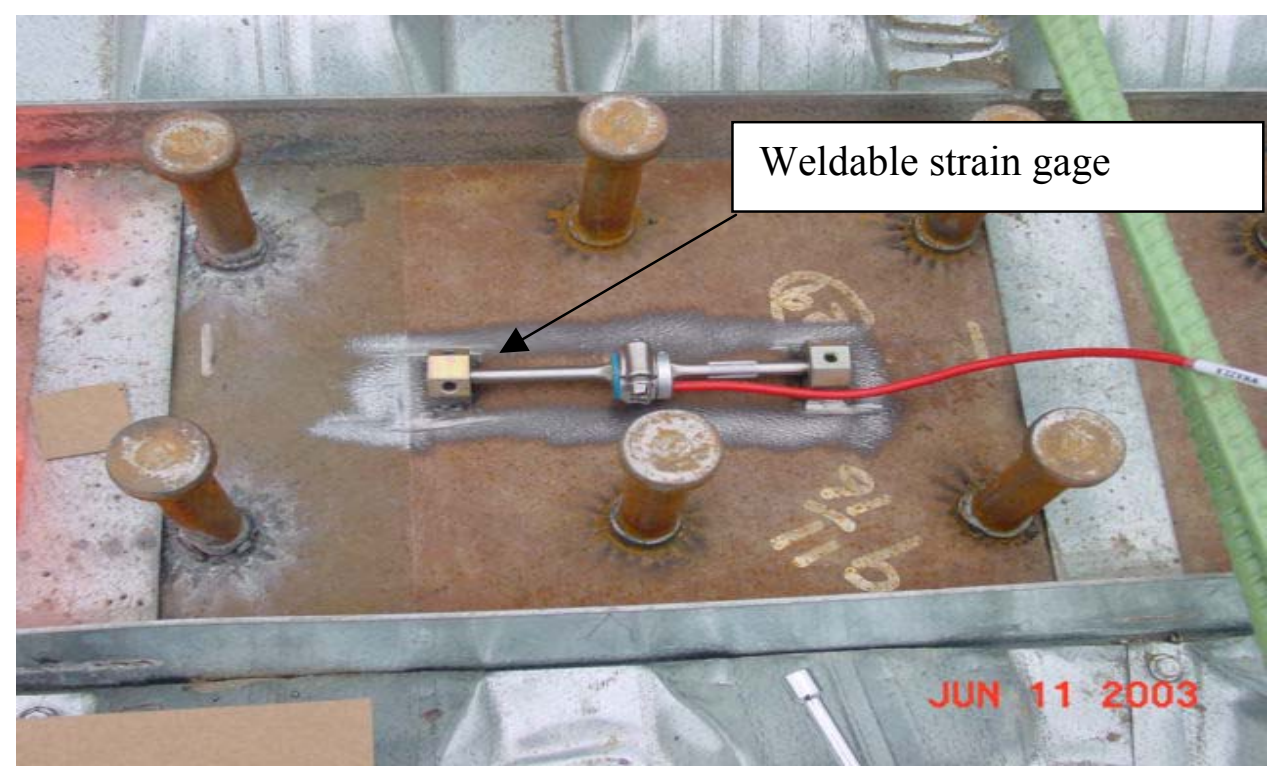

Figure3.9 Weldable strain gage on the top girder 


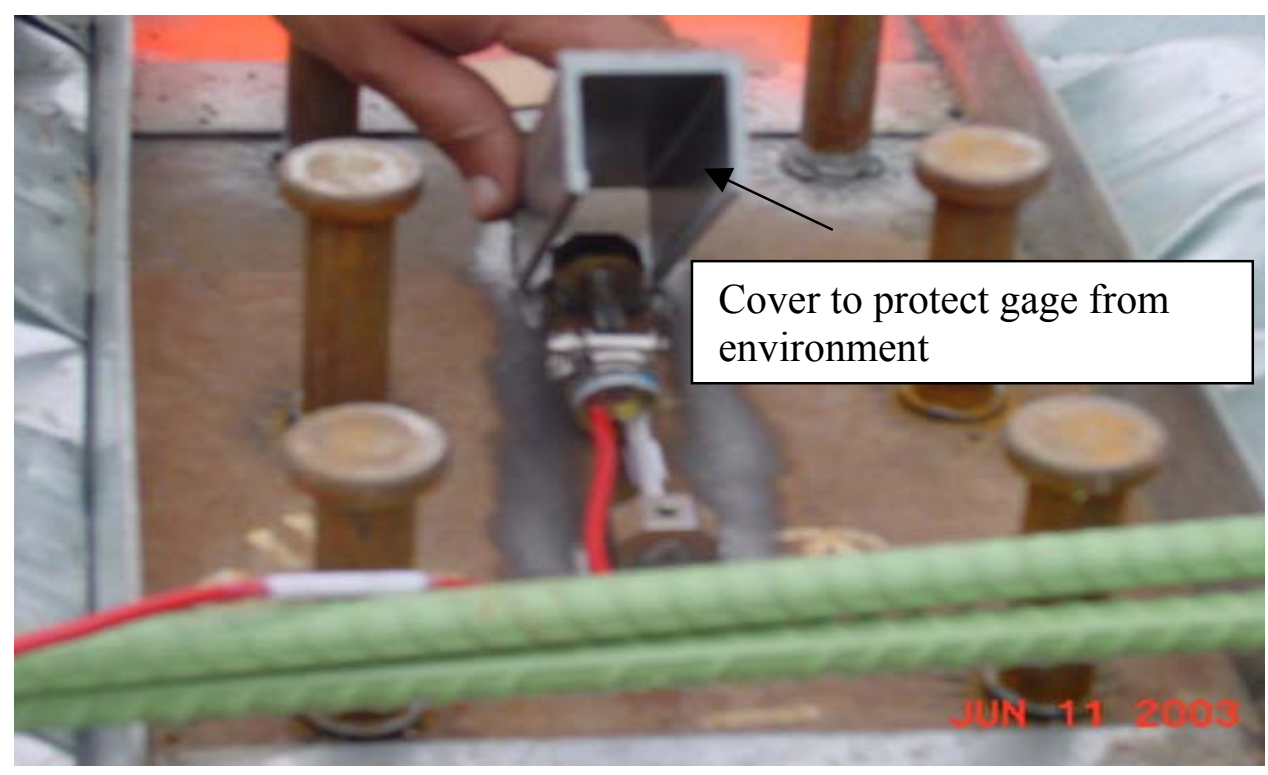

Figure 3.10 Covered weldable strain gage

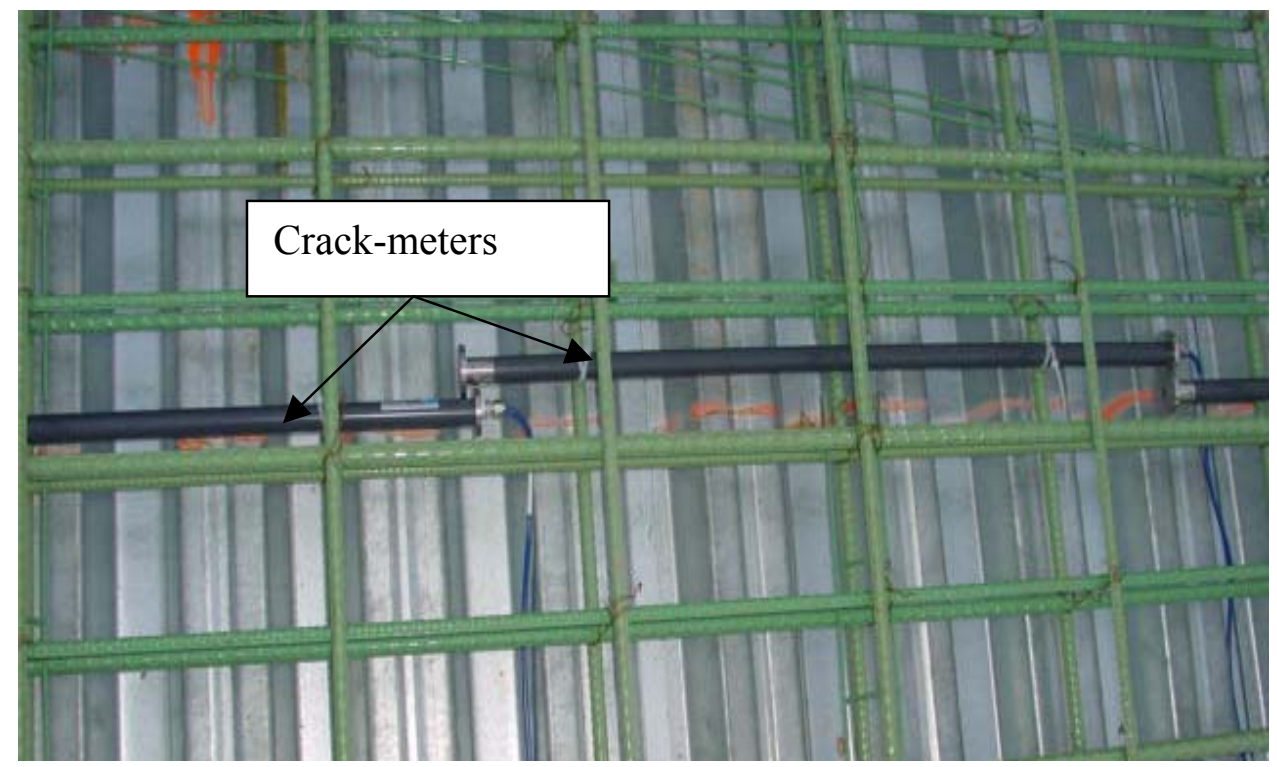

Figure 3.11 Crack-meter 


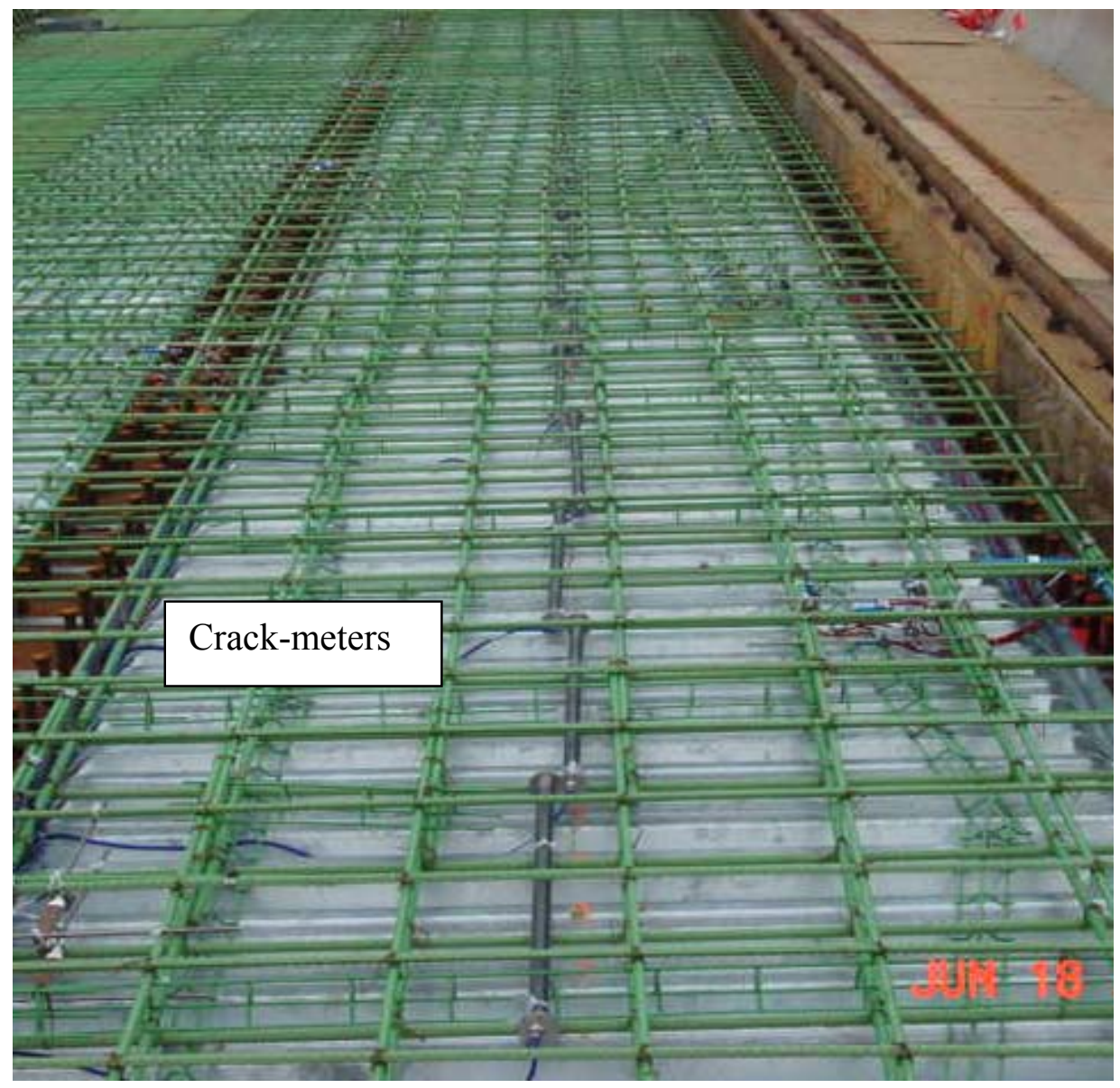

Figure 3.12 Crack-meters aligned over the bridge 


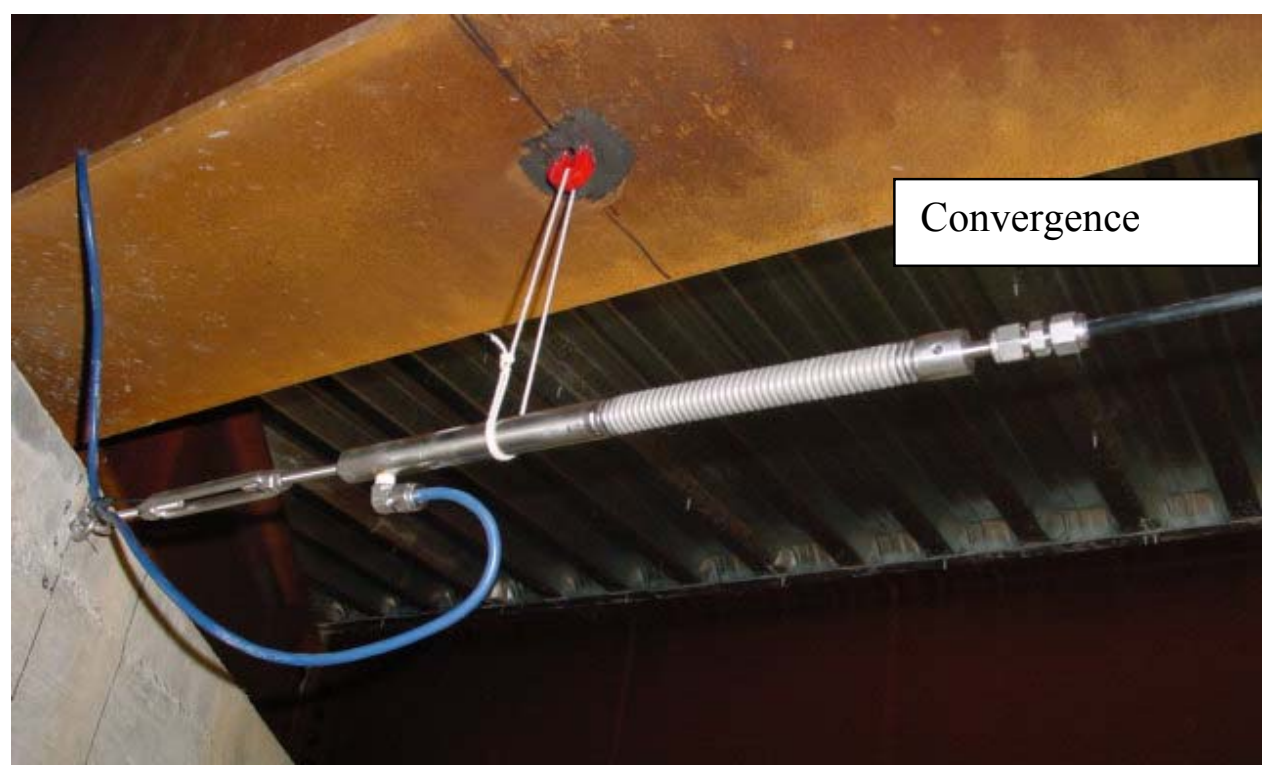

Figure 3.13 Convergence meter between abutment and pier 1

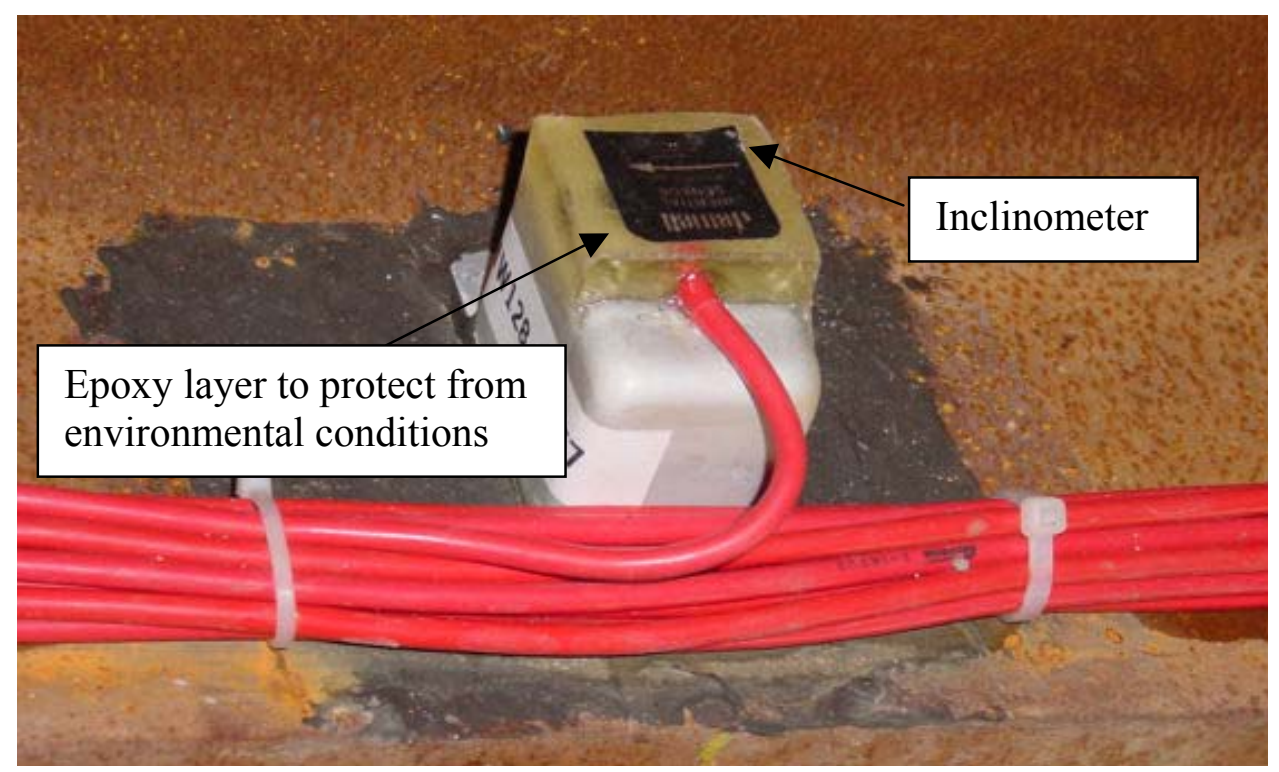

Figure 3.14 Inclinometer after installation 


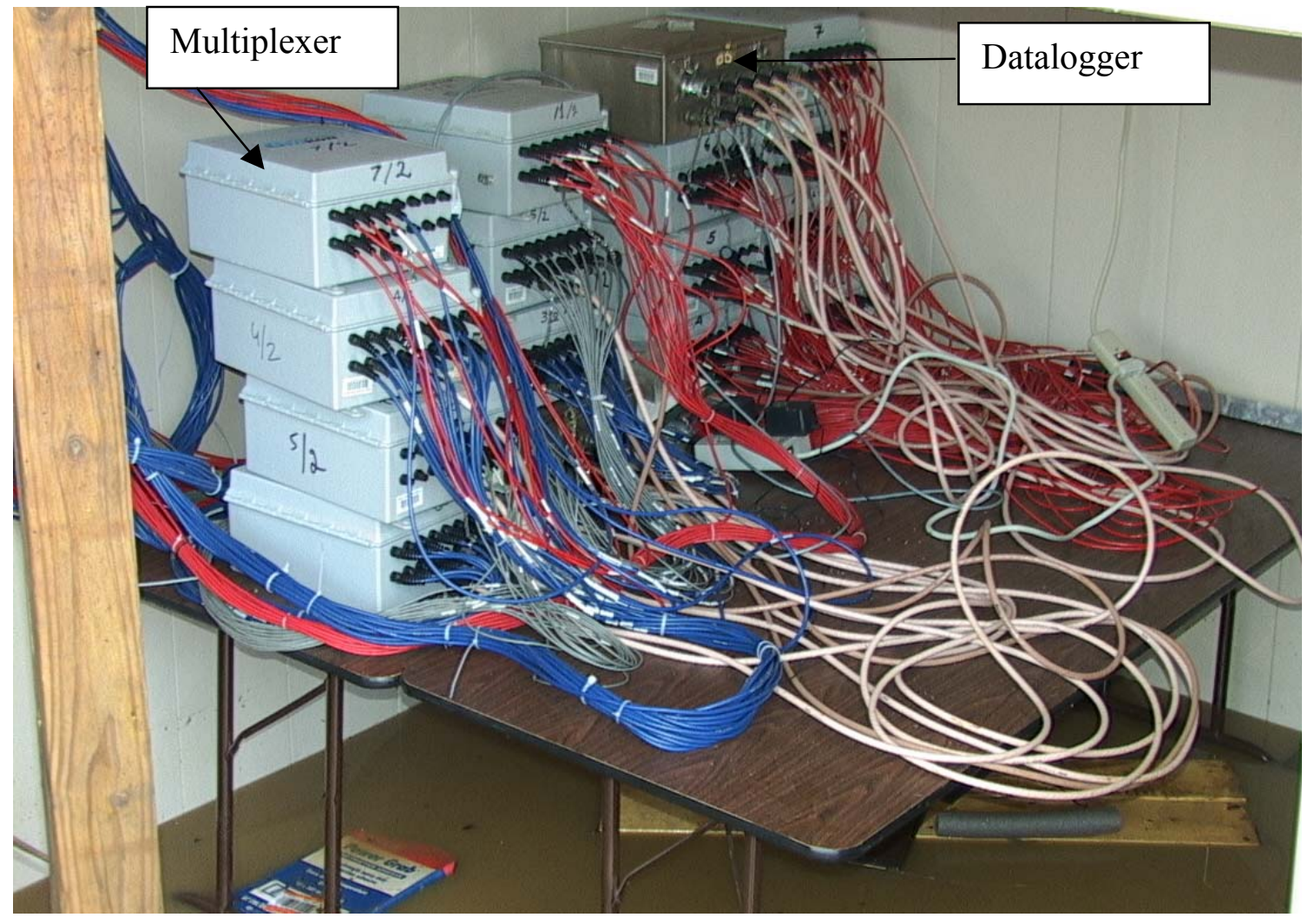

Figure 3.15 Multiplexers and Dataloggers used in the project 


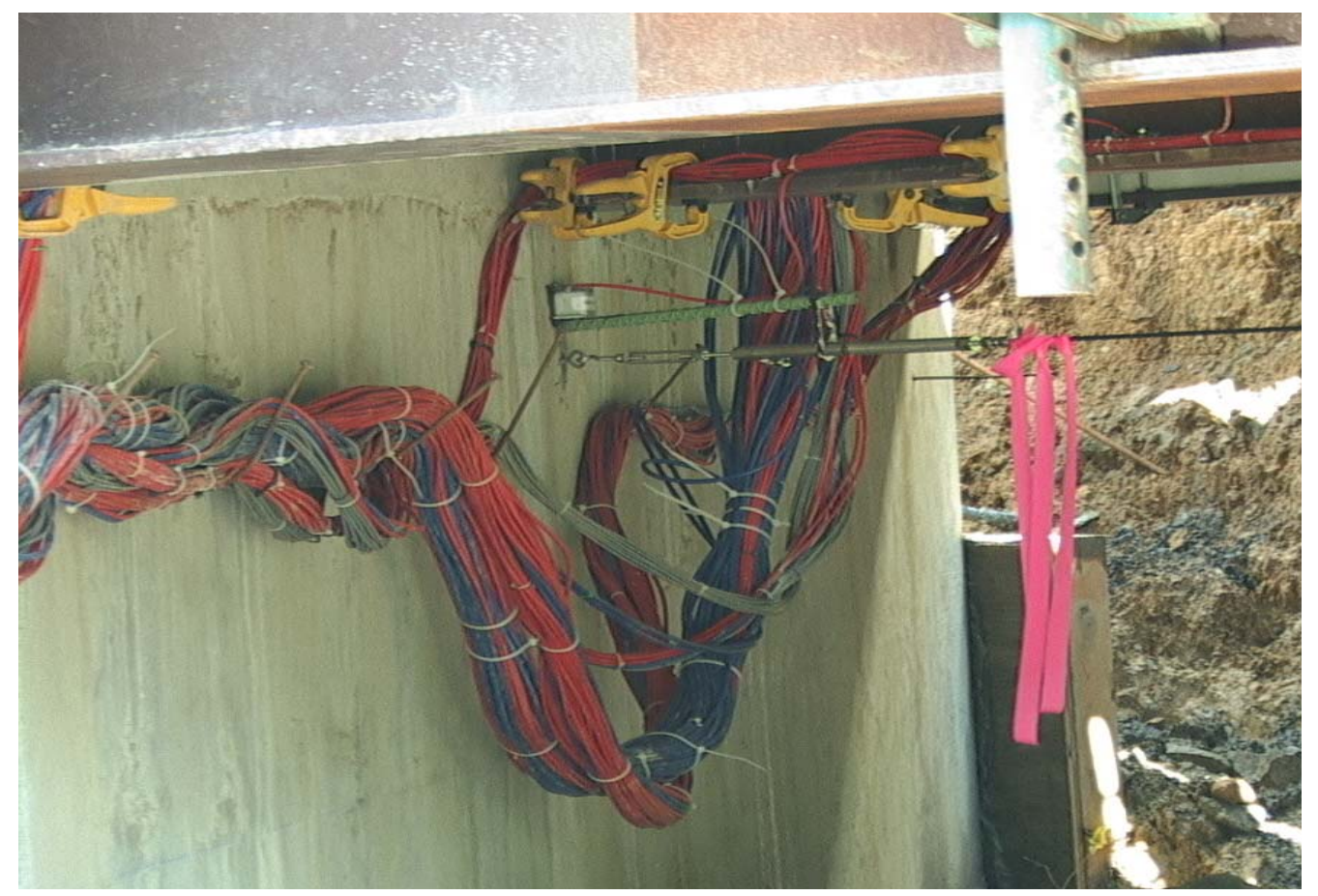

Figure 3.16 Cables to the instrumentation room 
Table 3.2 Calibration results for LCI Inclinometer

\begin{tabular}{|c|c|c|c|c|}
\hline Angles (degrees) & $\begin{array}{c}\text { Angles } \\
\text { (radians) }\end{array}$ & Sine (angle) & Datalogger voltage & $\begin{array}{c}\text { Corrected } \\
\text { voltage }\end{array}$ \\
\hline 14.5 & 0.252944444 & 0.2502558 & 5.07 & 4.973614 \\
\hline 12 & 0.209333333 & 0.2078078 & 4.23 & 4.133614 \\
\hline 10 & 0.174444444 & 0.173561 & 3.5515 & 3.455114 \\
\hline 8 & 0.139555556 & 0.139103 & 2.8563 & 2.759914 \\
\hline 5.7392 & 0.100117156 & 0.09995 & 2.0789 & 1.982514 \\
\hline 2.866 & 0.049995778 & 0.049975 & 1.0776 & 0.981214 \\
\hline 1.7191 & 0.029988744 & 0.0299842 & 0.6804 & 0.584014 \\
\hline 0.573 & 0.009995667 & 0.0099955 & 0.295 & 0.198614 \\
\hline 0 & 0 & 0 & 0.096386 & 0 \\
\hline-0.573 & -0.009995667 & -0.0099955 & -0.105 & -0.201386 \\
\hline-1.7191 & -0.029988744 & -0.0299842 & -0.5 & -0.596386 \\
\hline-2.866 & -0.049995778 & -0.049975 & -0.89956 & -0.995946 \\
\hline-5.7392 & -0.100117156 & -0.09995 & -1.8902 & -1.986586 \\
\hline-8 & -0.139555556 & -0.139103 & -2.674 & -2.770386 \\
\hline-10 & -0.174444444 & -0.173561 & -3.3548 & -3.451186 \\
\hline-12 & -0.209333333 & -0.2078078 & -4.04 & -4.136386 \\
\hline-14.5 & -0.252944444 & -0.2502558 & -4.8889 & -4.985286 \\
\hline
\end{tabular}

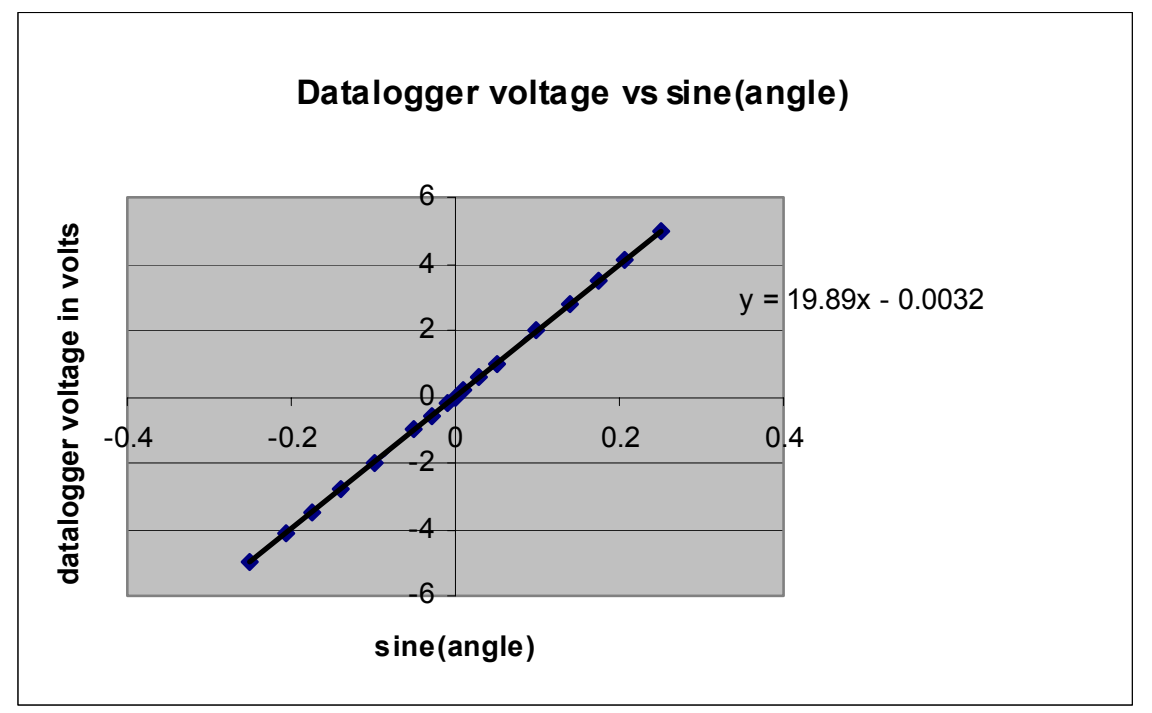

Figure3.17 Calibration of Jewell LCI Inclinometer 


\begin{tabular}{|c|c|c|c|c|c|}
\hline Sensors Type & Direction & X-Position & Y-position & Z-position & Serial No. / Batch No \\
\hline $\begin{array}{l}\mathbf{C}=\text { Crack-meter } \\
\mathbf{I}=\text { Inclinometer } \\
\mathbf{L}=\text { Convergence- meter } \\
\mathbf{V}=\text { Vibrating wire strain } \\
\text { gage } \\
\mathbf{T}=\text { Thermistor } \\
\mathbf{S}=\text { Sister bar } \\
\mathbf{E}=\text { Embedment wire } \\
\text { resistant gage } \\
\mathbf{W}=\text { Weldable vibrating } \\
\text { wire gage }\end{array}$ & $\begin{array}{l}\mathbf{W}=\text { Wheel path } \\
\mathbf{P}=\text { Perpendicular } \\
\text { to wheel path } \\
\mathbf{V}=\text { vertical }\end{array}$ & $\begin{array}{l}\mathbf{A}=\text { Abutment } \\
\mathbf{B}=\text { Quarter span } \\
\mathbf{H}=\text { Half span } \\
\mathbf{T}=\text { Three quarter } \\
\text { span } \\
\mathbf{P}=\text { Pier } \\
\mathbf{Q}=\text { Quarter midspan } \\
\mathbf{M}=\text { midspan } \\
\mathbf{Z}=\text { Abutment deck } \\
\text { connection }\end{array}$ & 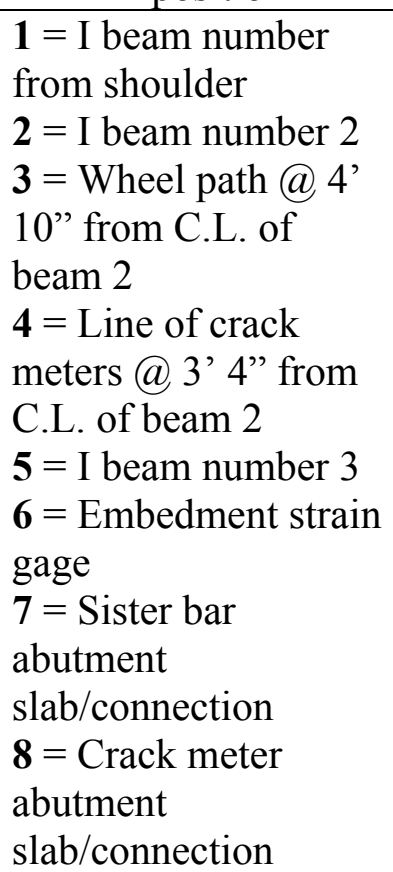 & $\begin{array}{l}\mathbf{0}=\text { Top slab } \\
\mathbf{1}=\text { Bottom slab } \\
\mathbf{2}=\text { Top upper } \\
\text { flange } \\
\mathbf{3}=\text { Bottom upper } \\
\text { flange } \\
\mathbf{4}=\text { Top web } \\
\mathbf{5}=\text { Mid web } \\
\mathbf{6}=\text { Bottom web } \\
\mathbf{7}=\text { Top lower } \\
\text { flange } \\
\mathbf{8}=\text { Bottom lower } \\
\text { flange }\end{array}$ & \\
\hline
\end{tabular}

Table 3.3 Sensor key codes 


\section{CHAPTER FOUR}

\section{CONCRETE MATERIAL TESTING}

\subsection{INTRODUCTION}

This chapter focuses on monitoring the mechanical behavior of concrete specimens at early age. The mechanical behavior of the concrete depends on its age, mix properties and curing conditions. Since these factors vary from one project to another, it is important to accurately estimate the properties of the concrete used in each individual project, especially when studying the early age behavior and cracking. This chapter illustrates an experimental program to monitor the development of the concrete mechanical properties with age.

\subsection{EXPERIMENTAL PLAN}

In order to capture the development of the mechanical properties of the concrete as it ages, a total of 38 cylinders specimens were prepared. A brief testing plan was discussed in table 4.1. The cylindrical specimens consisted of:

- Twenty one 6" X 12" cylinders to measure the compressive strength at different ages as shown in table 4.1

- $\quad$ Fourteen 4" X 8" cylinders to measure tensile strength of the concrete (Split tensile test) at different ages as illustrated in Table 4.2

- Three instrumented specimens to measure the stress-strain relations as well as the elastic properties of the concrete.

\subsection{SPECIMEN PREPARATION}

Twenty-one 6" X 12", fourteen 4" X 8" concrete cylinders were casted in a plastic molds near the bridge side to represent and monitor the actual behavior of the bridge. Three of the 6" X 12 " specimens were instrumented to monitor the stress-strain behavior 
at early ages and to determine the Young's modulus and Poisson's ratio of the concrete. Two vibrating wire gages model VK4100 are placed exactly perpendicular to each other with a thermistor to capture longitudinal strain, lateral strain and internal temperature of the concrete specimens. To avoid misalignment of the gages they are glued and tied to each other in position with a dichrome thread. The two gages were positioned exactly at the center of the cylinder by cutting the cylinder into two halves and opening a small groove on the lower half to pull the wires out of the cylinder as shown in Figure 4.1. Figure 4.1 to 4.4 explain the steps in casting the instrumented cylinders.

All concrete specimens were compacted in three layers. Each layer of the concrete specimen was rodded 25 times with a 5/8 " diameter rod for 6" X 12 " specimen and with a 3/8"diameter rod for 4" X 8 " diameter rod, to allow slight penetration while tamping the second and third layers. The top surface of the mold is then finished with a flat trowel to get a smooth surface. Then the specimens were covered with wet burlap to avoid moisture loss. Once the specimens are made they were shipped to the laboratory. After a day of pour, the molds were stripped and stored in a temperature and moist control room. The instrumented specimens were cured under a temperature control water bath, as shown in Figure 4.5.

\subsection{CONCRETE CYLINDER TESTS}

\subsubsection{Compressive Strength Tests}

Initially, the uninstrumented 6" X 12 " specimens, were tested on the FORNEY LT 700-2 compression testing machine as illustrated in Figure 4.6, with a maximum load capacity of 350,000 lbs. AASHTO standards require the surfaces of the compression test specimens to be plane within $0.05 \mathrm{~mm}$ and perpendicular to the axis within $0.5^{\circ}$. To ensure uniform load distribution over the specimen, the ends are usually capped while conducting the compression tests with nipper pad and steel caps. Specimens are loaded between two bearing blocks with the lower block fixed and the upper block is spherically seated to rotate to mate the specimen surface. These specimens were loaded up to the 
point of failure. Figure 4.7 shows a typical compression specimen at failure. Compressive strengths are then calculated by dividing the maximum applied load with cross section area of the specimen.

Three specimens were tested on the each day of the testing to avoid human errors and to account for material variability and the average value is taken as the compressive strength of the concrete. Table 4.2 shows the results of the tests conducted at concrete ages of approximately one, three, seven, 18, 32 and 60 days. Compressive strengths results and the percentage error were tabulated in the Table 4.2. Gain in the compressive strengths with the time was plotted in Figure 4.19

\subsubsection{Splitting Tensile Tests}

Splitting tensile tests involve compressing the cylinder (4" $\mathrm{X} 8$ " dimension) on its side until a crack forms, causing the specimen to fail in the form of splitting, as seen in Figure 4.9. The tests were performed on the FORNEY LT 700-2 compression testing machine in Figure 4.8, with a maximum load capacity of 60,000 lbs. In this test, specimens are placed horizontally between the platens of the testing machine and the load is increased until failure, the failure takes place by splitting along the vertical diameter as shown in Figure 4.9. During the tests, align the center of the specimens to the center of the bearings so that they are in the same axial plane. The advantages of the splitting test are that it is simple to perform and give more uniform results.

Two specimens were tested on the same day and average value is taken as tensile strength of the concrete. Tests were conducted at concrete ages of approximately one, three, seven, 18, 32 and 60 days. Tensile strengths and percentage error were tabulated in the Table 4.3.

\subsubsection{Instrumented cylinders}

The instrumented cylinders were tested on the manual compression-testing machine as shown in Figure 4.10. To avoid any eccentric loads on the cylinder, the end 
faces of the cylinders are machined with diamond saw for even and smooth surface finish. However, any small lack of parallelism between the end surfaces can be taken care by spherical mounted seat of the compression-testing machine.

The embedded vibrating wire gages are then hooked to two Geokon reading units to read the temperature, vertical and horizontal strains. The specimen should be placed carefully on the table or platen of the testing machine. The center of the specimen was aligned carefully with the center of the machine axis. The ends of the specimen were covered with rubber pads to permit even stress distribution while applying load. Initially, the load indicator was set to zero. The load was applied gradually to the specimen from zero to $10,000 \mathrm{lbs}$ (well before the failure load) and removed gradually. A precision load cell with capacity of 50,000 lb. in tension was used to measure the applied load. As the load applied, the corresponding temperature and strains were recorded. The specimens were loaded to a load well below its failure load. When a material is loaded and then unloaded, the graph of the unloading may not quite correspond to that for the loading. The boundary of the two graphs is called a hysteresis loop. The area inside this loop represents the energy dissipated during the loading and unloading process. The Young's modulus can be calculated from the slope of linear portions in the graph. This can be used to predict the deformation of a material under a particular load. Tests were conducted at approximately concrete ages of two, four, 18, 28, 60 and 96 days. The corresponding Poisson's ratio and Young's modulus were calculated and tabulated in the Table 4.4. The gain of Poisson's ratio, $\gamma$ and Young's modulus, E was illustrated in Figure 4.11 and 4.12 respectively. For each test, the stress-strain relationships were plotted as shown below, Figures 4.13-4.18.

\subsection{MATURITY OF THE CONCRETE}

The purpose of the concrete tests at the laboratory is to determine the mechanical properties of the concrete used in the bridge. But in fact the properties of the concrete in 
the bridge and the concrete specimens are different. One reason is due to difference in temperatures and the environmental conditions of the bridge and laboratory.

Concrete maturity is used to correlate the gain in the strength in the field to the strength in the standard laboratory condition, given the history of temperatures the concrete experienced in the field (Nawy, 1987).

To estimate the strength gain, researchers (Knusden, 1980 and Geiker, 1983) came up with a hyperbolic equation to fit the curve for the data obtained from the laboratory results.

$$
S=S_{u} \frac{\sqrt{k\left(t-t_{o}\right)}}{1+\sqrt{k\left(t-t_{o}\right)}}
$$

where,

$\mathrm{S}$ is Compressive strength at age $\mathrm{t}, \mathrm{d}$

$\mathrm{S}_{\mathrm{u}}$ is Limiting strength

$\mathrm{K}$ is Rate constant, $1 / \mathrm{d}$

$t_{0}$ is Age at start of strength development, $d$

Eq. (4.1) was used to fit the curve for compressive strength of the concrete as shown in Figure 4.19. The values for S, Strength and Constant, $\mathrm{k}$ is obtained using trial and error method to fit a close curve for the data points.

In Figure 4.19, the red points represents the data values from the laboratory results, and the solid black line represents the curve fit for the data points, after trial and error method using Eq (4.1). In Figure 4.19 and 4.20, the $\mathrm{S}$ and $\mathrm{k}$ values, i.e. strength and constant values of $72,00 \mathrm{psi}$ and 1.15 respectively proves to give good fit to the data points. For Figure 4.20, i.e. for tensile strengths, the values of S and k were taken as 700 psi and 1.15 respectively. 
The compressive strength of the concrete at the bridge was then predicted (McCullough 1999) using Eq (4.2), with the temperature histories obtained from the thermistor tree installed on the bridge and using the constants $\mathrm{S}$ and $\mathrm{k}$ obtained from the hyperbolic function (Eq. 4.1)

$$
t_{e}=\sum_{t=0}^{\operatorname{age}}\left[e^{\left[\frac{\phi}{R}\left(\frac{1}{T+273}-\frac{1}{T_{r}+273}\right)\right]} \bullet \Delta t\right]
$$

where,

$t_{e}$ is Equivalent age, $\mathrm{h}$,

$\phi$ is Activation energy, $39050 \mathrm{~J} / \mathrm{mol}$

$\mathrm{t}$ is Time, $\mathrm{h}$

$\mathrm{R}$ is Universal gas constant, $8.3144 \mathrm{~J} / \mathrm{mol} /{ }^{\circ} \mathrm{C}$

$\mathrm{T}$ is Nodal PCC temperature, ${ }^{\circ} \mathrm{C}$ and

$\mathrm{T}_{\mathrm{r}}$ is Reference temperature, $20{ }^{\circ} \mathrm{C}$

Figure 4.21 illustrates the comparison of the compressive strength of the in-situ concrete and concrete specimen respectively. As seen from Figure 4.21, the actual properties of the in-situ concrete are different from the concrete specimens at the laboratory.

\subsection{COEFFICIENT OF THERMAL EXPANSION}

The coefficient of thermal expansion is the change in length per unit length of material per one degree centigrade change in temperature (Neville, 1973). Each of the three-instrumented specimens has thermistor for monitoring temperature changes. The three-instrumented specimens are placed in the temperature controlled water bath, as

shown in Figure 4.5. The temperature of the water bath is changed periodically to measure the expansion and contraction of the concrete specimen for the corresponding 
temperature change. All the sensors from the cylinders are connected to 32 channels Geokon multiplexer, which is connected to the data acquisition system to collect and store the data acquired. Data acquisition system is a datalogger, which runs by multilogger software 2.1.0 version developed by Campbell scientific company. It has CR10-X control module with multi sensor interface. These special features enable the datalogger to collect different types of sensors using 8032 16/32 channel multiplexer. The datalogger is then programmed for vibrating wire gage and data is continuously collected and stored in the datalogger.

For all the three cylinders (cylinder A, cylinder B, cylinder C), applying data reduction on the collected data, strain-temperature history graphs were shown in Figures 4.22-4.24 respectively. Concrete has a positive coefficient of thermal expansion, means it expands with rise in temperature. But its value depends on composition of the mix like constituents of the concrete, cement paste, aggregate. The coefficient of thermal expansion varies between about $11 \times 10^{-6}$ and $20 \times 10^{-6}$ per ${ }^{\circ} \mathrm{C}$. Coefficient of thermal expansion is calculated from the data collected, by dividing the change in strain due to degree temperature change. The average thermal coefficient of expansion from the three cylinders is found to be $11.2616 \times 10^{-6}$ per ${ }^{\circ} \mathrm{C}$.

\subsection{CONCLUSIONS}

The experimental results show a very similar behavior between the compressive strength, modulus of elasticity, and Poisson's ratio. From the stress-strain curves, we could see the hystersis loop is getting closer and closer with the age, which clearly explains the change in the concrete behavior from the plastic property to the elastic property. Young's modulus, E value calculated from the graph is very close to the young's modulus from compression test.

Maturity of the concrete function gives accurate concrete properties at the bridge using the laboratory tests. From the strain-temperature history graphs, it could be cleared that the concrete has positive thermal coefficient of expansion, i.e. rise in strain values 
due to temperature rise. The high value in the Poisson's ratio of the concrete is observed in this experimental study i.e. 0.19-0.31, may be due to dynamic measurement. 
Table 4.1 Testing plans for concrete material tests

\begin{tabular}{|l|c|c|c|c|c|c|c|}
\hline Test & 1 Day & 3 Days & 7 Days & 14 Days & 28 Days & 60 Days & 1 Year \\
\hline Compressive Strength & 3 & 1 & 3 & 3 & 3 & 3 & 3 \\
\hline Split Tensile Test & 2 & 2 & 2 & 2 & 2 & 2 & 2 \\
\hline Modulus of Elasticity & 1 & 1 & 1 & 1 & 1 & 1 & 1 \\
\hline Poisson Ratio & 1 & 1 & 1 & 1 & 1 & 1 & 1 \\
\hline $\begin{array}{l}\text { Coefficient of thermal } \\
\text { Expansion }\end{array}$ & - & - & - & - & 2 & - & - \\
\hline
\end{tabular}




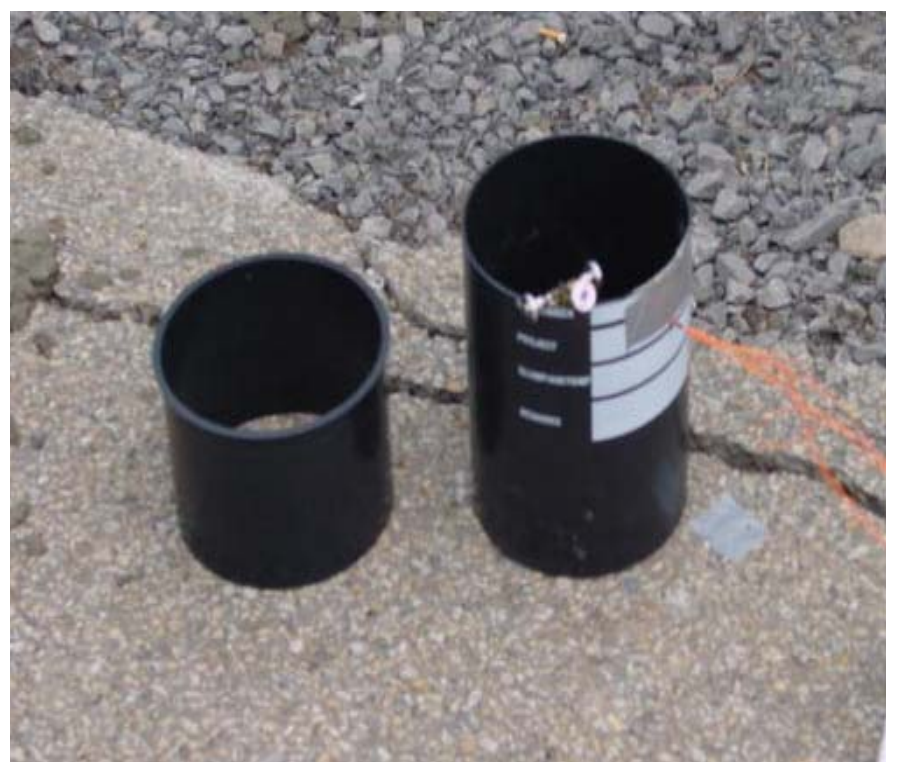

Figure 4.1 Instrumented concrete cylindrical molds with strain gage

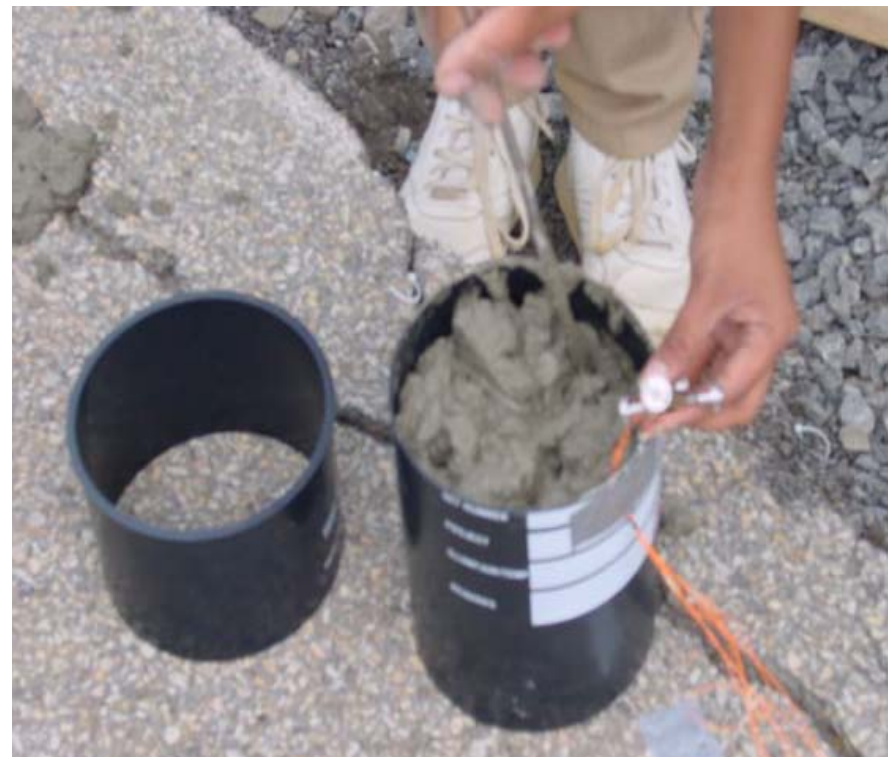

Figure 4.2 Casting the cylinders with strain gages 


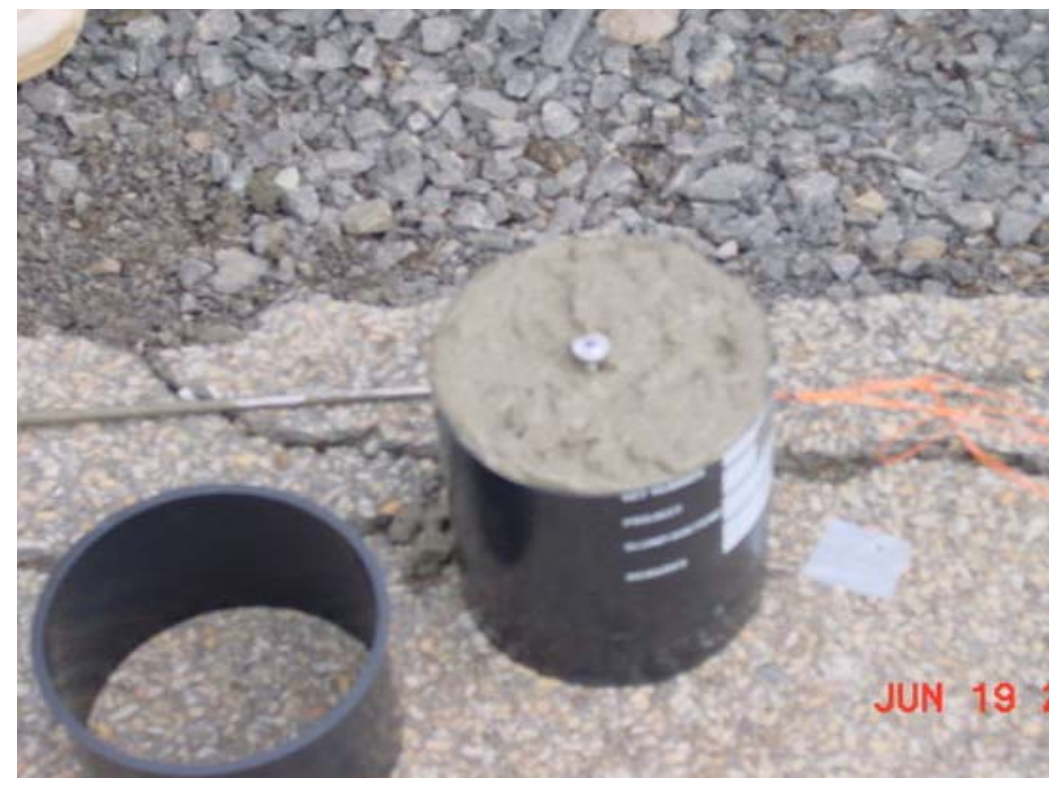

Figure 4.3 Concrete cylinder with strain gage

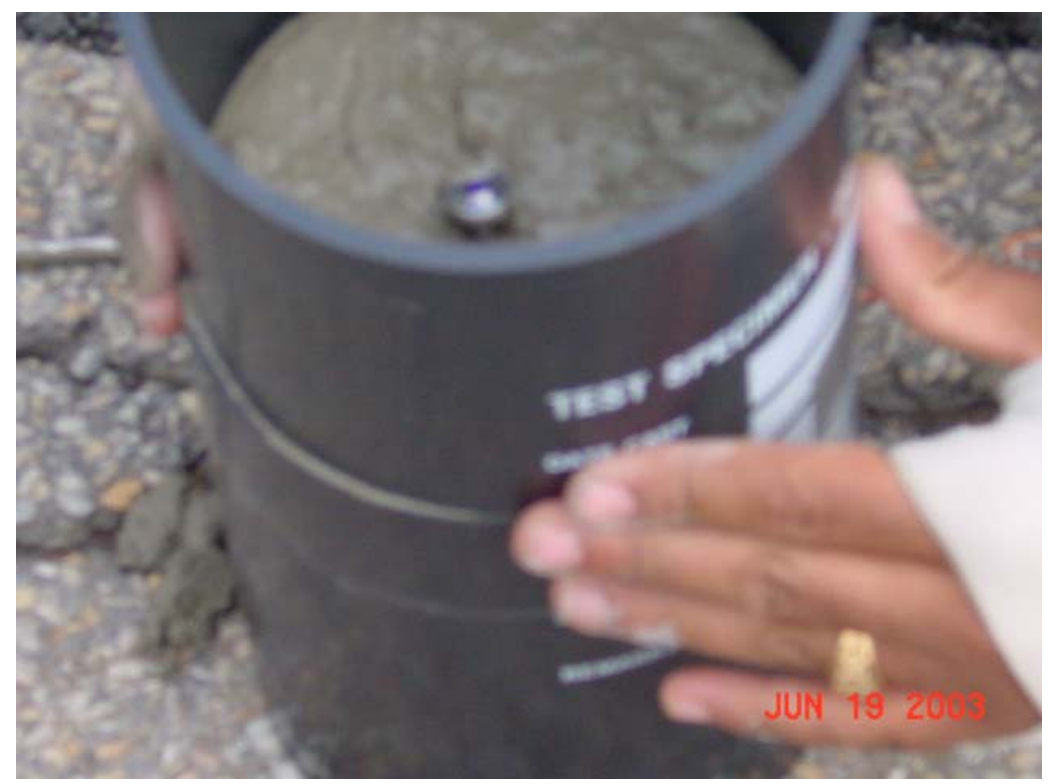

Figure 4.4 Combining the other half of the cylinder after installing the sensor in the lower half. 


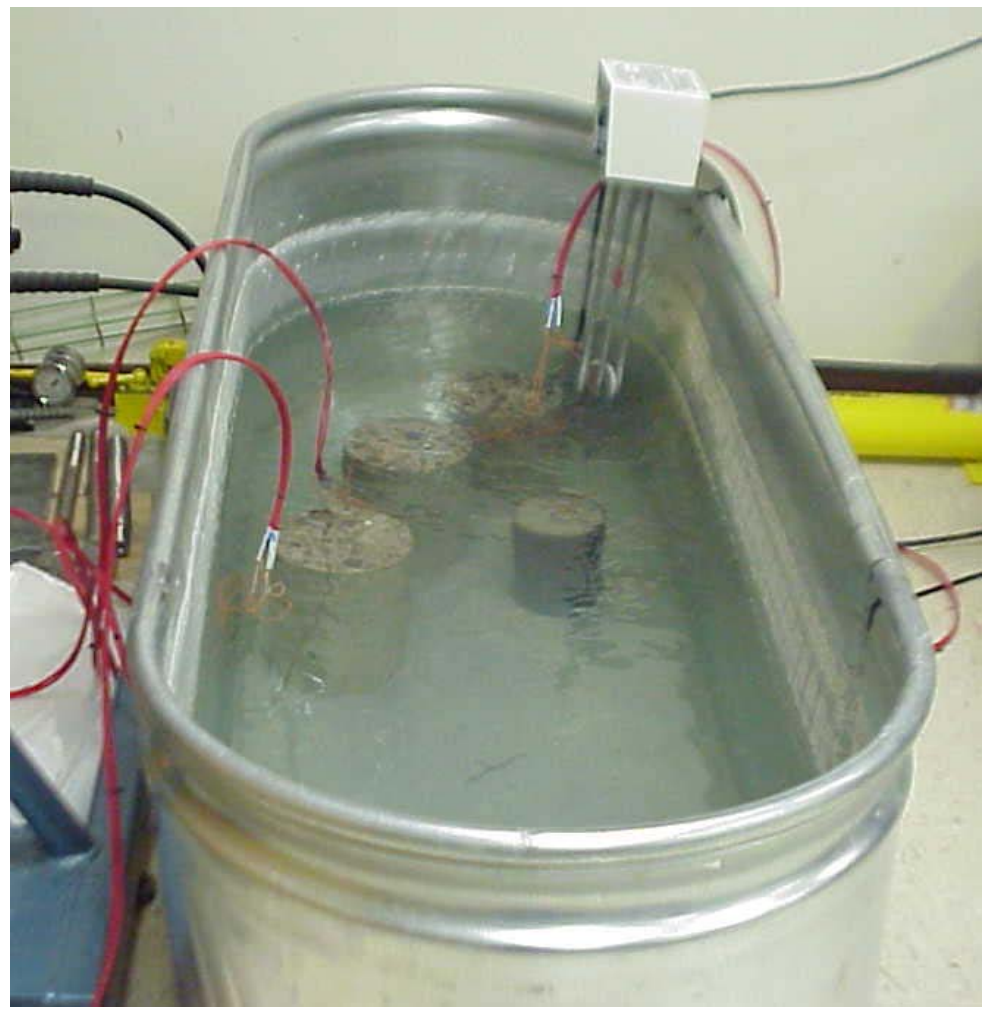

Figure 4.5 Curing of cylindrical specimens at the laboratory 


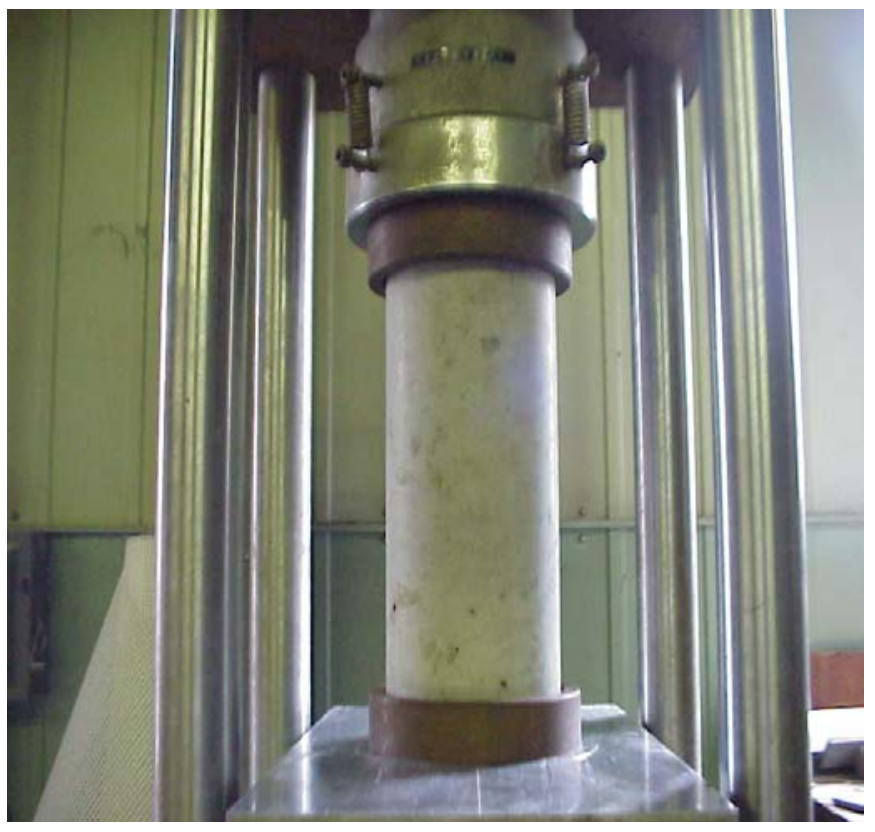

Figure 4.6 Experimental setup for 6" X 12" cylindrical specimen

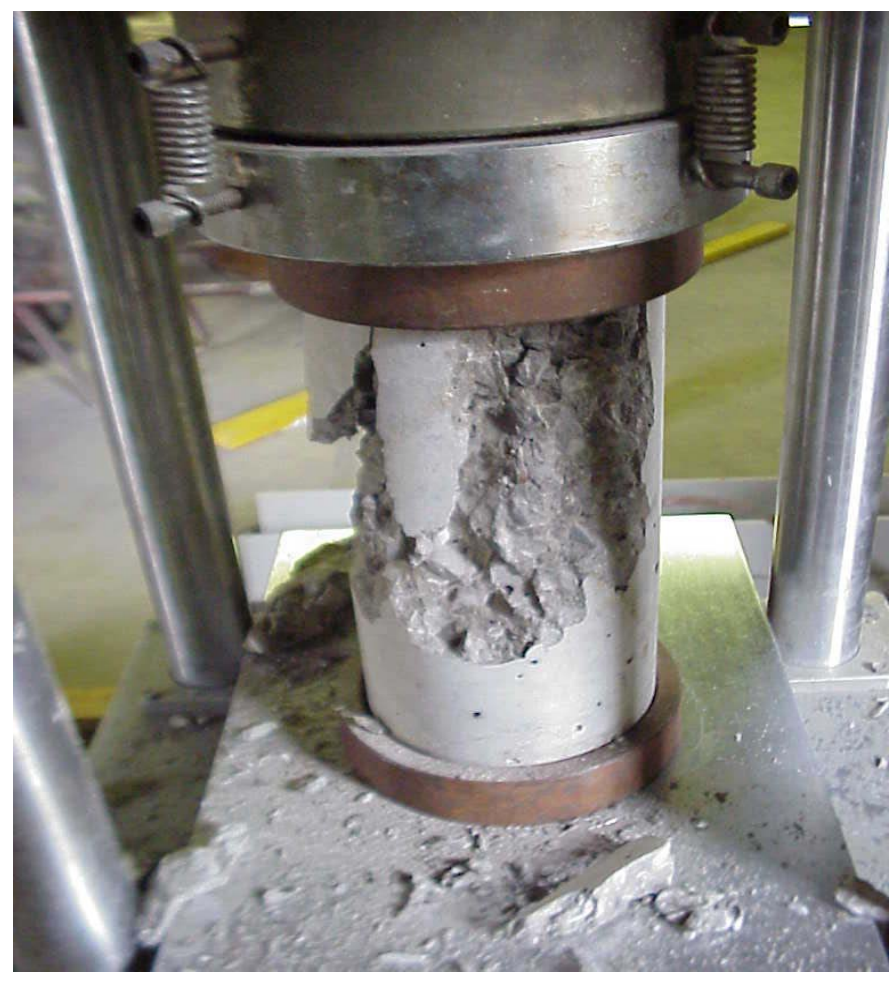

Figure 4.7 6" X12" cylindrical specimen at failure 
Table 4.2 Compressive strength properties

\begin{tabular}{|c|c|c|c|c|c|c|}
\hline & & Specimen 1 & Specimen 2 & Specimen 3 & Average & Error \\
\hline \multirow[b]{2}{*}{ Day 1} & Load (Lb) & 87,000 & 88,000 & 90,000 & & \multirow[b]{2}{*}{$1.7 \%$} \\
\hline & Strength (psi) & 3,077 & 3,112 & 3,183 & 3,124 & \\
\hline \multirow[b]{2}{*}{ Day 3} & Load (Lb) & 125,000 & 124,000 & 115,000 & & \multirow[b]{2}{*}{$4.5 \%$} \\
\hline & Strength (psi) & 4,421 & 4,386 & 4,067 & 4,291 & \\
\hline \multirow[b]{2}{*}{ Day 7} & Load (Lb) & 132,000 & 126,000 & 125,000 & & \multirow[b]{2}{*}{$3.0 \%$} \\
\hline & Strength (psi) & 4,669 & 4,456 & 4,421 & 4,515 & \\
\hline \multirow[b]{2}{*}{ Day 18} & Load (Lb) & 165,000 & 160,000 & 160,000 & & \multirow[b]{2}{*}{$1.8 \%$} \\
\hline & Strength (psi) & 5,836 & 5,659 & 5,659 & 5,718 & \\
\hline \multirow[b]{2}{*}{ Day 32} & Load (Lb) & 175,000 & 185,000 & 170,000 & & \multirow[b]{2}{*}{$4.3 \%$} \\
\hline & Strength (psi) & 6,189 & 6,543 & 6,013 & 6,248 & \\
\hline \multirow[b]{2}{*}{ Day 60} & Load (Lb) & 180,000 & 185,000 & & & \multirow[b]{2}{*}{$1.9 \%$} \\
\hline & Strength (psi) & 6,366 & 6,543 & & 6,455 & \\
\hline
\end{tabular}

Table 4.3 Tensile strength properties

\begin{tabular}{|c|c|c|c|c|c|c|}
\hline & & Specimen 1 & Specimen 2 & Specimen 3 & Average & Error \\
\hline \multirow[b]{2}{*}{ Day 1} & Load (Lb) & 20,000 & 17,000 & 16,500 & & \multirow[b]{2}{*}{$10.6 \%$} \\
\hline & Strength (psi) & 398 & 338 & 328 & 355 & \\
\hline \multirow[b]{2}{*}{ Day 3} & Load (Lb) & 20,000 & 21,000 & 22,000 & & \multirow[b]{2}{*}{$4.8 \%$} \\
\hline & Strength (psi) & 398 & 418 & 438 & 418 & \\
\hline \multirow[b]{2}{*}{ Day 7} & Load (Lb) & 23,000 & 26,000 & - & & \multirow[b]{2}{*}{$8.7 \%$} \\
\hline & Strength (psi) & 458 & 517 & - & 487 & \\
\hline \multirow[b]{2}{*}{ Day 18} & Load (Lb) & 26,000 & 28,000 & - & & \multirow[b]{2}{*}{$5.2 \%$} \\
\hline & Strength (psi) & 517 & 557 & - & 537 & \\
\hline \multirow[b]{2}{*}{ Day 32} & Load (Lb) & 30,000 & 32,500 & - & & \multirow[b]{2}{*}{$5.7 \%$} \\
\hline & Strength (psi) & 597 & 647 & - & 622 & \\
\hline \multirow[b]{2}{*}{ Day 60} & Load (Lb) & 34,000 & - & - & & \multirow[b]{2}{*}{$0 \%$} \\
\hline & Strength (psi) & 676 & - & - & 676 & \\
\hline
\end{tabular}




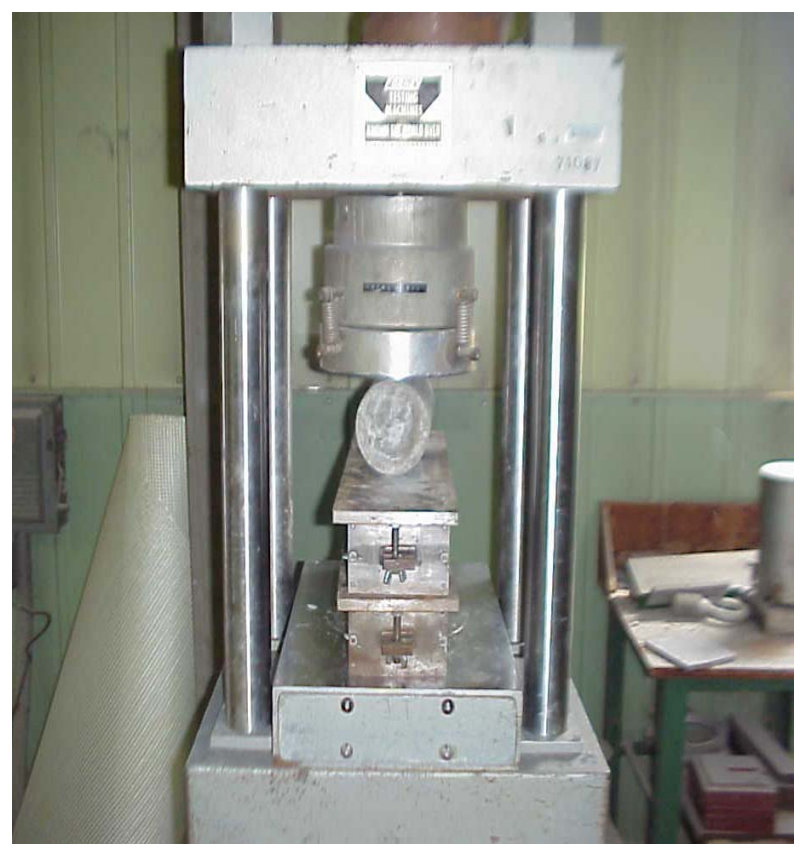

Figure 4.8 Experimental setup for 4" X 8" cylindrical specimen

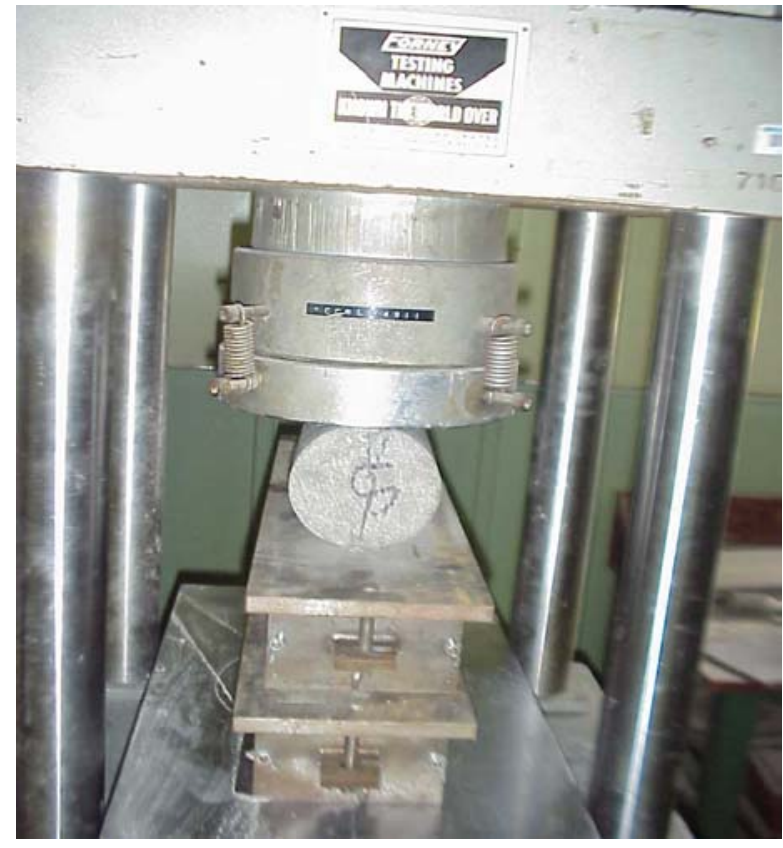

Figure 4.9 4" X 8" cylindrical specimen at failure 


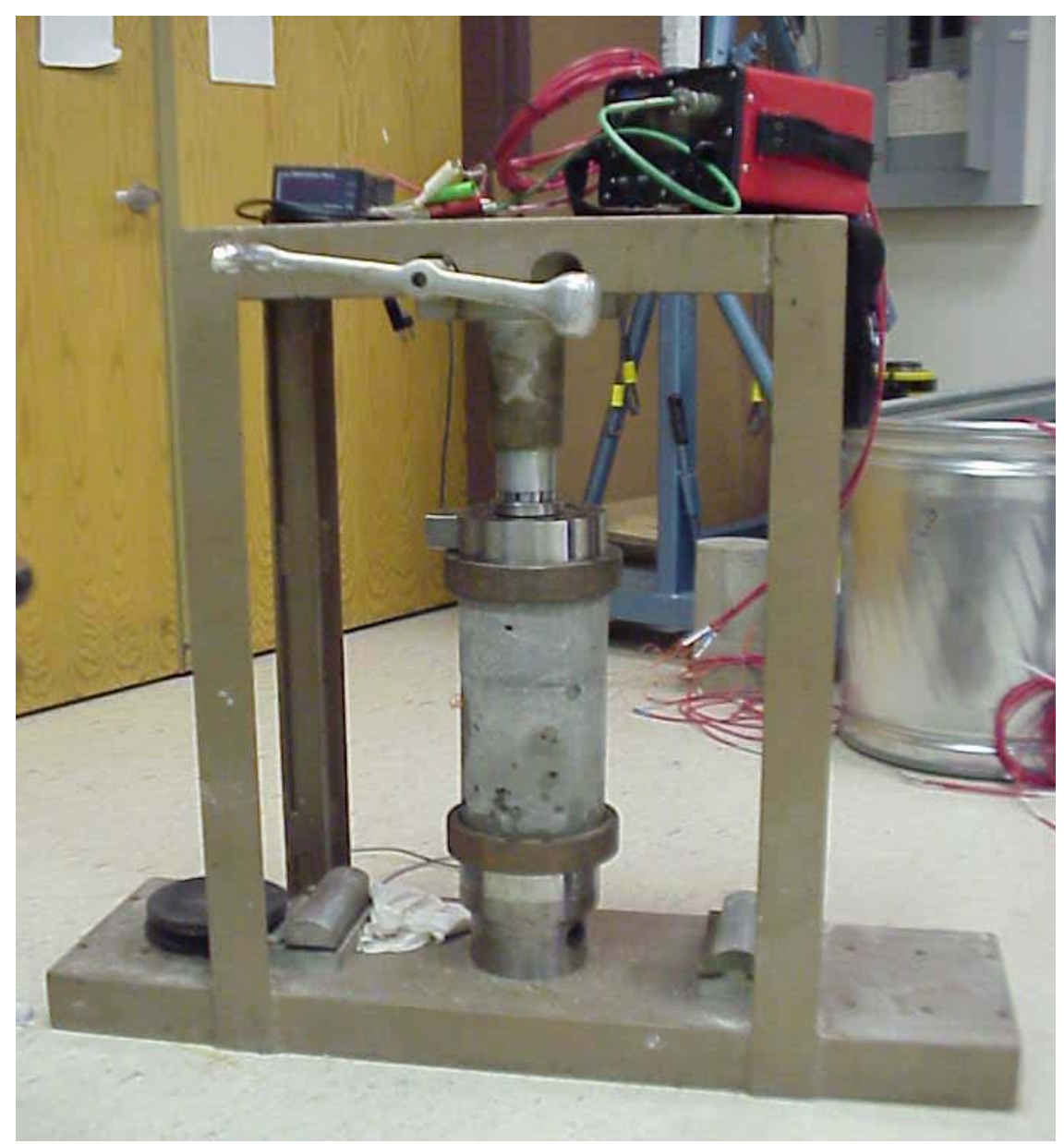

Figure 4.10 Experimental setup for 6“ X 12” instrumented specimen 
Table 4.4 Concrete properties

\begin{tabular}{|c|l|l|}
\hline $\begin{array}{c}\text { Concrete Age } \\
\text { (days) }\end{array}$ & $\begin{array}{c}\text { Modulus of } \\
\text { Elasticity, } \mathbf{E} \\
\text { (psi) }\end{array}$ & \multicolumn{1}{|c|}{$\begin{array}{c}\text { Poisson's } \\
\text { Ratio, } \mathbf{m}\end{array}$} \\
\hline 2 & 3367064 & 0.193036 \\
\hline 4 & 3786918 & 0.202757 \\
\hline 18 & 4058325 & 0.239454 \\
\hline 28 & 4174813 & 0.2434 \\
\hline 60 & 5053188 & 0.3089 \\
\hline 96 & 5225915 & 0.310612 \\
\hline
\end{tabular}




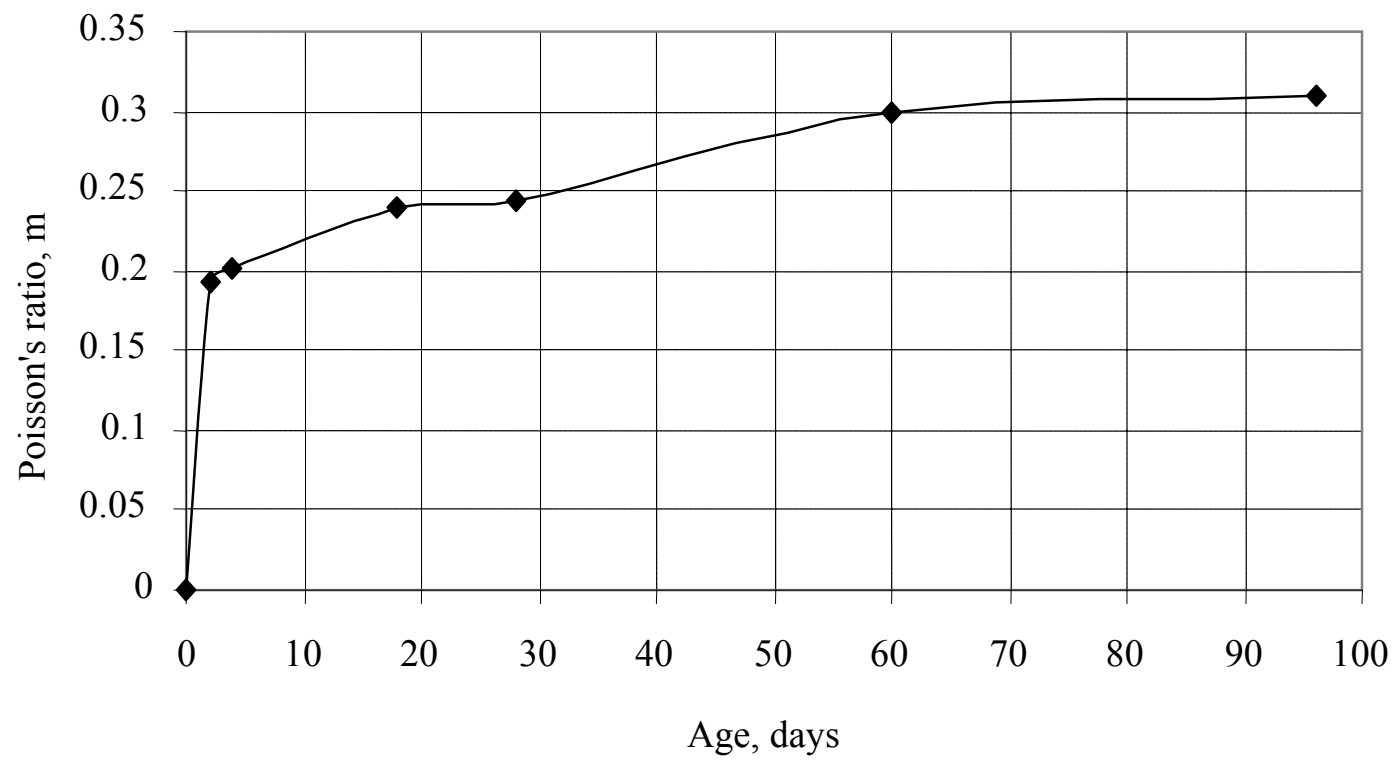

Figure 4.11 Poisson's ratio - Concrete age

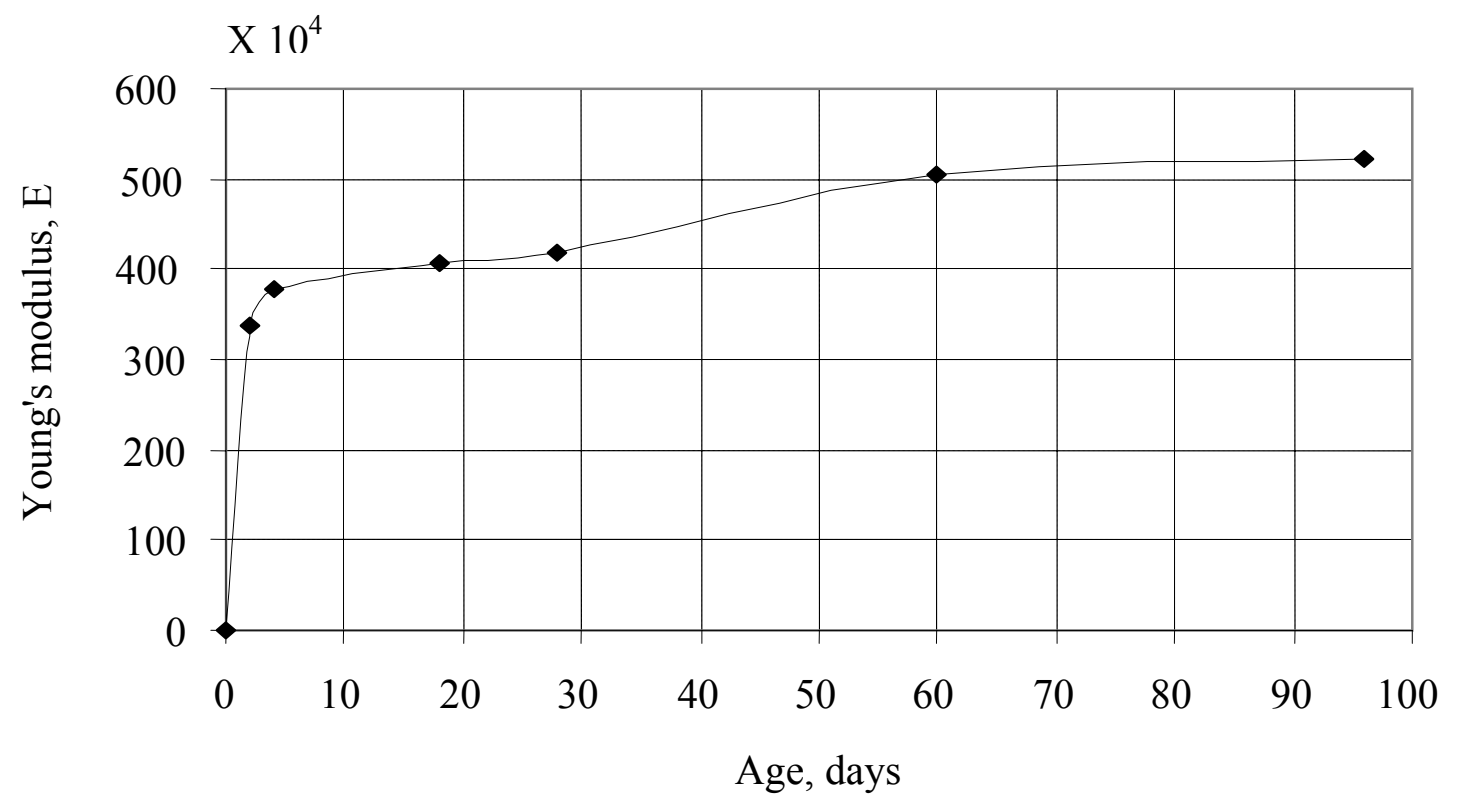

Figure 4.12 Young's modulus - Concrete age 


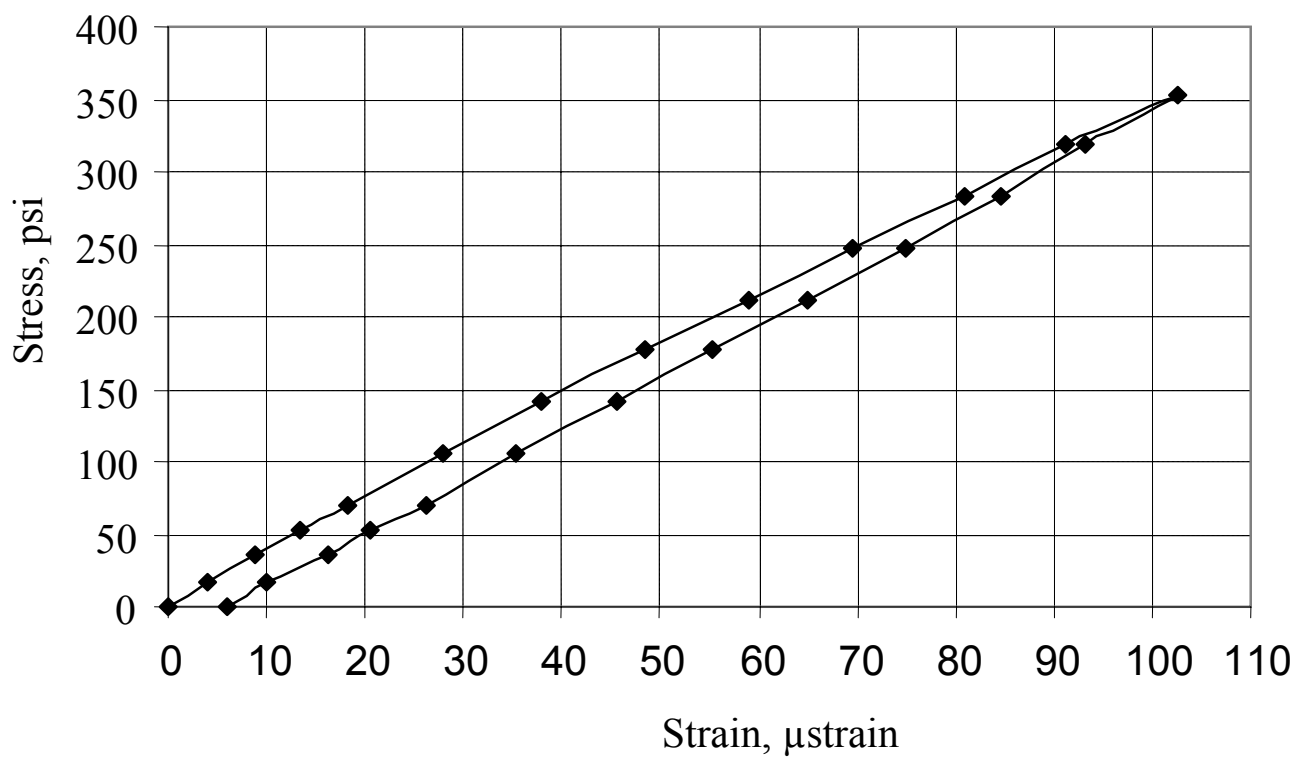

Figure 4.13 Stress - Strain curve for cylinder B, at an age of 2 days

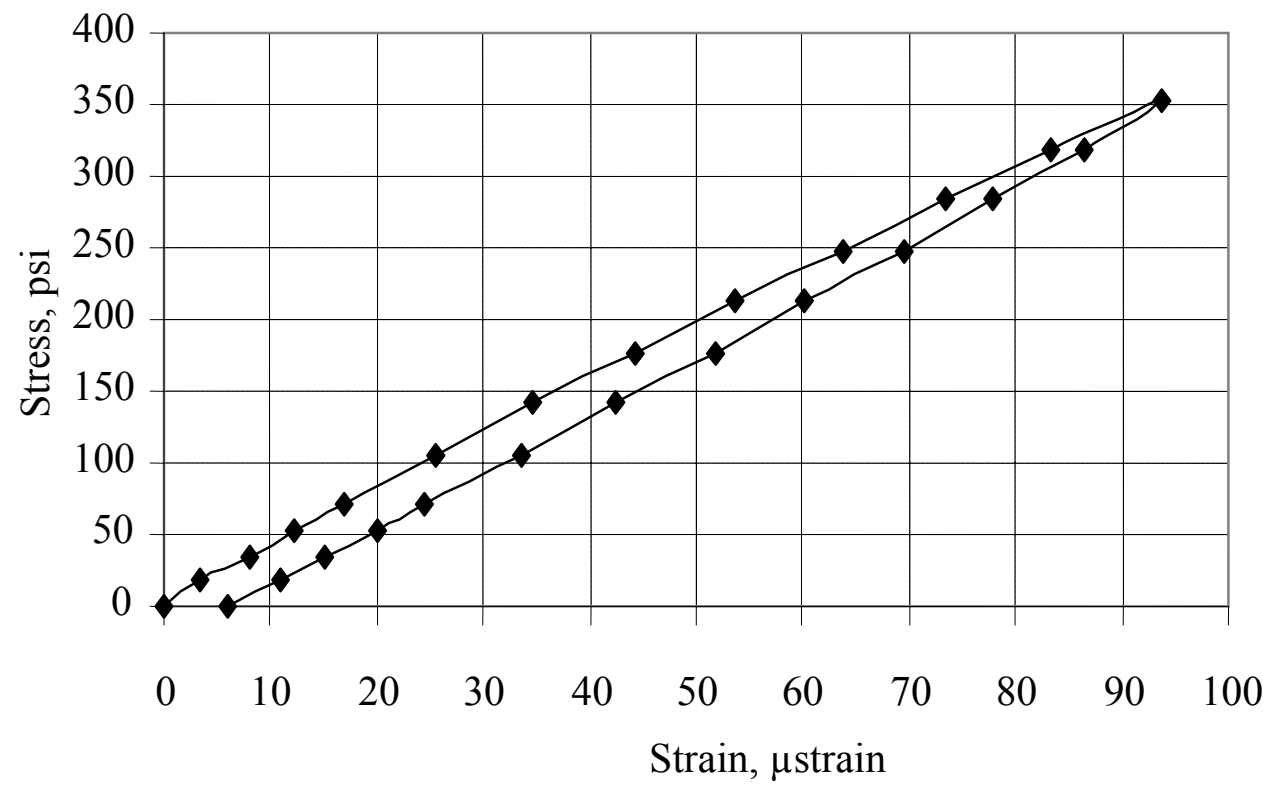

Figure4.14 Stress - Strain curve for cylinder B, at an age of 4 days 


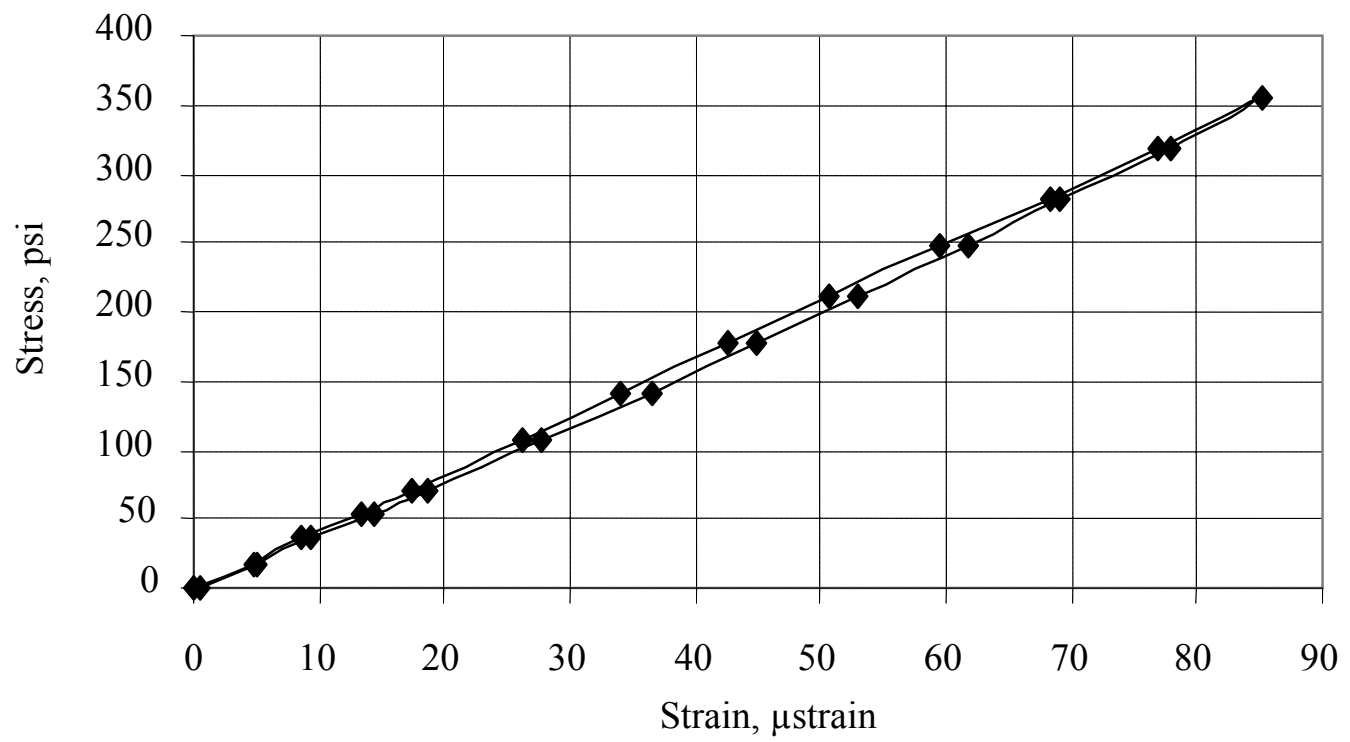

Figure 4.15 Stress - Strain curve for cylinder B, at an age of 18 days

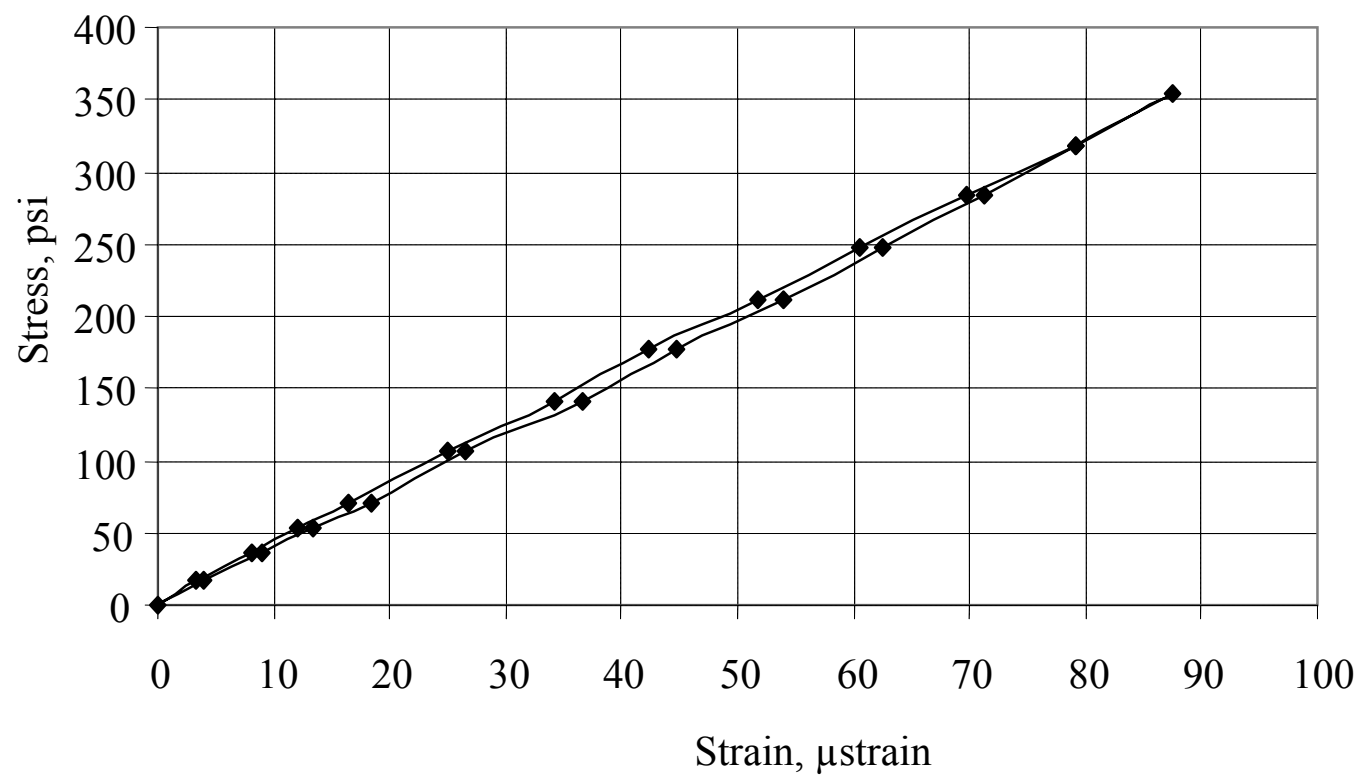

Figure 4.16 Stress - Strain curve for cylinder B, at an age of 28 days 


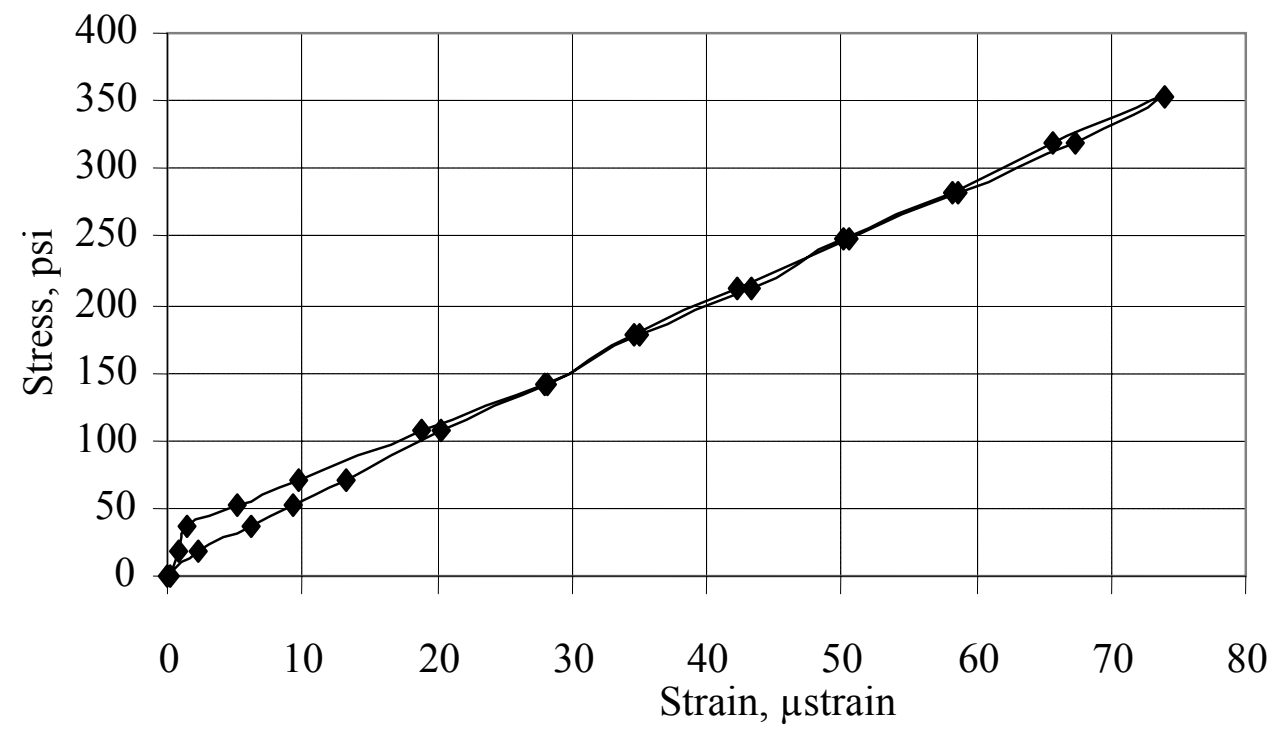

Figure 4.17 Stress - Strain curve for cylinder B, at an age of 60 days

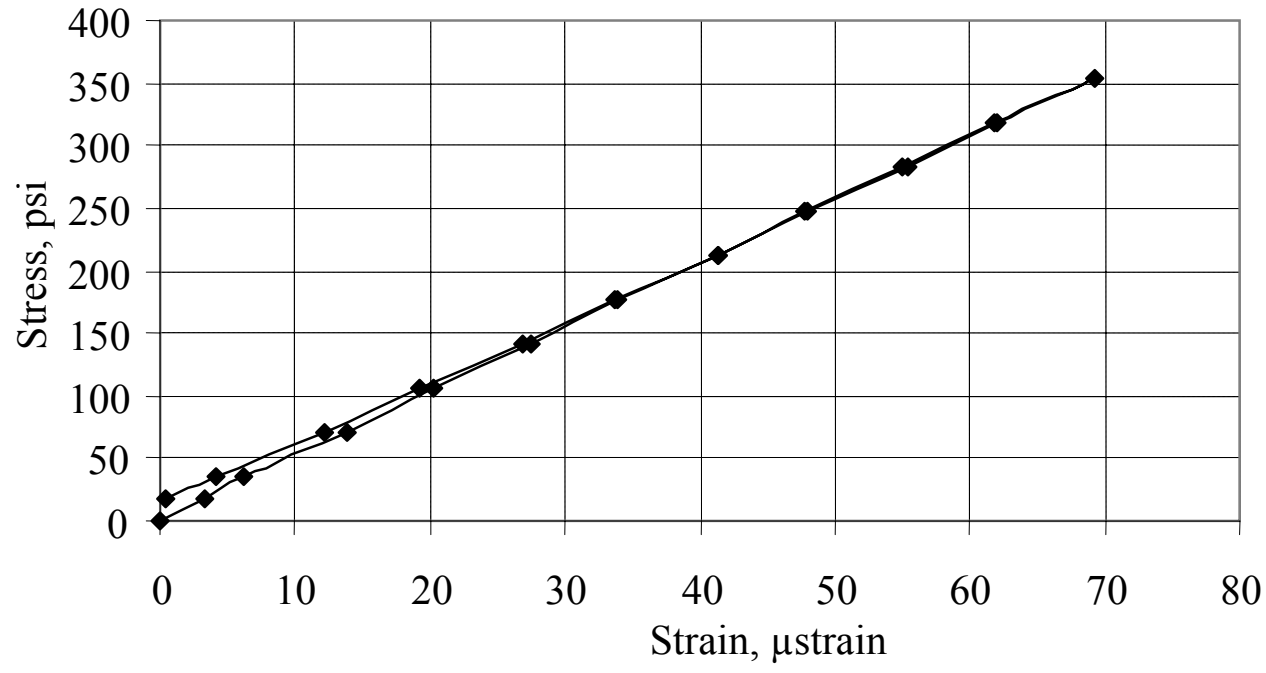

Figure 4.18 Stress - Strain curve for cylinder B, at an age of 90 days 


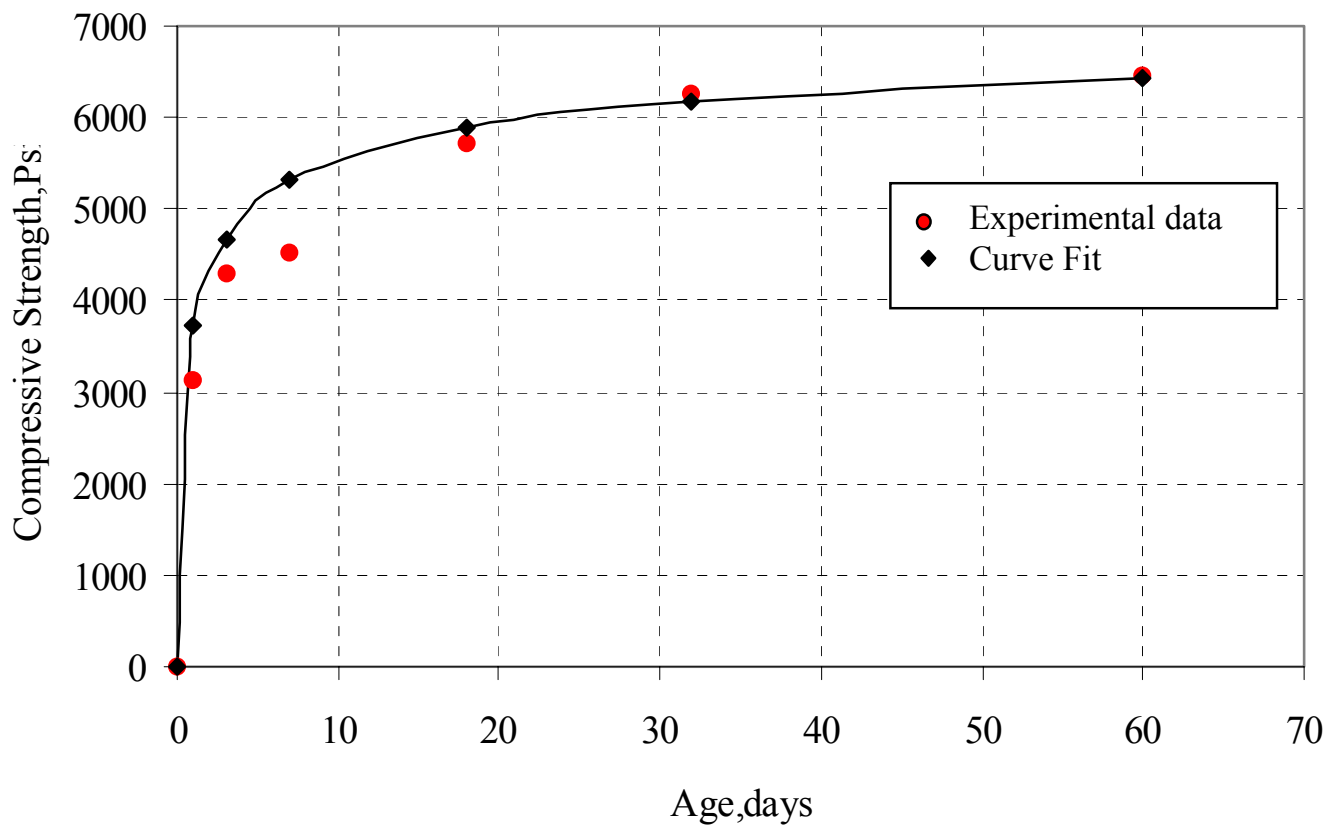

Figure 4.19 Curve fit of compressive strength - age models to the data

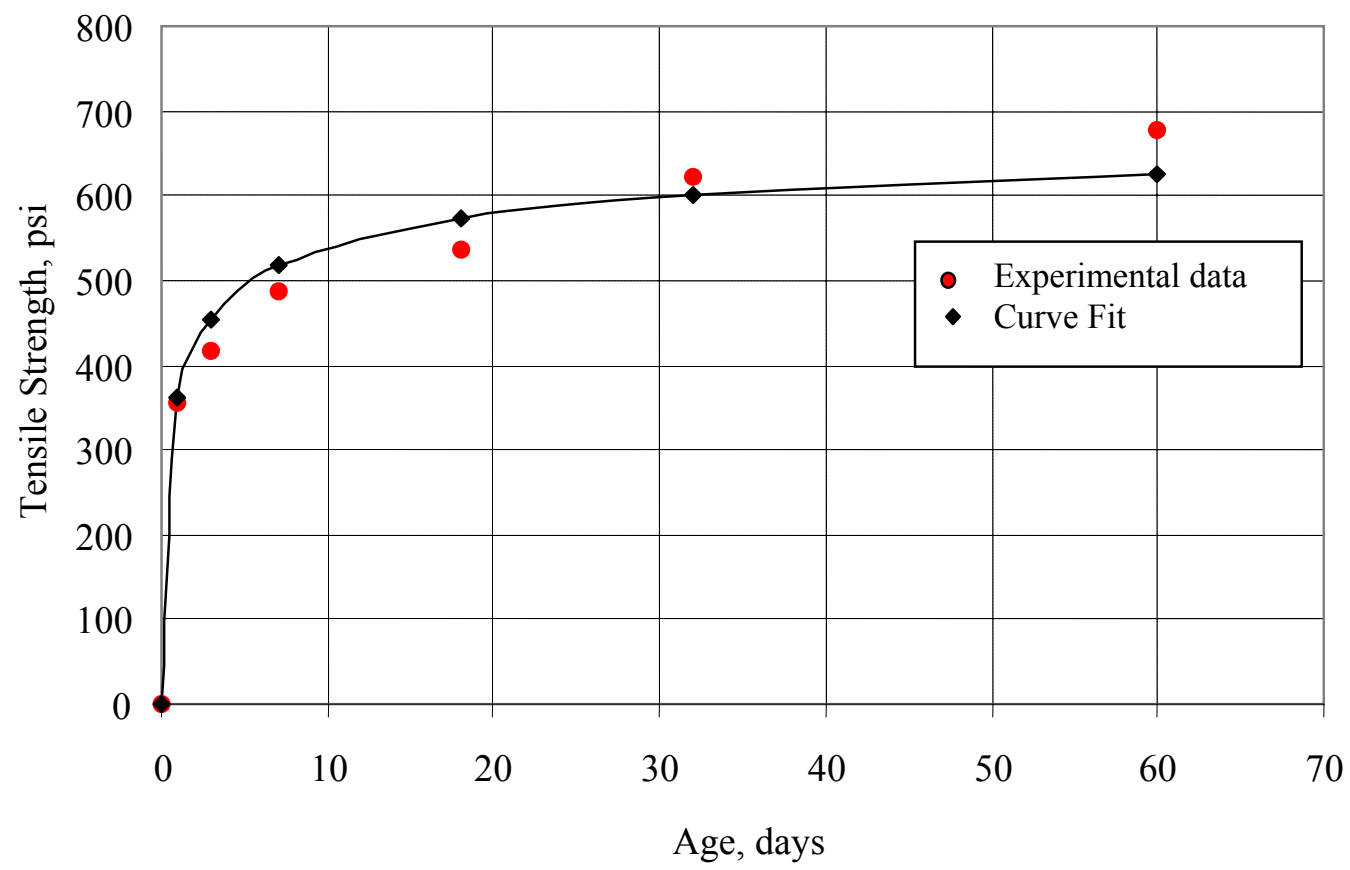

Figure 4.20 Curve fit of tensile strength - age models to the data 


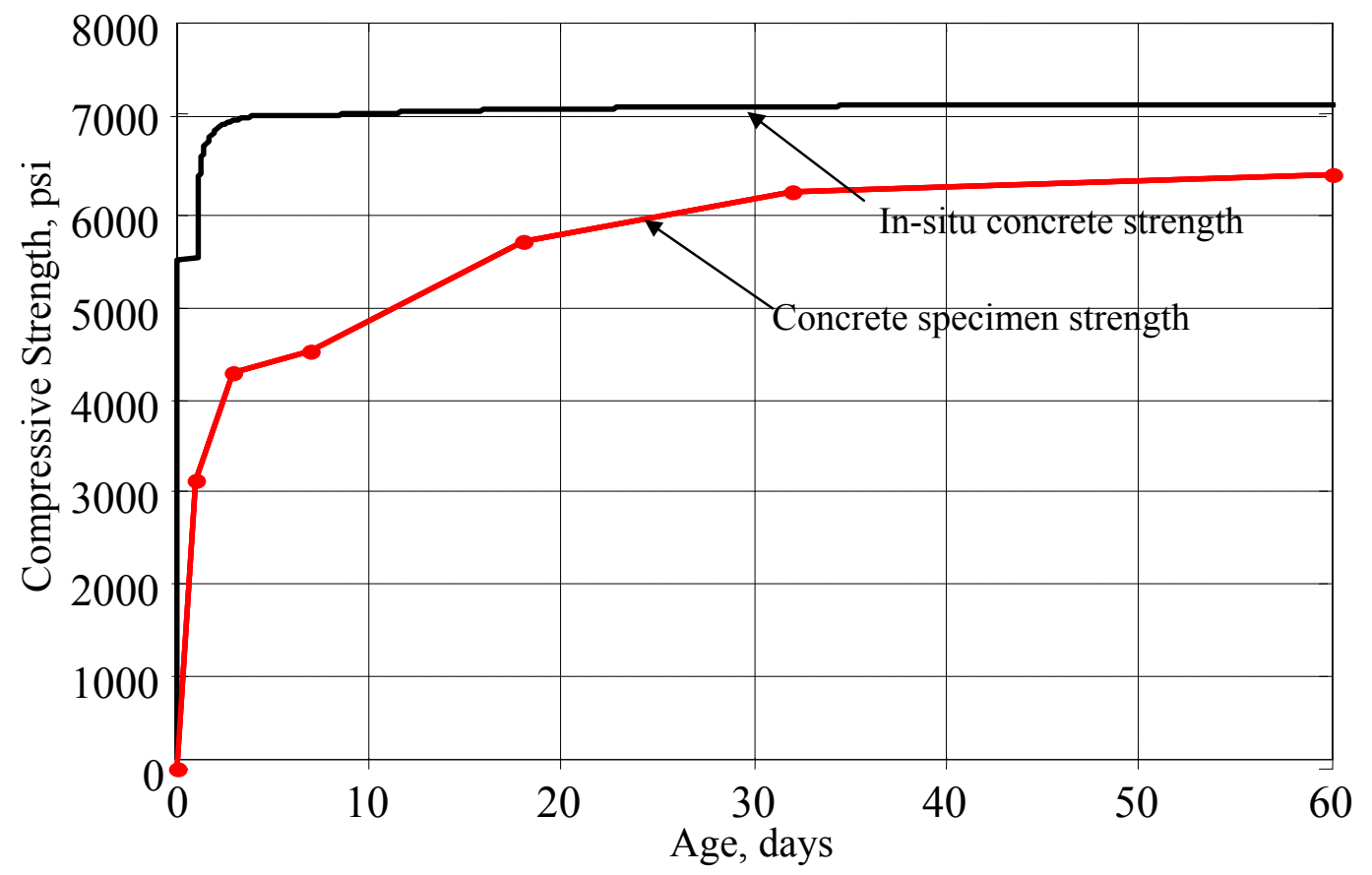

Figure 4.21 Comparison between in-situ compressive strength and concrete specimen 


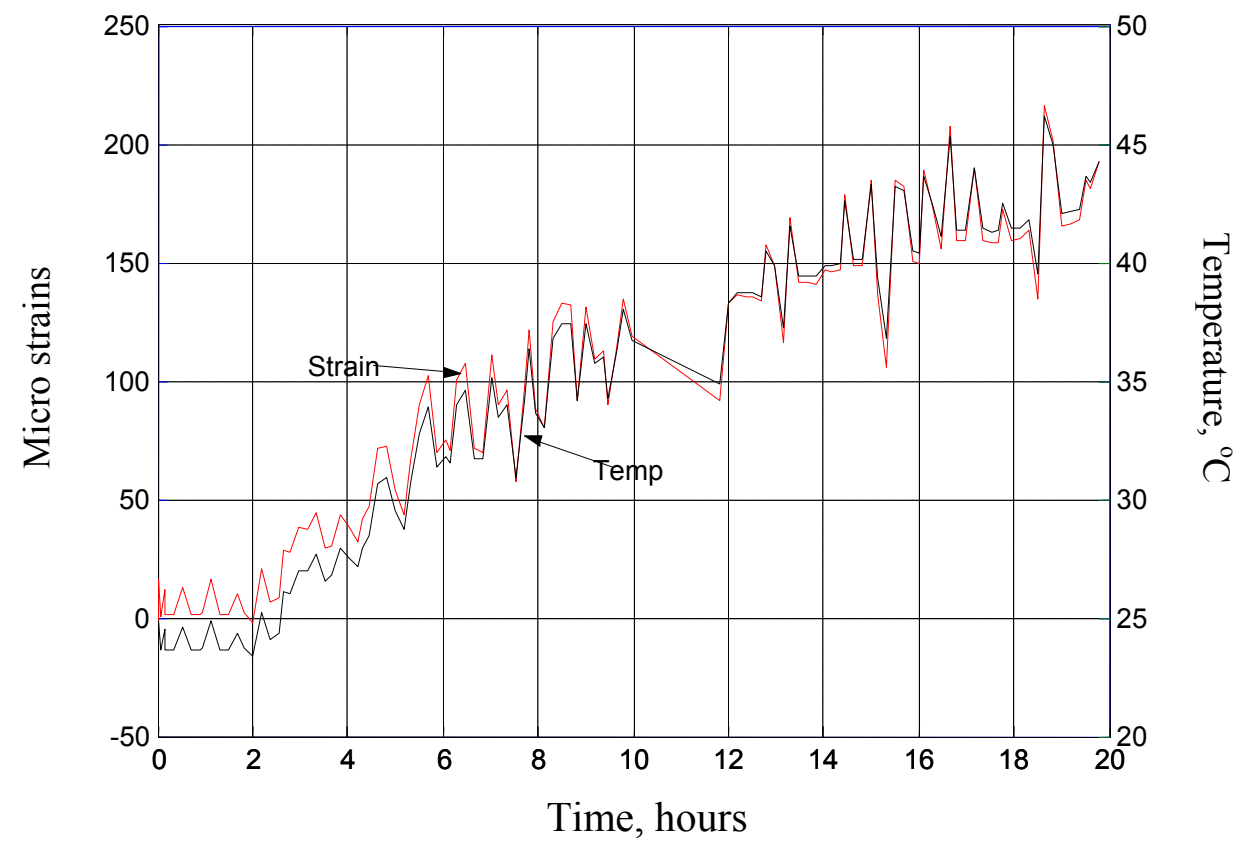

Figure4.22 Strain - Temperature history for cylinder A

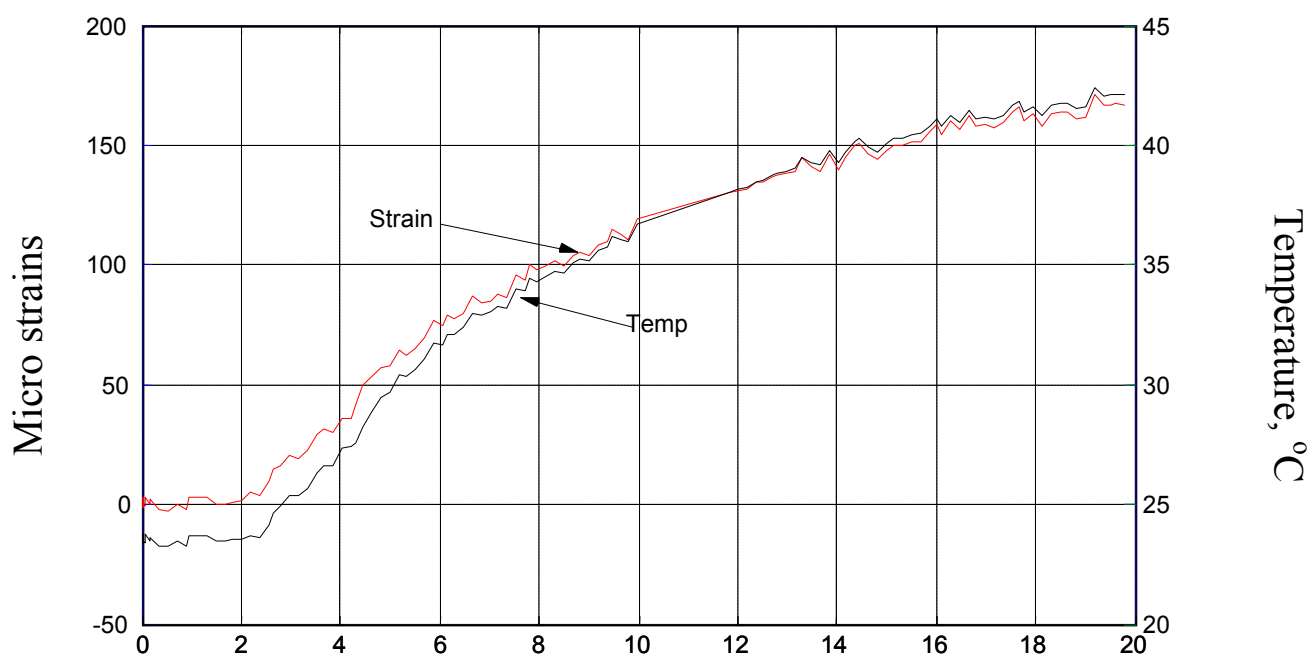

Time, hours

Figure 4.23 Strain - Temperature history for cylinder B 


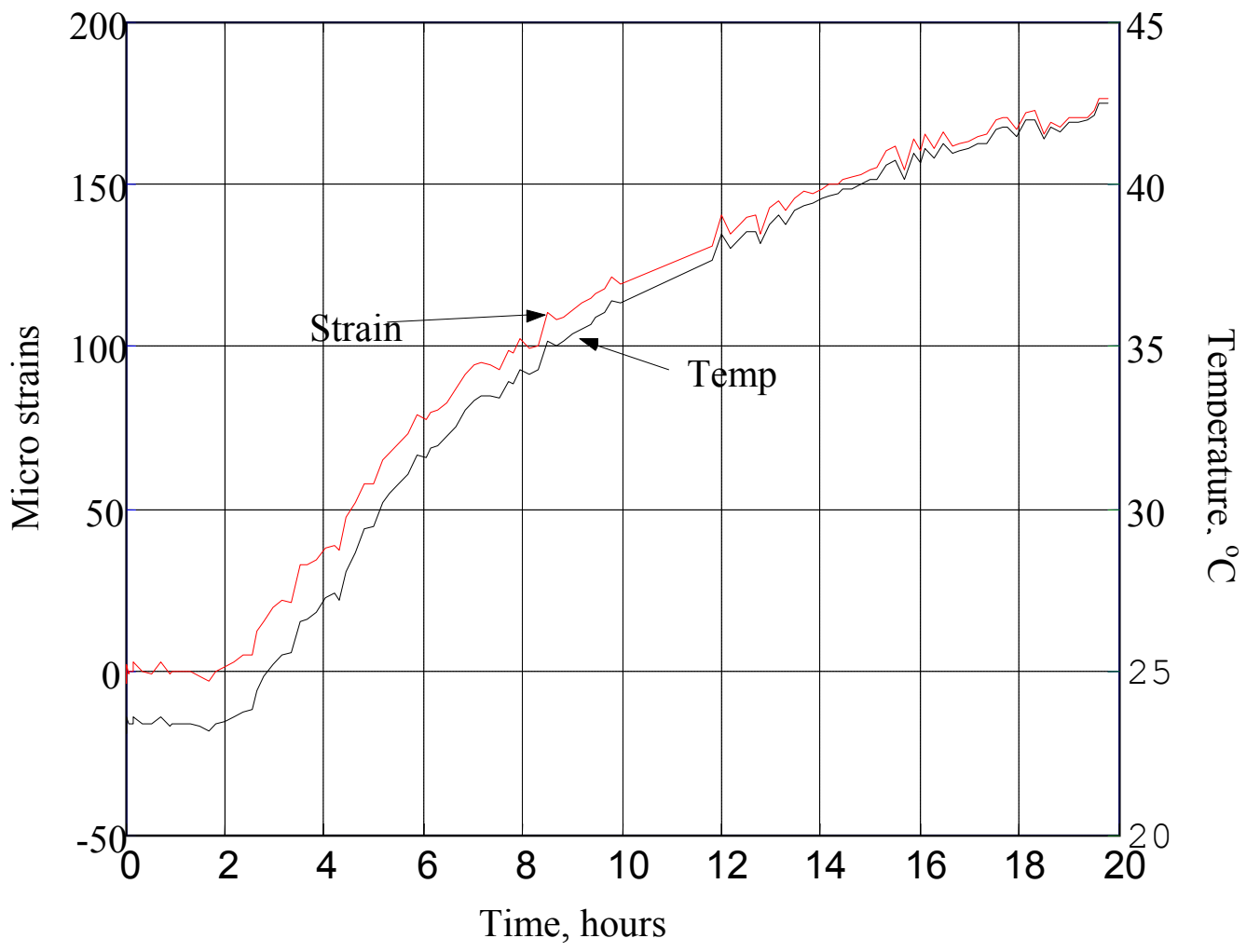

Figure 4.24 Strain - Temperature history for cylinder C 


\section{CHAPTER FIVE}

\section{DATA ANALYSIS AND INTERPRETATION}

\subsection{DATA REDUCTION}

In multi sensor measuring systems, different types of sensors are used to collect the information using a common data acquisition system with a common objective. Hence, all collected data are contained in a single file. In order to monitor the behavior of the bridge, efficient data reduction techniques are required to group or separate the data from each type of sensors for further analysis. Also, for handling large amount of data generated, data reduction techniques are used.

The raw data collected from all sensors have to be compensated for the temperature changes as specified by the sensors manufacturers (Geokon, 1996). The temperature compensation method differs from a sensor type to another. However, data from similar sensors were grouped together in a single file before the temperature compensation formula was applied to get the corrected data, which should be used in the data analysis.

The main task of the reduction method was to convert the output digits from the datalogger file to deformation values in inches, with temperature compensation. This was done using MATLAB software. Calibration factor was applied to the data, while programming the datalogger. The sequence of steps followed to reduce the data from the raw data file, and to apply the temperature compensations are detailed in the appendix III.

\subsection{FILTER DESIGN}

Deformation and temperature readings were monitored continuously to capture the axial deformation and/or the crack openings along the bridge deck as the temperature changes. Figure 5.1 (a) illustrates a typical signal obtained from a crack-meter in the 
bridge deck as the concrete temperature varied over time as shown in Figure 5.1 (b). The plots in Figure 5.1 indicate that:

1. The crack-meter reading is influenced by the daily change in temperature, which can be seen from the high frequency content recorded in the signal. A signal blowup shown in Figure 5.1 indicates that the Signal/Noise ratio of the recorded signal is very high and all the oscillations observed are due to the daily changes in the temperature between day and night.

2. Due to the short duration of data monitoring from the bridge (the bridge age is 145 days), the effect of the seasonal temperature variations on the recorded signal is not yet clear.

The process of the crack opening in concrete may occur after a long time of concrete placement. In order to interpret the crack-meters data as opening of cracks, it would be appropriate to distinguish the long term effects from daily temperature variations and concrete shrinkage by removing the high frequency component from the signal. In this case, the resulting trend would show the average crack opening and/or deformation at any time through the life of the concrete bridge deck. This could be done through developing a universal low-pass digital filter that allows the low frequencies to pass through, but attenuate the high frequency content from the signal. However, the main concern in designing such a filter is not to lose the characteristics of the collected signal.

Since the collected data from Evansville Bridge are available for only about 145 days (the bridge age), the trend of the seasonal temperature variation is not yet clear. Therefore, using the available amount of data to design such a filter may not result in a universal filter that can be used with another set of data collected over a period of years. In other words, if the filter is designed for use with the available set of data, it might not be suitable for use with the same data after a year or so when it includes seasonal temperature effects. 
To overcome this problem, another set of data collected from similar four crackmeters installed at the transverse joints of an instrumented concrete slabs along Corridor H near Elkins, West Virginia (Shoukry et al., 2002, 2003) were used for the sole purpose of designing the filter. This set of data contain a two-year history of recorded measurements that clearly show the effect of seasonal temperature variations on the crack-meter readings as illustrated in Figures 5.2. Noticeable is the similarity between the trends in data collected from Corridor $\mathrm{H}$ project and those of Evansville Bridge. Therefore, such set of data seems to be very suitable for use to design a universal filter that can be used with any other set of measured data.

In order to remove the high frequency contents from the measured signal, initially a technique was developed to identify the cutoff frequencies of the measured signal. To deduce the daily thermal effects from the overall deformation, the frequencies of the measured temperature histories were calculated and used in the filter design as the cutoff frequency. Fast Fourier Transformation (FFT) is adopted to calculate the frequency of the temperature profiles. Fourier transform (in the form of FFT), is a very commonly used technique to compute Digital Fourier Transform (DFT), which is useful for analyzing and filtering digital signals. FFT operation includes, transformation of the input signal into a frequency domain signal (spectrum) and computing signal frequencies. The advantage of the FFT is that it is much quicker because it decreases the number of calculations required to analyze the signal. The number of Fourier transformations for a given data signal with $\mathrm{N}$ data points are equal to $\mathrm{N}^{2}$, but for a FFT this number reduces to $(\mathrm{N} / 2) \log _{2}(\mathrm{~N})$.

The main disadvantage associated with the FFT is the restricted data range that can be transformed and the need to apply a window technique for large number of data points, to compensate for spectrum leakage. The flowchart shown in Figure 5.3 illustrates the steps of filtering the measured signal to remove the high frequencies. These steps are explained in details as follows: 
Filter design needs data to be sampled at uniform rate, hence starting with the temperature compensated and uniformly sampled data, resampling can be done using the MATLAB interp or decimate function depending on the sampling period of the data points. MATLAB interp will resample the data at higher rate using low pass interpolation, where as decimate function will resample at lower rate after low pass filtering. (Here, a data are sampled for every 15 minutes).

\section{- Fast Fourier Transform}

The Fourier transform is then a frequency domain representation of a data unlike the original time domain signal. Fast fourier transformation is used to compute the discrete fourier transform of data (DFT detailed in the Appendix IV) to identify the frequencies of the signal.

\section{- FFT Plot}

FFT plot, (Detailed in Appendix IV) to determine the maximum frequency and frequency content of the particular signal

\section{- Filter Design}

Butter low pass filter was designed, (Detailed in Appendix III) the range of frequencies extends from $\omega=0$ to $\omega=\omega_{c} \mathrm{rad} / \mathrm{sec}\left(\mathrm{f}_{\mathrm{c}}\right.$ in $\left.\mathrm{Hz}\right)$. The highest frequency to be transmitted is $\omega_{c}$ (also called cutoff frequency), determined from the FFT plots. Frequencies above cutoff are prevented from passing through the filter and they constitute the filter stop band. The low frequencies, which are passed is called commonly known as passband of the filter.

\section{- Filtration}

Finally the data was filtered for all frequencies else the mentioned frequency in the design with zero phase distortions. The zero phase digital filter, will process the 
input data in both the forward and reverse directions i.e. after filtering in the forward direction, it reverses the filtered sequence and runs it back through the filter for zerophase distortion. MATLAB function, filtfilt minimizes start-up and ending transients by matching initial conditions, and works for both real and complex inputs.

- Finally, Data is cleared from all the unnecessary frequencies and become easier for further and analysis interpretation purpose.

Figure 5.4 illustrates a comparison between the filtered response and the original measured signal. It can be noticed that the resulting response is deviated from the original signal and also not representing the actual trend of the signal. The reason is due to the fact that the data are having a large number of array points with seasonal fluctuations and hence the filter is subjected to fluctuations in the array points. Hence it is required to modify the current filter design, so that it can be better account for seasonal fluctuation in the data.

\subsubsection{Overlapping Technique}

This can be achieved through applying the overlapping technique in conjunction with filter. In overlapping technique, the filter is applied to total array points in a sequence, covering a fixed number of array points each time and the process is repeated itself till the end of the array point. The input number of arrays will overlap itself for every sequence of steps and hence called overlapping technique. The main factor in this design is the size of the window, as it affects the total error in the filter design, as well as the smoothness in the resultant trend. Increasing the size of the window, increases the total error, but improves the smoothness in the curve i.e. lessens the total fluctuations in the resultant curve. Trial and Error is the only method to find the appropriate window size for particular data points, to minimize the total error and fluctuations in the curve. From the experience gained from this work, the overlapping technique is suggested for use with data points for more than 6 months to take care of seasonal fluctuations. 
Elkins data has over 50,000 arrays points, filter design was applied to different window sizes and the errors were compared for improved design. The error is calculated by applying the root means square on the original signal and on the filtered data. One observation from Figures 5.5 (a), (b), (c) and (d) was, as the window size increases the error increases, however the curve smoothness improves. Therefore, engineering judgment should be used to decide between the percentage of total error and the smoothness of the curve.

From Figure 5.5 (d), when the size of the window is 9000 array points, the error in this case is approximately $11 \%$. Also, it is very clear that the curve very much deviate itself from the original signal. The observations from examining the effect of the window size are:

1. Increasing the window width (the number of selected array points) will increase the percentage of total error and also the resultant curve deviates from the original signal.

2. When error exceeds $10 \%$, the resultant curve is very much moving away from the original signal, so it is suggested to maintain the percentage of error well below $10 \%$, for good results.

3. The optimum overlapping design should have a window size with reasonable percentage of error, and also it should very much represent the original signal.

\subsection{CRACK ANALYSIS IN EVANSVILLE BRIDGE DECK}

The filter design developed in this study was used to filter out the high frequency content from the crack-meters data collected from Evansville Bridge deck. Figure 5.6 shows a layout of the distribution and location of crack-meters along the bridge. In total thirty crack-meters were used. The first four crack-meters were placed over the bridge abutment to measure the opening of the construction joint between the bridge deck and the approach slab. Twenty-six crack-meters were placed along the wheel path to measure the axial deformation in the concrete bridge deck due to shrinkage as well as temperature variations. 
The opening of the construction joint between the approach slab and the bridge deck was measured at four locations as shown in Figure 5.6. The measured histories of the openings of such joints are shown in Figure 5.7 (a) to (d). The crack-meters' readings indicate an increase in the joint opening as the measured concrete temperature decreases. This is expected due to the fact that, at the construction joint, both the deck and approach slab have free edges, as the temperature decreases, the approach slab and the deck contract creating a wider gap in between which is evident from the four crack-meters readings.

The plots (Figure 5.7 (a)-(d)) also indicate that the joint opening increases as we move from the parapet towards the longitudinal construction joint (i.e. from crack-meters no: 1 to 4$)$. This can be explained by the following reasons:

1. The deck edge at the parapet side is tied to the approach slab by the continuous reinforced concrete parapet, which is constructed over the deck and approach slab, which means that this side of construction joint is more constrained than the other edge.

2. The effect of the moving traffic over the wheel path, which would be reflected as more deformation over the wheel path.

3. The presence of crack-meter No: 4 near the corner of two free edges: 1) the construction joint between the deck and the approach slab, 2) the longitudinal construction joint as shown in the Figure 5.6.

Another advantage of measuring the change in the openings of the construction joint between the approach slab and the bridge deck is that it could give a good idea about the expected reading of the crack-meters placed along the wheel path after concrete cracks. The idea is that if the crack-meter is located in the uncracked zone, its reading should follow the measured temperature (i.e. increases due to expansion of the concrete when temperatures rises, and decreases due to concrete contraction when temperature drops). However, if it was placed in a cracked zone, the measured behavior will be 
similar to that observed with the crack-meters placed at the construction joints, i.e. the reading increases when the measured concrete temperature decreases. This approach will be used in the next section to identify the crack location along the bridge wheel path.

The crack-meters readings measured along the wheel-path are illustrated in Figures 5.9 to 5.15 together with the corresponding measured temperatures. Two types of trends could be identified in these plots:

1. Continuously increasing axial deformation readings, even when the temperature is decreasing as in crack-meters No: $1-4,8,11,13,16,18,20-$ 22, 24 and 29-30.

2. Axial deformations following the pattern of the measured temperature change as in crack-meters No: 5-6, 9-10, 12, 14-15, 17, 19, 23, 25-26 and 28.

In this first group, the continuously increasing deformation indicates the presence of cracks in the zone of the crack-meter. The increasing reading could be explained in terms of the excessive crack opening due to the contraction of the concrete on both sides of the crack as the temperature decreases as illustrated in Figure 5.8. It can also be noticed that the slope of the measured deformation curve decreases with time. This can be attributed to the fact that the reinforcement steel bars are holding the crack from the continuous opening due to contraction as the temperature decreases.

The second group of crack-meters readings represents the behavior of the concrete bridge deck in uncracked zones. In this case, the decreasing axial deformation with the temperature drop represents the contraction of the deck due to the decrease in its temperature.

To better view the distribution of the transverse cracks along the bridge wheelpath, the average axial deformation reading measured on a randomly selected day (chosen to be after 115 days from concrete placement was plotted along the distance) as 
shown in Figure 5.16. It can be noticed that the part of the deck near to the abutment as well as mid-first span are the zones that showed cracks with considerable opening. It should be emphasized here that the crack-meters were installed at level of the bottom reinforcement, i.e. approximately one inch above the bottom of the deck. Therefore, their readings are only indicative to the cracks that occur at the deck bottom.

The cracks at the abutment zone could be attributed to the stresses concentrations at the connection between the mass of the concrete of the abutment wall and the concrete deck, Figure 5.17 (a) and the end of the steel girder and concrete mass as shown in Figure $5.17(b)$.

At mid-span, the positive bending moment due to the own weight of the superstructure as well as the live loads is maximum. This produces maximum tensile stresses at the bottom of the deck. Such stresses would be added to those tensile stresses resulting from the temperature decrease and the resultant longitudinal stress is the main cause for the transverse cracks that initiate from the bottom surface of the deck in this region.

At the pier region, the bending moment due to the own weight of the bridge deck is negative. So it produces tensile stresses on the top of the deck and compressive stresses at the bottom. Therefore, any cracks at the region most likely initiate from the top and propagate towards the bottom, which explains the low axial deformation readings at the region. Additionally, the amount of the longitudinal steel reinforcement is doubled in this region, which adds extra strength to the deck cross section, which would also lessen the possibility of transverse cracking.

\subsection{APPROACH VALIDATION}

The triaxial state of strain induced in the concrete bridge deck and the corresponding temperature were measured at several locations along the bridge deck as described in Chapter Three. Knowing the concrete material properties, which were 
experimentally measured as described in Chapter Four, we can calculate the state of stress induced in the concrete deck. If the calculated longitudinal stress at any location exceeds the concrete modulus of rupture, it would indicate that the concrete developed crack at that location. Using such an approach to predict the occurrence of cracks in concrete and comparing the results with those of the technique of using the crack-meters would give a good validation for the latter technique.

Based on the theory of thermoelectricity, the longitudinal stress at any point within the concrete bridge deck can be calculated by:

$$
\sigma_{x}=E\left[\varepsilon_{x}-v\left(\varepsilon_{y}+\varepsilon_{z}\right)-\alpha \Delta T\right]
$$

where: $\varepsilon_{\mathrm{x}}$ is the measured longitudinal strain (in traffic direction)

$\varepsilon_{\mathrm{y}}$ is the measured transverse strain (perpendicular to traffic direction).

$\varepsilon_{z}$ is the measured vertical strain.

$\mathrm{E}$ is the concrete modulus of elasticity

$v$ is Poisson's ratio of the concrete.

$\Delta \mathrm{T}$ is the measured temperature change.

For the purpose of validation, strain trees nearest the line of crack-meters were selected, i.e. strain trees along Girder C. Eq. (5.1) was used to calculate the stresses on top and bottom of the concrete deck at seven locations along the bridge and the results were compared with crack-meter prediction as shown in Figures 5.18 to 5.31.

In order to authenticate the reliability of the data analysis presented above in predicting cracks in concrete bridge decks, the results are compared with the stresses developed on the concrete bridge deck for validating the resultant analysis. For validation, strain trees near crack-meter, i.e. in the girder $\mathrm{C}$ were selected. As discussed in the previous chapter, each strain tree is having six vibrating wire gages, each of two in three perpendicular directions, i.e. wheel path, vertical and perpendicular direction (Figure 3.14). Data from the two strain gages along the wheel path, one at the top and 
other at the bottom of the tree were reduced in a matrix. Thus the collected data are reduced to gives us the strain values in terms of stresses developed on the bridge deck along the wheel path. Then the stresses are compared with the tensile strength of the concrete with the time, to check for any damage sensitive crack information. That is, for the formation of crack, at a stage where the stresses developed on the bridge reaches or exceeds the tensile strength of the concrete.

Figure 5.18 plots the stresses developed at the top and bottom of the bridge deck, and the tensile strength of the concrete with the time. The bottom graph (Figure 5.19) on the page represents the deformation reading values around that location. The same trend was observed on the both graphs, the formation of crack. That is, due to the fact that the stresses developed on that location exceeds the tensile strength of the concrete, implies the formation of crack and the same increasing deflection values or trend implies the formation of crack. The similar trend was observed on Figures 5.20 - 5.21, Figures 5.22 5.23, Figures 5.26 - 5.27 and Figures 5.30 - 5.31. The visual inspection also proved the formation of cracks at the same location as from the stress calculations and the filter design technique, Figure 5.32-5.33.

Figure 5.18 shows that the stresses developed along the wheel path at location A3 were well below the tensile strength of the concrete, which means that there is no guarantee for the crack. The second graph, Figure 5.19 illustrates the same behavior, i.e. there is no increase in the deflection trend at that location, implies no formation of crack.

As seen from Figure 5.28, the graph shows the definite formation of crack at that location, due to intersection of stresses developed to the tensile strength curve. But Figure 5.29 fails to confirm the formation of crack, since the strain tree is located near the pier, which suppose to have heavy reinforcement at that particular location, which would have suppressed the crack not to propagate itself, hence the crack meter fails to detect the crack at that location. 

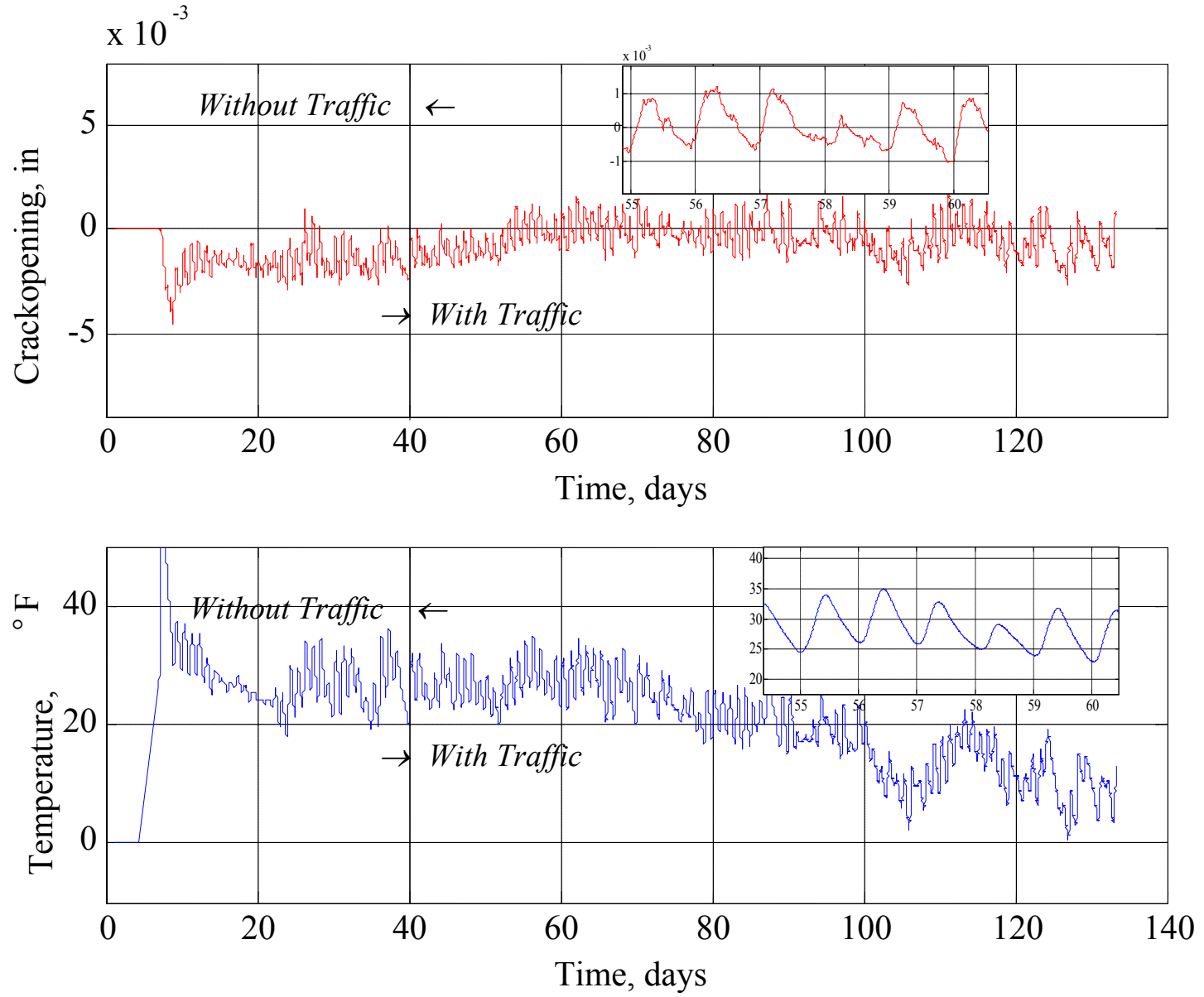

Figure 5.1 Crack-meter signals from Evansville Bridge 

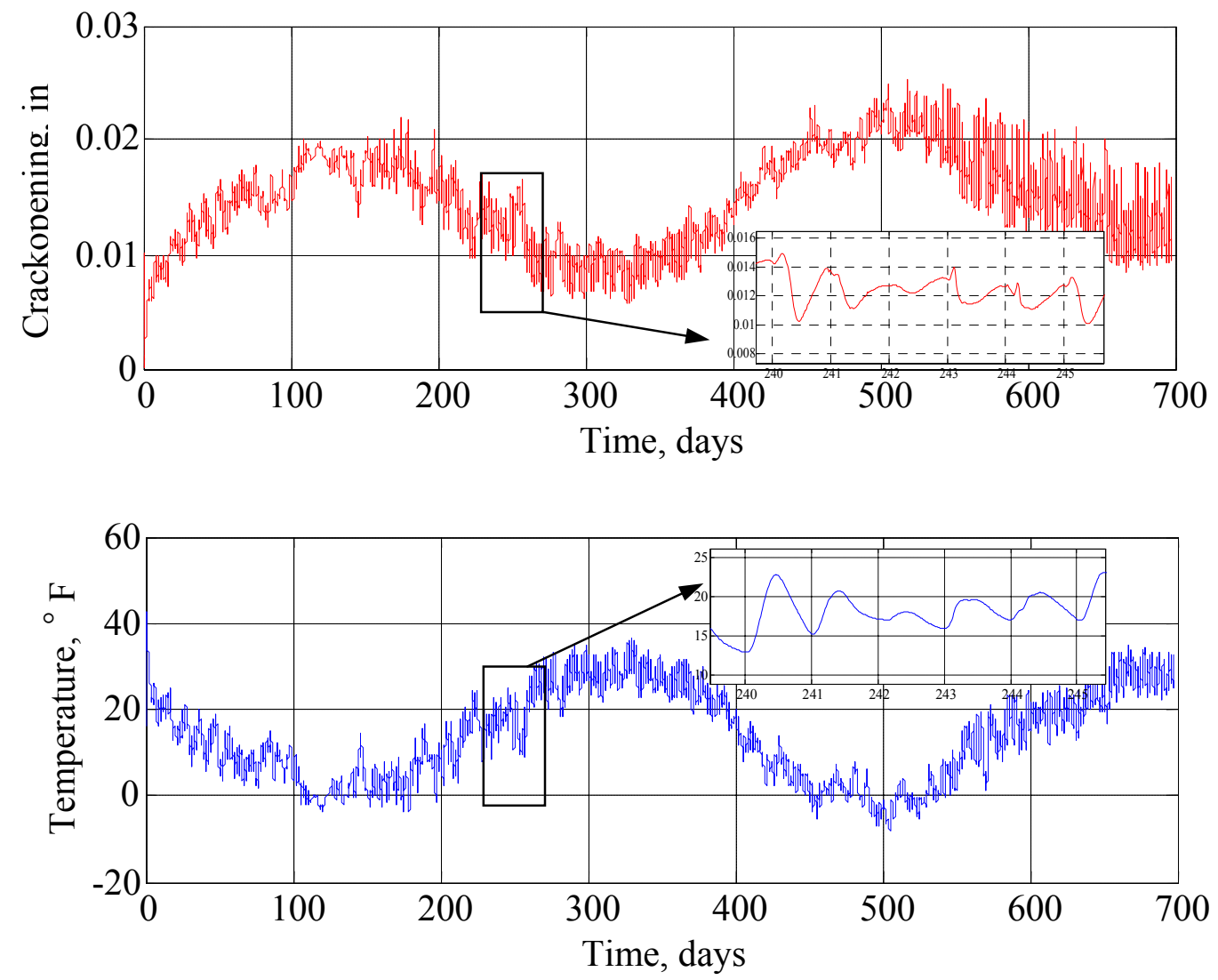

Figure 5.2 Crack-meter signals from Elkins 


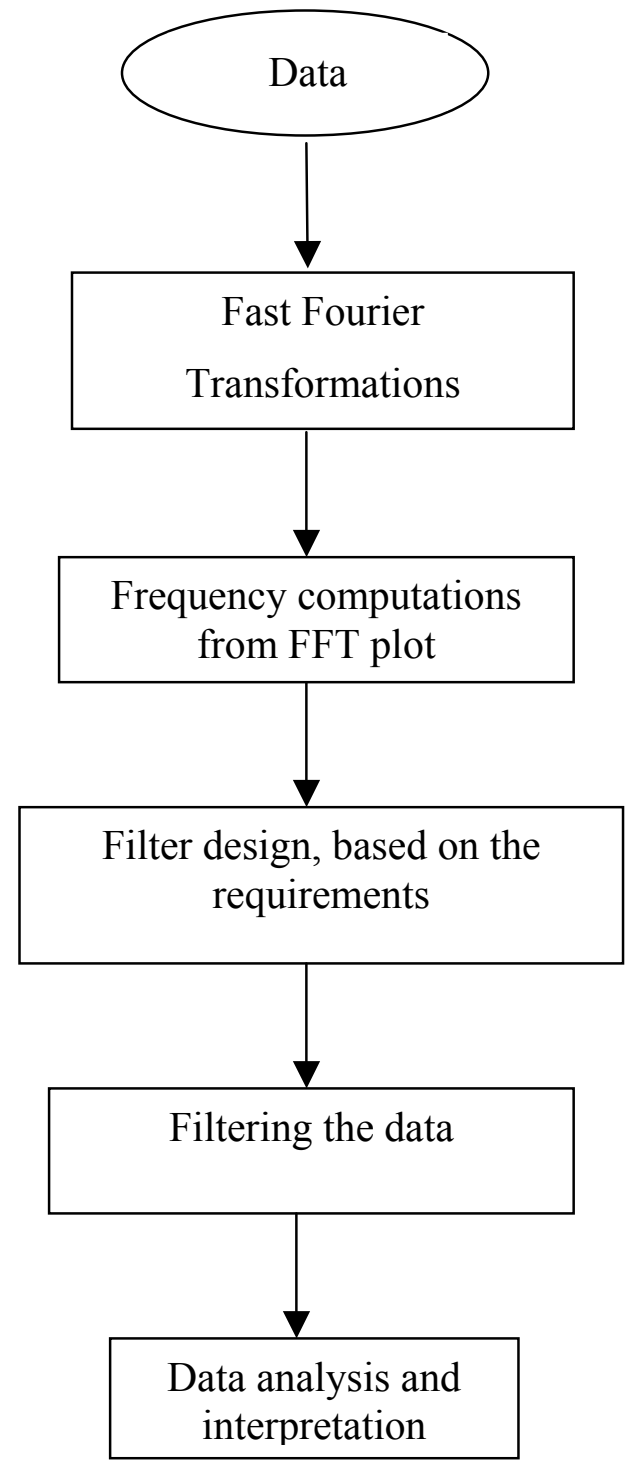

Figure5.3 Flow chart to represent the overview of the filter design technique 

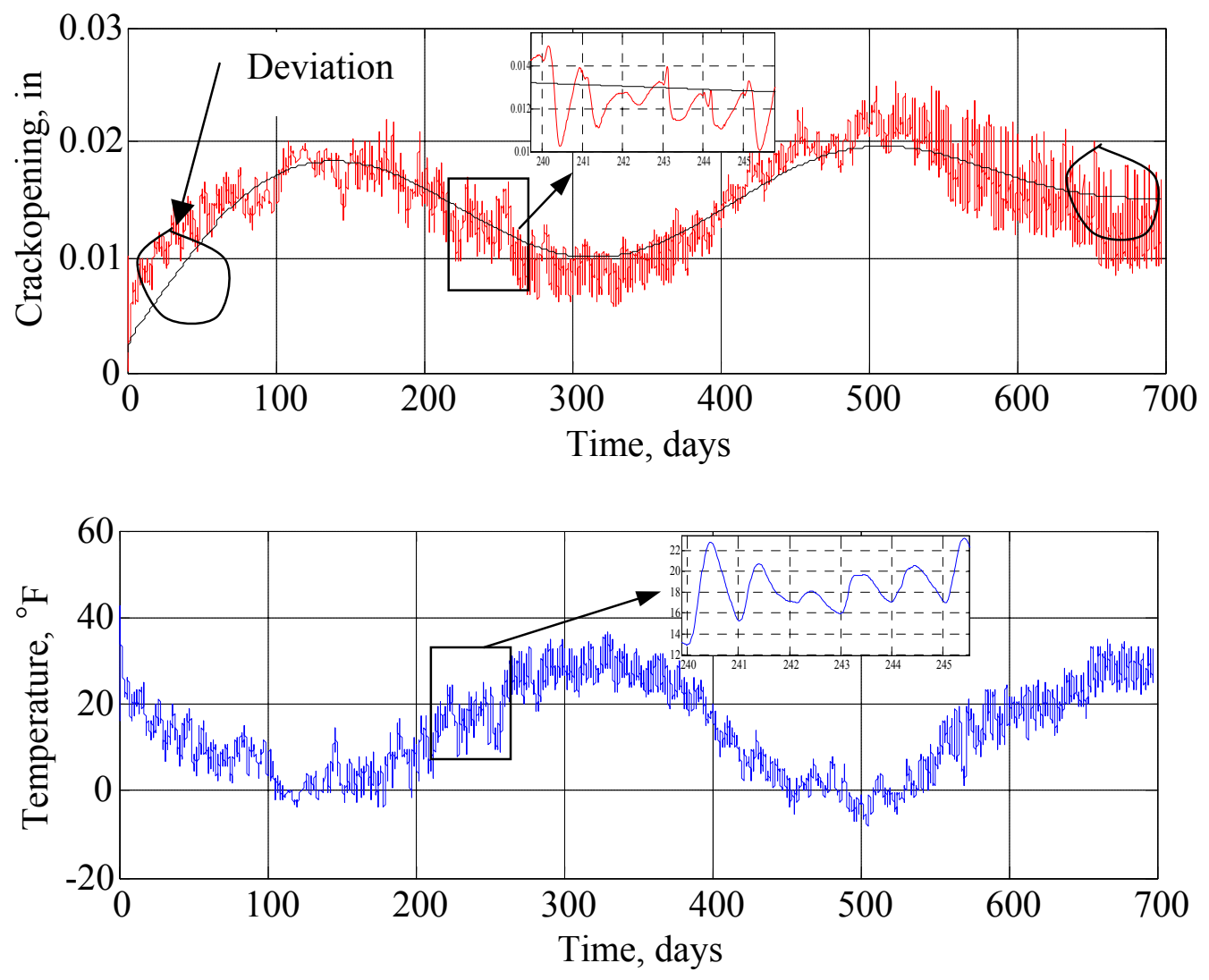

Figure 5.4 Filter design technique on Elkins data 


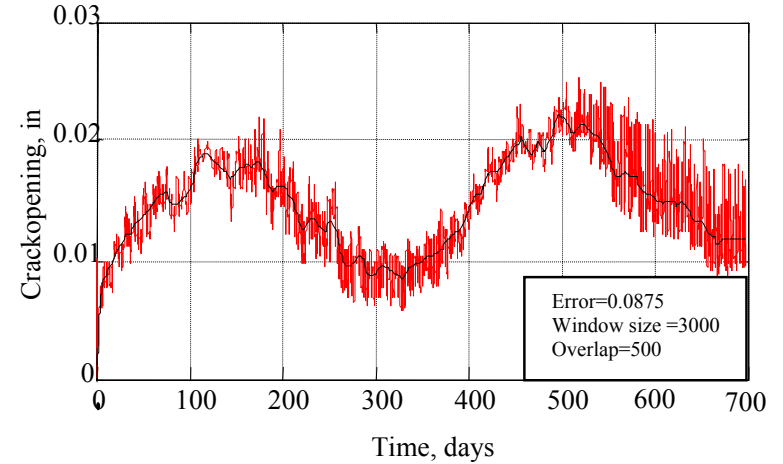

(a)

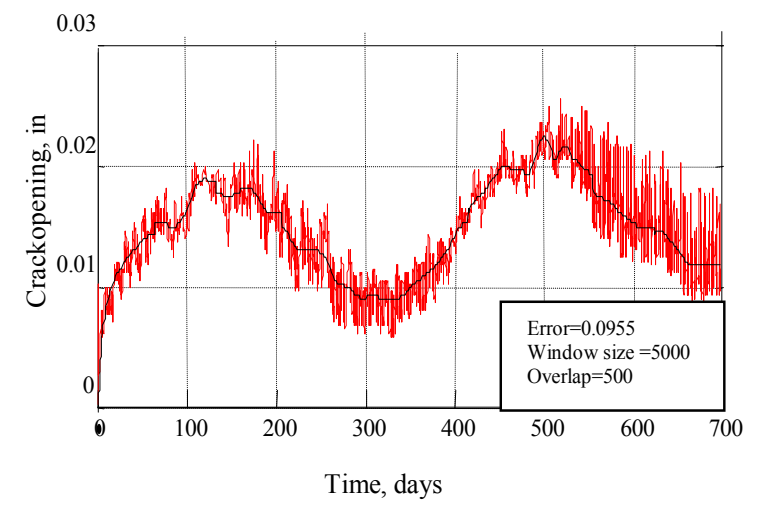

(c)

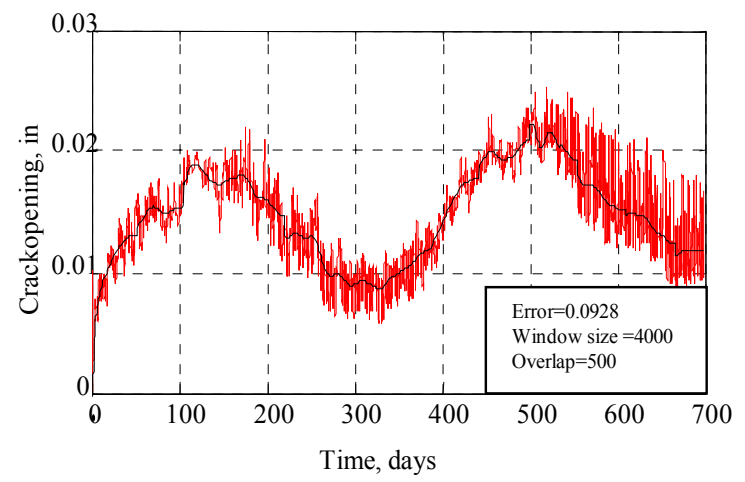

(b)

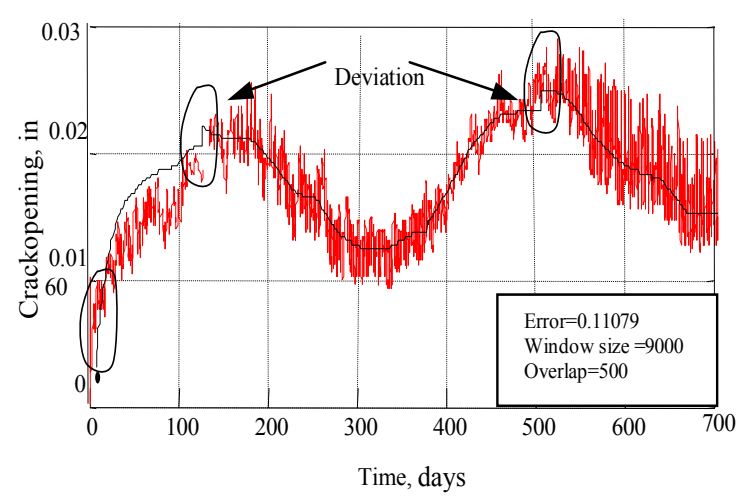

(d)

Figure 5.5 Overlapping filter design technique with different window sizes

(a) 3000 (b) 4000 (c) 5000 (d) 9000 


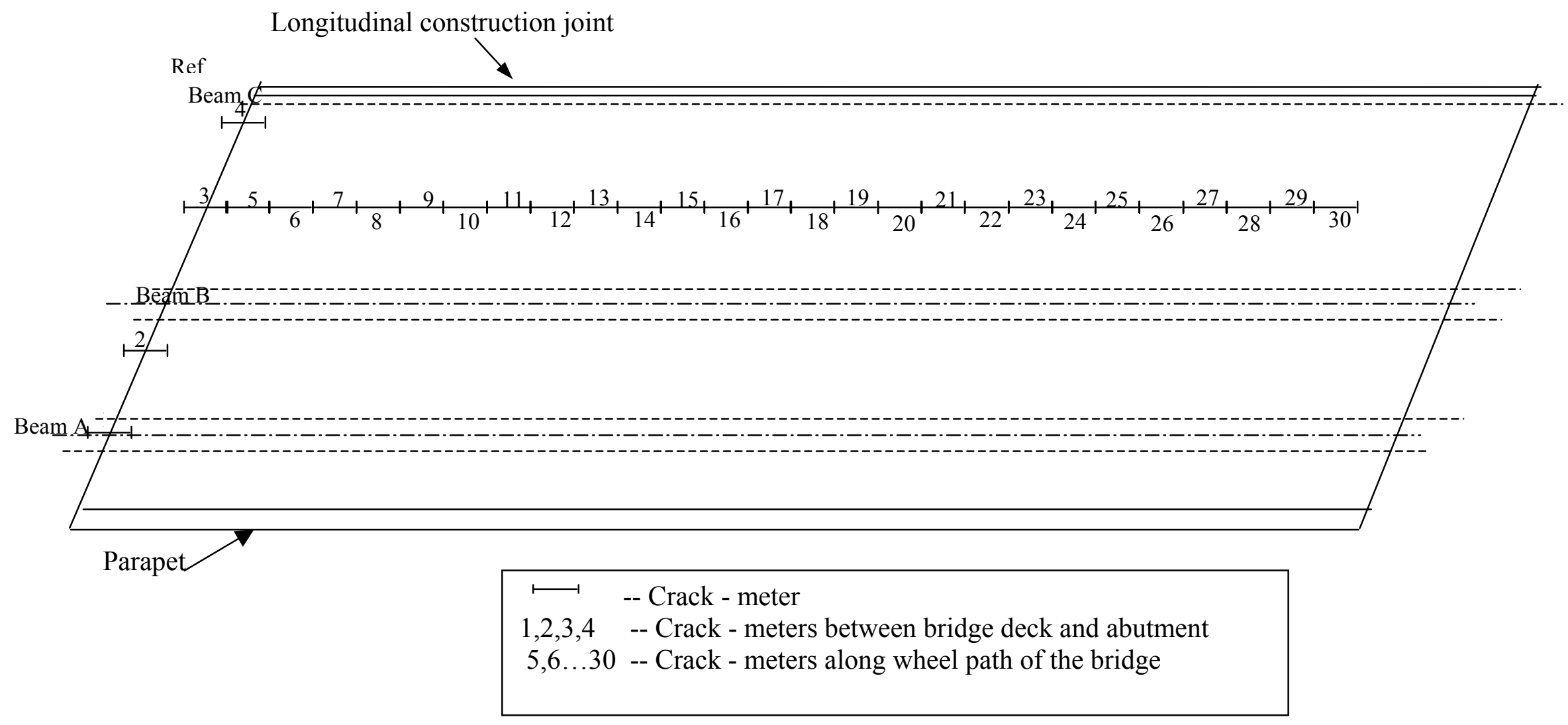

Figure 5.6 Location of different crack-meters along the bridge 


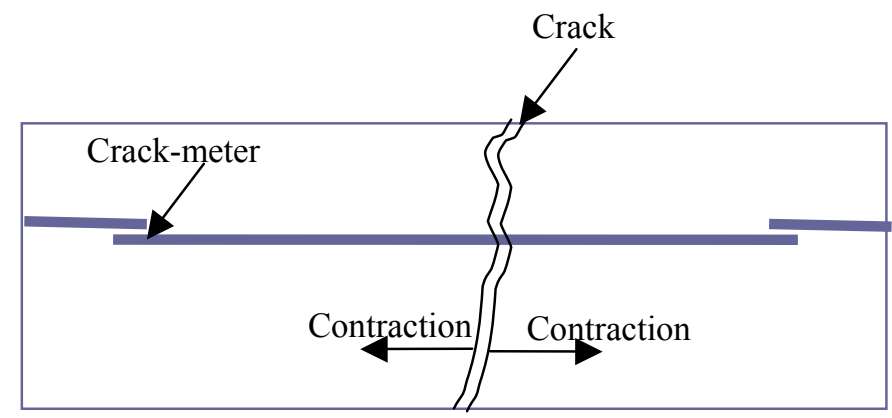

Figure 5.7 Crack openings on the bridge with temperature drops 

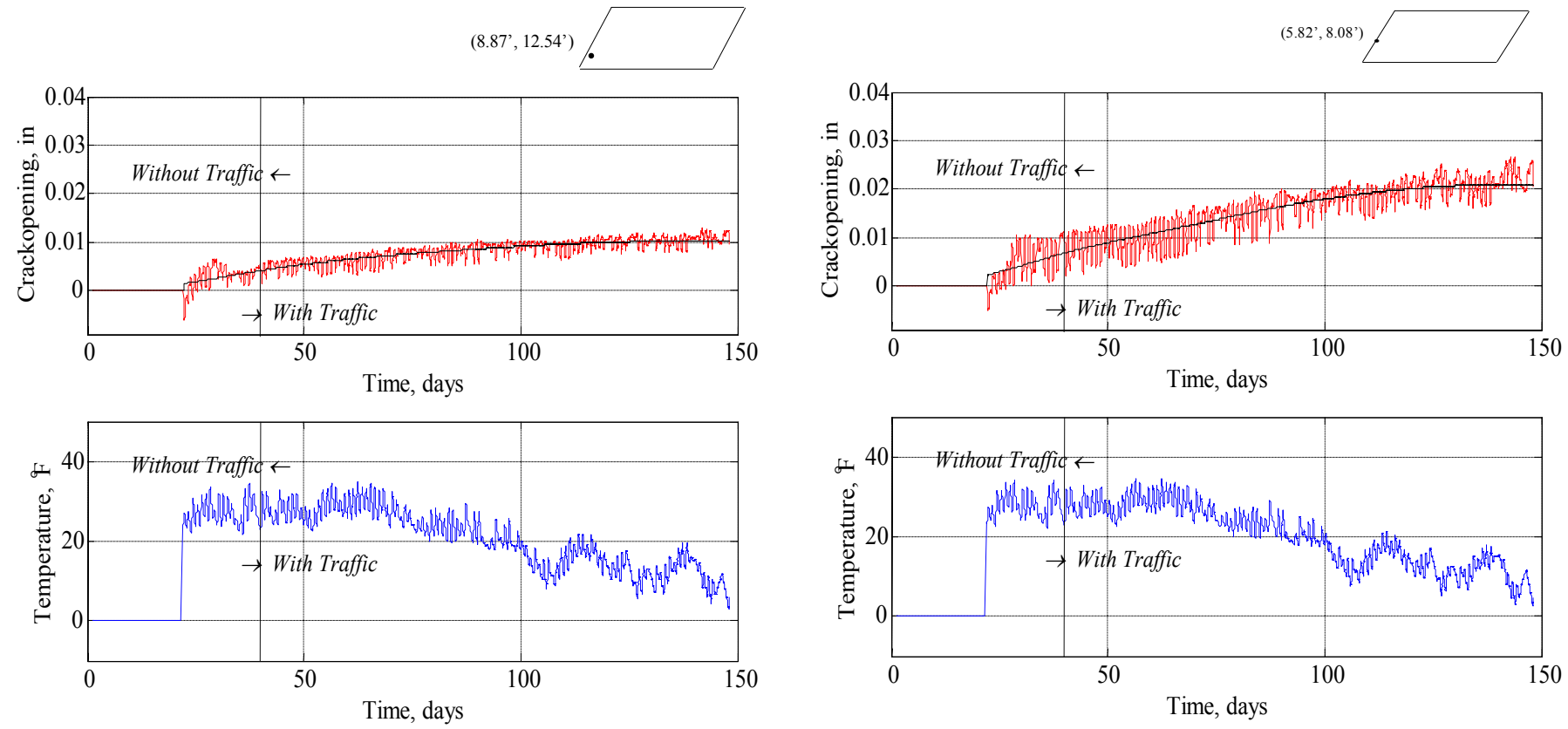

(a)

(b)
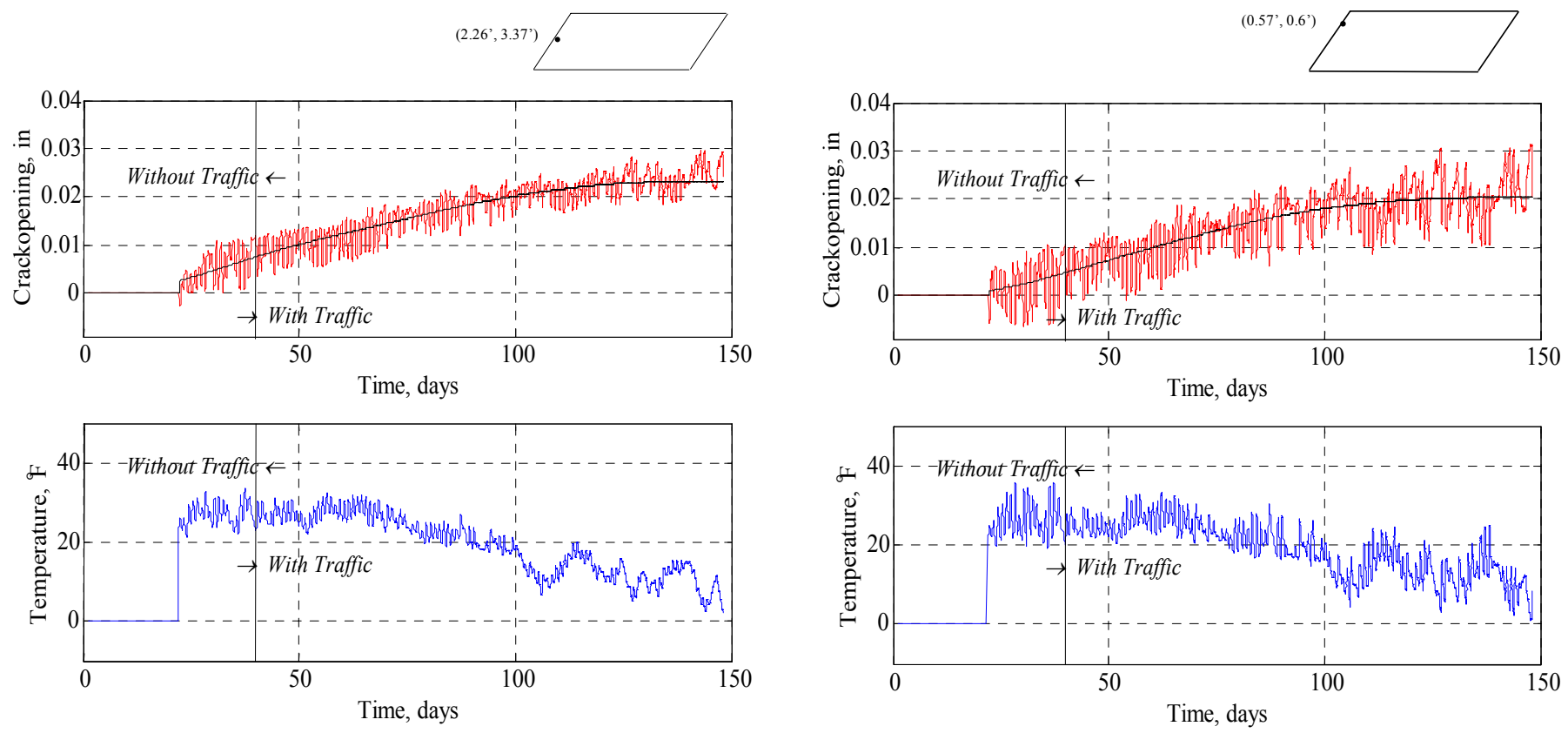

(c)

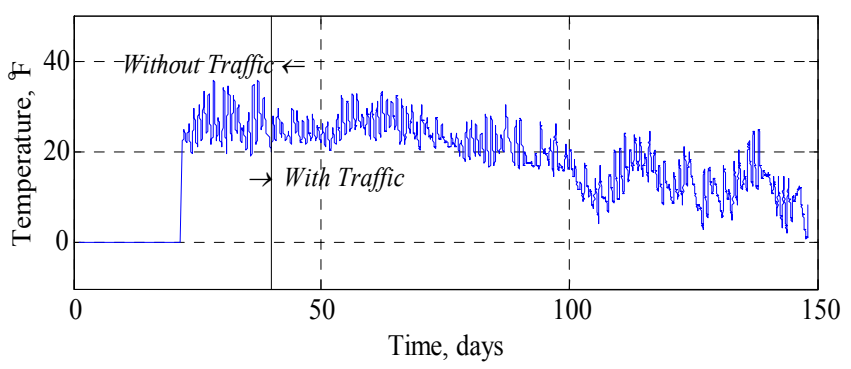

(d)

Figure 5.8 Crack opening trend and corresponding temperature profile (a) Crack-meter No. 1 (b) Crack-meter No. 2 (c) Crack-meter No. 3 (d) Crack-meter No.4 

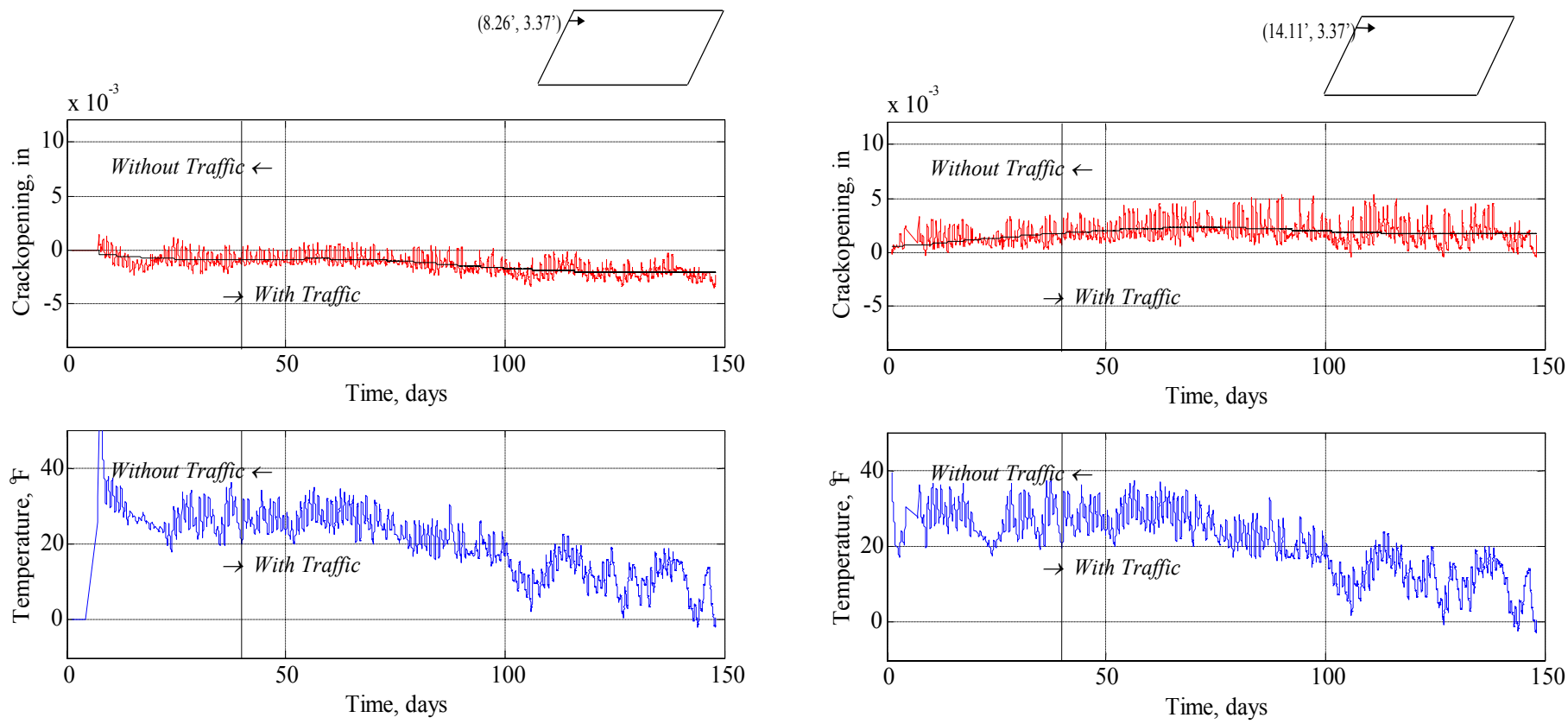

(a)

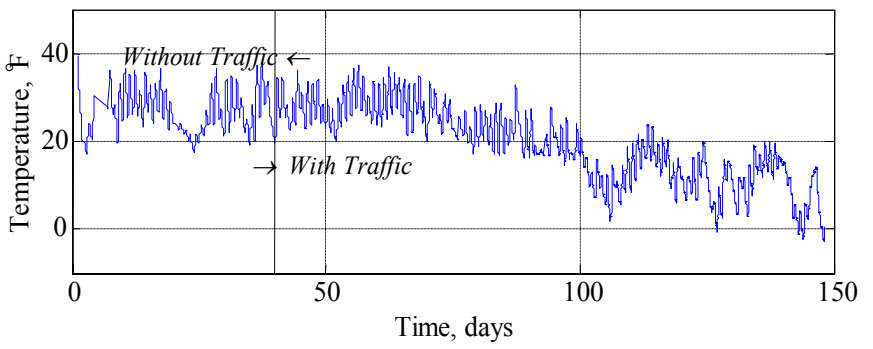

(b)
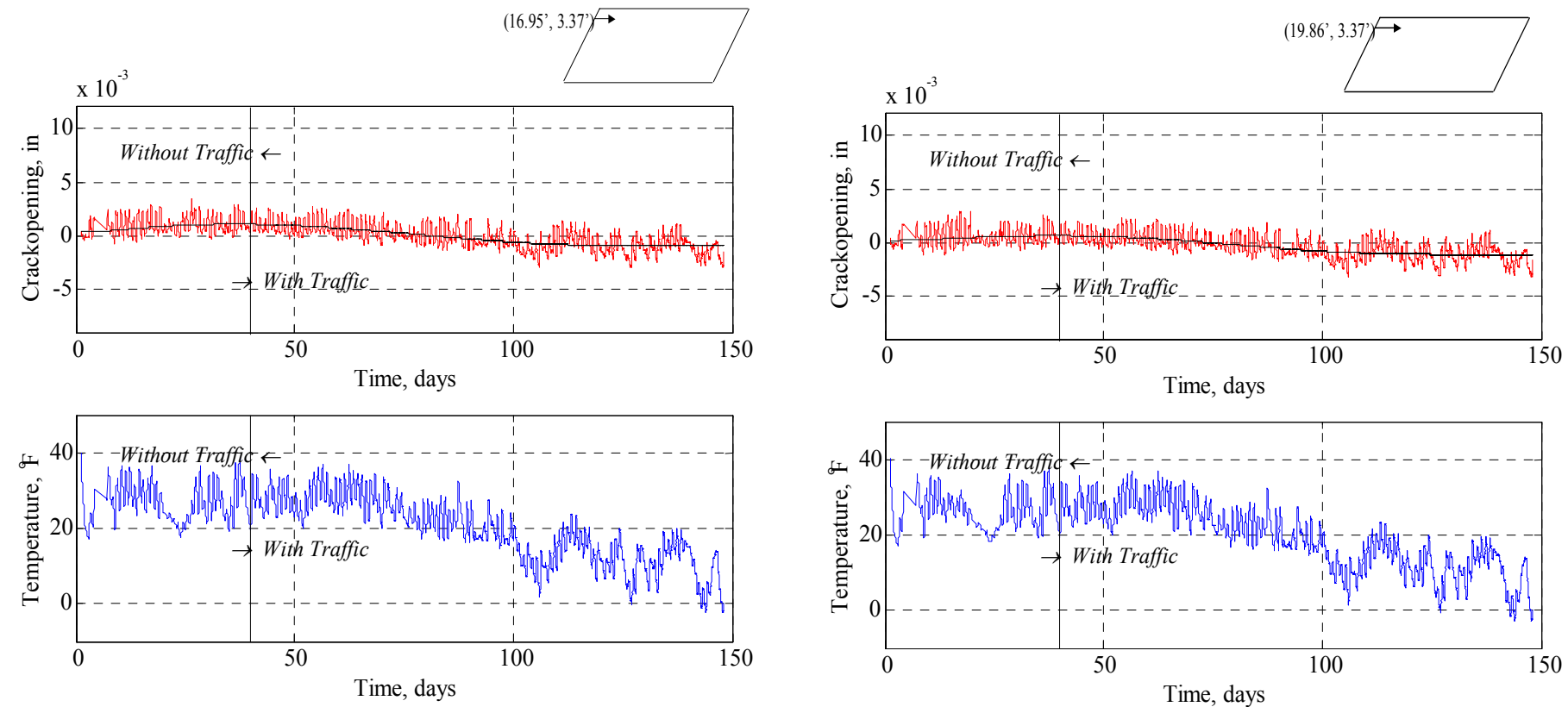

(c)

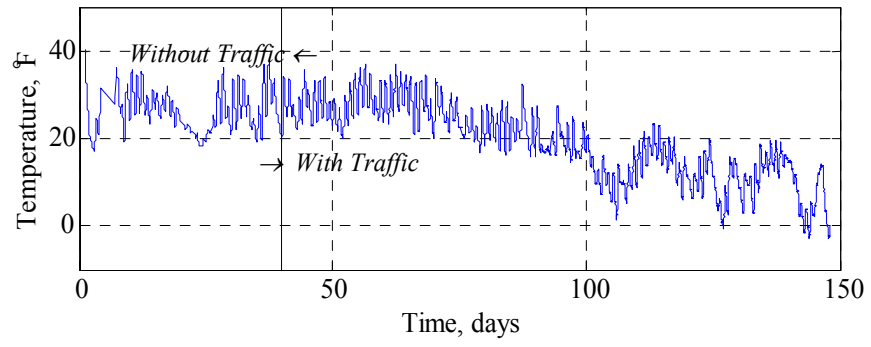

(d)

Figure 5.9 Crack opening trend and corresponding temperature profile (a) Crack-meter No. 6 (b) Crack-meter No. 8 (c) Crack-meter No. 9 (d) Crack-meterNo.10 

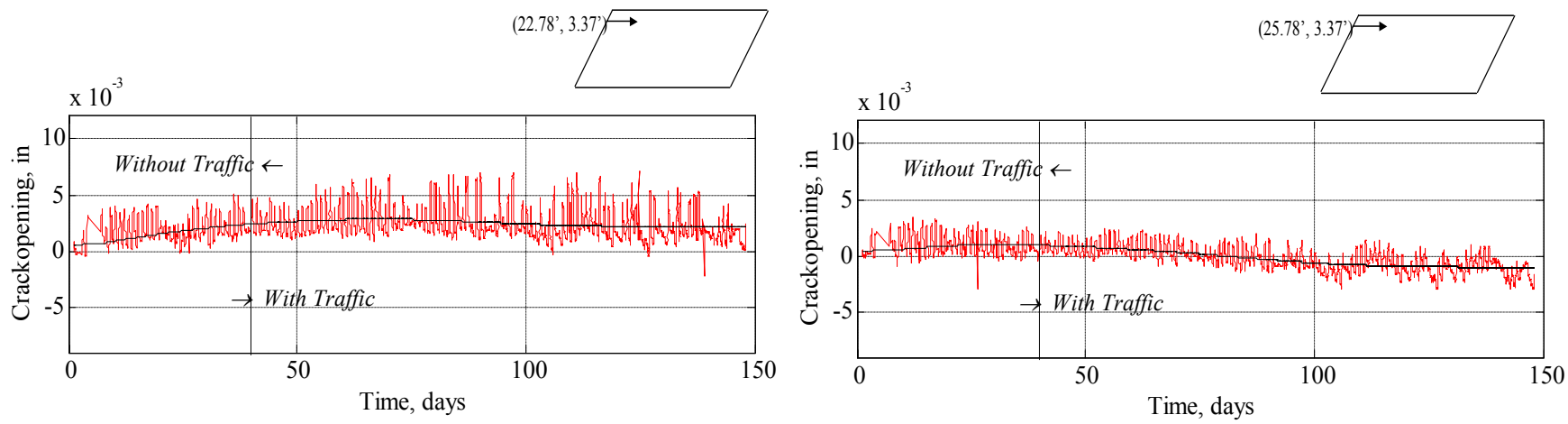

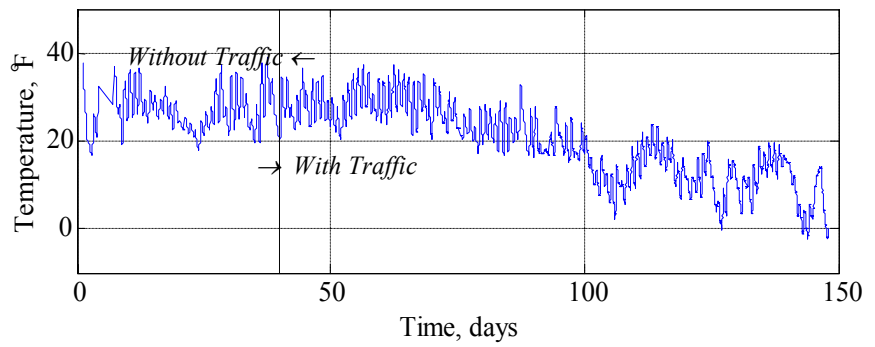

(a)
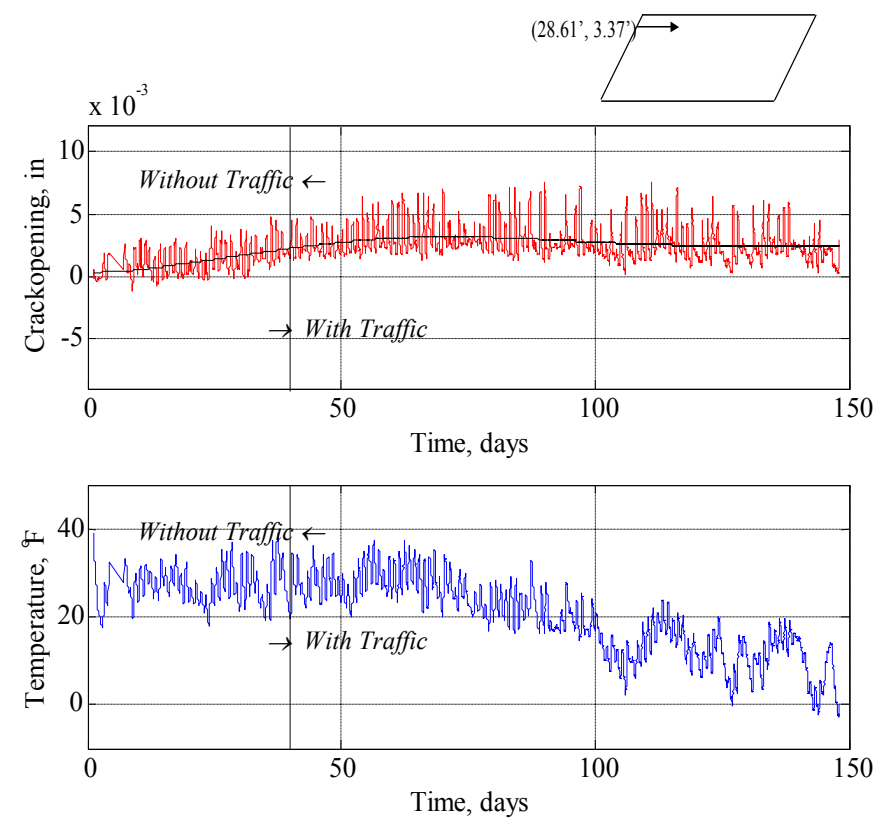

(c)

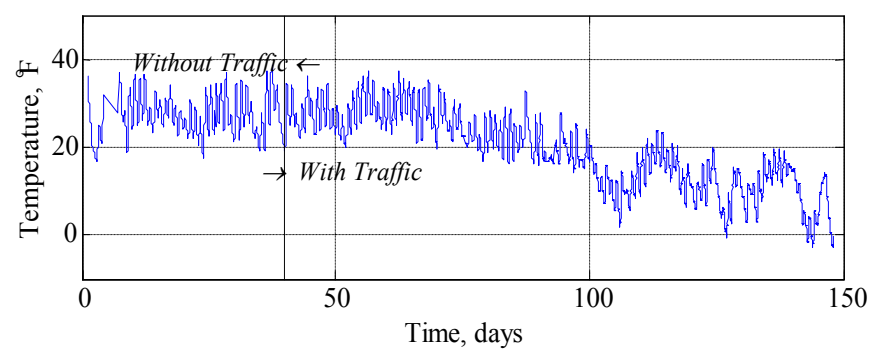

(b)
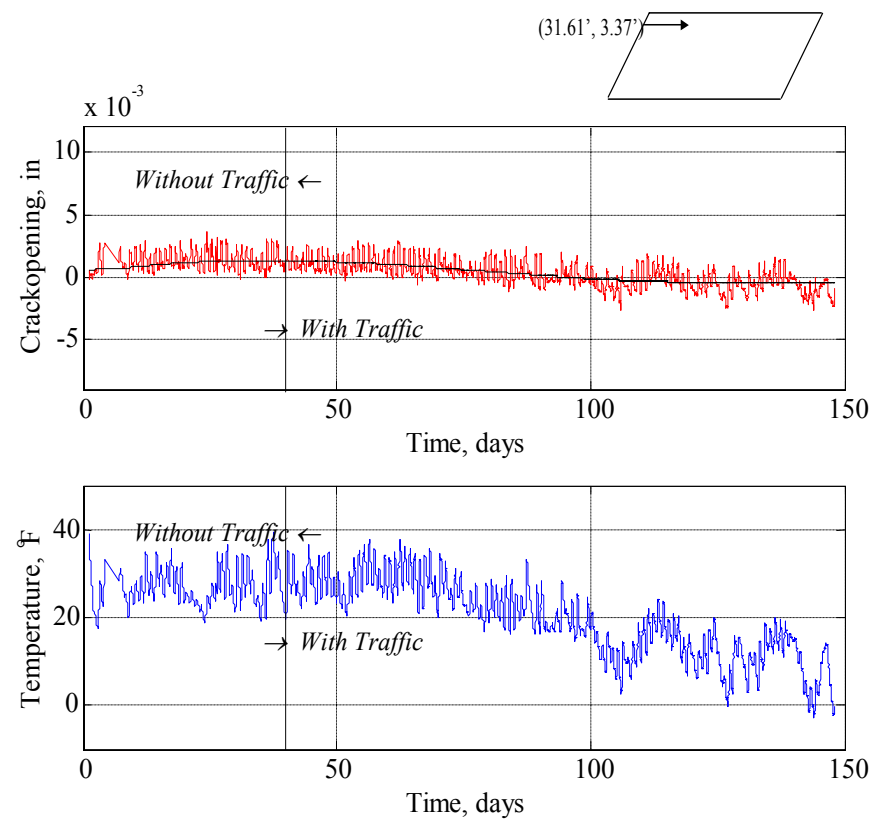

(d)

Figure 5.10 Crack opening trend and corresponding temperature profile (a) Crack-meter No.11 (b) Crack-meter No.12 (c) Crack-meter No.13 (d) Crack-meter No 14 

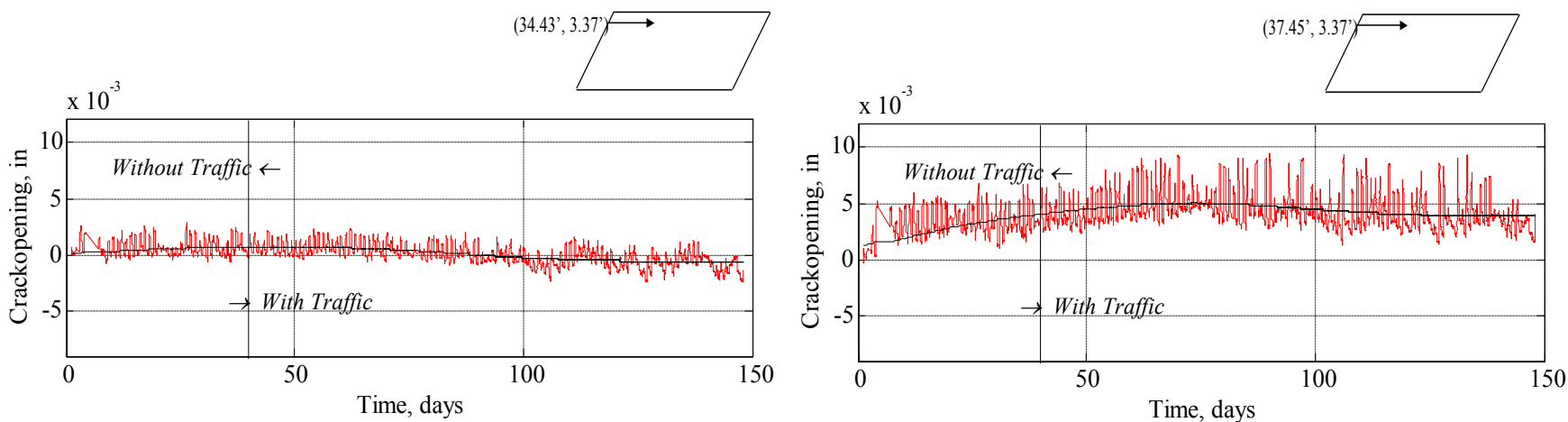

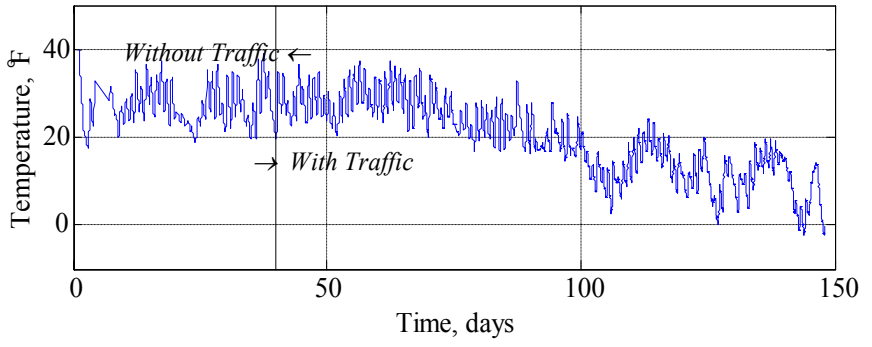

(a)
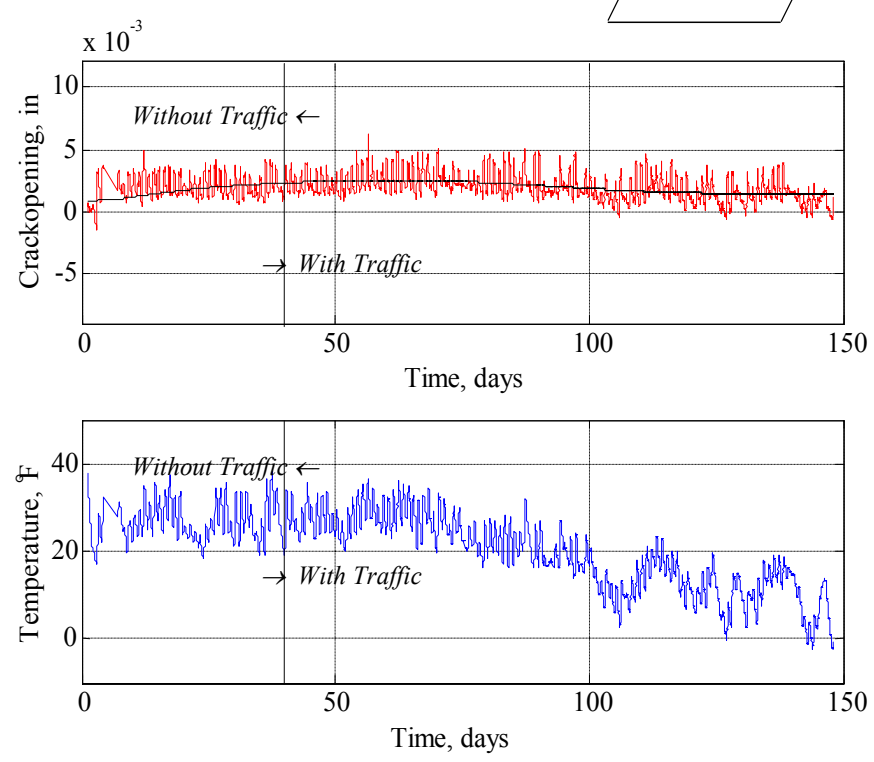

(c)

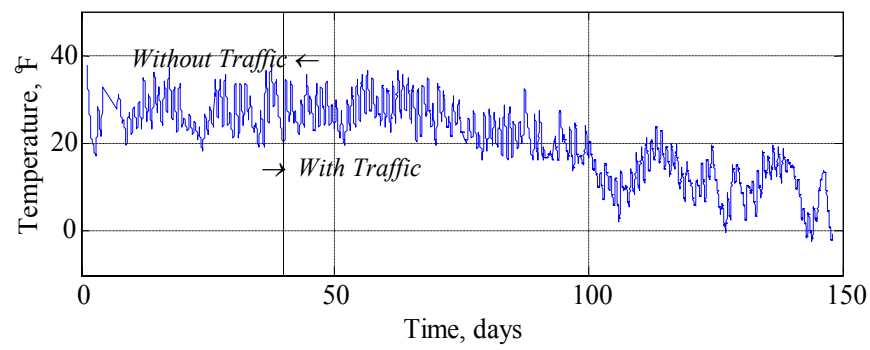

(b)
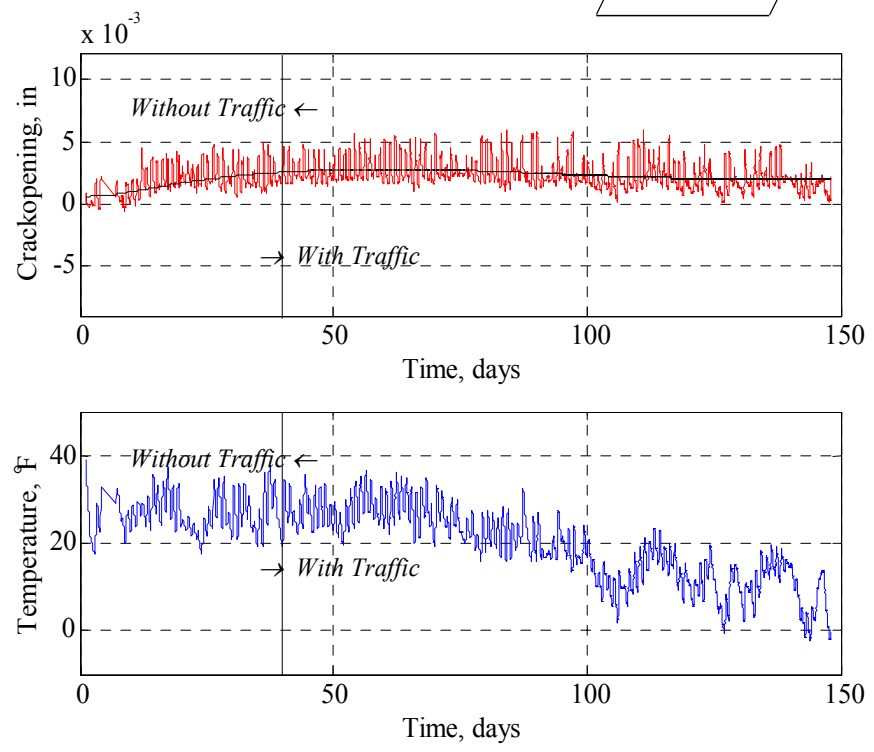

(d)

Figure 5.11 Crack opening trend and corresponding temperature profile (a) Crack-meter No. 15 (b) Crack-meter No. 16 (c) Crack-meter No. 17 (d) Crack-meter No. 18 

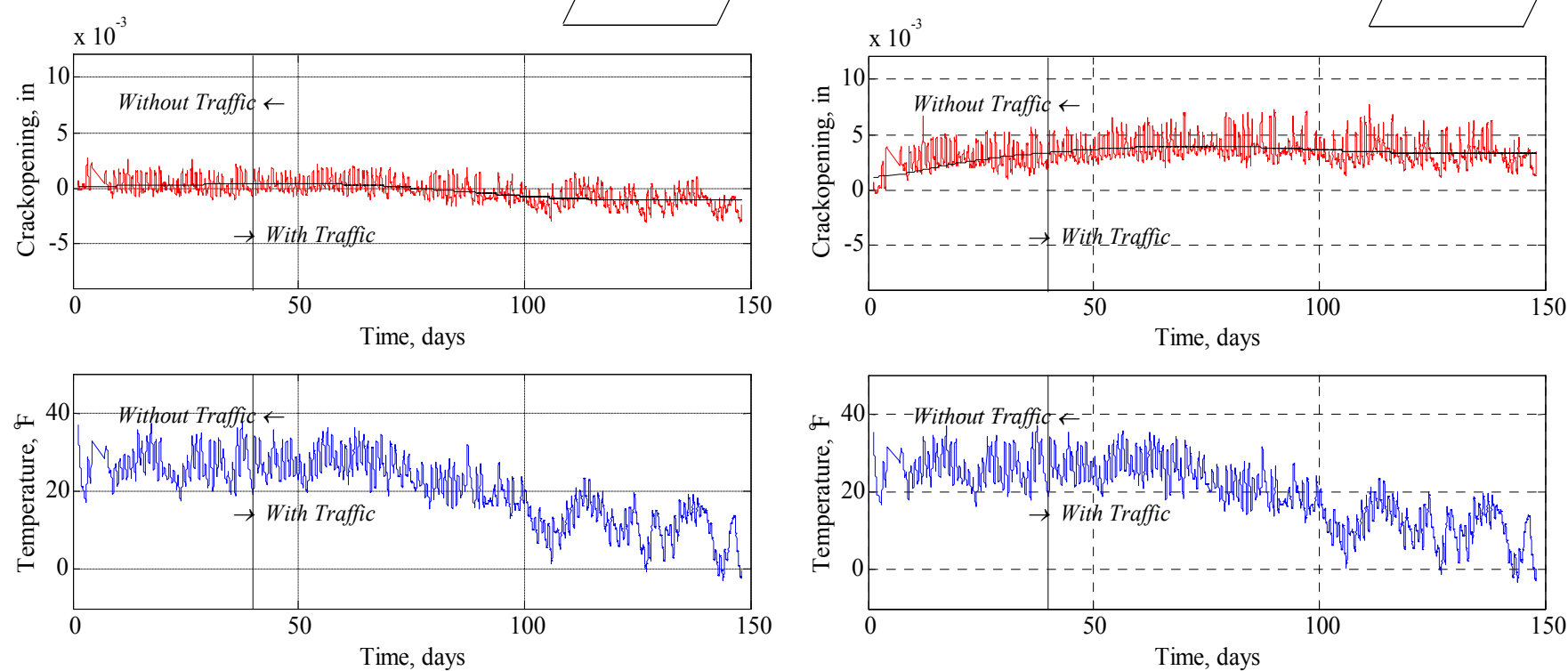

(a)

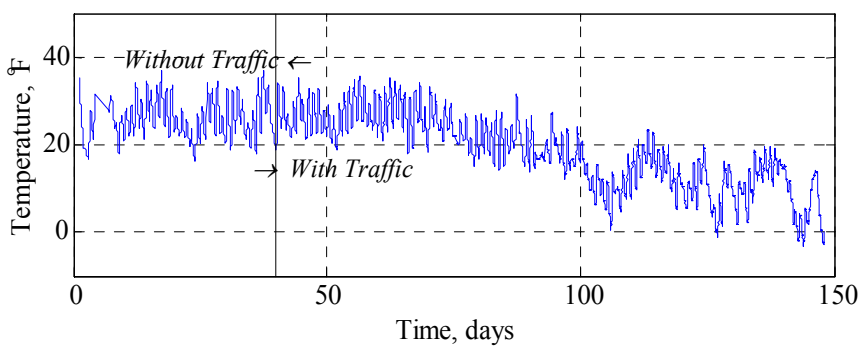

(b)
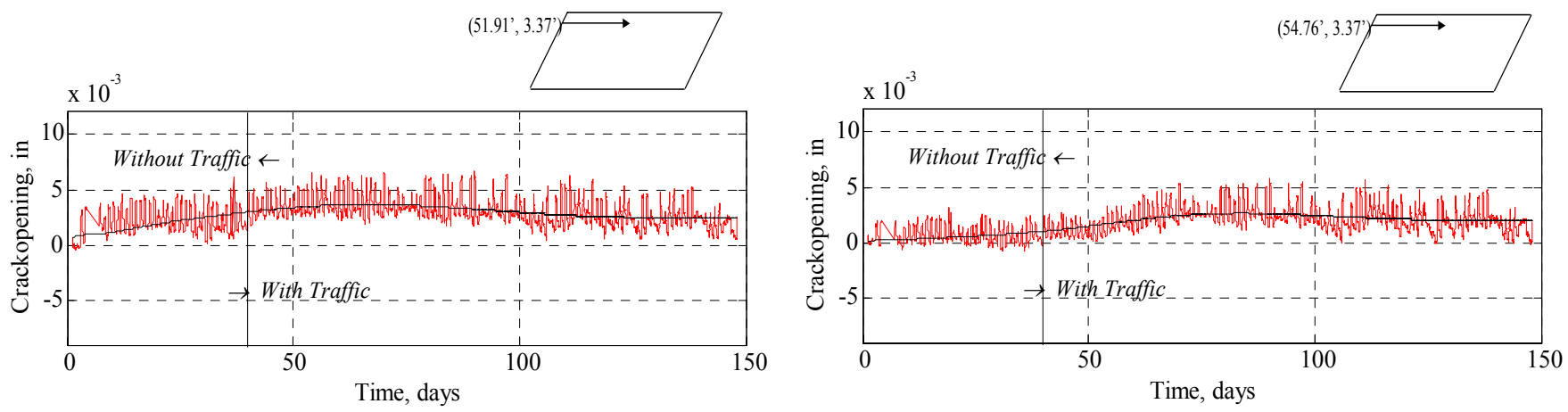

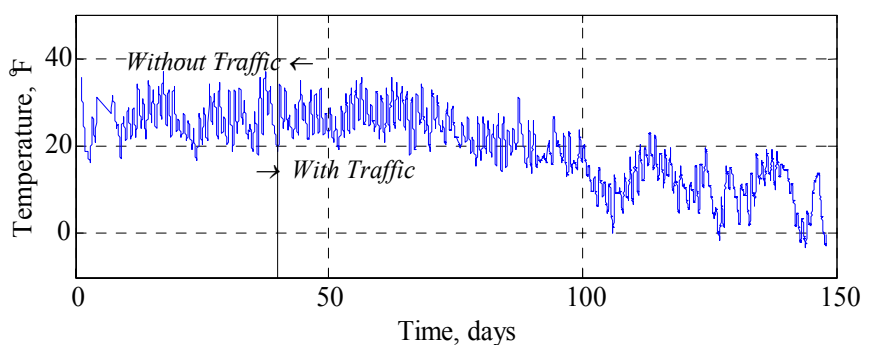

(c)

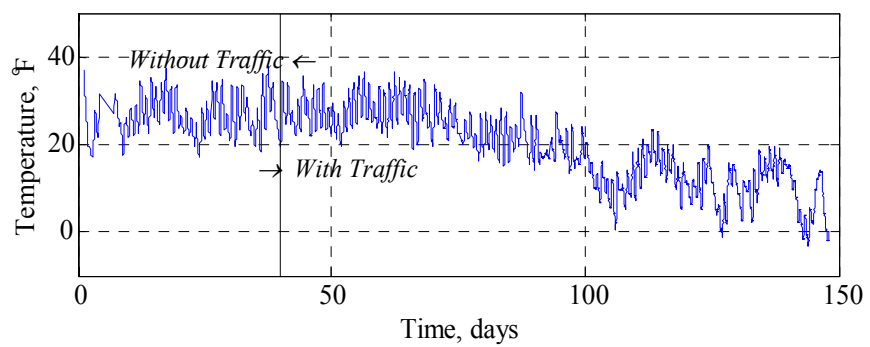

(d)

Figure 5.12 Crack opening trend and corresponding temperature profile (a) Crack-meter No. 19 (b) Crack-meter No. 20 (c) Crack-meter No. 21 (d) Crack-meter No. 22 

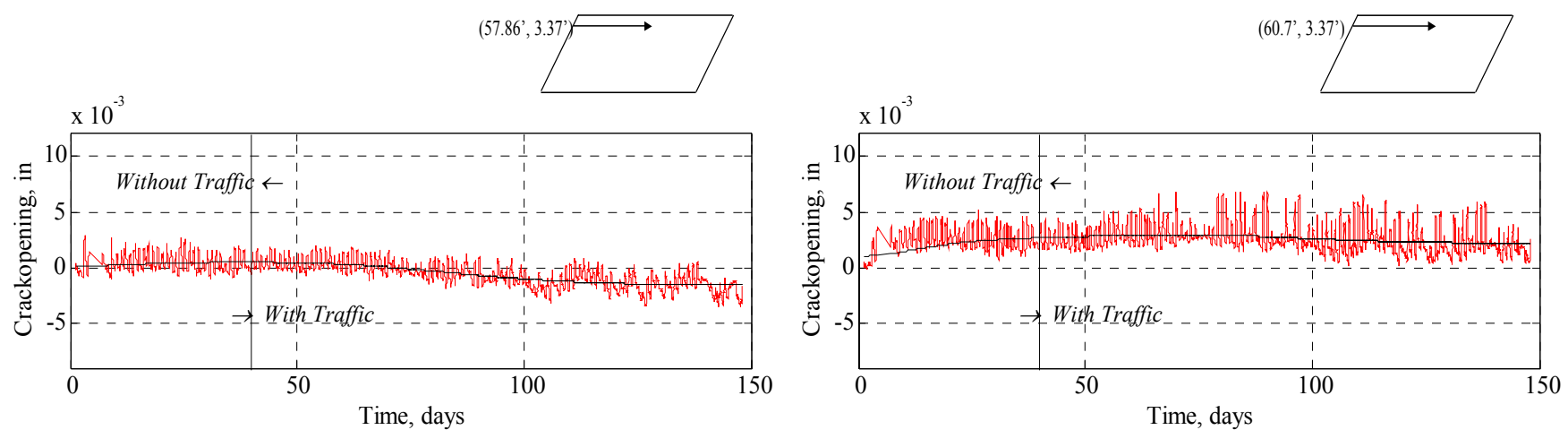

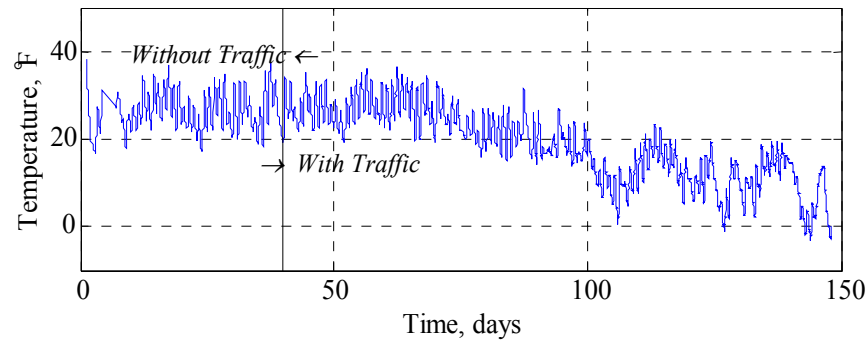

(a)
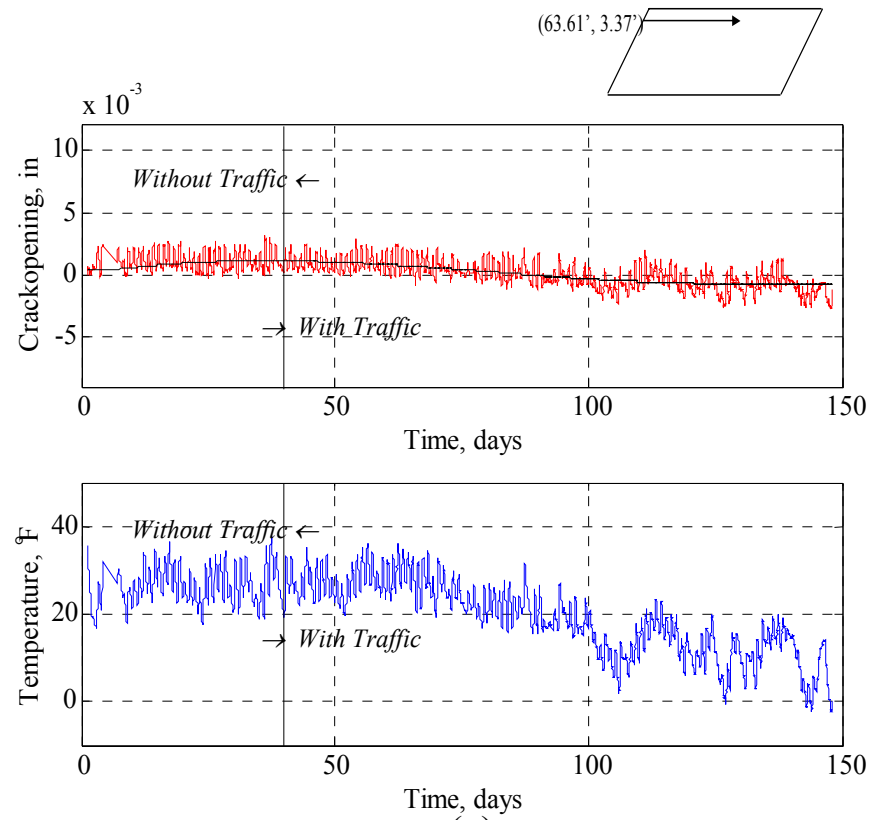

(c)

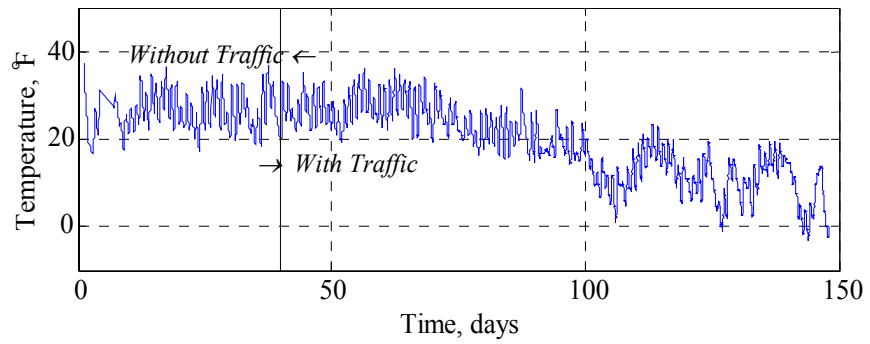

(b)

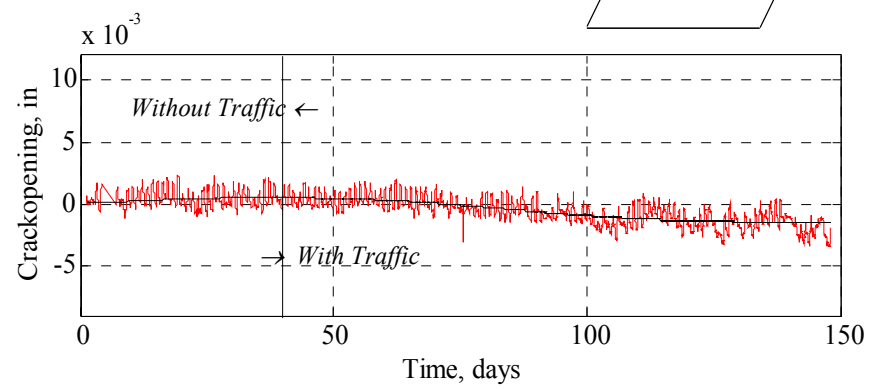

Figure 5.13 Crack opening trend and corresponding temperature profile (a) Crack-meter No. 23 (b) Crack-meter No. 24 (c) Crack-meter No. 25 (d) Crack-meter No. 26 

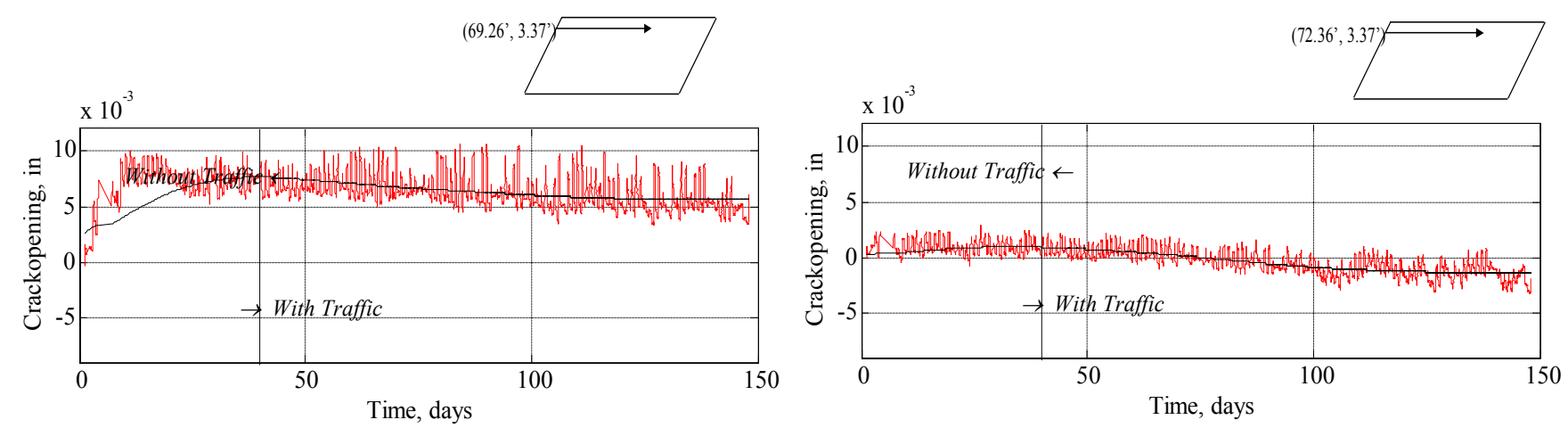

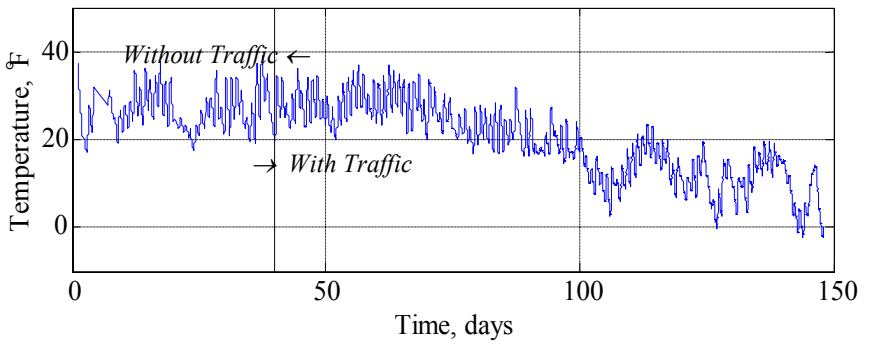

(a)
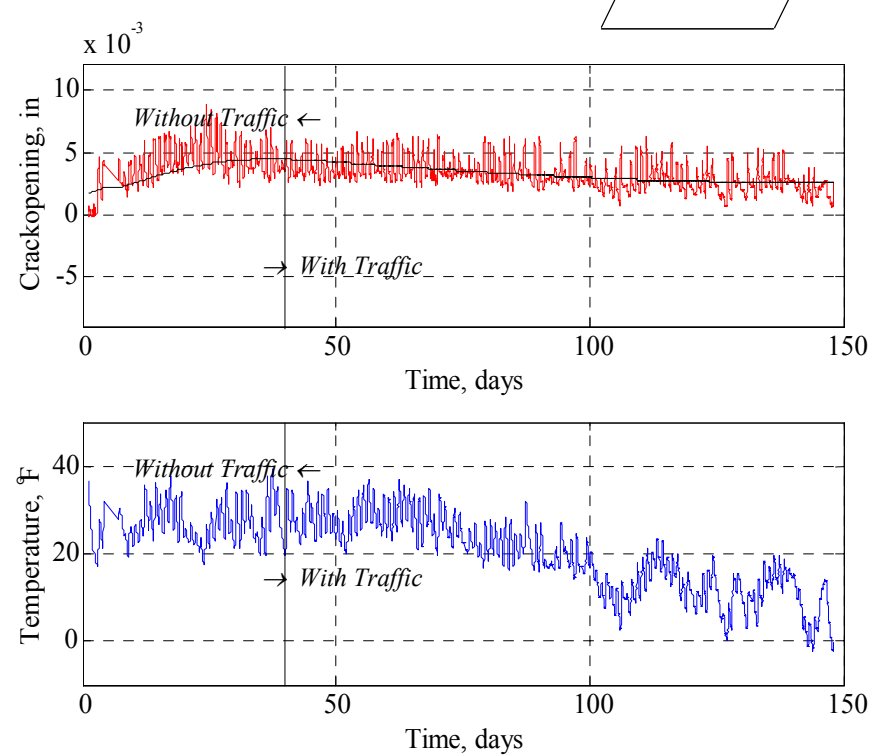

(c)

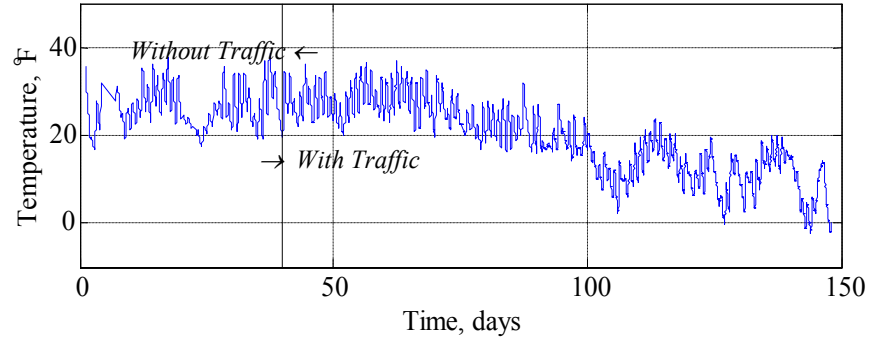

(b)
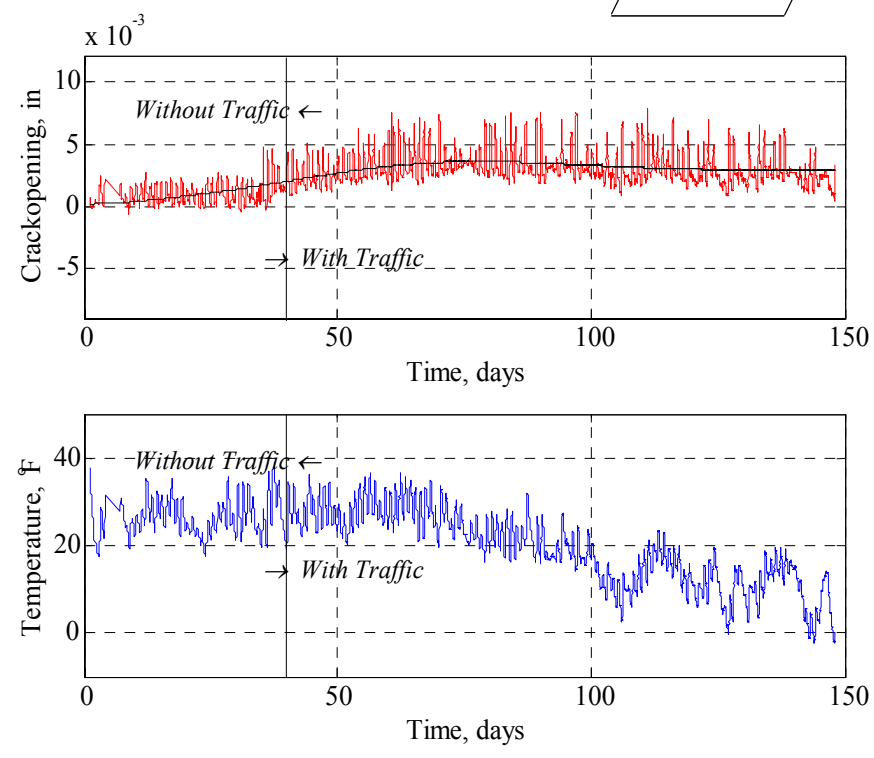

(d)

Figure 5.14 Crack opening trend and corresponding temperature profile (a) Crack-meter No. 27 (b) Crack-meter No. 28 (c) Crack-meter No. 29 (d) Crack-meter No. 30 


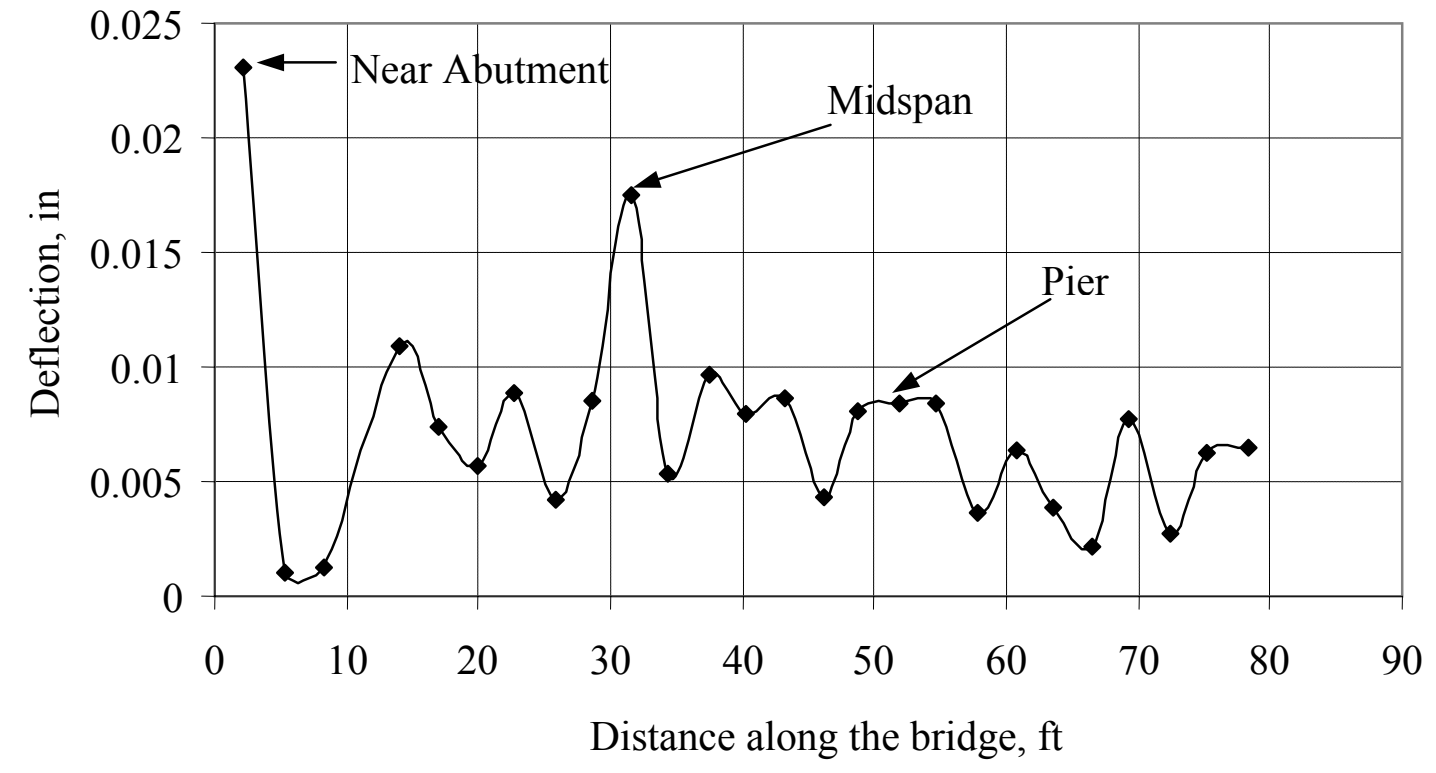

Figure 5.15 Average deflection along the bridge, on $115^{\text {th }}$ day 


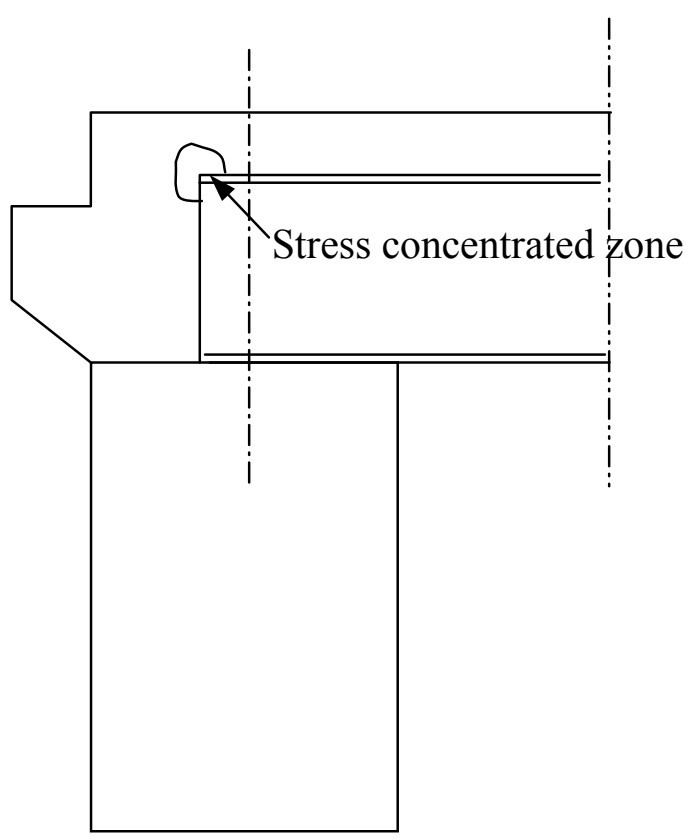

(a)

Typical section behind the beam

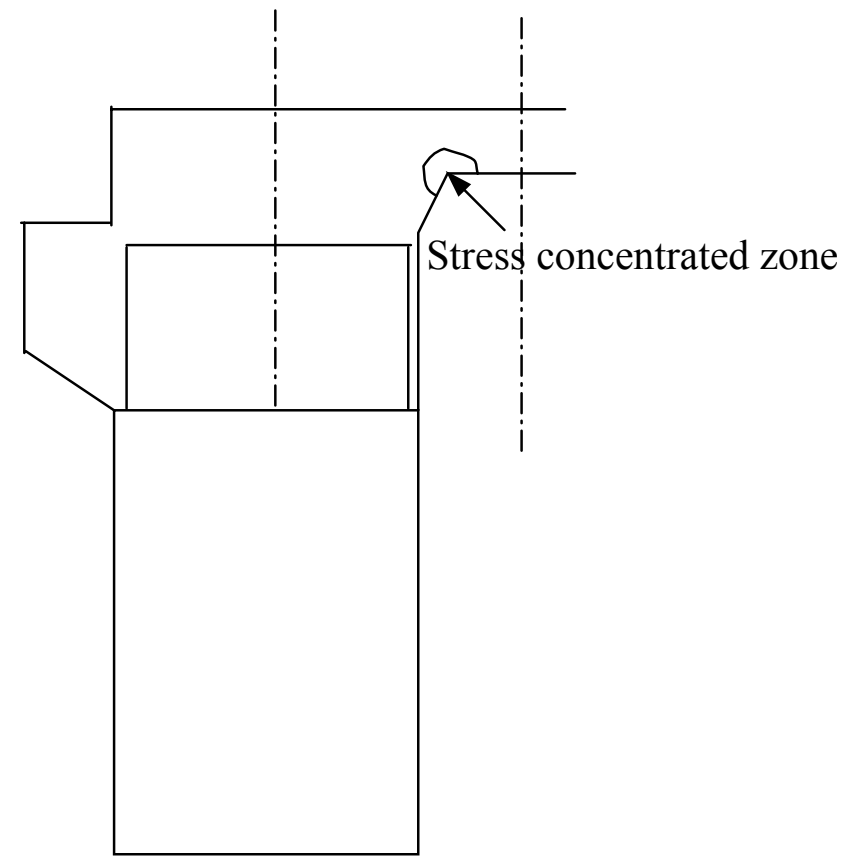

(b)

Typical section between the beam

Figure 5.16 Typical abutment section 

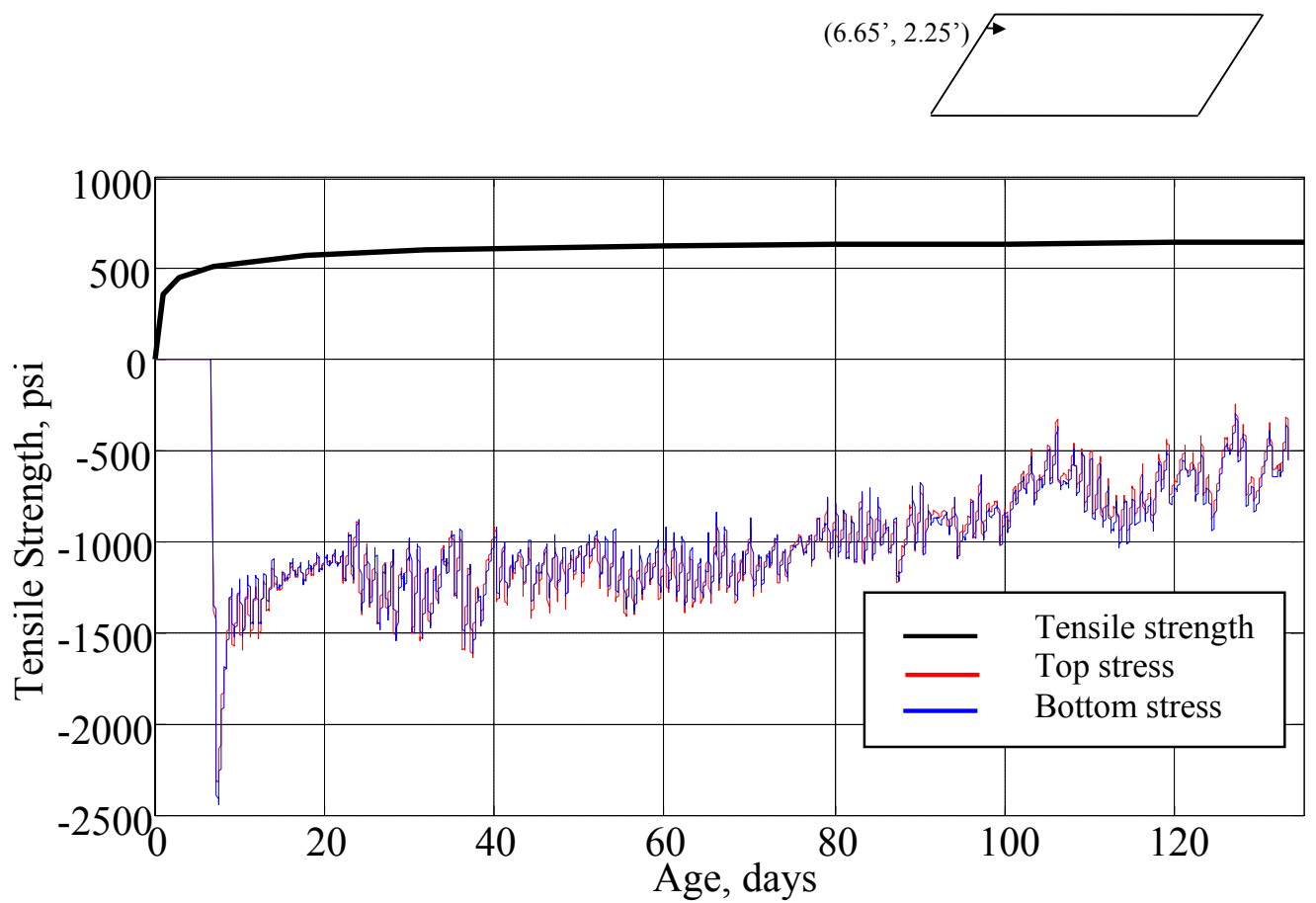

Figure 5.17 Tensile strength-Stresses measured comparison@ location A3,6.65'

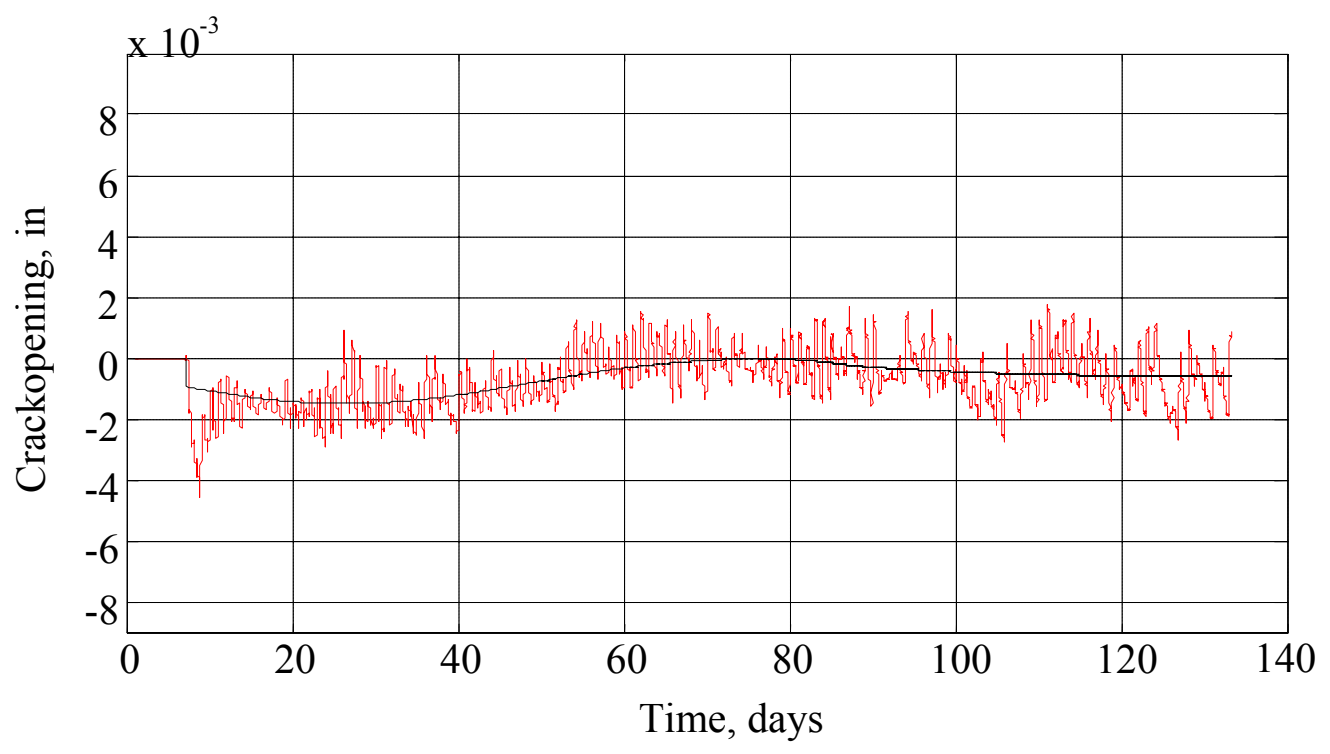

Figure 5.18 Crack-meter reading, near 6.65' 

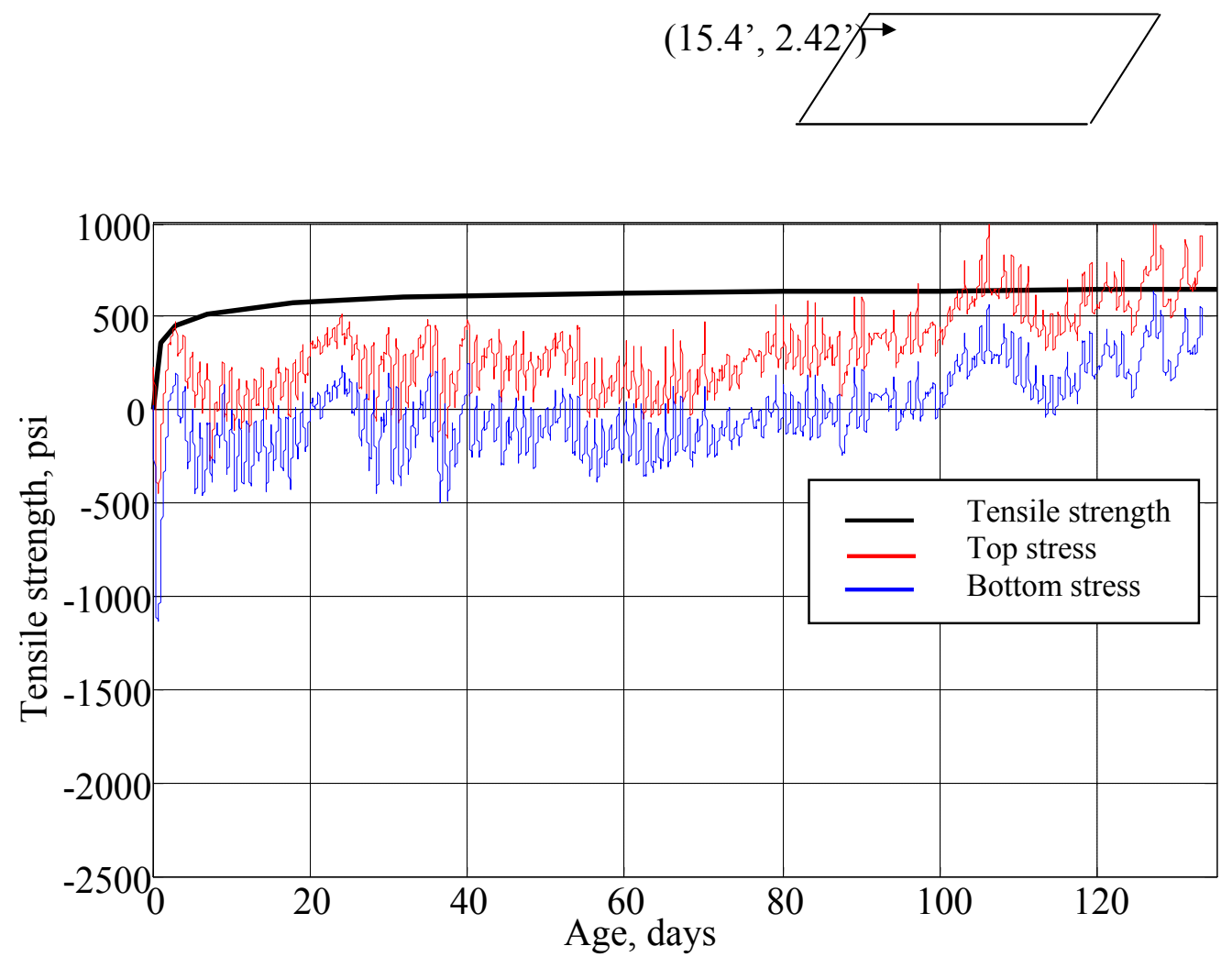

Figure 5.19 Tensile strength-Stresses measured comparison @ location B3, 15.4'

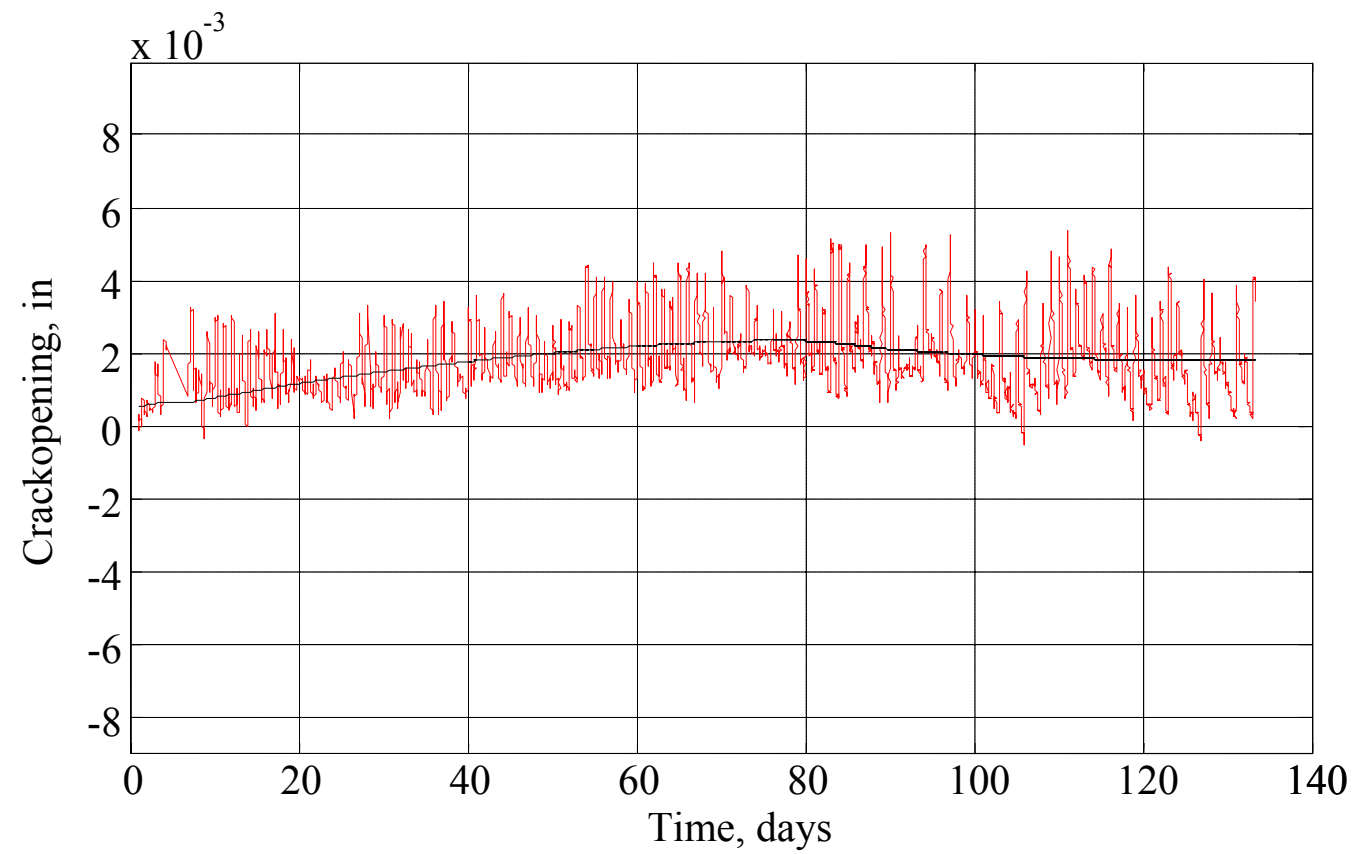

Figure 5.20 Crack-meter reading, near 15.4' 

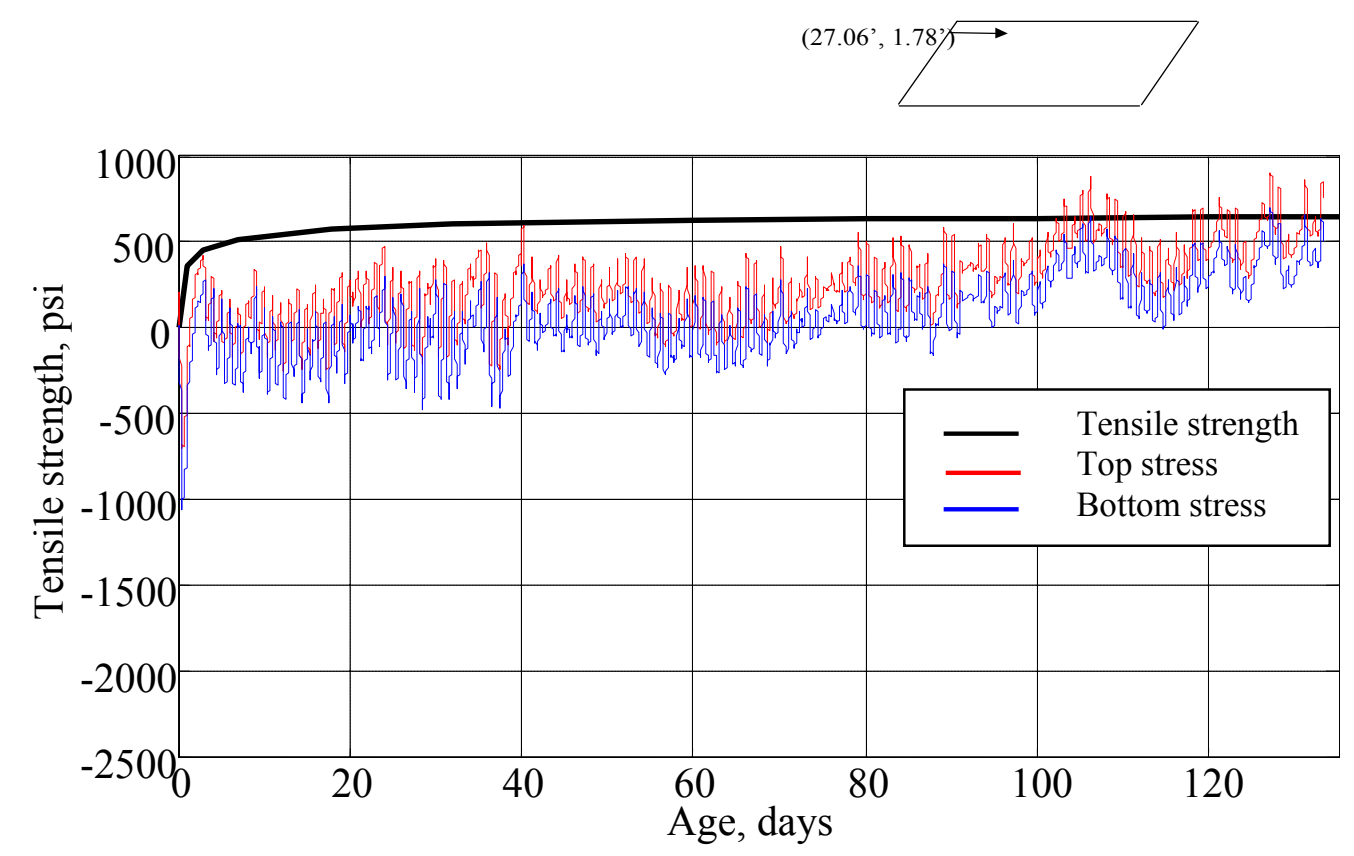

Figure 5.21 Tensile strength-Stresses measured comparison @ location H3, 27.06'

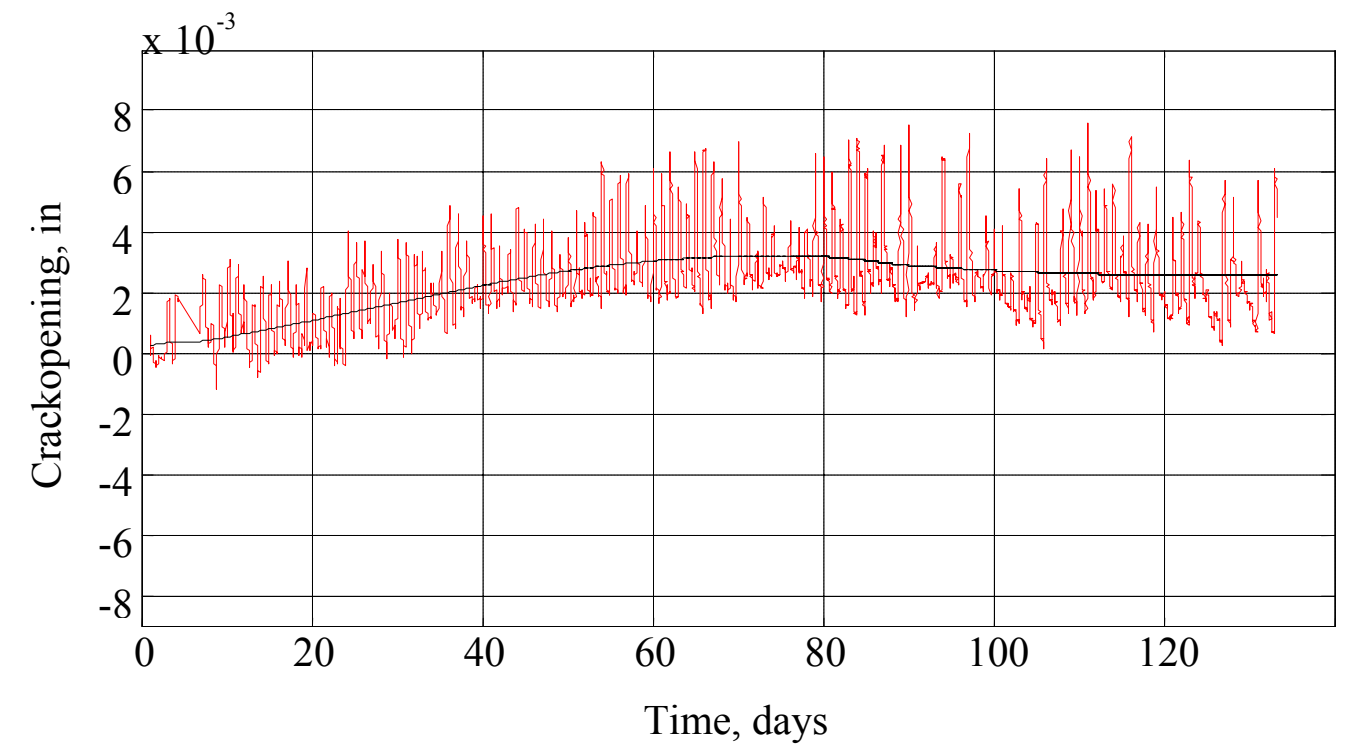

Figure 5.22 Crack-meter reading, near 27.06’ 


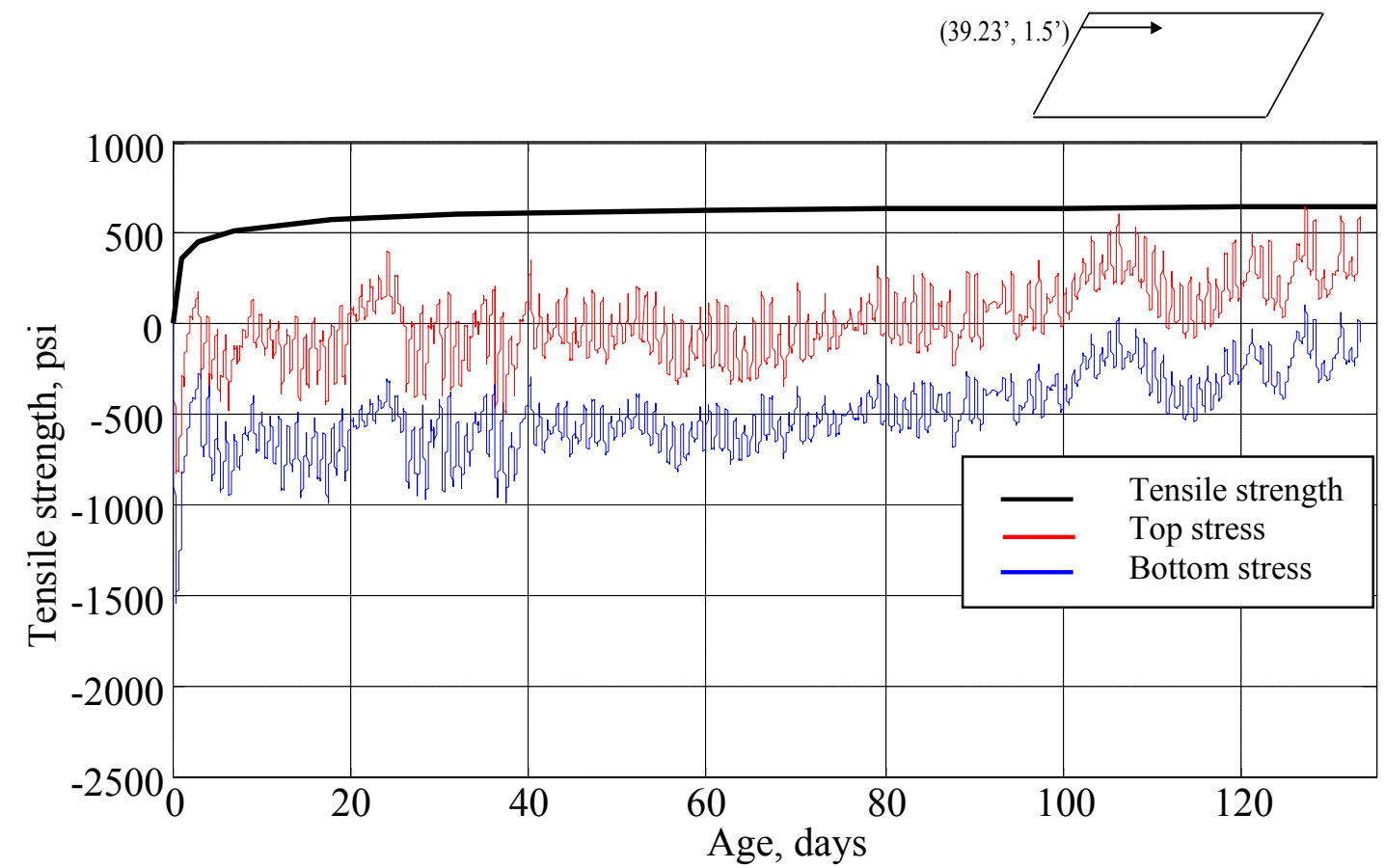

Figure 5.23 Tensile strength-Stresses measured comparison @ location T3, 39.23’

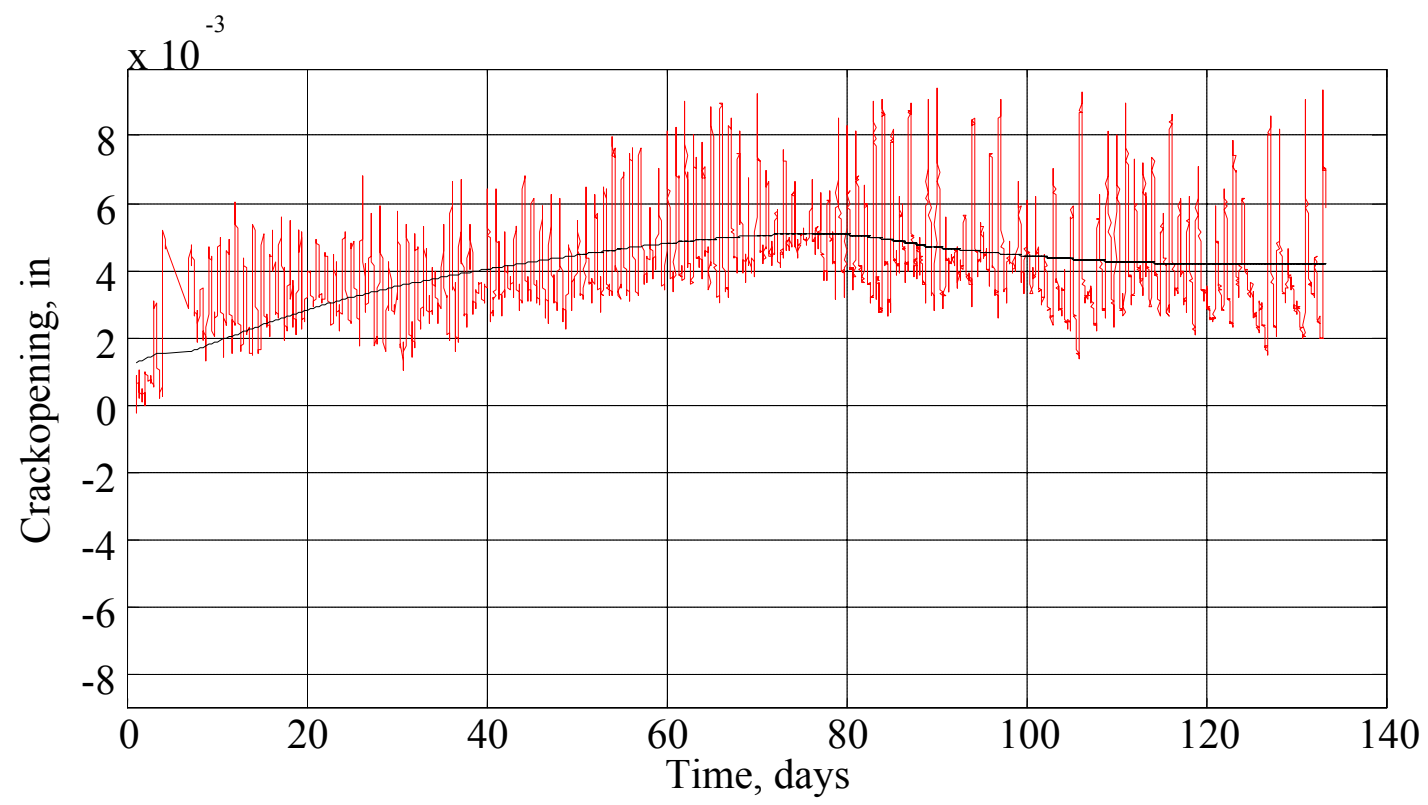

Figure 5.24 Crack-meter reading, near 37.45', 


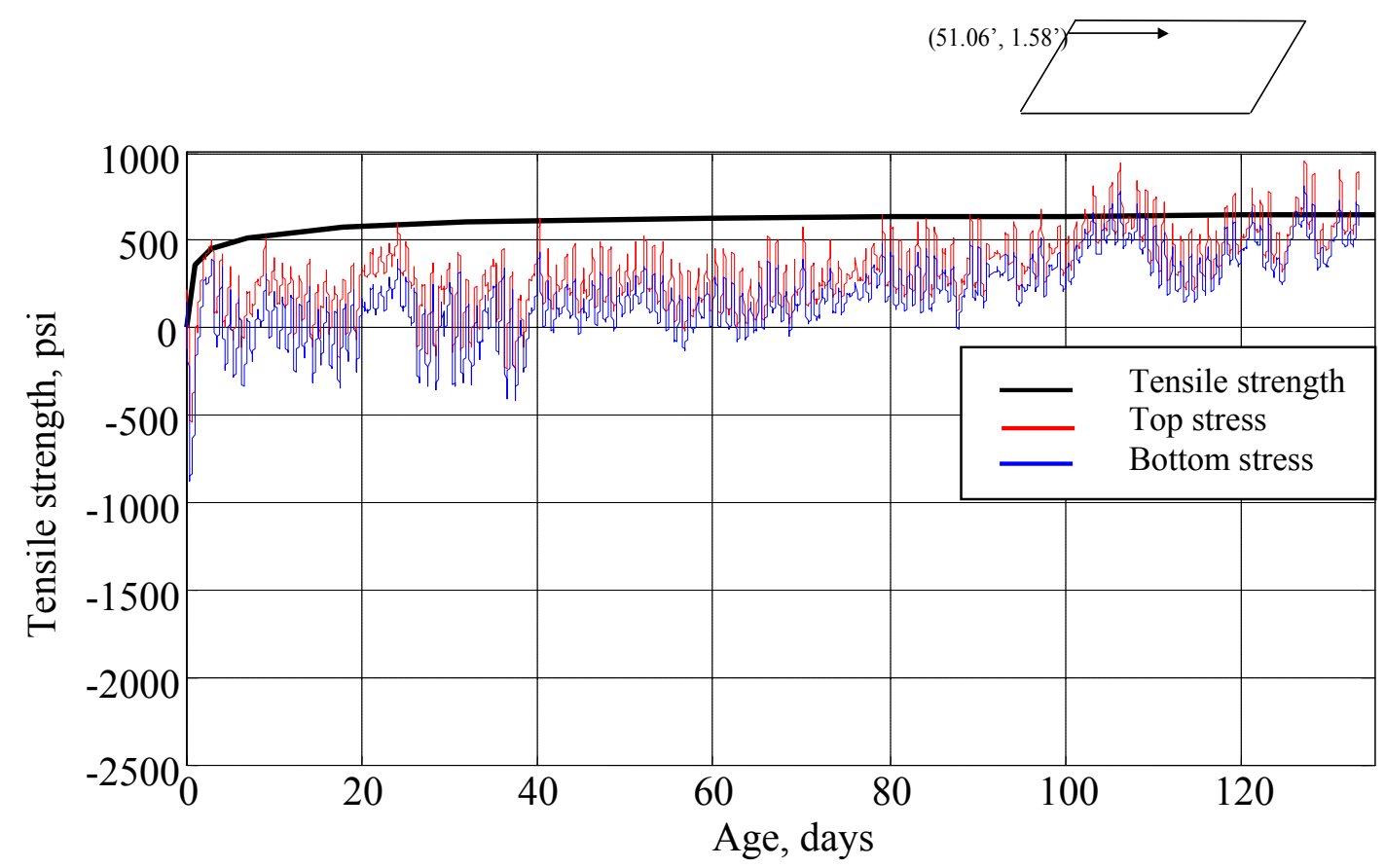

Figure 5.25 Tensile strength-Stresses measured comparison @ location P3, 51.06’

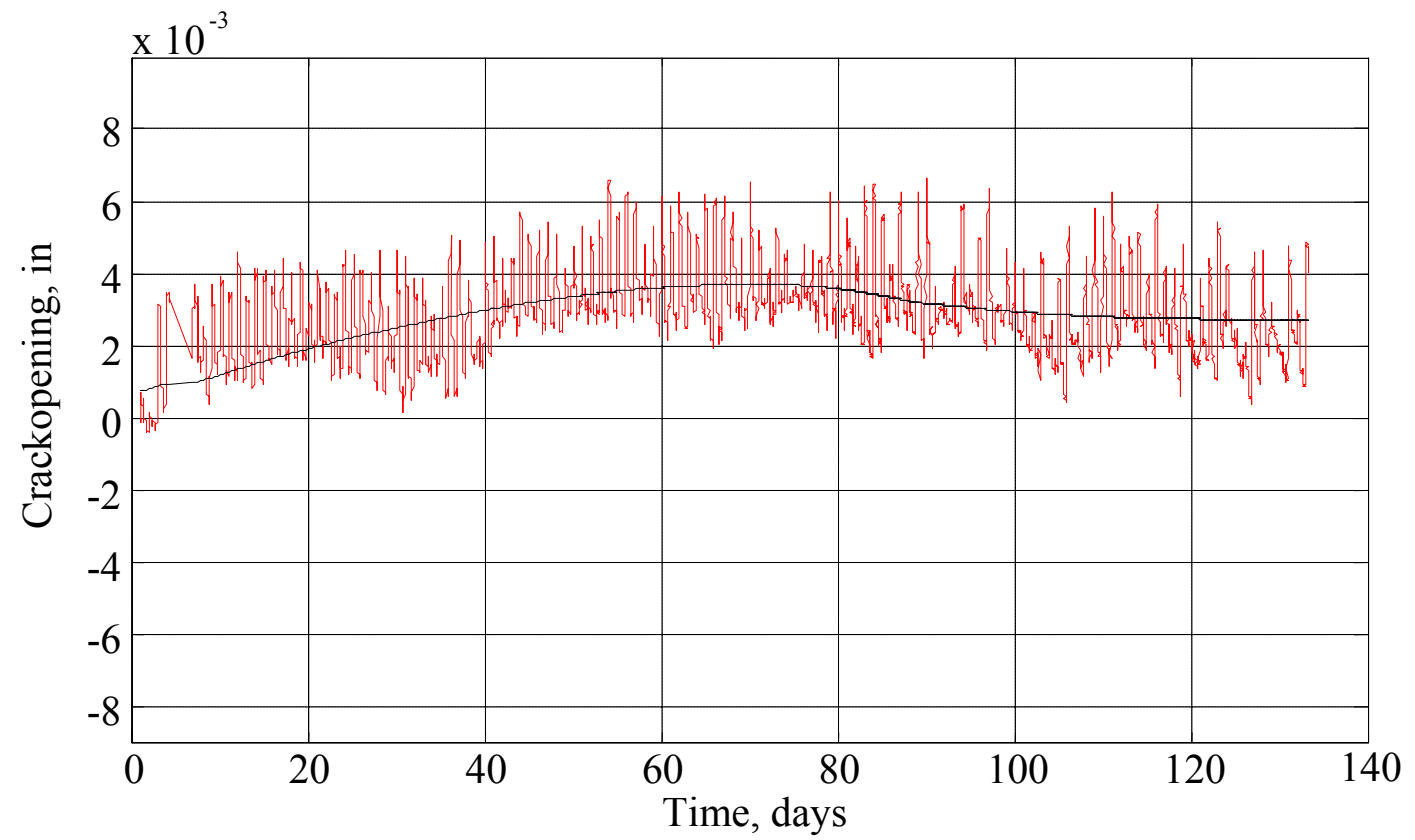

Figure 5.26 Crack-meter reading, near 51.06' 


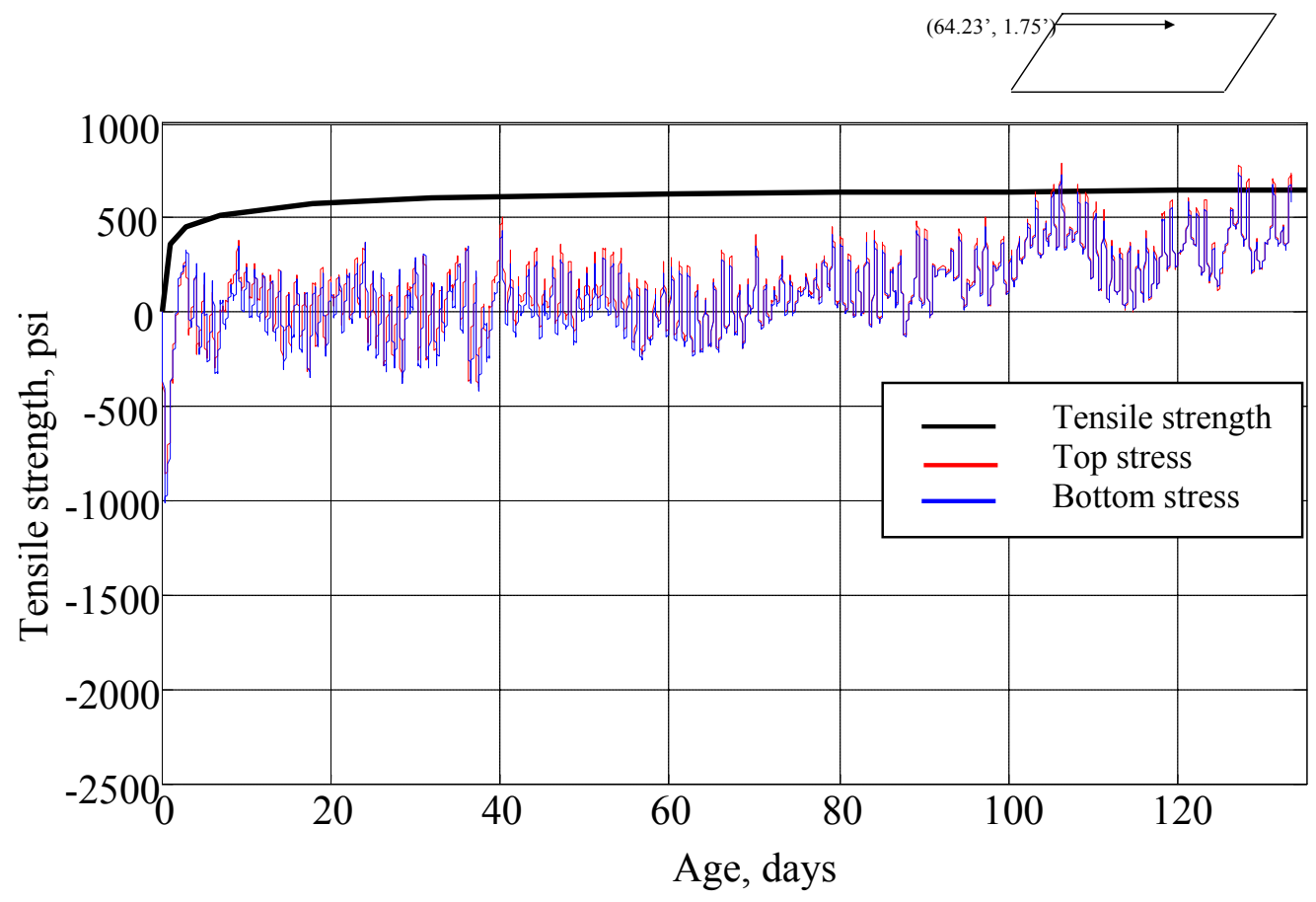

Figure 5.27 Tensile strength-Stresses measured comparison@ location Q3, 64.23’

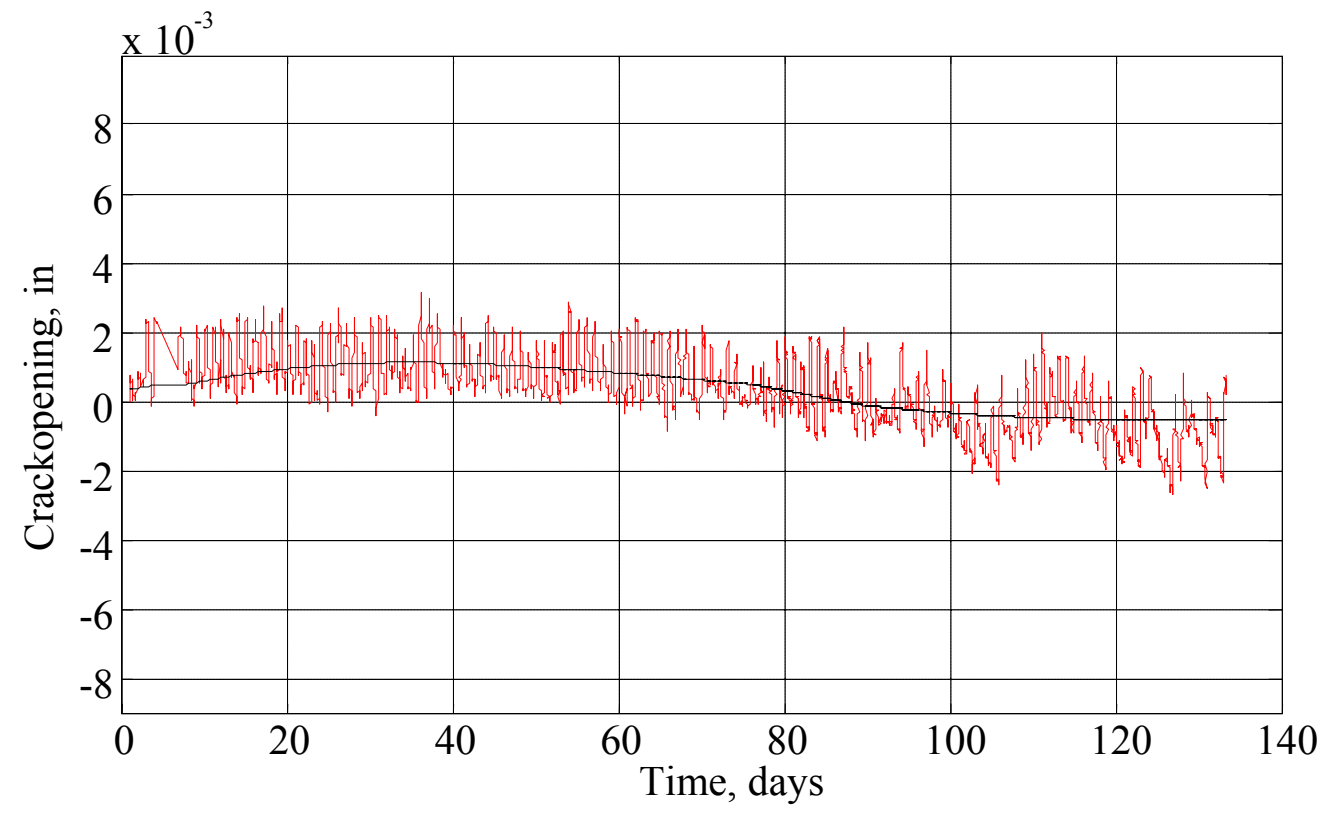

Figure 5.28 Crack-meter reading, near 63' 


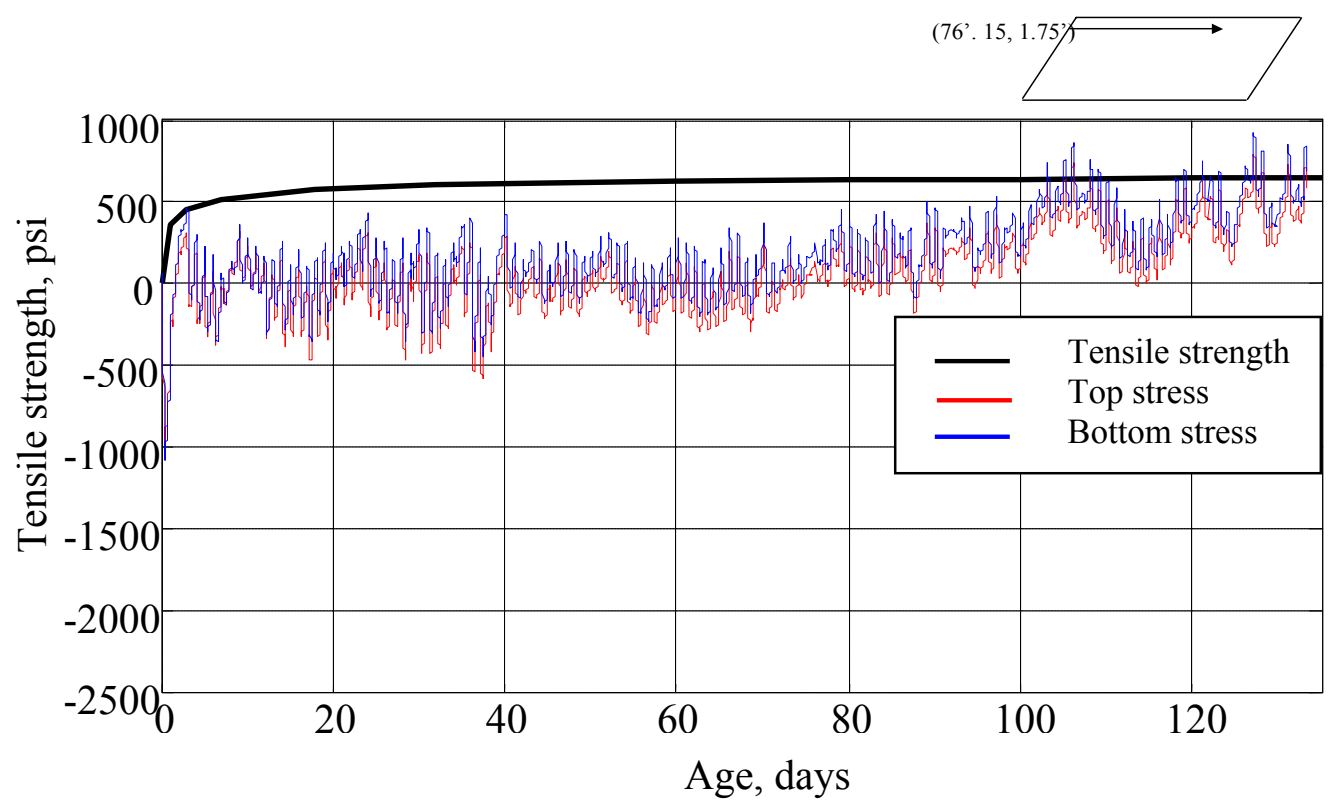

Figure 5.29 Tensile strength-Stresses measured comparison@ location M3, 76.15'

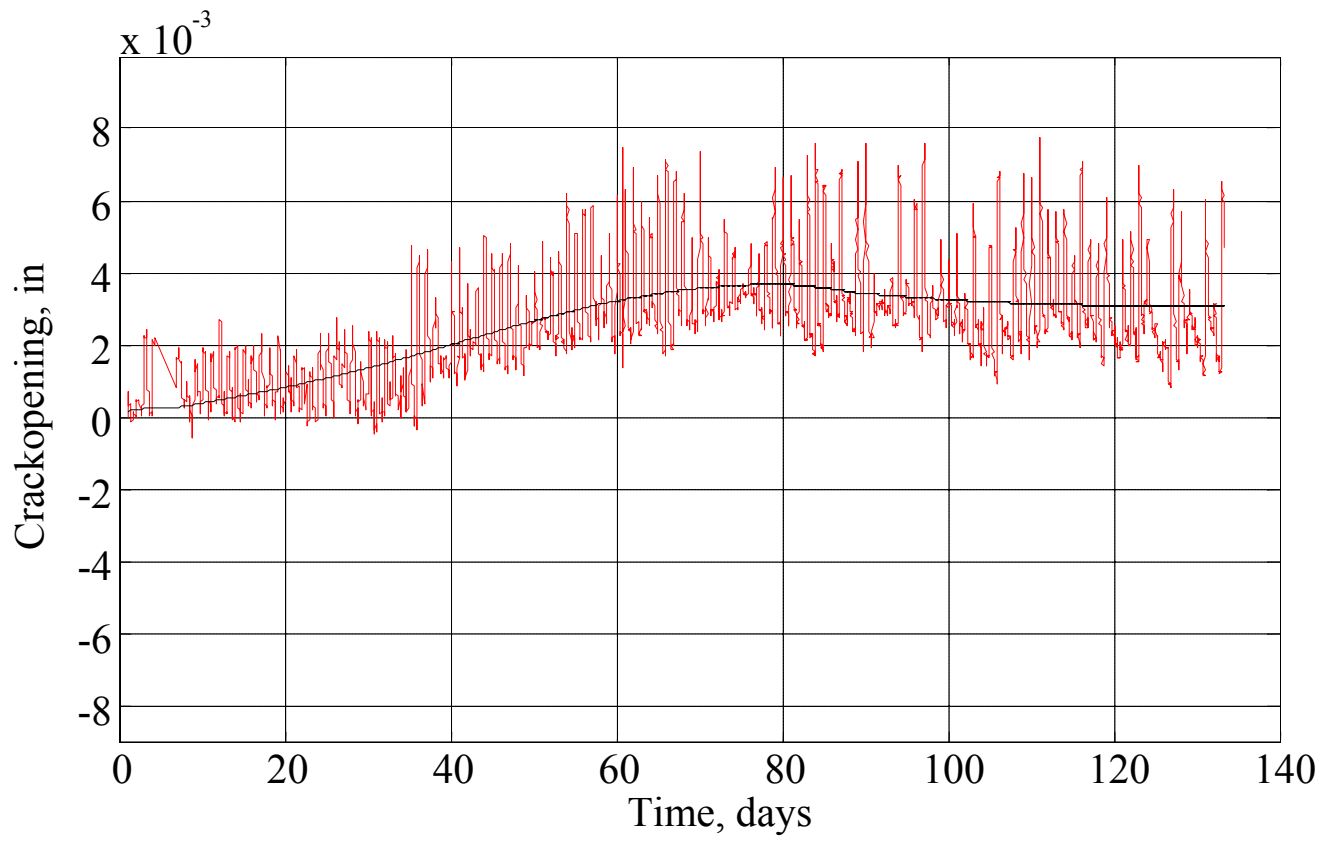

Figure 5.30 Crack-meter reading, near 76' 


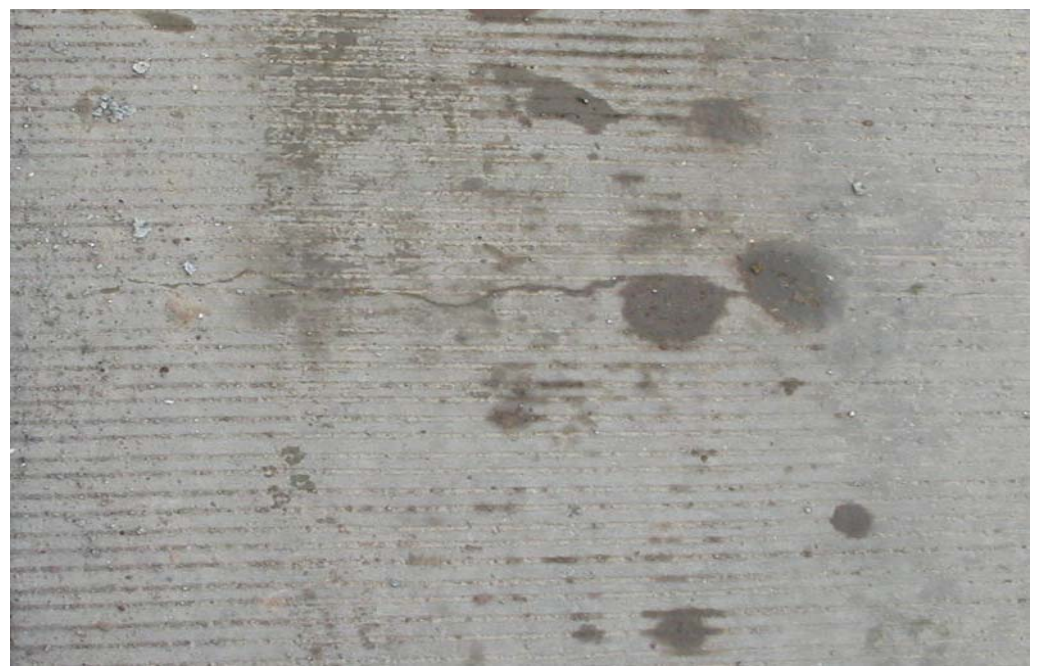

Figure 5.31 Crack was identified at pier, during visual inspection of bridge

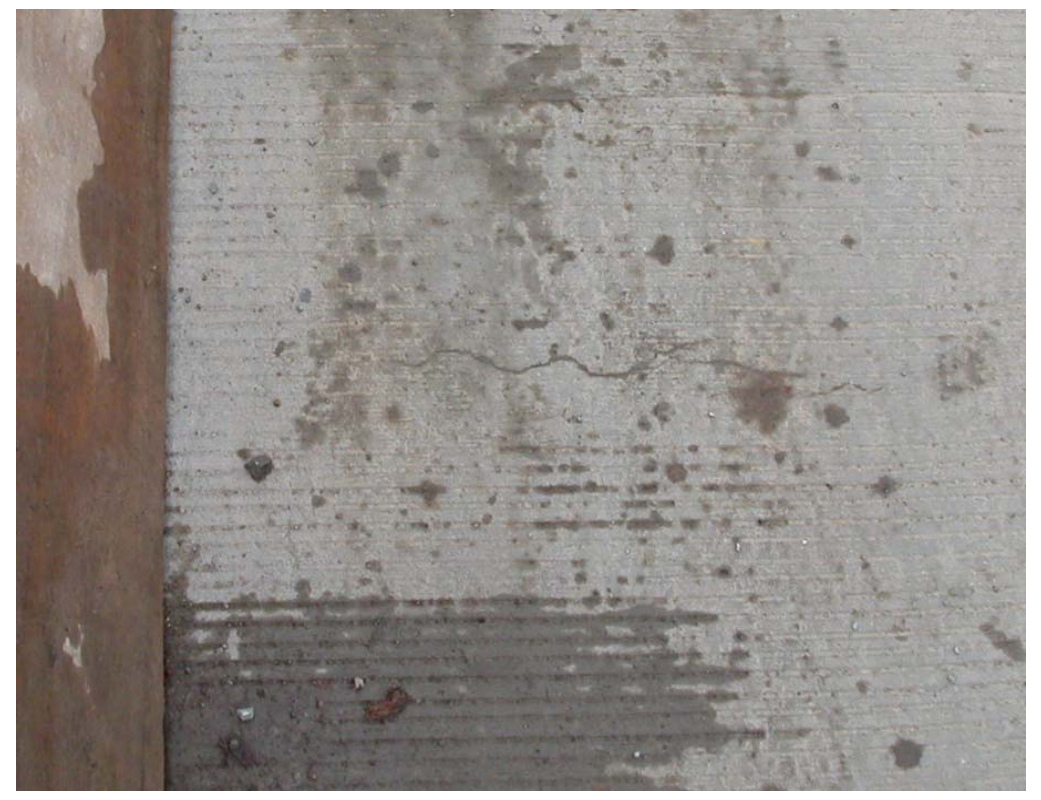

Figure 5.32 Crack was identified at midspan, during visual inspection of bridge 


\section{CHAPTER SIX}

\section{CONCLUSION AND RECOMMENDATIONS}

\subsection{CONCLUSIONS}

The work presented in this thesis dealt with the instrumentation of reinforced concrete bridge deck to monitor the development of early age cracking. A new technique has been developed to detect the cracks and it is suitable for use with decks constructed on stay-in-place forms, where usual inspection is impossible. The new technique was validated by visual inspection and by calculating the tensile stresses developed in the deck at the same locations.

Based on the results presented, the following conclusions could be made

1. Temperature changes are the main reason for initiating cracks in the bridge decks. This is because of the constraining action from: (a) corrugated stay-inplace forms, (b) integral abutments, (c) shear studs. Therefore, the stresses resulting from the constraints should be accounted for in the design.

2. Cracks were formed on the bridge before opening the bridge to traffic, and the crack opening increased with the repeated traffic load and the changes in ambient temperature.

3. The filter design technique (FDT) clearly showed the formation of cracks and crack openings on the bridge deck and its behavior due to various effects like daily temperature changes, seasonal effects and traffic loads.

4. The technique clearly identified the crack intensive zones, wide crack zones helps to modify the design specification of the bridge, to minimize the potential for crack on those places. 


\section{REFERENCES}

(1) American Society for Testing and Materials (1994). ASTM book of Standards: Concrete and Aggregates, Vol 04.02, PP 469-94, ASTM Standard C 39: Standard Test Method for Static Modulus of Elasticity and Poisson's Ratio of Concrete in Compression, ASTM, Philadelphia, USA.

(2) American Society for Testing and Materials (1999). ASTM book of Standard s: Concrete and Aggregates, Vol 04.02, PP 39M-99., ASTM Standard C 39: Standard Test Method for Compressive Strength of cylindrical Concrete Specimens, ASTM, Philadelphia, USA.

(3) Beckwith, T.G., R.D.Marangoni and J.H. Leinhard V (1993). Mechanical Measurements, Fifth Edition, Addison-Wesley Publishing Co., LTD.

(4) Campbell Scientific (1997). CR10X Measurements and Control Module Operator's Manual, Revision: 5/97, Campbell Scientific, Inc., Logan, Utah, USA

(5) Canary systems (1997). MultiLogger Software User's Guide Version 2.0, Canary Systems, Inc., New London, NH, USA

(6) Canary systems (1997). MultiSensor Interface User's Guide, Canary Systems, Inc., New London, NH, USA

(7) Cusson, D., W.L. Repette (2000) Early Age Cracking in Reinforced Concrete Bridge Barrier Walls, ACI Materials Journal, Vol. 97, No. 4, July-August 2000, pp. 438-446.

(8) Elwell, D.J., and G. Fu (1995). Compression Testing of Cylinders: Cylinder Vs Cubes. Special Report to Transportation Research and Development Bureau, New York State Department of Transportation, State Campus, Albany, NY. 
(9) French, C., L. Eppers, Q. Le, J.F. Hajjar (1999). Transverse Cracking in Concrete Bridge Decks. Transportation Research Record, Various Bridge Design Issues, Bridges, Other Structures, Hydraulics and Hydrology, Transportation Research Board, National Research Council, National Academy Press, 1688:21-29.

(10) Furr, H.L., F.H. Fouad (1981). Bridge Slab Concrete placed adjacent to moving loads.Res.Rep.No. 266-IF, Texas Transportation Institute, State Department of Highways and Public Transportation, College Station, Texas.

(11) Geokon (1996), Installation Manual Models VCE-4200/4202/4210 Vibrating Wire Strain Gages.Geokon, The world Leader in Vibrating Wire Technology, Lebanon, NH, USA.

(12) Geokon (1996), Installation Manual Models 4911 A/4911 VW Rebar Strain Meters. Geokon, The world Leader in Vibrating Wire Technology, Lebanon, NH, USA.

(13) Geokon (1996), Instruction Manual Model VSM-4000 Vibrating Wire Strain Gage. Geokon, The world Leader in Vibrating Wire Technology, Lebanon, NH, USA.

(14) Geokon (1996), Instruction Manual Model 4425 VW Convergence Meter.Geokon, The world Leader in Vibrating Wire Technology, Lebanon, NH, USA.

(15) Geokon (1996), Instruction Manual Model 4430 VW deformation meter (crackmeter).Geokon, The world Leader in Vibrating Wire Technology, Lebanon, NH, USA.

(16) Geokon (2001), Instruction Manual Model 8032 16/32 Channel Multiplexer.Geo Technical Instrumentation, Geokon, Inc., Lebanon, NH, USA.

(17) Graybeal, A.B., B.M. Phrases, D.D. Rolander, M.Moore, G. Washer (2002). Visual Inspection of Highway Bridges, Journal of Non Destructive Evaluation, Vol. 21, No. 3 pp 67-83. 
(18) Gopalaratnam, V.S. and M. Eatherton (2001). Instrumentation and Monitoring of High Performance Concrete Prestressed Bridge Girders, Final Report.RDT 01-007, Missouri Department of Transportation (MoDOT), Columbia, Missouri.

(19) Hadidi, R., M.A.Saadeghaziri, C.T.Hsu (2001). Cause and Control of Transverse Cracking in Concrete Bridge Decks, Interim Report, New Jersey Department of Transportation (NJDOT), New Jersey.

(20) Halabe, U.B., K.R. Master, E.A. Kausel, (1995). Condition Assessment of Reinforced Concrete Structures using Electromagnetic Waves. American Concrete Institute (ACI) Materials Journal, Vol. 92, No. 5, pp. 511-523

(21) Issa, M.A. (1999). Investigation of Cracking in Concrete Bridge Decks at Early Ages, Journal of Bridge Engineering Vol. 4, No. 2, pp. 116-124.

(22) Jewell Instruments, Manual for Jewell LCI Inertial Inclinometers, http://www.jewellinstruments.com.

(23) Jones, R. (1962) Non-Destructive Testing of Concrete, Cambridge University Press.

(24) Kadir, R. (1992). Detection of Highway Pavement Cracks through Infrared Thermography and Digital Image Processing, Master thesis, University of West Virginia, Morgantown, West Virginia.

(25) Kayle, N.H. (2001), Subsidence Cracking of Concrete Over Steel Reinforcement Bar in Bridge Decks, Master Thesis, Virginia Polytechnic Institute and State University, Blacksburg, Virginia. 
(26) Lenett, M.S., V.J. Hunt, A.J. Helmicki, A.E. Aktan (2001), Instrumentation, Testing and Monitoring of a Newly Constructed reinforced Concrete Deck-on-steel Girder Bridge -Phase -III, Report \#UC-CII 01/1, university of Cincinnati, Ohio.

(27) Levi, A. (1997). Instrumented Monitoring \& Diagnostic Load Testing for Condition Assessment and Evaluation of Bridges, PhD Dissertation, University of Cincinnati, Ohio.

(28) Luxmoore, A. (1973). Holographic Detection of Cracks in Concrete. Journal of Non Destructive Testing, October 1973, pp. 258-263.

(29) McCullough B.F., R.O.Rasmussen (1999). Fast-Track Paving: Concrete Temperature Control and Traffic Opening Criteria For Bonded Concrete Overlays Volume I: Final Report FHWA -RD-98-167, U.S. Department of Transportation, Mclean, VA.

(30) Micro measurements, Manual for EGP-5-120 Embedment Strain Gages, http://www.vishay.com/brands/measurements_group/guide/500/lists/esg_list.htm

(31) Nawy E.G (1997). Concrete Construction Engineering Hand book, CRC press, Boca Raton, New York.

(32) Neville A M (1973). Properties of Concrete, Second Edition, John Wiley and Sons, New York.

(33) Newman, K. (1966). Concrete Systems. Composite Materials .Edited by L. Holliday. Elsevier Publishing Co, London, pp. 336-452.

(34) Oppenheim, A.V., R.W., Schafer (1989). Discrete Time Signal Processing, Seventh Edition, Prentice - Hall, Inc., Englewood Cliffs, N.J., USA. 
(35) Owen, C.K.V. (1976). Capacitance Strain Gauge for Monitoring Cracks, The Detection and Measurement of Cracks, The welding Institute, Abington Hall, Abington Cambridge CBI 6AL, pp. 1-6.

(36) Pape, J.J. (1998). Impact of Bridge Decks Cracking on Durability, Master Thesis, Iowa State University, Ames, Iowa.

(37) Russell, H. (1996). Implementation Program on High Performance ConcreteGuidelines for Instrumentation of Bridges. Final Report FHWA-SA-96-075, Federal Highway Administration, Washington, DC.

(38) Schmit, J.R., (1992). Field Instrumentation of Bridges. Masters Thesis, University of Minnesota, Minneapolis.

(39) Schmitt, T.R. and D. Darwin (1999). Effect of Material Properties on Cracking in Bridge Decks. Journal of Bridge Engineering Vol. 4, No. 1, pp. 8-13.

(40) Shahawy, M.A., and M.Arockiasamy (1996). Field Instrumentation to Study the Time-Dependent Behavior in Sunshine Skyway Bridge. Journal of Bridge Engineering Vol.1, No.2, pp. 76-86.

(41) Shiu, K.N., J.D.Aristizabal and H.G.Russell (1981). Instrumentation of Denny Creek Bridge, Final Report.Y-1837, Washington, Department of Transportation (Wa DOT), Seattle, Washington

(42) Shoukry, S.N., G.W.William, S.Srinivasan (2002). Analysis of Midslab Transverse Cracking in Jointed Concrete Pavements. The International Journal of Pavements, Vol. 1, No. 3, pp. 81-94.

(43) Shoukry, S.N., M.Riad, G.William (2003). West Virginia Smart Road-Early Age Behavior of Doweled Concrete Pavements. Proceedings of the International Conference 
on Highway Pavement Data, Analysis and Mechanistic Applications. Vol.1. Columbus, Ohio, pp. 51-62

(44) Xi, Y., B. Shing, N.A Hejleh, A. Asiz, A. Suwito, Z. Xie, A. Ababneh (2003). Assessment of the Cracking Problem in Newly Constructed Bridge Decks in Colorado. Final Report CDOT-DTD-R-2003-3, The Colorado Department of Transportation, Denver, CO. 


\section{APPENDIX I}

\section{INCLINOMETER TO DATALOGGER}

\section{A.1.1 Steps followed to connect Inclinometer to CR10X Data logger}

1. Multiplexer was set to 16-channel mode, by connecting the jumper pin to terminal $1 \& 2$ on the circuit board of the multiplexer.

2. Black (+ Power, $+12 \mathrm{~V})$ and Red (-Power, $-12 \mathrm{~V})$ terminals from the inclinometer should connect to $1 \mathrm{H}$ and $1 \mathrm{~L}$ terminals on the multiplexer respectively.

3. Green (Ground) and White (Output) terminals from the inclinometer should connect to $2 \mathrm{H}$ and $2 \mathrm{~L}$ terminals on the multiplexer respectively.

4. If Shield wire exists, then connect Shield to $1 \mathrm{~S}$ terminal on the multiplexer

5. The multiplexer is connected to the MUX1 Ion the CR10X datalogger.

6. Connect RS 232 port on the CR10X datalogger to any PC /Laptop.

\section{A.1.2 Steps followed to configure Multilogger software}

1. Open a new configuration file.

2. Assign the datalogger ID as 1 (Any number between 1 and 511).

3. To configure the multiplexer, connected to the datalogger:

- Select the multiplexer option from the program menu bar.

- In the multiplexer dialog box, select MUX 1(The connected MUX).

- Set the Model to 8032, Gage type to multisensor and the Channel to 16.

4. To edit the individual channels of the multiplexer, press edit channel button on the multiplexer dialog box.

5. To configure the channel, connected to the multiplexer:

- Select the channel number to which inclinometer is connected, on the channel configuration dialog box

- Enter the label and description to provide additional information regarding the instrument channel

- Set the Gage type to " Tilt meter", Make to "Geokon" and the Model to "6200" 
- Select the conversion method to Linear

- Set the zero reading and gage factor as they are.

- Click the accept button on the channel configuration dialog box and on the multiplexer dialog box to save the file.

6. Select the interval type to single interval of 60 secs.

7. The text monitor was configured to display the monitor location values during the experiment.

8. Save the file. 


\section{APPENDIX II}

\section{SPECIFICATIONS}

\section{A.2.1 Geokon Model 4200 Vibrating Wire Strain gage}

\section{A.2.1.1 VW Strain gage specifications}

\begin{tabular}{|c|c|}
\hline Gage length & 1 meter (40 inches) \\
\hline Gage Dimensions & $6.125 \times 0.750$ “ \\
\hline Range & $3000 \mu \varepsilon$ \\
\hline Resolution & $1.0 \mu \varepsilon$ \\
\hline Accuracy & $2.0 \% \mathrm{FSR}$ \\
\hline Linearity & $2.0 \% \mathrm{FSR}$ \\
\hline Stability & $0.1 \% \mathrm{FS} / \mathrm{yr}$ \\
\hline Thermal Coefficient & $12.2 \mu \varepsilon /{ }^{\circ} \mathrm{C}$ \\
\hline Temperature range & -20 to $80^{\circ} \mathrm{C}$ \\
\hline Coil Resistance & $150 \Omega$ \\
\hline Cable Type & 4-Conductor Shielded \\
\hline Length & 1 meter, 40 inches \\
\hline Dimension coil & $\begin{array}{l}0.875 \times 0.875 \text { “ } \\
22 \times 22 \mathrm{~mm}\end{array}$ \\
\hline
\end{tabular}

\section{A.2.1.2 VW Thermistor specifications}

\begin{tabular}{|l|l|}
\hline Range & -80 to $+150^{\circ} \mathrm{C}$ \\
\hline Accuracy & $\pm 0.5^{\circ} \mathrm{C}$ \\
\hline
\end{tabular}




\section{A.2.2 Geokon Model VSM 4000 Vibrating Wire Strain gage (Weldable Strain Gage)}

\section{A.2.2.1 Weldable strain gage specifications}

\begin{tabular}{|l|l|}
\hline Length X Diameter & 155 X $19 \mathrm{~mm}$ \\
\hline Gage Dimensions & 6.125 X 0.750 “ \\
\hline Range & $3000 \mu \varepsilon$ \\
\hline Resolution & $0.1 \mu \varepsilon$ \\
\hline Accuracy & $2.0 \% \mathrm{FSR}$ \\
\hline Linearity & $2.0 \% \mathrm{FSR}$ \\
\hline Stability & $0.1 \% \mathrm{FS} / \mathrm{yr}$ \\
\hline Thermal Coefficient & $12.2 \mu \varepsilon /{ }^{\circ} \mathrm{C}$ \\
\hline Temperature range & -20 to $80^{\circ} \mathrm{C}$ \\
\hline Coil Resistance & $150 \Omega$ \\
\hline Cable Type & $4-\mathrm{Conductor} \mathrm{Shielded}$ \\
\hline Dimension coil & $\begin{array}{l}0.875 \mathrm{X} 0.875 \text { “ } \\
22 \mathrm{X} 22 \mathrm{~mm}\end{array}$ \\
\hline
\end{tabular}

\section{A.2.2.2 Weldable thermistor specifications}

\begin{tabular}{|l|l|}
\hline Range & -80 to $+150^{\circ} \mathrm{C}$ \\
\hline Accuracy & $\pm 0.5^{\circ} \mathrm{C}$ \\
\hline
\end{tabular}




\section{A.2.3 Geokon Model 4911 Vibrating Wire Rebar Strain meters}

\section{A.2.3.1 Rebar strain meter specifications}

\begin{tabular}{|l|l|}
\hline Length & 54.25 “, $1378 \mathrm{~mm}$ \\
\hline Range & $2500 \mu \varepsilon$ \\
\hline Sensitivity & $0.025 \%$ FSR \\
\hline Accuracy & $0.25 \%$ FSR \\
\hline Linearity & $0.25 \%$ FSR \\
\hline Stability & $0.1 \%$ FS/ yr \\
\hline Operating Frequency & $1200-2800 \mathrm{~Hz}$ \\
\hline Operating Temperature & -40 to $90^{\circ} \mathrm{C}$ \\
& -40 to $200^{\circ} \mathrm{F}$ \\
\hline Coil Resistance & $50 \Omega$ \\
\hline Electrical cable & $2-$ Twisted pair (4 conductor) $22 \mathrm{AWG}$ \\
& Foil Shield, PVC jacket, nominal OD $=6.3 \mathrm{~mm}\left(0.25^{\prime}\right)$ \\
\hline Material & Grade $60 \mathrm{Rebar}$ and High Strength Steel \\
\hline
\end{tabular}

\section{A.2.3.2 Rebar stain meter thermistor specifications}

\begin{tabular}{|l|l|}
\hline Range & -80 to $+150^{\circ} \mathrm{C}$ \\
\hline Accuracy & $\pm 0.5^{\circ} \mathrm{C}$ \\
\hline
\end{tabular}




\section{A.2.4 Geokon Model 4430 VW Deformation meter(crack-meter)}

\section{A.2.4.1 Deformation meter(crack-meter) specifications}

\begin{tabular}{|l|l|}
\hline Gage length & 1 meter (40 inches) \\
\hline Ranges available & $0.5,1,2$ ” (12,25,50 mm) \\
\hline Over range & $115 \%$ \\
\hline Resolution & $0.02 \%$ FSR \\
\hline Accuracy & $0.1 \%$ \\
\hline Linearity & $0.25 \%$ FSR \\
\hline Stability & $<0.2 \% / \mathrm{yr}$ (Under Static condition) \\
\hline Temperature range & -40 to $+120^{\circ} \mathrm{F}$ or -40 to $120^{\circ} \mathrm{C}$ \\
\hline Frequency Range & $1200-2800 \mathrm{~Hz}$ \\
\hline Coil Resistance & $180 \Omega, \pm 10 \Omega$ \\
\hline Cable Type & $4-$ Conductor Shielded \\
\hline Length & 1 meter, 40 inches \\
\hline Diameter & $26.7 \mathrm{~mm}, 1.050$ “(body) \\
& $51 \mathrm{~mm}, 2$ ”(flange) \\
\hline Weight & $1 \mathrm{Kg} ., 2.2$ lbs \\
\hline
\end{tabular}

\section{A.2.4.2 Deformation meter(crack-meter) thermistor specifications}

\begin{tabular}{|l|l|}
\hline Range & -80 to $+150^{\circ} \mathrm{C}$ \\
\hline Accuracy & $\pm 0.5^{\circ} \mathrm{C}$ \\
\hline
\end{tabular}




\section{A.2.5 Geokon Model 4425 VW Convergence meter}

\section{A.2.5.1 Convergence meter specifications}

\begin{tabular}{|l|l|}
\hline Ranges available & $0.5,1,2,4$ and $6^{\prime \prime}(12,25,50,100$ and $150 \mathrm{~mm})$ \\
\hline Over range & $115 \%$ \\
\hline Resolution & $0.025 \% \mathrm{FSR}$ \\
\hline Accuracy & $0.1 \%$ \\
\hline Linearity & $0.25 \% \mathrm{FSR}$ \\
\hline Stability & $<0.2 \% / \mathrm{yr}($ Under Static condition) \\
\hline Thermal Zero Shift & $<0.05 \% \mathrm{FSR} /{ }^{\circ} \mathrm{C}$ \\
\hline Temperature range & -40 to $+120^{\circ} \mathrm{F}$ or -40 to $60^{\circ} \mathrm{C}$ \\
\hline Frequency Range & $1200-2800 \mathrm{~Hz}$ \\
\hline Coil Resistance & $180 \Omega, \pm 10 \Omega$ \\
\hline Cable Type & $\begin{array}{l}2 \text { Twisted pair }(4-\text { Conductor }) 22 \mathrm{AWG} \\
\text { Foil Shield, PVC jacket, } \\
\text { Nominal OD }=6.3 \text { mm }\left(0.25^{\prime \prime}\right)\end{array}$ \\
\hline Length & 285 mm or 11.250 inches \\
\hline
\end{tabular}

\section{A.2.5.2 Convergence meter thermistor specifications}

\begin{tabular}{|l|l|}
\hline Range & -80 to $+150^{\circ} \mathrm{C}$ \\
\hline Accuracy & $\pm 0.5^{\circ} \mathrm{C}$ \\
\hline
\end{tabular}




\section{A.2.6 LCI -14.5 Flexure Suspension Servo Inclinometer}

\section{A.2.6.1Inclinometer specification}

\begin{tabular}{|l|l|}
\hline Input Range & $\pm 14.5^{\circ}$ \\
\hline Full Range Output & $\pm 5.00 \mathrm{VDC} \pm 0.5 \%$ \\
\hline Non linearity & $0.02 \%$ (FRO) \\
\hline Scale Factor & $20.0 \mathrm{Volts} / \mathrm{g}$ nom \\
\hline Scale Factor Temp Sensitivity & $100 \mathrm{PPM} /{ }^{\circ} \mathrm{C} \max$ \\
\hline Natural Frequency & $5 \mathrm{~Hz}$ nom \\
\hline Band width (-3 dB) & $5 \mathrm{~Hz}$ nom \\
\hline Input Axis Misalignment & $0.50{ }^{0} \max$ \\
\hline Bias & 0.050 Volts max \\
\hline Bias Temperature Sensitivity & 0.0005 Volts $/{ }^{\circ} \mathrm{C} \max$ \\
\hline Resolution and Threshold & $1 \mu \mathrm{radian} \max$ \\
\hline
\end{tabular}

\section{A.2.6.2 Inclinometer electrical specification}

\begin{tabular}{|l|l|}
\hline Input & \pm 12 to $\pm 18 \mathrm{VDC}$ \\
\hline Input Current & $25 \mathrm{~mA} \max$ \\
\hline Output Impedance & 100 ohms nom \\
\hline Noise & 0.0005 Vrms max \\
\hline
\end{tabular}

\section{A.2.6.2 Inclinometer environmental specification}

\begin{tabular}{|l|l|}
\hline Operating Temp Range & -40 to $+85^{\circ} \mathrm{C}$ \\
\hline Survival Temp Range & -60 to $+90{ }^{\circ} \mathrm{C}$ \\
\hline Shock & 3 foot drop \\
\hline Seal & Mil - Std 202, Method 112 \\
\hline
\end{tabular}


A.2.7 Micro Measurements EGP -5-120 Embedment Strain Gage

A.2.7.1 Embedment strain gage specification

\begin{tabular}{|l|l|}
\hline Gage length & 4 in, $100 \mathrm{~mm}$ \\
\hline Resistance & $120 \pm 0.8 \%$ \\
\hline Temperature Range & +25 to $+125 \mathrm{deg}$ F (-5 to +50 deg C) \\
\hline Cable & $\begin{array}{l}\text { Three } 10-\mathrm{ft}(3-\mathrm{m}) \text { leads of } 22-\mathrm{AWG} \\
(0.643-\mathrm{mm} \text { dia. }) \\
\text { Stranded tinned copper in } 0.015-\text {-in } \\
(0.4-\mathrm{mm}) \text { thick PVC insulation }\end{array}$ \\
\hline
\end{tabular}




\section{APPENDIX III}

\section{TEMPERATURE COMPENSATION}

\section{A.3.1 Steps followed to reduce the crack-meters data, with temperature compensation}

1. Corrected deformation contains three components; absolute deformation, temperature correction and gage length correction.

$$
\begin{aligned}
D_{\text {Corrected }} & =D_{\text {Absolute }}+T_{\text {correction }}+L_{\text {Correction }} \\
& =\left(\left(R_{1}-R_{0}\right) * C\right)+\left(\left(T_{1}-T_{0}\right) * K\right)+L_{c}
\end{aligned}
$$

2. Absolute deformation is nothing but the difference in the current and initial reading of the crack-meter time's calibration factor

$$
\text { .i.e. }\left(\left(R_{1}-R_{0}\right) * C\right)
$$

3. Temperature correction is equal to the difference between the initial temperatures minus the current temperature time thermal coefficient. The value of $\mathrm{K}$ can be read from the table, in the Geokon manual.

$$
\text { i.e. }\left(\left(T_{1}-T_{0}\right) * K\right)
$$

4. Gage length correction, $L_{c}$ is calculated from the equation,

$$
L_{c}=17.3 X 10^{-6} * L^{*}\left(T_{1}-T_{0}\right)
$$

Where, $\mathrm{L}$ is the length of the crack-meter in inches. 


\section{APPENDIX IV}

\section{DIGITAL SIGNAL PROCESSING}

\section{A.4.1 LOW PASS FILTER}

Low-pass filter has the property to pass low frequencies and to attenuate high frequency content. In general, a low pass filter might be used to remove noise from a signal. Low range passing frequencies is called the pass band or the bandwidth of the filter. From figure A.1.a it clearly shows that the pass band allows an error of $\pm \delta$, but the magnitude of the frequency response must be unity. Low pass filter range extends from $\omega=0$ to $\omega=\omega_{\mathrm{c}} \mathrm{rad} / \mathrm{sec}$ or $\mathrm{fc}$ in Hz. The highest frequency to be transmitted is called as cutoff frequency $\left(\omega_{c}\right)$, Frequencies above cutoff $\left(\omega_{c}\right)$ are prevented from passing through the filter and they constitute the filter stop band.

In ideal low pass filter design must provide a zero transition bandwidth, as shown in Figure A.1.c which means magnitude response changes smoothly from pass band to stop band as shown in figure A.1.b

In low pass filter design, we can adjust the order of the function, which is the number of points in the correlation function. The higher the order, the sharper the cutoff, but the operation also becomes slower. In general, order can be found by simple trial and error method. Filter design needs the number of data points equal to a power of 2 , if not, it is important to execute a zero-fill to next higher power of 2 before executing the digital filter 


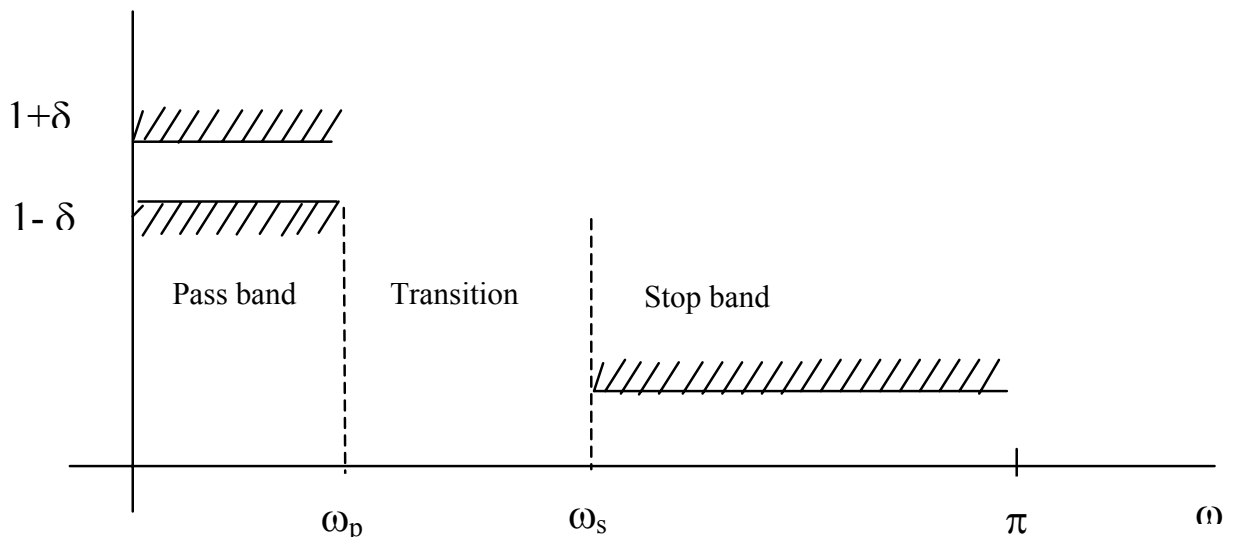

Figure A.1.a Low pass filter

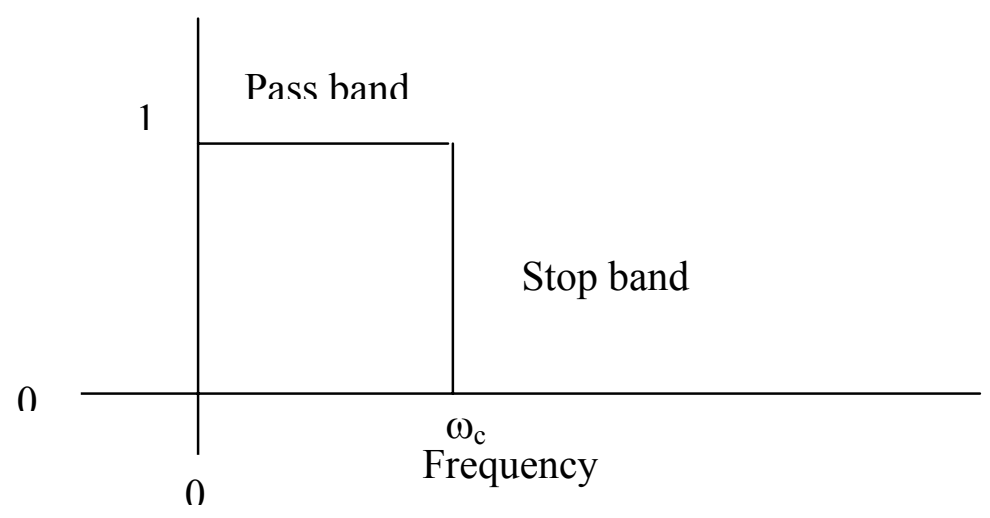

Figure A.1.b Frequency response of an ideal low pass filter

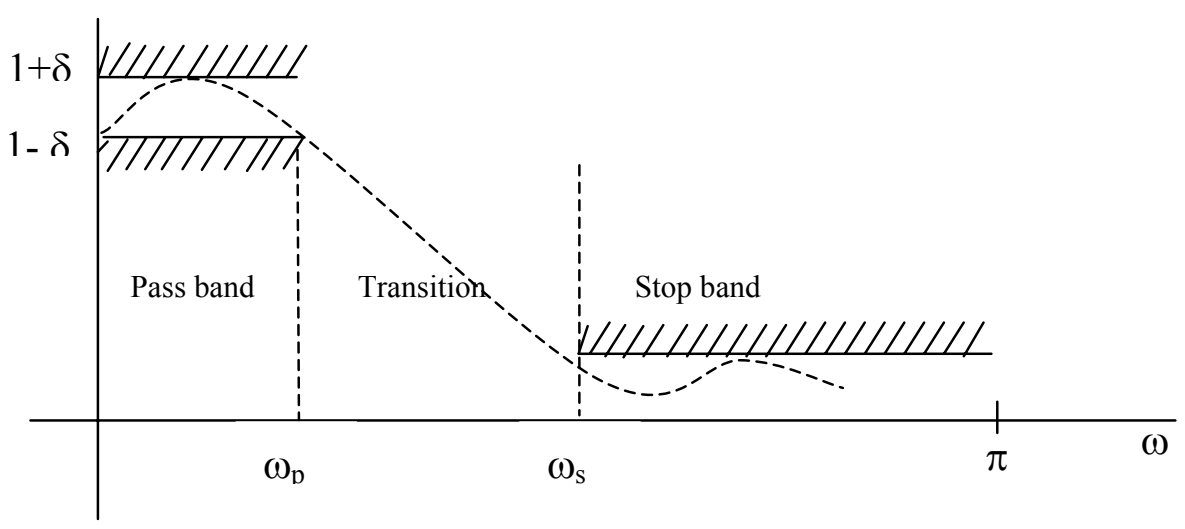

Figure A.1.c Optimum low pass filter 


\section{A.4.2 FOURIER TRANSFORMS}

The Fourier transform is a mathematical method that converts a continuous input signal from the time domain to the frequency domain.

The Fourier transform of a continuous-time signal $\mathrm{x}(\mathrm{t})$ is defined as

$$
x(w)=\int_{-\alpha}^{\alpha} x(t) e^{-j w t} d t, w \in(-\alpha, \alpha)
$$

\section{A.4.3 DISCRETE FOURIER TRANSFORM (DFT)}

Unlike the Fourier Transform, the Discrete Fourier Transform (DFT) represents the same information using discrete number of frequencies.

$$
x\left(w_{k}\right) \triangleq \sum_{n=0}^{N-1} x\left(t_{n}\right) e^{-j w_{k} t_{n}}, k=0,1,2, \ldots ., N-1
$$

\section{A.4.4 FAST FOURIER TRANSFORM (FFT)}

FFT is an efficient algorithm to compute the discrete fourier transform . The FFT decreases the number of calculations to analyze the wave function.

The number of Fourier Transformations for a given data signal is

$$
n^{2}
$$

But for a FFT this reduces to:

$$
(n / 2) \log _{2}(n)
$$

The main disadvantage associated with the FFT is the restricted number of data points, and the need to apply a window function to the waveform to compensate for spectral leakage 


\title{
APPENDIX V
}

\section{PROGRAM CODE}

\begin{abstract}
A.5.1 Temperature compensation A.5.1.1Crack-meter

$\%$ Code to withdraw temperature compensated strain values of VW strain gages
\end{abstract}

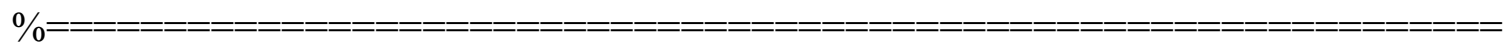

// Initial values from the excel file //

ini=dlmread('C: $\mid$ Evansville Bridge $\backslash$ datalinitial_value_DL2.dat','ไt');

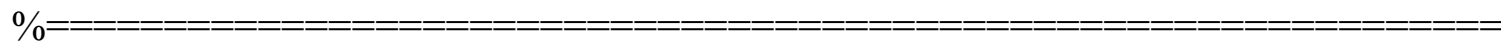

// Loading and appending the noise free raw matrices//

load('dl_two_bt.mat'); load('dl_two_at.mat');

data $=\left[\mathrm{DL} \_2 \mathrm{BT} ; \mathrm{DL} \_2 \mathrm{AT}\right]$;

$\%=$

// Time calculation: Conversion of Julian day from the datalogger to days//

time $=(\operatorname{data}(:, 3) / 365+\operatorname{fix}(\operatorname{data}(:, 4) / 100) /(24 * 365)+\operatorname{rem}(\operatorname{data}(:, 4), 100) /(60 * 24 * 365)) * 365 ;$

days $=$ time-time $(1)$;

time_mat $=[\operatorname{data}(:, 2), \operatorname{data}(:, 3), \operatorname{data}(:, 4), \operatorname{data}(:, 6)$, days $]$;

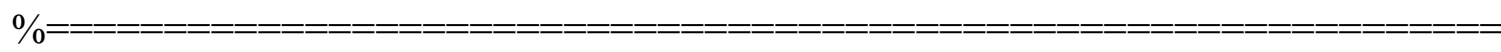

// Gage factor for all crack-meters //

gage fact $=[0.0001678 ; 0.0001685 ; 0.0001671 ; 0.0001697 ; 0.0001686 ; 0.0001647 ; 0.00016$

79;0.0001685;0.0001659;0.0001702;0.0001674;0.0001693;0.0001662;0.0001672;

0.0001673;0.0001691;0.0001676;0.0001655;0.0001637;0.0001692;0.0001657;

$0.0001671 ; 0.0001657 ; 0.0001661 ; 0.0001686 ; 0.0001701 ; 0.0001676 ; 0.0001678 ; 0.0001666$ ;0.0001667];

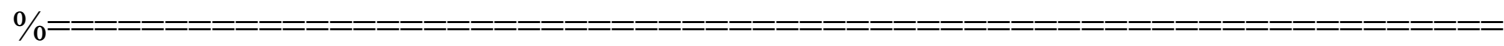




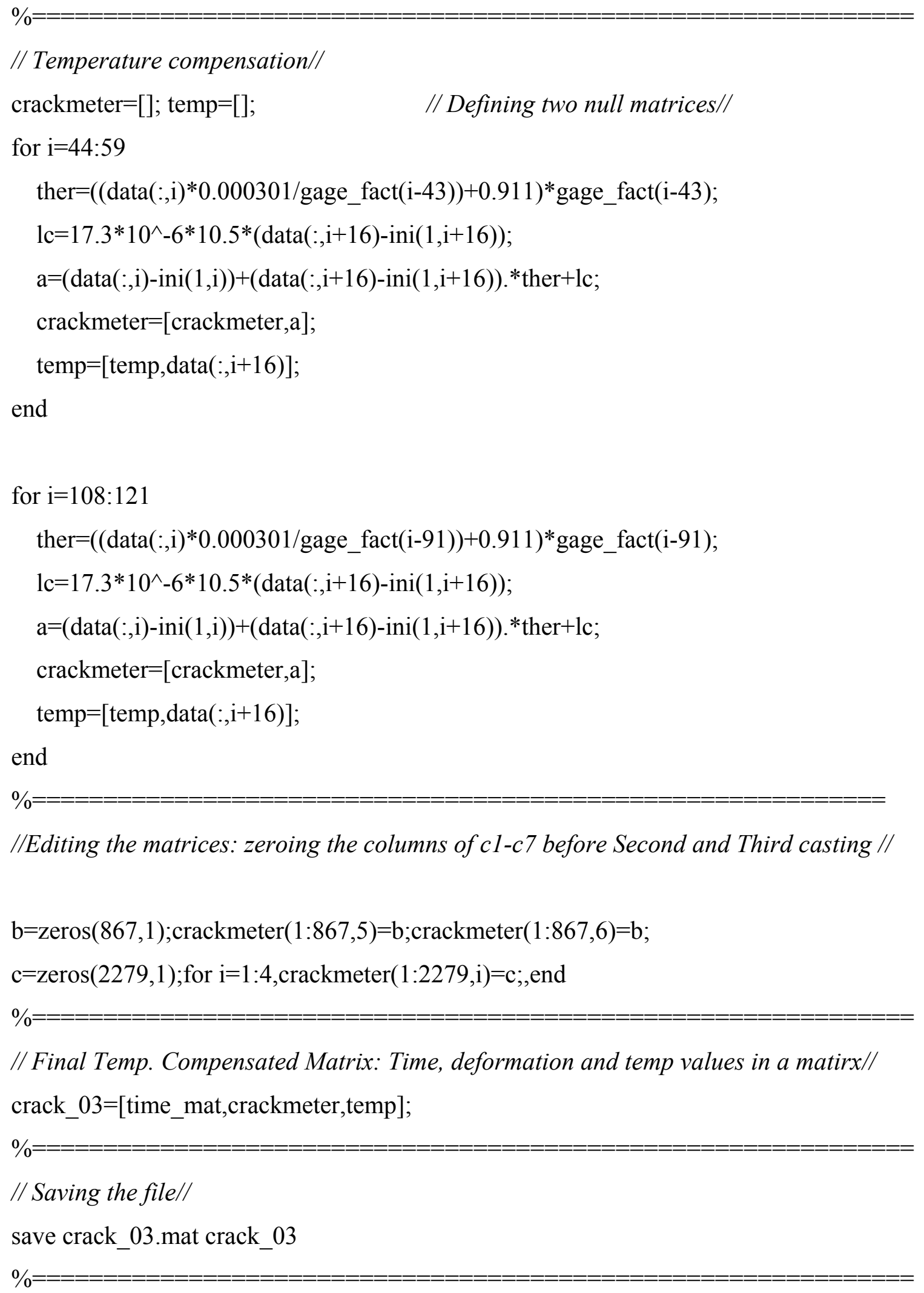




\section{A.5.1.2 VW strain gage}

$\%$ Code to withdraw temperature compensated strain values of VW strain gages

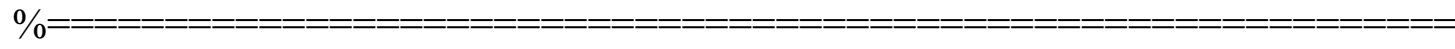

// Loading the initial values from the excel file //

ini=dlmread('C: $\mid$ Evansville Bridge $\backslash$ datalinitial_value_DL1.dat','\t');

load('dl_one_bt.mat'); // Loading the strain gage data file //

data $=\left[\mathrm{DL} \_1 \mathrm{BT}\right] ; \quad$ // Matrix//

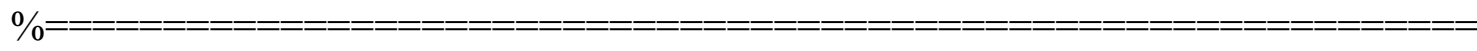

// Time calculation: Conversion of Julian day from the datalogger to days//

time $=(\operatorname{data}(:, 3) / 365+$ fix $(\operatorname{data}(:, 4) / 100) /(24 * 365)+\operatorname{rem}(\operatorname{data}(:, 4), 100) /(60 * 24 * 365)) * 365 ;$

days $=$ time-time $(1)$;

time_mat $=[\operatorname{data}(:, 2), \operatorname{data}(:, 3), \operatorname{data}(:, 4), \operatorname{data}(:, 6)$, days $]$;

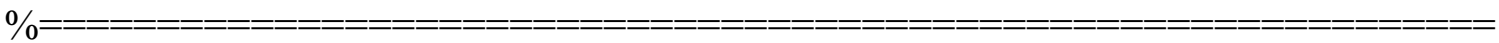

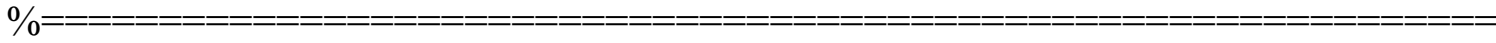

// Temperature compensation//

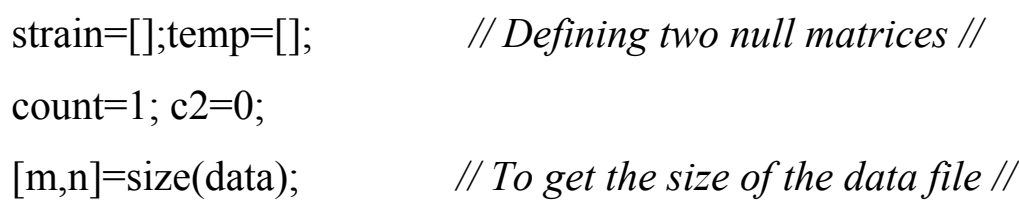

for $\mathrm{i}=12: \mathrm{n} \quad$ // Strain values are stored in the data file from $12^{\text {th }}$ column onwards//

if (count $<=16$ ) // Corresponding temperatures are stored after, for every 16-

count $=$ count $+1 ; \quad$-strain columns //

$\mathrm{a}=(\operatorname{data}(:, \mathrm{i})-\mathrm{ini}(1, \mathrm{i}))+((\operatorname{data}(:, \mathrm{i}+16)-\mathrm{ini}(1, \mathrm{i}+16)) * 12.2)$;

strain $=[$ strain, a $]$;

elseif $($ count $==17)$

$\mathrm{c} 2=\mathrm{c} 2+1$;

temp $=[\operatorname{temp}, \operatorname{data}(:, \mathrm{i})]$; 


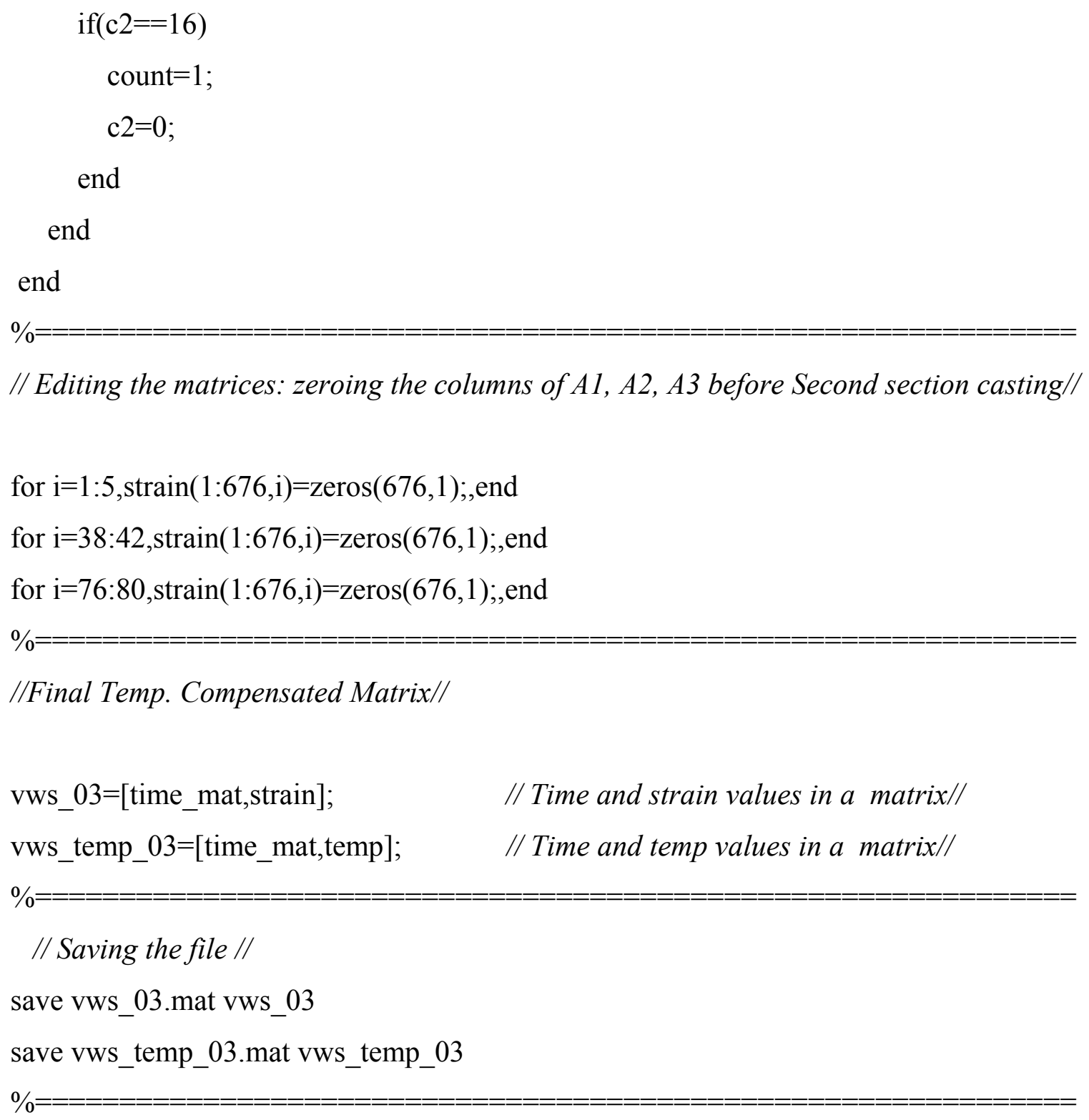




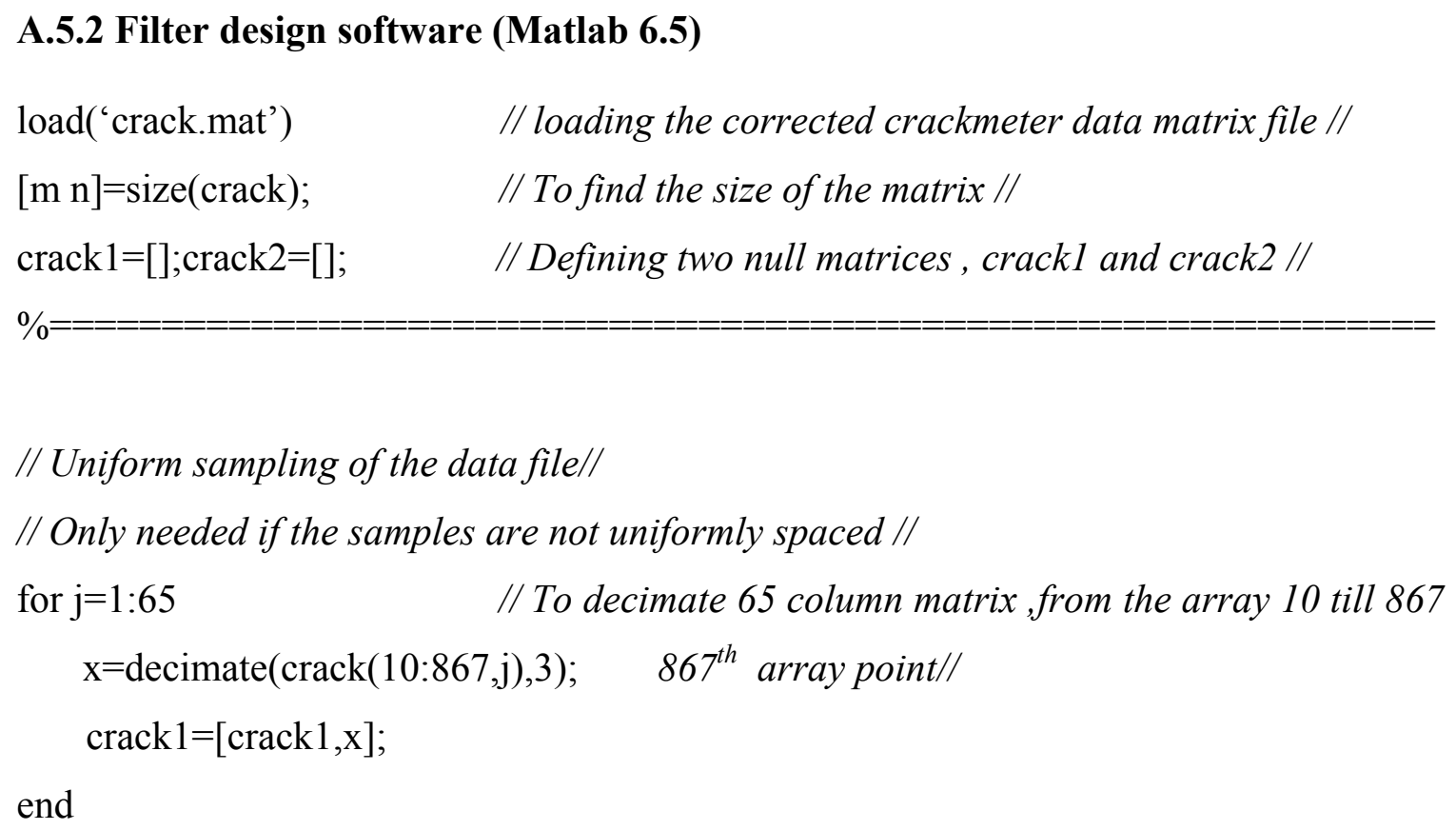

// File format: first five columns have time related columns and the columns from 6 to 35 have crackmeter values and the rest 30 has the corresponding temperature values, hence 65 columns in total //

\footnotetext{
$\%==============================$
// Data Filtration: Using Butter-Worth Filter //

$[\mathrm{x} y]=\operatorname{size}($ crackmeter);

filter_crackdata $=[]$; filter_data $1=[] ;$ filter_data $2=[]$; filter_data $3=[]$;
} 
// ** If loop is used beco's of three different casting dates for crackmeters, which means different size matrices, crackmeter from 1 to 4 are of same size, crackmeter $5 \& 6$ are of same size and rest are of same size ** //

for $\mathrm{n}=6: 35 \quad$ // where the crackmeter data values are stored // if $(\mathrm{n}<=9) \quad$ // First four crackmeters //

Temp= crackmeter(1710:x,n+30); // To get corresponding temp values in the file// $\mathrm{Y}=\mathrm{fft}(\mathrm{Temp}) ; \mathrm{N}=$ length$(\mathrm{Y}) ; \quad / / F F T / /$

Power $=\operatorname{abs}(\mathrm{Y}(1: \mathrm{N} / 2)) . \wedge 2 ; \quad$ // To get the frequency of the temp signal//

Nyquist $=1 / 2 ;$ freq $=(1: \mathrm{N} / 2) /(\mathrm{N} / 2) *$ Nyquist;

[high index $]=\max ($ Power $)$;

F_days $=$ freq(index);wn1=F_days $* 60 / 15$;

$[\mathrm{b} 1, \mathrm{a} 1]=\operatorname{butter}\left(3, \mathrm{wn} 1\right.$, 'low'$\left.^{\prime}\right) ; \quad / /$ Butter filter using frequency form the temp signal// $\mathrm{y} 1=$ filtfilt(b1,a1,crackmeter(:,n));

filter_data1=[filter_data1,y1]; //Storing the filtered data file in a matrix//

elseif $((\mathrm{n}<=11) \quad \&(\mathrm{n}>9)) \quad / / 5^{\text {th }}$ and $6^{\text {th }}$ crackmeters //

Temp= crackmeter(299:x,n+30); // To get the corresponding temp values in the file// $\mathrm{Y}=\mathrm{fft}(\mathrm{Temp}) ; \mathrm{N}=$ length(Y); $\quad$ // FFT//

Power $=\operatorname{abs}(\mathrm{Y}(1: \mathrm{N} / 2))$. $^{\wedge} ; \quad$ // To get the frequency of the temp signal//

Nyquist $=1 / 2$; freq $=(1: \mathrm{N} / 2) /(\mathrm{N} / 2) *$ Nyquist;

[high index $]=\max ($ Power $)$;

F_days $=$ freq(index);wn2 $=F$ _days $* 60 / 15$;

$[\mathrm{b} 2, \mathrm{a} 2]=\operatorname{butter}\left(3, \mathrm{wn} 2\right.$, 'low' $\left.^{\prime}\right) ; \quad$ // Butter filter using frequency form the temp signal// $\mathrm{y} 2=$ filtfilt(b2,a2, crackmeter(:,n));

filter_data2=[filter_data2,y2]; //Storing the filtered data file in a matrix//

elseif (n>9) // For rest //

Temp= crackmeter(:,n+30); // To get corresponding temp values in the file// $\mathrm{Y}=\operatorname{fft}(\mathrm{Temp}) ; \mathrm{N}=$ length(Y); $\quad$ // FFT// 
Power $=\operatorname{abs}(\mathrm{Y}(1: \mathrm{N} / 2)) .^{\wedge} 2 ; \quad$ // To get the frequency of the temp signal//

Nyquist $=1 / 2$; freq $=(1: \mathrm{N} / 2) /(\mathrm{N} / 2) *$ Nyquist;

[high index $]=\max ($ Power);

F_days $=$ freq(index);wn3 $=F \_$days $* 60 / 15$;

$[\mathrm{b} 3, \mathrm{a} 3]=\operatorname{butter}\left(3, \mathrm{wn} 3\right.$, 'low'$\left.^{\prime}\right) ; \quad$ // Butter filter using frequency form the temp signal// y3=filtfilt(b3,a3, crackmeter(:,n));

filter_data3=[filter_data3,y3]; // Storing the filtered data file in a matrix//

end

end

$\%================================================$

//Appending filtered crack-meter \& Temperature data in a single matrix//

filter_crackdata $=[$ crackmeter(:,1:5),filter_data1,filter_data2,filter_data3, crackmeter(:,36:65)];

$\%=$

// Saving the file //

save filter_crackdata.mat filter_crackdata

$\%=================================================$ 